\title{
SLIME-MOLD BEETLES OF THE GENUS AGATHIDIUM PANZER IN NORTH AND CENTRAL AMERICA, PART I. COLEOPTERA: LEIODIDAE
}

\author{
QUENTIN D. WHEELER \\ Department of Entomology, Cornell University \\ Current address: Department of Entomology \\ The Natural History Museum \\ Cromwell Road \\ South Kensington SW7 5BD, United Kingdom \\ (q.wheeler@nhm.ac.uk) \\ KELLY B. MILLER \\ Department of Entomology, Cornell University \\ Current address: Department of Integrative Biology \\ Brigham Young University \\ Provo, Utah 84042 \\ (kbm46@email.byu.edu)
}

BULLETIN OF THE AMERICAN MUSEUM OF NATURAL HISTORY CENTRAL PARK WEST AT 79TH STREET, NEW YORK, NY 10024

Number 290, 95 pp., 53 figures, 1 table

Issued March 24, 2005 

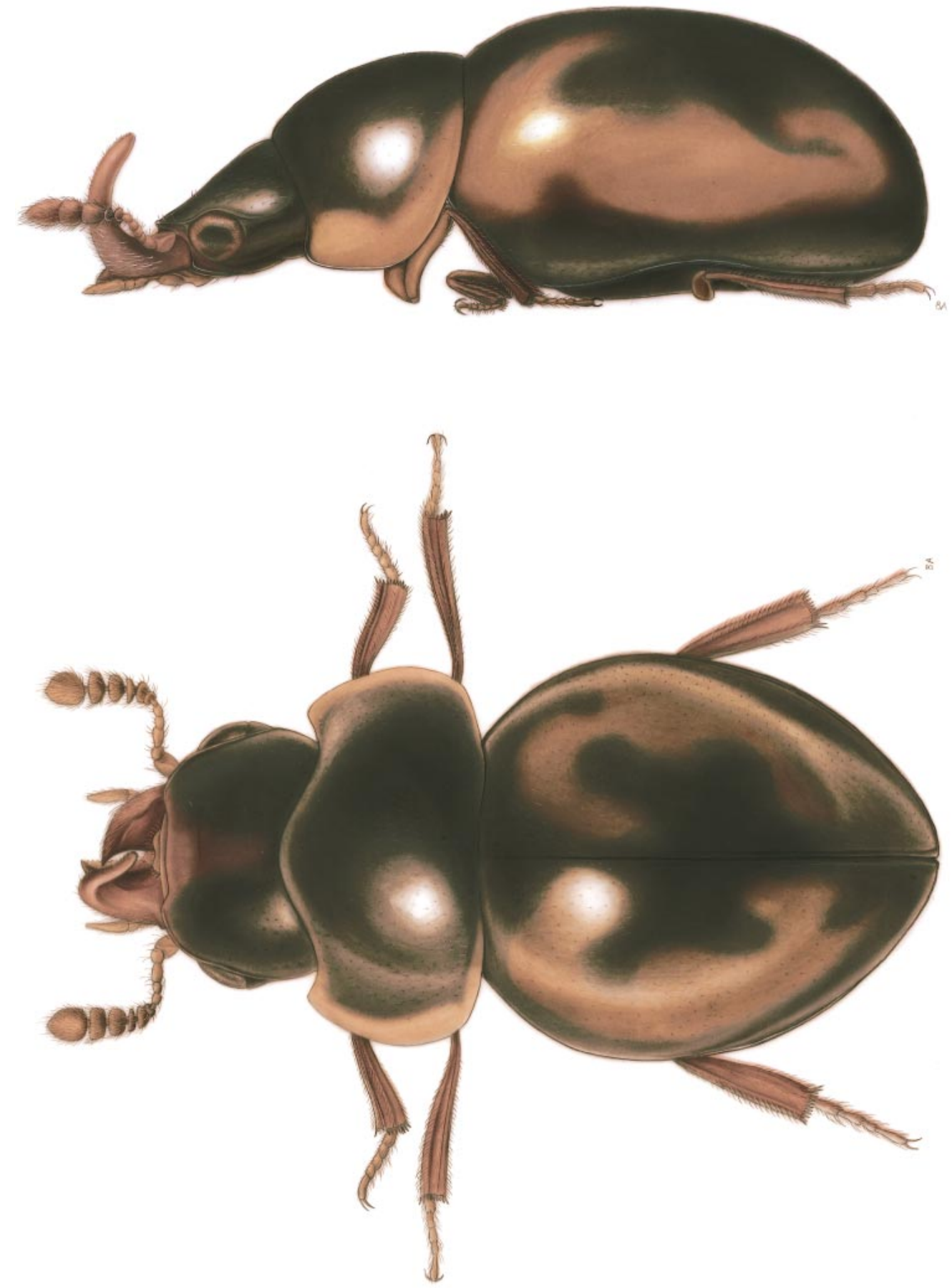

Male Agathidium pulchrum LeConte habitus, dorsal and lateral. Original by Byron Alexander. 


\section{CONTENTS}

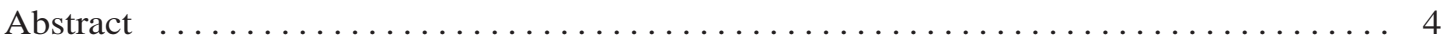

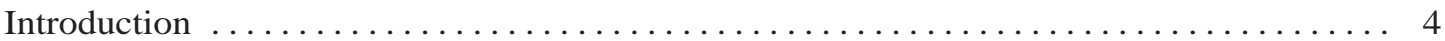

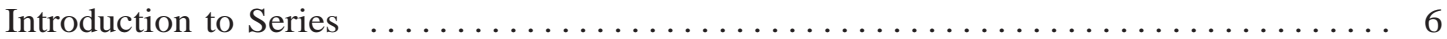

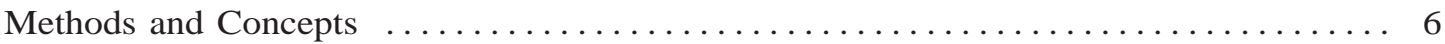

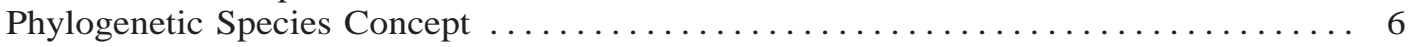

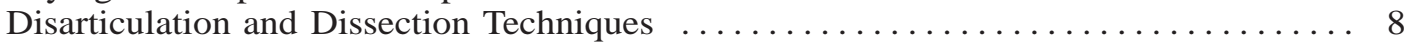

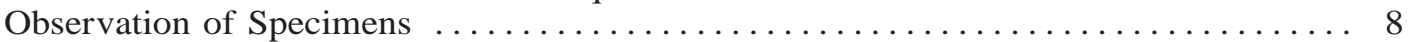

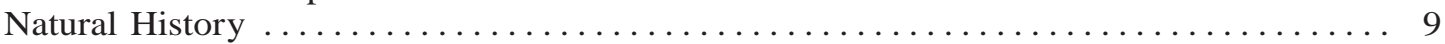

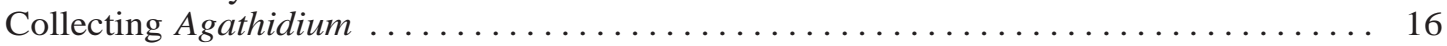

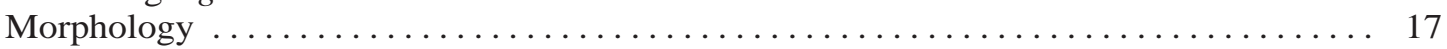

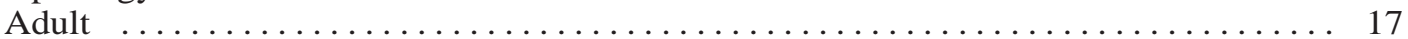

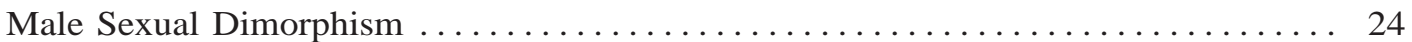

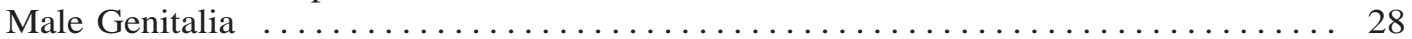

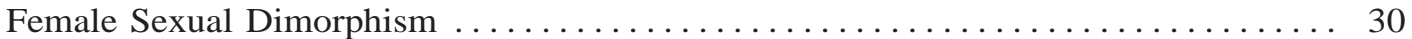

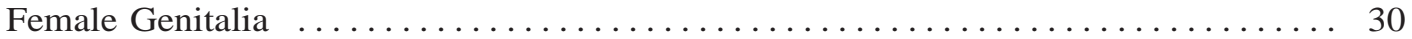

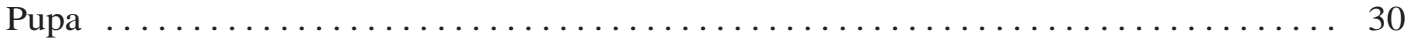

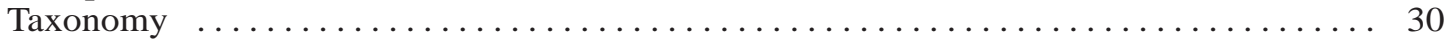

Key to Genera of Agathidiini of North and Central America . . . . . . . . . . . . 33

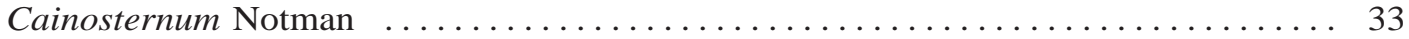

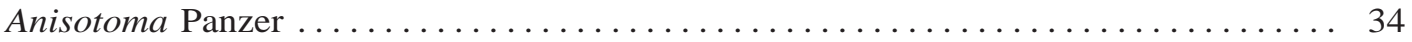

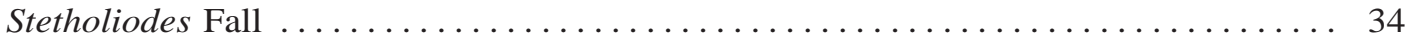

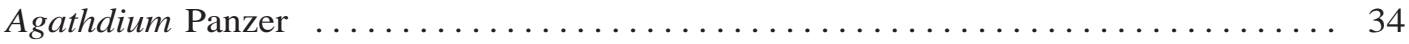

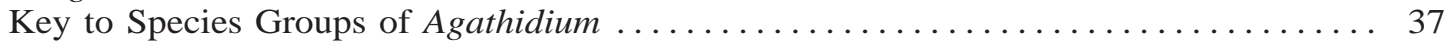

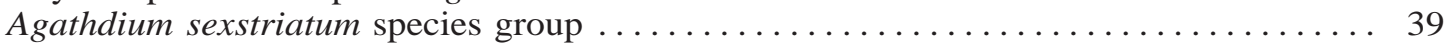

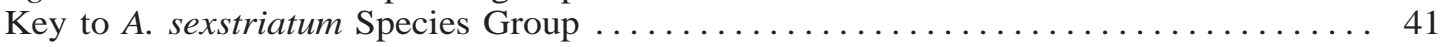

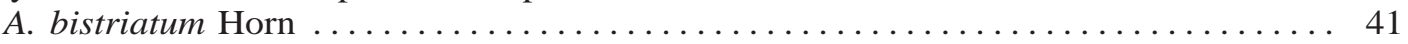

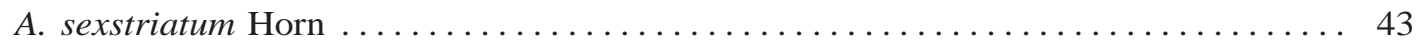

A. estriatum Horn ................................... 45

Agathidium brevisternum Species Group $\ldots \ldots \ldots \ldots \ldots \ldots \ldots \ldots \ldots \ldots \ldots \ldots$

Key to A. brevisternum Species Group $\ldots \ldots \ldots \ldots \ldots \ldots \ldots \ldots \ldots \ldots \ldots$

A. brevisternum Fall ................................ 49

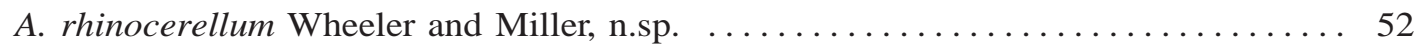

A. dioperculum Wheeler and Miller, n.sp. ...................... 54

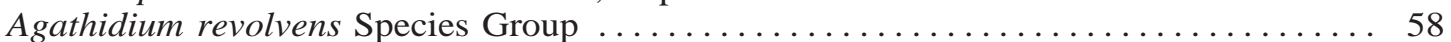

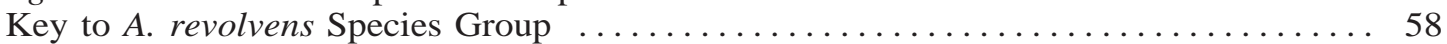

A. revolvens LeConte ................................... 59

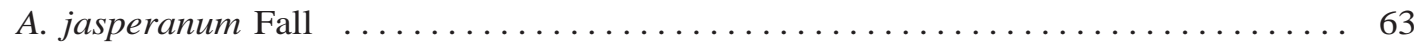

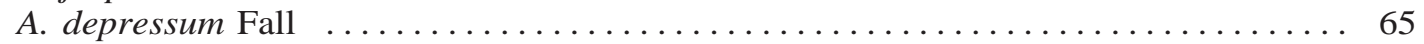

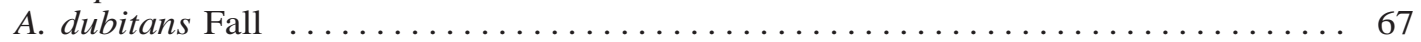

A. dubitanoides Wheeler and Miller, n.sp. ....................... 69

A. omissum Fall ...................................... 70

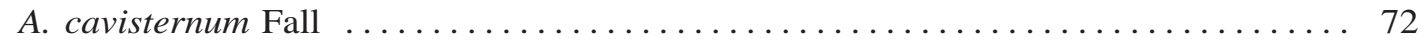

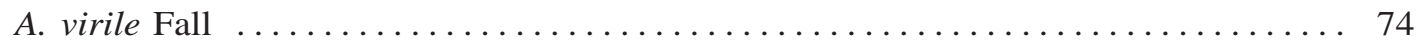

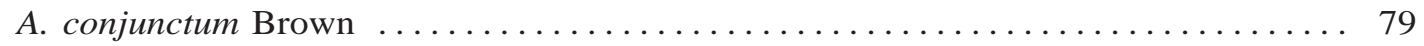

A. angustoperculum Wheeler and Miller, n.sp. ................... 81

A. falcatoperculum Wheeler and Miller, n.sp. ..................... 83

Checklist of Agathidium Species: Part $1 \ldots \ldots \ldots \ldots \ldots \ldots \ldots \ldots \ldots \ldots \ldots \ldots$

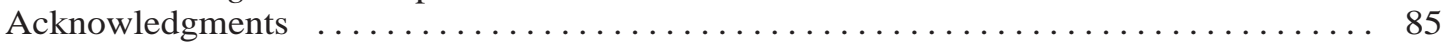

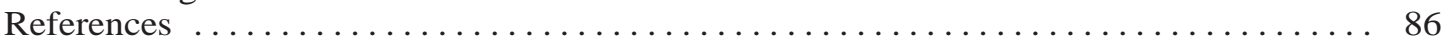

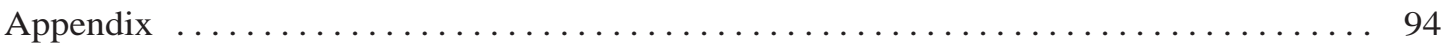




\begin{abstract}
The external morphology of the adult, egg, larva, and pupa of Agathidium oniscoides Beauvois is described. The natural history of the genus is reviewed, including associations with Myxomycetes and fungi and techniques for field collection and laboratory study. The phylogenetic species concept is discussed and applied in this study. A key and brief diagnoses are provided for the genera of Agathidiini (Coleoptera: Leiodidae: Leiodinae) of North and Central America. Volvoxis Kugelann is regarded as a nomen oblitum, and its junior synonym Agathidium Panzer is regarded as the valid name (nomen protectum) for this taxon by invoking article 23.9 of the International Code of Zoological Nomenclature. A key to species groups of Agathidium Panzer is presented. Species are revised for the A. sexstriatum, A. brevisternum, and $A$. revolvens species groups, including keys, diagnoses, descriptions, and figures of important morphological features. Lectotypes are designated for A. bistriatum Horn and A. sexstriatum Horn. The following new species are described: A. angustoperculum, n.sp., A. dioperculum, n.sp., A. dubitanoides, n.sp., A. falcatoperculum, n.sp., and A. rhinocerellum, n.sp.
\end{abstract}

\section{INTRODUCTION}

The genus Agathidium Panzer (Coleoptera: Leiodidae: Leiodinae) includes minute to small beetles $(1-6 \mathrm{~mm})$ that are generally round, convex, shiny, usually concolorous, and frequently capable of contracting their body into a compact ball-like shape when disturbed. Most species for which biological data exist are associated with slime-molds (Myxomycetes or Mycetozoa), in either their mature (sporocarp) or immature (plasmodium) stages. Unlike related genera in Agathidiini, Agathidium has also been associated with a substantial number of fungi, primarily Basidiomycetes. The full extent of the geographic range of the genus is not yet known, although most species inhabit temperate or montane tropical forests of the Northern Hemisphere.

When the body is contracted, the antennae are retracted into ventral cephalic antennal grooves, the legs are folded beneath the body, and the broad lateral extensions of the pronotum fold over the sides of the elytra to achieve, in its ultimate expression, a nearly completely spherical form. Such contractility is seen only rarely among phylogenetically unrelated Coleoptera, including Clambidae, Nitidulidae (Cybocephalinae), and Scarabaeidae (Cryptocephalinae). Within the Leiodidae, this kind of defense is approached only by the single North American species of Aglyptinus Cockerell, Agl. laevis LeConte, but not by its numerous tropical congeners. In the case of Agl. laevis, however, the body is extremely convex and hemispherical but not contractile, whereas other (mostly tropi- cal) species of the genus are far less convex. Interestingly, Agl. laevis has been found in association with slime-mold plasmodia (Stephenson et al., 1994), whereas Neotropical relatives of that species appear to be feeders on agarics (Wheeler, 1979a). The contractility of various species of Agathidium no doubt contributed to one common name for the Leiodidae, the "round fungus-beetles" (e.g., Arnett, 1971).

The genus Agathidium is the largest possibly monophyletic group of insects documented to be principally slime-mold feeding. Such myxomycophagous habits are so widespread within the genus and related genera of Agathidiini (= Anisotomini) that it is reasonable to infer such associations with Myxomycetes were present in the common ancestor of both the genus and the tribe (Newton, 1984; Wheeler, 1984a, 1984b). Myxomycophagy has also been documented in Aglyptinus (see above) and in the southern temperate tribe Neopelatopini in the Leiodidae, and occurs outside leiodids sporadically across the Coleoptera. Putative slime-mold associates include certain Rhysodidae, Clambidae, Eucinetidae, Scaphidiinae (Staphylinidae), Cerylonidae, Latridiidae (= Lathridiidae), and Sphindidae (Blackwell, 1984; Lawrence and Newton, 1980; McHugh, 1993; Russell, 1979; Stephenson et al., 1994; Wheeler, 1979b, 1984a, 1984b, 1987).

Agathidium is remarkably diverse in both morphological structure and ecological habits. Species vary dramatically in size (ranging from barely $1 \mathrm{~mm}$ to more than $6 \mathrm{~mm}$ when fully extended), body shape (from con- 
vex and noncontractile to elongate-oval and partially contractile, to broadly rounded, highly convex, and fully contractile), presence/absence of certain male sexual dimorphisms (i.e., enlarged basal tarsomeres on front and middle legs, a setose fovea on the metasternum, a tooth near the posteroapical angle of the metafemur, and a tusk on the left mandible), coloration (from reddish-brown to black and, rarely, with striking color patterns), and punctation (from nearly impunctate to confused punctation to serial punctation of elytra). Ecologically, Agathidium is one of few myxomycophagous taxa with species that have been found associated with both spores of mature fruiting bodies and the plasmodial stage of the hosts (Wheeler, 1984a, 1984b, 1987). Although firm host associations have not been made for a complex of anophthalmic and microphthalmic and flightless species in the Appalachian Mountains of the eastern United States, phylogenetic affinity, modifications of the mouthparts, and field observations are consistent with plasmodial predation in these species (Wheeler, 1984a).

Palearctic species number about 200 and are comparatively well known (Angelini, 1995), whereas those of other regions continue to be described in large numbers. About 350 species have been described from the Oriental region where large numbers of flightless endemic forms are known. As an example, 50 out of 52 species of Agathidium known from Taiwan are endemic to that island (Angelini and de Marzo, 1995). Whereas substantial progress has been made on the faunas of these regions, that of the New World has remained largely unstudied (Angelini, 1988, 1990; Angelini and de Marzo, 1983, 1984, 1987a, 1987b, 1988, 1990, 1995).

When Fall (1934: 99) revised the North American species, he stated that "A recent critical survey of the Agathidium material in my collection has revealed the presence of a considerable number of undescribed species. There is nothing surprising in this fact when it is recalled that the last published treatment of the genus was that of Dr. Horn in his Silphidae paper of more than fifty years ago." In fact, between the works of Horn and Fall, only four new species had been described
(Brown, 1928, 1930, 1933; Fall, 1901). Today, more than 50 years have passed since Fall's work, and a similar situation exists. Little taxonomic work has been done since Fall's revision (Arnett, 1971; Hatch, 1957), and a considerable number of undescribed species have accumulated in collections. The current expansion in numbers of species is the result of three factors: (1) discovery of a large complex of flightless species in the Appalachian Mountains; (2) species of Mexico and Central America have nearly been ignored to date; and (3) characters of the aedeagus, which are extremely valuable diagnostic features at the species level, have not been previously examined. Only four species have been described from Latin America (Hendrichs, 1979; Matthews, 1887) despite evidence from collections that suggests the genus is very diverse in montane regions in this area.

Our interest in the genus was a natural continuation of the senior author's previous work on the related genus Anisotoma Panzer (Wheeler, 1979b), and it was intensified during studies of material at the American Museum of Natural History in 1974 when he first observed an undescribed microphthalmic and flightless species endemic to the southern Appalachian Mountains of the United States. A subsequent field trip in the spring of 1975 resulted in rediscovery of this and a related microphthalmic species. These species appear to be specialized predators of plasmodia, living in the rich, deep, moist leaf litter of high elevation forests with significant levels of precipitation (Wheeler, 1984a, 1984b). Such aptery and microphthalmy is highly unusual among fungivores in general and slime-mold beetles in particular. Interestingly, flightless species of Dasycerus Brongniart (Staphylinidae) also exist in this region and feed upon a range of fungus hosts (Wheeler, 1984c; Wheeler and McHugh, 1994).

Whereas this taxonomic study will increase our knowledge of the species diversity of the Agathidium of North and Central America, it is no more than the next logical step in the scientific exploration of this fascinating clade. Knowledge of the species diversity of Agathidium is far from complete. Additional species remain to be discovered 
in the United States, particularly in the Appalachian and Ozark regions and in the coastal forests of northern California, Washington, and Oregon. Further, based on the relative paucity of specimens examined from Latin America and the proportion of undescribed species among them, it is clear that no more than a small percentage of those species that live in montane, temperate forests of Mexico and Central America have been collected. It can be hoped only that this work will facilitate identification of known species and encourage the collection of those not yet known, so that another revision may be done in the future to more completely document the diversity of this remarkable genus.

\section{INTRODUCTION TO SERIES}

This is the first of two publications that will collectively constitute a taxonomic revision of the species of Agathidium of North and Central America. This part provides an introduction to the genus Agathidium, a detailed account of the external morphology of a representative highly contractile species ( $A$. oniscoides), a key to species groups, and revisions of the A. brevisternum, A. revolvens, and $A$. sexstriatum species groups. The subsequent part will include taxonomic treatments of the remaining species groups.

All species in this study will be interpreted within the phylogenetic species concept as discussed by Nixon and Wheeler (1990, 1992), Wheeler and Nixon (1990), Wheeler and Platnick (2000a, 2000b), and Platnick and Wheeler (2000) as modified from Eldredge and Cracraft (1980), Nelson and Platnick (1981), and Cracraft (1983) (see also Cracraft, 1992). This concept, discussed below, can be anticipated to increase the number of species where the biological species concept has been subjectively applied and used to recognize as subspecies those populations that are holomorphologically distinct and more or less allopatric (Nelson and Platnick, 1981). In the case of Agathidium, however, species have historically been based on a morphological concept and closely approximate phylogenetic species.

This monograph will serve as a steppingstone toward a complete accounting of the species of the genus for the New World. As field studies in areas of the U.S., Mexico, and Central and northern South America increase, many additional species of Agathidium await discovery and description. Just as recent work by Angelini (see references) has greatly increased our knowledge and estimates of the species diversity of the genus in Europe and Asia, this study will suggest that the diversity of American Agathidium has been seriously underestimated in the past.

\section{METHODS AND CONCEPTS}

Phylogenetic Species Concept: The biological species concept (BSC) has dominated the zoological literature for half a century (Mayr, 1942, 1963, 1982). Despite considerable controversy over modes of speciation based on insect models, the BSC has remained nearly unquestioned in the literature on insects. Never fully embraced by botanists, the BSC has recently been widely criticized on general conceptual grounds (Cracraft, 1983; Cronquist, 1978; de Queiroz and Donoghue, 1988; Donoghue, 1985; Mishler and Donoghue, 1982; van Valen, 1976). In particular, the emergence of rigorous phylogenetic theories has indicated the need for a species concept more in line with the goals of phylogenetic analyses and classifications (Wheeler and Meier, 2000). One consequence of the adoption of phylogenetic theory is the need to recognize elements analyzable by cladistic methods and not ones that are themselves divisible into smaller units with this property (Nixon and Wheeler, 1990). Stated another way, we need to identify the smallest units for which unequivocal historical evidence of phylogeny may be retrieved. Thus, since the appearance of Hennig's phylogenetic theory, cladists have sought with increasing intensity a "phylogenetic" concept of species.

Hennig (1966) modified the BSC to correct for ambiguity associated with time of speciation. The result, an "inter-nodal" concept, represented an advance (Ridley, 1989) but fell short of a clearly phylogenetic concept. Rosen (1978) introduced an autapomorphic concept describing species as minimum autapomorphic units (see also de Queiroz and Donoghue, 1988; Hill and Crane, 1982). Autapomorphic species, however, are 
based on the inappropriate use of phylogenetic analyses and application of concepts of monophyly and synapomorphy below the level of species. Such attempts to analyze demonstrably tokogenetic relationships through cladistic analyses are misguided at best (Wheeler and Nixon, 1990).

This study uses the phylogenetic species concept (PSC), introduced by Eldredge and Cracraft (1980) and Nelson and Platnick (1981), and more recently discussed by Cracraft $(1983,1992)$ and amplified and extended by Nixon and Wheeler $(1990,1992)$ and Wheeler and Platnick (2000b). Stated simply, phylogenetic species are "the smallest aggregation of populations (sexual) or lineages (asexual) diagnosable by a unique combination of character states in comparable individuals (semaphoronts)" (Nixon and Wheeler, 1990). The PSC is consistent with phylogenetic theory, but independent of phylogenetic analysis. This is necessary since one goal of the PSC is to identify the elements for cladistic studies.

Hennig (1966) distinguished between tokogenetic and phylogenetic relationships. Tokogenetic or birth relationships are shared by individuals within sexually reproducing populations and result in more or less reticulate patterns of relationship. Phylogenetic relationships are shared among species, involve character transformation, and are hierarchic in pattern. In evolutionary history, hierarchic relationships exist because characters of an ancestral species are inherited by its descendants, either in their original or some modified form (Platnick, 1979). Application of cladistic analysis to populations may result in a "cladogram". However, where evidence or inference of tokogenetic relationships exists, such a diagram may be artifactual rather than phylogenetic. The assumption that the outcome of such an analysis may be interpreted as a hierarchy is not valid. Thus, a species concept is desired that can distinguish among species prior to the cladistic analysis.

Nixon and Wheeler (1990, 1992) drew a strict contrast between the terms character and trait. Traits are heritable attributes that vary within terms of a cladogram whereas characters are heritable attributes that are constant (fixed) throughout each term. In the case of sexually reproducing animals, traits vary among individuals within a population whereas characters are constant among all individuals of one or more populations. However, constancy does not equate to invariability. A subapical tooth is frequently present on the metafemur of male Agathidium, yet the structure of that tooth varies from small straight structures to large curved ones.

As Cracraft (1983) stated, another goal of a species concept is to recognize the end products of evolution. Because evolutionary history results from unpredictable interactions among many biotic and abiotic forces, references to "the" evolutionary process are illusory. Given the existence of many evolutionary processes, the advantages of recognizing historical patterns independent of any one of them become apparent. Regardless of the mode of speciation (e.g., allopatric, parapatric, sympatric, allochronic), the distribution of characters provides a mechanism for recognizing their end products. Thus, the PSC serves also as a unit species concept, making comparisons of numbers of species in different groups, and resulting from different speciation processes, meaningful. Because clonal systems result in new species with each mutation, numbers of species in asexual groups have been grossly underestimated by the BSC. It is logical, however, that such a system would result in greater numbers of end products than would sexual systems.

The PSC has numerous advantages. Most importantly, it is based on observable characters so that the PSC is imminently testable and it provides logical elements among which cladistic relationships may be analyzed. For those who are compelled to build some ontological construct for species, the PSC provides a logical interface between the reticulate patterns of descent observed among individuals within populations of sexually reproductive organisms and the unique sequence of patterns of common ancestry shared among species belonging to a clade. The PSC gives to us both the maximum tokogenetic construct and the minimum phylogenetic element. For us, the epistemological linkage of the PSC to characters is not a philosophical weakness, but a strength. Its definition makes clear its connection in prac- 
tice to empirical data. Just as for cladistic analysis, the only ontological concern that must be addressed is the assumption that phylogenetic species share a common history (i.e., that evolution has occurred).

Disarticulation AND Dissection TeCHNIQUES: Confirmation of species identity for many Agathidium beetles requires examination of the male aedeagus. Males can usually be sorted from females by one or more of the following dimorphisms: (1) enlargement of pro- and mesobasotarsomeres and/or presence of spatulate ventral setae on basotarsomeres; (2) presence of an apical or preapical tusk or horn on the dorsum of the left mandible; (3) presence of a metasternal fovea, varying from single or paired punctiform structures to much larger transverse oval eroded areas bearing more or less long and frequently dense setae; or (4) presence of a preapical or apical tooth on the posterior margin of the metafemur. Examination of the protarsus is usually sufficient. In their extreme form, the basal segments are distinctly expanded with large, dense patches of spatulate setae beneath. In their least developed form, however, the tarsi are only indistinctly laterally expanded. Even in these individuals, however, a small number of ventral, spatulate setae are visible at moderate magnifications.

Once identified, male specimens were relaxed by heating them in water with a mild detergent. Once thoroughly relaxed, the elytra were teased apart, exposing the membranous tergum of the abdomen. The tergum was then incised by a minuten nadeln, and the aedeagus was removed from the abdomen by the points of minute forceps, a hooked insect pin, or minuten nadeln. The elytra were then replaced over the incision and the specimen was dried and remounted. Meanwhile, the aedeagus was heated gently in a $10 \%$ potassium hydroxide solution to macerate adhering muscle tissues. It was then rinsed completely in distilled water and placed in glycerin or a 50:50 \% mixture of glycerin:glycerin jelly. Structures were then placed in a depression slide and examined with a Leitz Dialux 20 or 22 compound microscope with Nomarski differential interference contrast illumination.

Female specimens, when dissected for study of ovipositor and spermatheca, were treated similarly except for the following. The entire abdomen was removed from the relaxed specimen and heated in $10 \% \mathrm{KOH}$. While rinsing in $\mathrm{H}_{2} \mathrm{O}$, the apical two segments of the abdomen were pulled from the basal segments. This effectively removes both the ovipositor and spermatheca. After additional clearing, these structures were gently removed from the terminal segments and studied under cover glass.

For detailed comparative morphological work, entire specimens were often disarticulated. In such cases, the entire specimen was placed in $\mathrm{KOH}$ and the major somatic segments were teased apart. Components of the mouthparts, antennae, and legs were removed and examined. The sclerites of such preparations, thoroughly rinsed in water, were stored in glycerin in microcups cut from glass vials and stored in "Watrous trays" (Wheeler and McHugh, 1987).

ObSERVATION of SPECIMENS: The convex shape and subtle differences in dorsal punctation of many Agathidium make their study and illustration difficult. Certain conventions were adopted for this study that standardize both our observations and the presentation of certain characters in scientific illustrations. Mention of these conventions will facilitate effective use of this publication and comparison of species.

An outline drawing showing the dorsal body shape is presented for each species. The foreshortening of the curvature of the body combined with the degree of contraction of the body in its state of preservation make simultaneous observation of both the head and the elytra nearly impossible for many species. Thus, the dorsal drawings are actually composites. For the head, the specimen was tilted backward until the base of the labrum was just visible. For the elytra, the specimen was tilted forward until the apex of the lateral bead was just visible. By so doing, the shape of the cranium and elytra are both communicated in a single drawing, although in practice orientation of the specimen will have to be changed to examine these structures.

The appearance of the punctation is influenced to a considerable extent by the quality of lighting. Our observations and drawings were done using a very bright fiber optic 
light source. A Mylar film shield was used to diffuse the light. Under such light, it is far easier to discern serial rows of punctures that nearly blend in with the intervening, randomly distributed punctures under less diffuse light. We strongly recommend viewing punctation under such conditions when the presence or absence of subtle punctation difference is in question.

To achieve such diffuse lighting, two approaches were used. For illustrations, where maximum diffusion was important and where specimens did not have to be moved once set into position for drawing, a tube was fashioned from Mylar and set around the specimen. Light was then shown through these curved walls. For routine observation and description, when the specimen had to be manipulated by hand constantly, and when less diffuse light was sufficient to observe punctation patterns, a piece of Mylar was bent into a loosely bowed shape and attached to the tips of the arms of the fiber optic illuminator. This results in sufficient diffusion, with no interference in specimen manipulation.

\section{NATURAL HISTORY}

Beetles of the genus Agathidium are hypothesized to be predominantly and ancestrally associated with plasmodial slimemolds, the Myxomycetes or Mycetozoa. Plasmodial or true slime-molds include about 500 described species, most of which are more or less cosmopolitan in distribution (Martin and Alexopoulos, 1969). Large numbers of mature spores are liberated by wind, water, and arthropods into the air and environment where, given appropriate conditions, they germinate, releasing microscopic flagellated amoeboid cells. These myxamoebae later coalesce to form the large, multinucleated plasmodium typical of Myxomycetes. The Myxomycetes move about under bark, between lamellae of decaying wood or decomposing leaves, or within matrices of rotting vegetative matter like giant amoebae, sometimes attaining a diameter of several feet (e.g., Wheeler, 1987). The comparison with amoebae may be more than analogous since one current view is that Myxomycetes are more closely related to certain Protista than they are to true fungi. Given cues that can vary among myxomycete clades and species, the plasmodium wells upward, forming mature sporocarps over a period of a few to 24 or more hours.

Agathidium are, in general, found in moist forests. On a broad geographic scale, Agathidium are found in temperate forests of northern latitudes and southern montane regions. The genus is diverse in most forested areas of the northern hemisphere. On a local, habitat level, Agathidium are most easily found in dense forests where logs and litter are damp at the ground level. Whereas some other slime-mold beetles (e.g., Latridiidae, Sphindidae) frequent dry microhabitats also, such as in exposed fields, Agathidium seems less tolerant of low humidity situations. North American Agathidium are found from sea level to nearly 9000 feet elevation, in the case of A. estriatum in the Pinaleno Mountains of Arizona.

Like other myxomycophagous Coleoptera, most documented host associations for Agathidium are with mature sporocarps. Unlike most other slime-mold beetles, relationships with plasmodia have been documented in species of apparently distantly related groups of the genus (cf. Newton, 1984; Stephenson et al., 1994; Wheeler, 1984a, 1984c, 1987). Plasmodial and sporocarpic associations have been noted also in the sister genus Anisotoma (Russell, 1979; Wheeler, 1980), although plasmodial feeding is less frequently observed and, considering the well-developed mandibular mola structure, may be facultative. In contrast, at least those highly contractile species related to the common North American species A. oniscoides may be obligate associates of plasmodia (Newton, 1984; Wheeler, 1984a, 1984c). The only hints of similarly obligate plasmodial relations elsewhere are for certain cerylonids, eucinetids, and possibly rhysodids (Stephenson et al., 1994; Vit, 1977). Generalizations are problematic, however, because of the extremely secretive habits of plasmodia under natural conditions. Plasmodia of many species remain hidden throughout their sometimes ephemeral existence, emerging only hours before fruition. Because plasmodia occur among wet decaying leaves, within piles of decomposing vegetation, between lamel- 


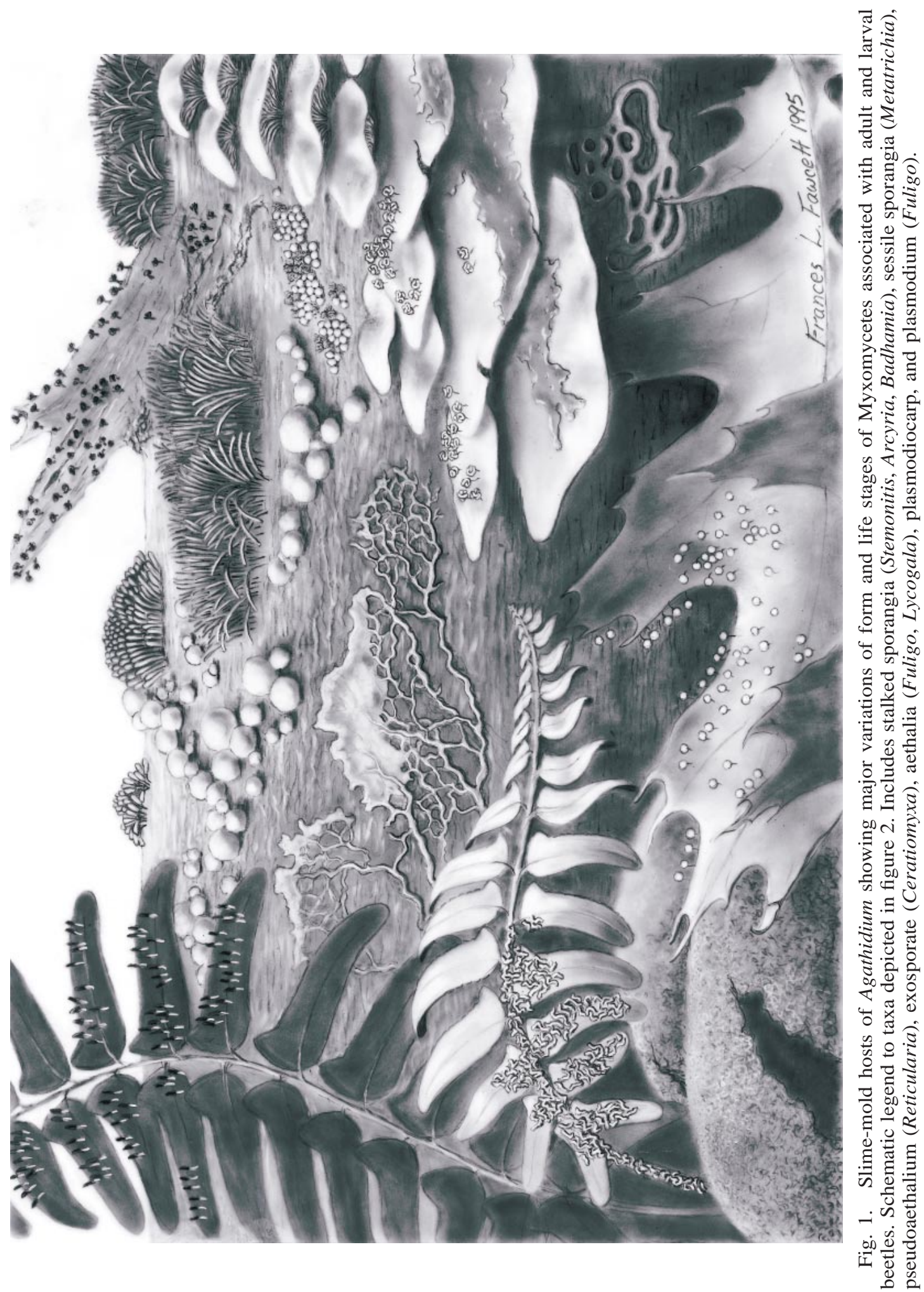




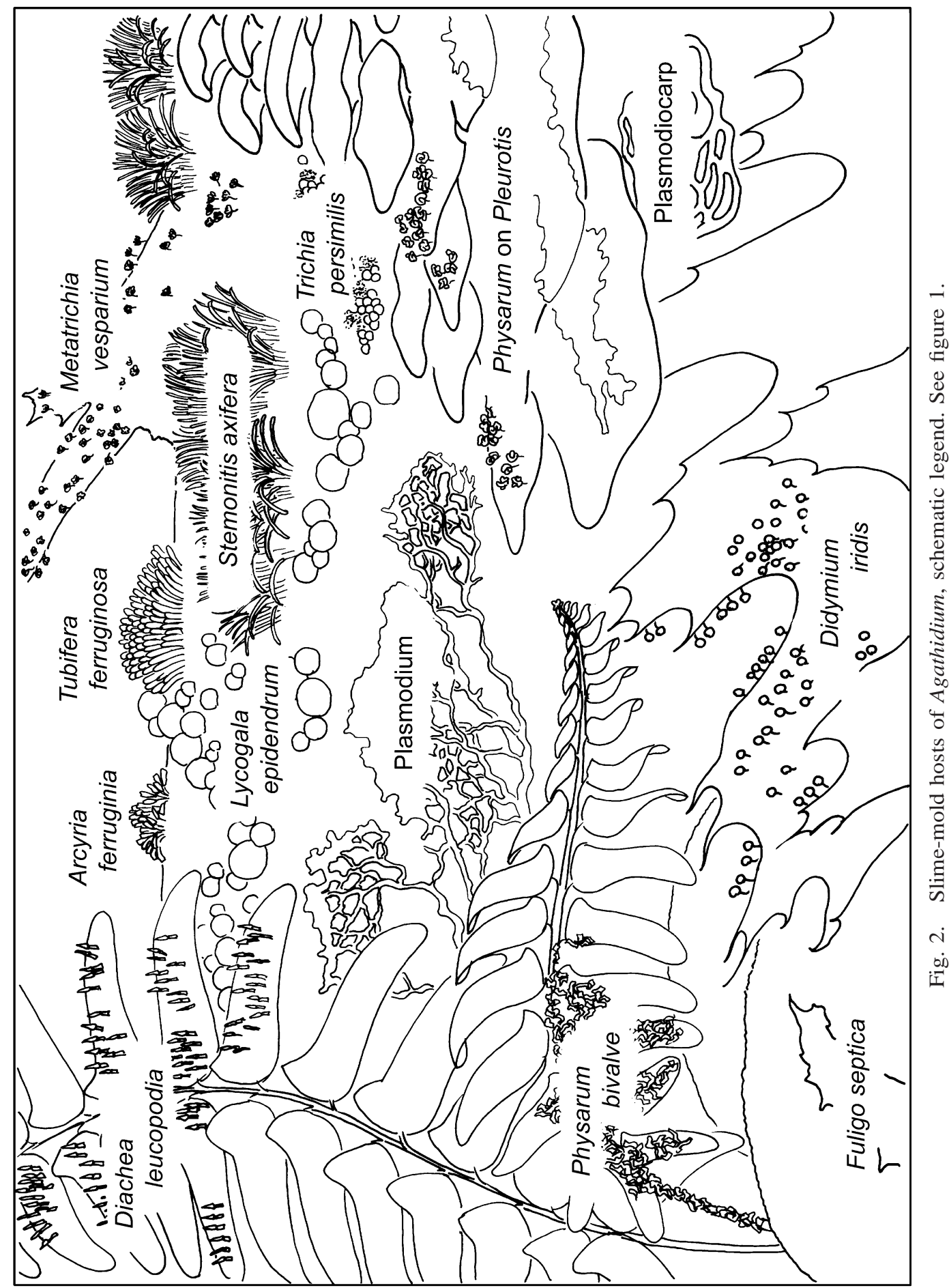


lae of rotting logs, and under loose-fitting bark on trunks of dead trees, they are seldom observed by collectors of beetles. Further, once disturbed, actual feeding is rarely observed. Agathidium have been reared on plasmodia in the laboratory (Wheeler, 1987), but field studies lag far behind circumstantial evidence for widespread, specialized plasmodial predation. It has been elsewhere (Wheeler, 1984a, 1984c) speculated that flightless species of Agathidium in the southern Appalachians of the United States are such plasmodial feeders based on their phylogenetic relationships and modifications of the mandibular mola that suggest a change from ancestral spore-crushing (see also Lawrence, 1977; Lawrence, 1989). The senior author most recently collected such species in the summer of 1994 from wet rhododendron leaf litter. Only once was he able to directly observe one of these flightless beetles sitting upon a plasmodium. However, such dense, wet layers of leaves are difficult microhabitats to investigate.

Slime-mold hosts utilized by Agathidium are numerous and phylogenetically diverse, encompassing most higher taxa of Myxomycetes. These hosts include nearly the full range of sizes, shapes, life stages, and sporocarp forms documented among slimemolds (figs. 1, 2), including stalked and sessile sporangia, cushionlike aethalia, densely packed pseudoaethalia, and plasmodia.

The possibility of spore dispersal by Agathidium and other slime-mold beetles remains poorly investigated. Simple, external, mechanical spore dispersal has been experimentally demonstrated (see Blackwell, 1984). Because some slime-mold spores are known to show increased germination rates given a $\mathrm{pH}$ shock, ingestion by beetles might result in the survival of fewer spores, among which are at least some with enhanced germination potential. Regardless of active beetle dispersal success, the simple act of eating a sporocarp has the effect of disrupting the peridium and releasing large numbers of spores into the immediate environment and into the air as well. Considering the cosmopolitan distribution of many species of Myxomycetes (Martin and Alexopoulos, 1969), it is evident that most disperse quite well unassisted.
In the following synopsis of reported host associations, host data are presented in descending taxonomic order, and the geographic regions covered by the records are indicated by a parenthetical letter following the Agathidium species $(\mathrm{O}=$ Oriental; $\mathrm{N}=\mathrm{Ne}$ arctic; $\mathrm{P}=$ Palearctic). Sources are cited for published records. Number of independent records for each host greater than one indicated in parentheses following "fungus" name. Table 1 shows a summary of these data.

A. angulare (N): Myxomycetes: Brefeldia maxima, Fuligo intermedia, F. septica (2), Stemonitis sp. (2), Tubifera sp. (Cooter, 1978; Lawrence and Newton, 1980; Newton, 1984); "fungus" (Newton, 1984). Comatricha sp., Stemonitis axifera. "Cream colored" and "orange-yellow" plasmodia. Basidiomycetes: Polyporus sp.

A. angustoperculum, n.sp. (N): Basidiomycetes: Polyporus anceps; $P$. sulfurous.

A. annulatum (P): Basidiomycetes: Fomes fomentarius (Hisamatsu, 1957).

A. $\operatorname{arcticum}(\mathrm{P})$ : Myxomycetes: undet.; Fuligo septica (Lundberg, 1960; Palm, 1951). Basidiomycetes: Hansenia abietina (2), Polyporus pinicola, Lactarius piperatus, polypore (Saalas, 1917; Saalas and Schaufuss, 1923); "fungus" (3), "mycelium under bark" (Cooter, 1978; Franz, 1943; Jansson and Palm, 1936; Jansson and Sjöberg, 1932; Palm, 1951, 1959; Rehfous, 1955).

A. aristerium (N): Myxomycetes: Physarum polycephalum (Wheeler, 1987).

A. athabascanum (N): "toadstools", "mushrooms".

A. atronitens (N): Basidiomycetes: Pleurotus ostreatus (Newton, 1984). Specimens identified in many collections as $A$. politum are actually $A$. atronitens. It is possible that host records for Hydnum septentrionale, Polyporus betulinus, and "fungi" therefore apply to this species (Minch, 1952; Park, 1931; Hamilton, 1895).

A. atrum (P): Myxomycetes: (Jansson, 1946). Basidiomycetes: Polyporus squamosus, Armillaria mellea, Hypholoma fasciculare, Tricholoma nudum, "agaricus" (Benick, 1952; Rehfous, 1955; Singer, 1955); "fungus" (6), "fungus dump", "fungusy branches" (Beare, 1899; Donisthorpe, 1911, 1939; Fowler, 1889; Joy, 1904; Polentz, 1938; Rueschkamp, 1928; Singer, 1955).

A. badium (P): Myxomycetes: Fuligo septica (Rehfous, 1955). Basidiomycetes: Hansenia abietina (2), Trametes gibbosa, Stereum hirsu- 
TABLE 1

Host Records for Agathidium Species

(Shaded areas indicate occurrence of species on host.)

\begin{tabular}{|c|c|c|c|c|c|c|c|c|c|c|c|c|c|c|c|c|c|c|c|c|c|}
\hline & 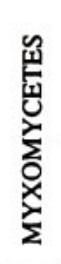 & 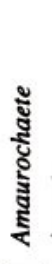 & 交 & 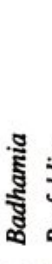 & ปั & 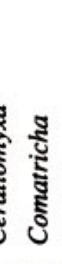 & ปี & 蛋 & 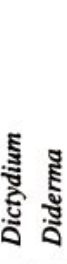 & है & 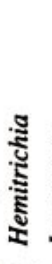 & 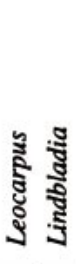 & 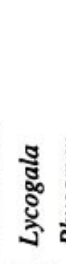 & 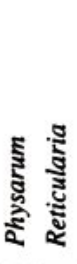 & 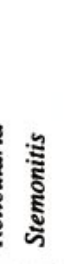 & 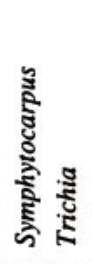 & : & 点 & 点 & & 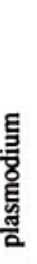 \\
\hline \multicolumn{22}{|l|}{ angulare } \\
\hline \multirow{2}{*}{\multicolumn{22}{|c|}{$\begin{array}{l}\text { annulatum } \\
\text { arcticum }\end{array}$}} \\
\hline & & & & & & & & & & & & & & & & & & $\square$ & 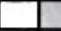 & 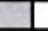 & \\
\hline \multicolumn{22}{|l|}{$\begin{array}{l}\text { angustoperculum } \\
\text { aristerium }\end{array}$} \\
\hline aristerium & & & & & & & & & & & & & & & & & & - & 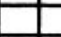 & 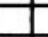 & \\
\hline \multicolumn{22}{|l|}{ athabascanum } \\
\hline \multicolumn{22}{|l|}{ atronitens } \\
\hline \multicolumn{22}{|l|}{$\begin{array}{l}\text { atrum } \\
\text { badium }\end{array}$} \\
\hline badium & & & & & & & & & & & & & & & & & 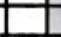 & 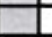 & 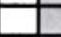 & - & \\
\hline \multicolumn{4}{|l|}{ bicolor } & & & & & & & & & & & & & & & & - & - & \\
\hline \multicolumn{22}{|l|}{ brevisternum } \\
\hline \multicolumn{22}{|l|}{ californicum } \\
\hline \multirow{2}{*}{\multicolumn{22}{|c|}{$\begin{array}{l}\text { compressidens } \\
\text { confusum }\end{array}$}} \\
\hline & & & & & & & & & & & & & & & & & & & & - & \\
\hline \multicolumn{15}{|l|}{ contiguum } & & & & & & 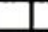 & \\
\hline \multicolumn{22}{|l|}{ convexum } \\
\hline \multicolumn{21}{|l|}{ dentatum } & \\
\hline depressum & & & & & & & & & & & & & & & & & & - & 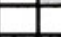 & & \\
\hline difforme & & & & & & & & & & & & & & & & & & - & & & \\
\hline discoideum & & & & & & & & & & & & & & & & & & - & - & - & \\
\hline estriatum & & & & & & & & & & & & & & & & & & & & & \\
\hline exiguum & & & & & & & & & & & & & & & & & $E$ & - & - & - & \\
\hline fawcettae & & & & & & & & & & & & & & & & & - & - & 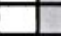 & - & \\
\hline globosum & & & & & & & & & & & & & & & & & & - & - & - & \\
\hline haemorrhoum & & & & & & & & & & & & & & & & & & & 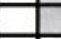 & & \\
\hline kashmirense & & & & & & & & & & & & & & & & & $E$ & & 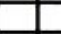 & & \\
\hline kimberlae & & & & & & & & & & & & & & & & & & & - & & \\
\hline laevigatum & & & & & & & & & & & & & & & & & & & - & & \\
\hline maculosum & & & & & & & & & & & & & & & & & & & - & & \\
\hline mandibulare & & & & & & & & & & & & & & & & & & & & & \\
\hline marginatum & & & & & & & & & & & & & & & & & & & E & & \\
\hline mollinum & & & & & & & & & & & & & & & & & & & & & \\
\hline nigrinum & & & & & & & & & & & & & & & & & & & - & - & \\
\hline nigripenne & & & & & & & & & & & & & & & & & & & - & 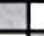 & \\
\hline oniscoides & & & & & & & & & & & & & & & & & & & E & & \\
\hline pallidum & & & & & & & & & & & & & & & & & & & - & & \\
\hline piceum & & & & & & & & & & & & & & & & & & & E & & \\
\hline plagiatum & & & & & & & & & & & & & & & & & & & E & & \\
\hline pulchrum & & & & & & & & & & & & & & & & & & & & & \\
\hline reitteri & & & & & & & & & & & & & & & & & & & E & & \\
\hline rhinoceros & & & & & & & & & & & & & & & & & & & - & & \\
\hline rotundatum & & & & & & & & & & & & & & & & & & & & & \\
\hline rubellum & & & & & & & & & & & & & & & & & & - & - & & \\
\hline seminulum & & & & & & & & & & & & & & & & & & & E & & \\
\hline sphaerulum & & & & & & & & & & & & & & & & & & & & & \\
\hline temporale & & & & & & & & & & & & & & & & & & & & & \\
\hline tribulograndum & & & & & & & & & & & & & & & & & & & 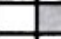 & & \\
\hline tumidiventre & & & & & & & & & & & & & & & & & & & 1 & & \\
\hline varians & & & & & & & & & & & & & & & & & & - & $\square$ & - & \\
\hline Agathidium spp. & & & & & & & & & & & & & & & & & & & & & \\
\hline
\end{tabular}


tum (Rehfous, 1955; Saalas, 1917; Saalas and Schaufuss, 1923); "fungus" (11), "tree fungus" (Bagnall, 1905; Donisthorpe, 1911; Koltze, 1901; Palm, 1951, 1959; Roubal, 1926, 1927; Rueschkamp, 1928; von Wanka, 1908; West, 1925, 1940).

A. bicolor (P): "fungus", "mycelium under bark" (Palm, 1951, 1959).

A. brevisternum (N): Myxomycetes: Fuligo septica (Russell, 1979).

A. californicum (N): Myxomycetes: Fuligo septica (Russell, 1979).

A. compressidens (N): Myxomycetes: Arcyria denudata; Comatricha-like.

A. confusum (P): Myxomycetes: Reticularia lycoperdon (Donisthorpe, 1935). Basidiomycetes: Polystictus versicolor, Coriolus hirsutus, Trametes gibbosa, Pholiota mutabilis, "polypore" (Donisthorpe, 1939; Palm, 1951; Rehfous, 1955); "fungus", "mycelium under bark" (Champion, 1907; Fowler, 1889; Gusmann, 1914; Horion, 1949; Joy, 1932; Koch, 1961; Palm, 1951, 1959; Sjöberg, 1928; West, 1940; Woerndle, 1950; Woodroffe, 1968).

A. contiguum (N): Myxomycetes: Fuligo septica (Russell, 1979).

A. convexum (P): "fungus" (Cooter, 1978).

A. dentatum (P): Myxomycetes: Fuligo septica (Rehfous, 1955); "fungus" (2) (Fleischer, 1910; Uhmann, 1925).

A. depressum (N): Myxomycetes: Stemonitis fusca; Badhamia.

A. difforme (N): Myxomycetes: Stemonitis sp.; Arcyria pomiformis, undet. (Newton, 1984).

A. discoideum (P): Myxomycetes: Fuligo septica, undet. (Lundberg, 1960; Palm, 1951). Basidiomycetes: Polyporus pinicola, Armillaria mellea (Lundberg, 1960; Palm, 1951); "fungus" (10) (Ammann and Knabl, 1922; Gerhardt, 1910; Heiss, 1971; Ihssen, 1939; Palm, 1959; Reitter, 1910; Roubal, 1926; Rueschkamp, 1928; von Wanka, 1915; Woerndle, 1950).

A. estriatum (N): Myxomycetes: Fuligo septica (Lawrence and Newton, 1980).

A. exiguum (N): Myxomycetes: Comatrichia nigra, Reticularia splendens, Stemonitis fusca, Tubifera ferruginosa, plasmodium (Lawrence and Newton, 1980; CUIC, unpubl.); "fungus" (2) (Cooper, 1935; Hamilton, 1895); "shelf fungus",

A. fawcettae n. sp. (Part II) (N): Myxomycetes: Badhamia; Fuligo; Hemitrichia; Leocarpus; Physarum; Tubifera; "fungus".

A. globosum (P): "fungus" (Tomlin, 1915).

A. haemorrhoum (P): "fungus" (2) (Jansson, 1946; Thérond, 1975).

A. kashmirense (O): Myxomycetes: Arcyria cinerea, A. denudata, Trichia favoginea, Tubifera ferruginosa, Cribraria argillacea, C. macrocarpa (?), C. vulgaris, Cribraria sp., Stemonitis axifera, S. hyperopta, Trichia decipiens, undet. (Newton and Stephenson, 1990).

A. kimberlae, n.sp. (part II) (N): Myxomycetes: leaf litter in proximity of plasmodium (Wheeler, 1984).

A. laevigatum (P): Myxomycetes: undet. (Jansson, 1946). Basidiomycetes: Boletus variegatus, Fomes fomentarius (2), Polyporus sp. (Donisthorpe, 1939; Gusmann, 1925; Lindroth and Palm, 1934; Platonoff, 1942); "fungus" (7) (Johnson, 1890; Lentz, 1879; Polentz, 1938; Richards, 1926; Roubal, 1927; von Wanka, 1908).

A. maculosum (N): Basidiomycetes: Fomitopsis pinicola, Phellinus gilvus (Newton, 1984).

A. mandibulare (P): Basidiomycetes: Polyporus sp. (Luigioni, 1920); "fungus", "fungus on aspen" (Jansson, 1924; Meinert, 1893; Palm, 1951, 1959; Roubal, 1927; Rueschkamp, 1928; Schiødte, 1862; Wiepken, 1886; Woerndle, 1950).

A. marginatum (P): Myxomycetes: (Jansson, 1946); "fungus", "fungusy bark" (3) (Jansson, 1946; Polentz, 1938; Rueschkamp, 1928).

A. mollinum (N): Myxomycetes: Leocarpus fragilis (Lawrence and Newton, 1980); Cribraria purpurea; Diderma floriforme; Stemonitis axifera.

A. nigrinum (P): Myxomycetes (2): Reticularia lycoperdon (Dajoz, 1966; Palm, 1951). Basidiomycetes: Polyporaceae (Palm, 1951); 'fungus", "mycelium under bark" (8) (Fowler, 1889; Jansson, 1918b; Palm, 1951, 1959; Rye and Sharp, 1865; Sharp, 1871; Thomson, 1862; Wiepken, 1886).

A. nigripenne (P): Basidiomycetes (5): Phellinus igniarius (1), Hansenia abietina (2), Polyporus squamosus (1), Polyporaceae (Hincks and Shaw, 1951; Jansson and Sjöberg, 1932; Nuss, 1975; Platonoff, 1942; Saalas, 1917). Ascomycetes: Daldinia concentrica (1) (Hingley, 1971); "fungus", "mycelia under bark', "fungusy bark" (14) (Bagnall, 1905; Barner, 1922; Donisthorpe, 1939; Ihssen, 1939; Lentz, 1879; Palm, 1951, 1959; Palmen, 1946; Poppius, 1905; Saalas, 1917; Sick, 1930; 1939; Singer, 1955; West, 1940).

A. oniscoides (N): Myxomycetes: Arcyria denudata, Craterium minutum, Diderma floriforme, Fuligo septica, Stemonitis fusca, plasmodium (2), undet. (Stephenson et al., 1994; CUIC, unpubl.). Basidiomycetes: Fomes applanatus, Hydnum septentrionale (Park, 1931; Park et al., 1931); "fungus" (2) (Blatchley, 1910; Hamilton, 1895); Ceratiomyxa fruticulosa, "yellow slime mold", and "clear myxomycete". 
A. pallidum (P): "fungus", "fungusy bark", "mycelium under bark" (3) (Palm, 1947, 1951).

A. piceum (P): Basidiomycetes: Boletus veriegatus (2) (Benick, 1952; Gusmann, 1925); "fungus" (3) (Hansen, 1922b; Thérond, 1975; West, 1940).

A. plagiatum (P): “fungus" (4) (Horion, 1949; Palm, 1959; Uhmann, 1925; von Wanka, 1915).

A. pulchrum (N): Myxomycetes: Arcyria denudata, A. incarnata, A. nutans, A. versicolor, Comatricha suksdorfi, Fuligo septica, Lycogala epidendrum, Stemonitis axifera, S. flavogenita, S. sp. (2), Trichia decipiens, Tubifera ferruginosa, Tubifera sp., undet. (Lawrence and Newton, 1980; Russell, 1979; Stephenson et al., 1994) Basidiomycetes: Coriolus versicolor, Lenzites betulina (Newton, 1984); fungus (Fall, 1901).

A. reitteri (P): Myxomycetes: Reticularia lycoperdon (Donisthorpe, 1935); "fungus" (Donisthorpe, 1929).

A. rhinoceros (P): Myxomycetes: Reticularia lycoperdon, Symphytocarpus flaccidus (Donisthorpe, 1935; Ing, 1967). Basidiomycetes: Fomes sp. (Angus, 1965); "fungus" (2) (Harwood, 1925; Roubal, 1909).

A. rotundatum (P): Myxomycetes: Arcyria denudata, Lycogala epidendrum, undet. (Ing, 1967; Palm, 1951; Russell, 1979). Basidiomycetes: Fomitopsis ungulata (2), Hansenia abietina, Polyporus fomentarius, Polyporus sp. (Jansson and Palm, 1936; Platonoff, 1942; Saalas, 1917; Saalas and Schaufuss, 1923); fungus (14) (Bennett, 1893, 1899; Cooter, 1978; Fowler, 1889; Harwood, 1925; Joy, 1904; Koltze, 1901; Palm, 1959; Roubal, 1926; Rye and Sharp, 1865; Saalas, 1917; Strand and Hanssen, 1932; Walker, 1874, 1875).

A. rubellum (N): Myxomycetes: Tubifera ferruginosa, "mushrooms".

A. seminulum (P): Myxomycetes: Fuligo septica (2), Reticularia lycoperdon, Trichia cinnabarina (3) (Donisthorpe, 1935, Perris, 1851; Rehfous, 1955; Weber, 1925; West, 1940) Basidiomycetes: Auricularia auricula; Coriolus versicolor, Lenzites betulina, Polyporus caudicinus, $P$. squamosus, Trametes gibbosa, Collybia platyphylla, Hypholoma fasciculare (Benick, 1952; Eisfelder, 1963; Rehfous, 1955; Saalas, 1917); "fungus", "mycelium under bark" (13) (Ammann and Knabl, 1922; Derksen, 1941; Donisthorpe, 1939; Koltze, 1901; Palm, 1951, 1959; Polentz, 1938; Roussin, 1947; Rueschkamp, 1928; Saalas, 1917; Saalas and Schaufuss, 1923; von Wanka, 1908; Williams, 1924).

A. sphaerulum (P): Basidiomycetes: Polyporus fomentarius, Polyporus sp. (Brundin, 1934;
Lindroth and Palm; 1934); "fungus" (8) (Allen, 1954; Jansson, 1924; Jansson and Sjöberg, 1932; Johnson, 1962; Lindberg, 1933, 1937; Sjöberg, 1928; West, 1940).

A. temporale (N): Myxomycetes: Fuligo septica (7) (S.L. Stephenson, unpubl. record).

A. tribulograndum, n.sp. (part II) (N): "fungusy wood chips".

A. tumidiventre, n.sp. (part II) (N): "gilled mushroom".

A. varians (P): Basidiomycetes: Anisoporus odorus, Polyporus fomentarius, $P$. squamosus, Polyporus sp., Pholiota mutabilis, Trametes gibbosa, Tricholoma terreum (Jansson, 1918a; Nuss, 1975; Rehfous, 1955; Rueschkamp, 1928); "fungus", "fungus on aspen", "fungusy branches", "moldy leaves" (10) (Gerhardt, 1890, 1910; Jansson, 1918b; Morley, 1899; Palm, 1951, 1953, 1959; Roeben, 1907; Rueschkamp, 1928).

Agathidium spp.: Myxomycetes: undet. plasmodium, sclerotium (Stephenson et al., 1994); Amaurochaete ferruginea, Arcyria denudata, A. nutans, A. pomiformis, A. stipata, Badhamia sp., Ceratiomyxa fruticulosa, Comatricha alpina, C. nigra, C. typhoides, Cribraria intricata (2, 1?), C. splendens (?), C. purpurea, C. rufa, Cribraria sp. (2), Dictydium cancellatum, Diderma floriforme, D. niveum, Fuligo intermedia, F. septica (2), Hemitrichia clavata, Leocarpus fragilis, Lindbladia tubulina, Lycogala epidendrum, Physarum viride, Reticularia splendens?, Stemonitis axifera, S. flavogenita, S. hyperopta, Stemonitis sp., Tubifera ferruginosa (Lawrence and Newton, 1980; Newton and Stephenson, 1990; Stephenson et al., 1994; Wheeler, 1984a). Basidiomycetes: Hansenia abietina (Saalas, 1917); “fungus" (5) (Anonymous, 1889; Lundberg, 1984; Rottenberg, 1864; Roubal, 1924; Weber, 1916).

From these data and those for Anisotoma (Blackwell, 1984; Lawrence and Newton, 1980; Russell, 1979; Wheeler, 1979b, 1984a, $1984 \mathrm{c}$ ) it is reasonable to conclude with Newton (1984) that whereas Anisotoma species appear to be obligate slime-mold feeders, evidence for Agathidium is less conclusive. Of 27 species reported from Myxomycetes, about $56 \%$ are reported also from Basidiomycetes. And of 21 species noted from Basidiomycetes, $38 \%$ are known also from Myxomycetes. Thirty-two species are reported from Myxomycetes, 23 from Basidiomycetes, and 14 are noted from both. Eighteen species of Agathidium are recorded from 
Myxomycetes exclusively, whereas nine species are recorded only from Basidiomycetes.

Some species have been reported so many times from diverse Basidiomycetes that an association with these higher fungi is strongly suggested. This is reinforced by reports of spores of Polyporus squamosus in the gut of Agathidium seminulum (Hlisnikovský, 1964). Further, whereas species of diverse species groups (including three subgenera as generally recognized: Agathidium s.s., $C y$ phoceble, and Neoceble) have been associated with Myxomycetes, species of these same groups have been repeatedly associated with Basidiomycetes also. For at least some of these species, however, there may be an alternative explanation.

Agathidium aristerium was observed feeding on plasmodia of the myxomycete Physarum polycephalum growing on the surface of oyster shell fungi (Pleurotus ostreatus: Tricholomataceae) on a beech tree in New York state (Wheeler, 1987). This epimycetic growth of Physarum polycephalum on Pleurotus is a phenomenon known well to mycologists, and the plasmodia of this and other slime-molds grow upon the surfaces of declining sporocarps of higher fungi. For at least some basidiomycete host reports for Agathidium it seems possible that plasmodia could have been present but undetected by collectors. In the future, special care should be taken to examine host Basidiomycetes carefully to ascertain if and when this may be the case.

The occurrence of apparently both slimemold and higher fungus feeding in Agathidium, combined with the occurrence of slime-mold feeding only in the related genus Anisotoma, reinforces the hypothesis that slime-mold associations may have been ancestral for the two clades combined and, by extension, for Agathidiini as a whole (Newton, 1984; Wheeler, 1984a, 1984c).

\section{COLLECTING AGATHIDIUM}

Specimens of Agathidium species may be collected either by hand directly from host slime-molds or indirectly by means of certain mechanical contrivances or traps. The most difficult part about searching for Agathidium on Myxomycetes is developing an eye (i.e., search image) for the hosts. Sporocarps of Myxomycetes are so diverse in size, shape, and color that learning to recognize all or most of them as slime-molds is in itself an accomplishment (figs. 1, 2). Fruiting bodies vary from minute, stalked forms less than 1 $\mathrm{mm}$ in height to enormous cushionlike fruitions of Fuligo or dense patches of hairlike Stemonitis that may be more than a foot in diameter. Similarly, plasmodia vary from microscopic, transparent, amoeboid forms to the world's largest polynucleated cells. Agathidium aristerium, for example, was first discovered breeding on a plasmodium of Physarum that was estimated to be larger than 4 feet in diameter! Some slime-molds are easily recognized, even in the plasmodial stage. Most are positively identified only with more careful, microscopic study (Martin and Alexopoulos, 1969).

Once located, slime-molds may be removed with a piece of their substrate for closer examination. It is useful to hold a white sheet or a white box under the fruiting body while it is cut away from its substrate with a sharp knife blade. Sporocarps may be returned to the laboratory, where they can be spread upon a light-colored background under the heat of a desk lamp for sorting. Beetles covered by host spores are amazingly difficult to see. However, once heated, beetles will become active and easily spotted and sorted from the mass of host spores. Vouchers of sporocarps may be kept by gluing them to the inner surface of the lid of a fungus specimen box and drying them completely.

Because plasmodia are easily damaged or desiccated, it is sometimes easier to simply examine them closely in the field. Both adult and larval beetles may be seen upon plasmodia since they lack the cover of spores afforded by mature hosts. Some plasmodia, particularly certain pigmented ones (such as the common yellow Physarum and Fuligo species), can be induced to mature by exposing them to intense light as, for example, setting them in a Petri dish in direct sunlight on a window sill. They can be collected and kept in the laboratory on either agar plates or damp filter paper onto which are placed one or two flakes of old-fashioned oatmeal. Upon fruition, such forms may be positively 
identified. Mycologists sometimes have clues to plasmodial identification that can be very helpful to the entomologist. Mustard yellow plasmodia that stain brick red upon "bruising" (that is, touching them with one's finger) are usually members of the genus Fuligo, though we do not know that similar bruising does not exist in other genera. Some plasmodia, including Fuligo, have a characteristic odor that can be quite strong when the plasmodium is expansive. Occasionally a plasmodium can be smelled before locating it visually. It has a sweet, earthy smell. Nonpigmented plasmodia are more difficult to see, such as the gray, jellylike Stemonitis plasmodium that can be quite substantial in size.

Flighted species may be collected using large-area flight-intercept traps of the kind described by Peck and Davies (1980). Both flighted and flightless species may be collected by sifting leaf litter, decaying wood, and similar substrates likely to include slimemolds and placing the siftate in a tullgren or Berlese funnel. This is particularly effective for collecting flightless species that are common in the Appalachians and Ozarks. In fact, during wet times of the spring and fall months in the Appalachians, sifting samples of mixed rhododendron-hardwood litter along mountain streams predictably yields one or more such species. In such circumstances leiodids often are exceeded in number of individuals only by carabids.

\section{MORPHOLOGY}

A detailed account of the morphology of Agathidium oniscoides is presented below. This is done to indicate through accurate illustrations the structures referred to in formal descriptions, and to establish a basis for comparative morphological studies within and outside of Agathidium. Agathidium oniscoides was selected as a representative species for biological and practical reasons. It is one of the most common and abundant species of northeastern North America, making many specimens available for study. Its comparatively large size made illustration of certain structures easier. Because its eggs, larvae, and pupae are known, adult structures may be seen in ontogenic context. Knowledge of slime-mold associations of A. oniscoides makes conjectures about the functional significance of its morphology possible. For theoretical reasons, one might prefer a species less removed from the ground plan for the genus Agathidium. For example, differences between species of the A. sexstriatum species group and related taxa, notably Anisotoma species, are few and as such one of these species might have made a good choice. However, the morphology of Anisotoma has already been discussed elsewhere (Wheeler, 1979b), and A. oniscoides is more typical of the highly contractile forms generally thought of as representative Agathidium.

The morphology of adult and pupal stages of A. oniscoides is given below. The eggs that have been seen in the course of female dissections have been oval, shiny, whitish colored, without striking structural details at low magnifications, and notable only in their large size relative to the abdominal cavity. Agathidium larvae are active, eruciform, and setose and are rather broad and dorsoventrally compressed in shape (Wheeler, 1990a). There are three postembryonic larval instars that are rich in external characters, particularly with regard to chaetotaxy. The comparative morphology and ontogeny of larval semaphoronts of three North American species of Agathidium were described elsewhere in detail (Wheeler, 1990a), including all postembryonic instars of $A$. oniscoides. These data were used in a critical evaluation of Nelson's (1978) biogenetic rule published separately (Wheeler, 1990b). Additional descriptions of larvae are given by Kilian (1998).

\section{AdulT}

\section{Figures 3-37}

BODY FORM (figs. 3-5): Very broadly round, combined elytra about as wide as long; very convex, hemispherical; pronotum laterally expanded; sterna, particularly prosternum and metasternum, short; capable of contracting body into compact, ball shape concealing venter and appendages; length about $4.0-6.0 \mathrm{~mm}$, extended; moderately heavily sclerotized; dorsum smooth, shiny, with at most microscopic setose punctures, but under low to moderate magnification 

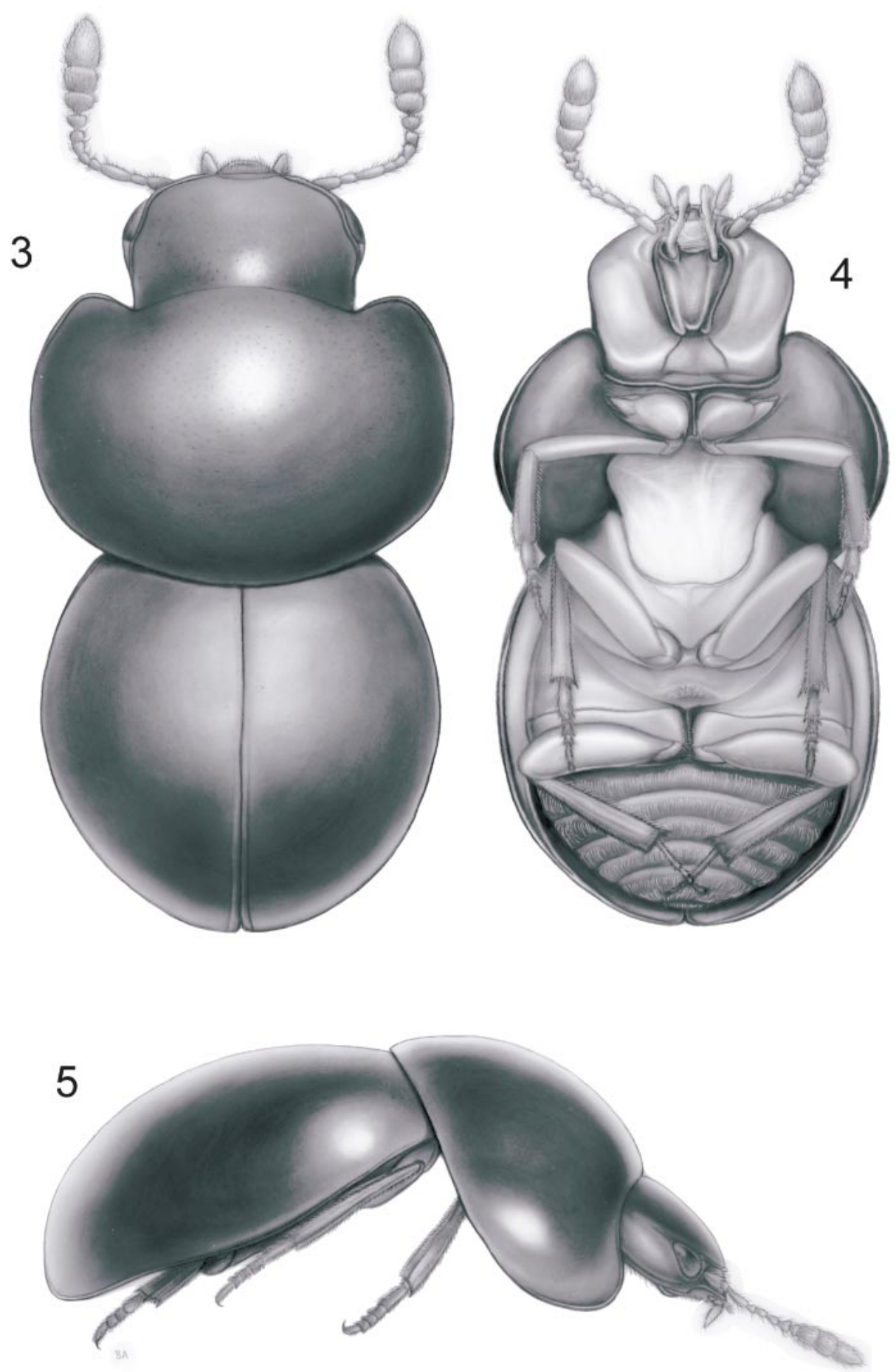

Figs. 3-5. Agathidium oniscoides Palisot de Beauvois, habitus: 3, dorsal; 4, ventral; 5, lateral. 
(e.g., 10-25×) nearly devoid of punctation or setation; color at maturity dark reddishbrown to black.

MORPHOMETRICS (figs. 6-8): If few specimens were available, then all of them were measured. If more material was available, then four or five of the smallest and largest individuals were measured to give an indication of the size range for the species. Measurements were made on a Wild M3C dissecting microscope at $64 \times$ magnification using a Lasico digital micrometer. Morphometrics referred to in this study include the following primary measures, some of which are presented in the text in the form of relative ratios:

OHW Ocular head width-measured at midpoint of longitudinal axis of eye.

PHW Postocular head width-measured at posterior margin of eye.

MDL Median head length-measured from base of labrum to posterior margin of cranium.

PNW Pronotal width-measured at midpoint of longitudinal axis, measured in practice in ventral view to avoid problems of curvature in dorsal orientation.

PNH Pronotal height—distance along imaginary axis from midpoints of dorsum and lateral margin, measured in lateral view.

PNL Pronotal length—measured along midline.

ELW Elytral width-combined elytral widths at longitudinal midpoint.

SEL Postscutellar elytral lengthlength of elytra along suture from posterior margin of scutellum to apex.

ELH Elytral height-measured along imaginary axis between halfway points of elytral dorsum and lateral margin in lateral view.

MSL Mesosternal length-measured at midline.

MTL Metasternal length—measured at midline.

MTW Metasternal width-measured between posterolateral corners.

TBL Total body length - the sum of head length (MDL) + pronotum length (PNL) + postscutellar elytral length (SEL).
MFD

$\begin{array}{ll}\text { greatest width. } & \\ \text { Antennomeres } & \text { Length of antennomeres-mea- }\end{array}$ I-XI sured along dorsal midline.

CRANIUM (figs. 9-12): Prognathous, very broadly quadrate (cf. figs. 11, 12); dorsoventrally compressed (figs. 9, 10), height less than one-third cranial width; wider than long $(\mathrm{OHW} / \mathrm{MDL}=1.4)$; vertex large, flat; with distinct supraocular ridge from edge of clypeus nearly to posterior margin of head; postocular temporum short, not prominent in dorsal view; eyes anterolaterally positioned, rounded in dorsal view, more angulate in ventral view, finely faceted; genae broad, each nearly as wide as clypeus; clypeus quadrate; frontoclypeal suture faint medially, incompletely separating clypeus from frons; gular sutures convergent posteriorly and slightly divergent at apices; ventral antennal grooves present between eyes and gular sutures, convergent posteriorly, shallowly impressed; occipital foramen small, about onethird width of cranium (fig. 9); tentorium with distinct anterior and posterior bridges (fig. 9); antenna inserted anterior to eye, beneath supraocular ridge (fig. 10).

Members of other species of Agathidium (especially the $A$. concinnum and A. pulchrum groups) often have a moderately distinct crease extending transversely across the medial portion of the head. With the head fully extended forward, this crease receives the anterior, curved margin of the pronotum. Agathidium oniscoides lacks this crease.

ANTENNA (figs. 13, 14): Short, with abrupt 3-segmented club; antennomere I large, narrow and geniculate at base, wider distally, with sparse setae; antennomere II short, wide; antennomere III elongate, much longer than II, slightly expanded at apex, with sparse setae, including subapical circle of larger setae; antennomeres IV and V short, wider in apical half, with sparse fine setae and subapical circle of larger ones; antennomeres VII and VIII short and comparatively more transverse, with comparable setation; antennomeres IX and X subquadrate, similarly proportioned, with dense fine setation, and subapical "ring" of larger setae; antennomere XI elongate, narrowed apically, surface similar to antennomeres IX and X. Antennomeres IX and X with two Hamann's 

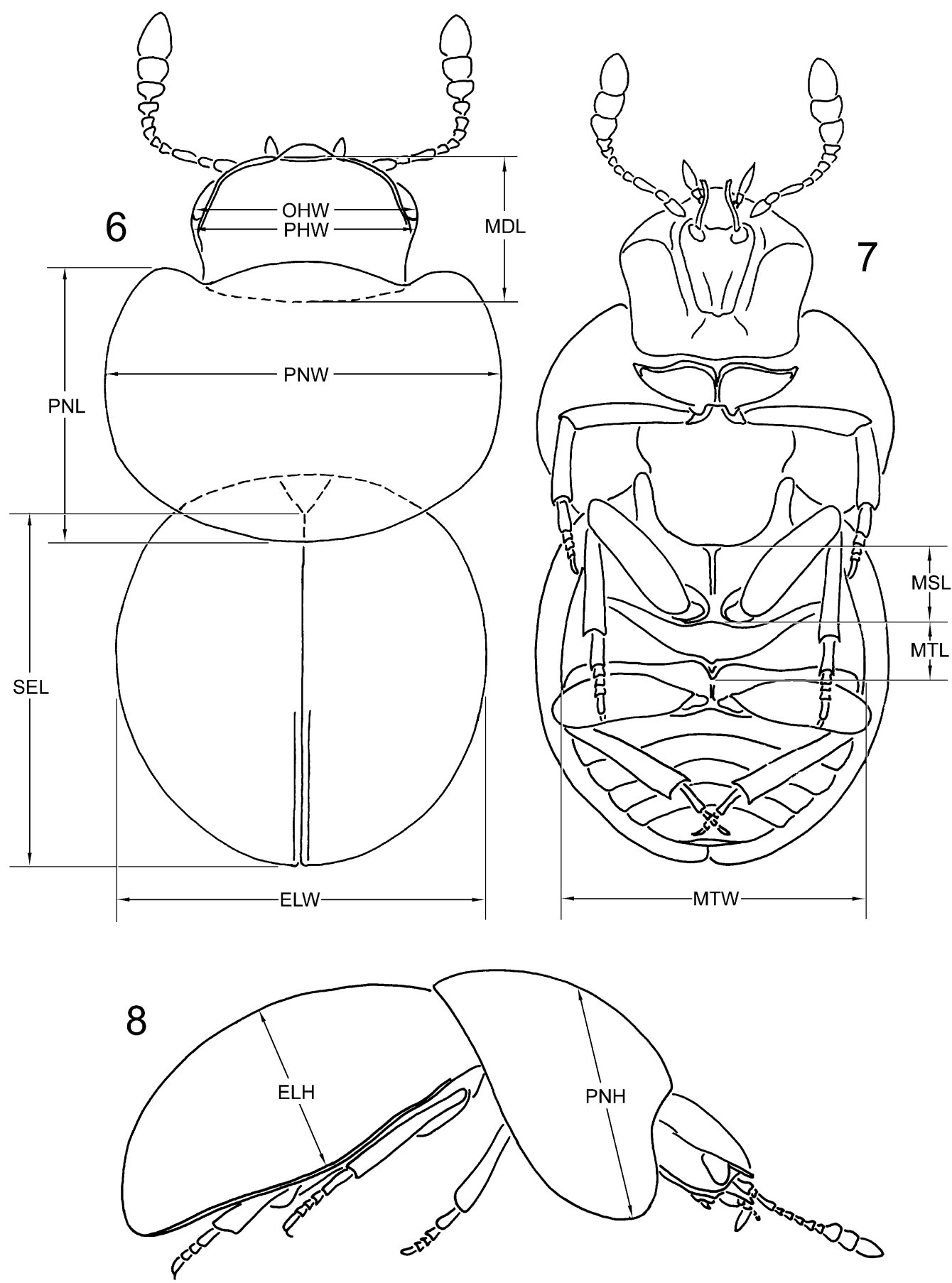

Figs. 6-8. Schematic drawings of Agathidium oniscoides Palisot de Beauvois showing various body measurements: $\mathbf{6}$, dorsal; $\mathbf{7}$, ventral; $\mathbf{8}$, lateral. See text for explanation of abbreviations. 

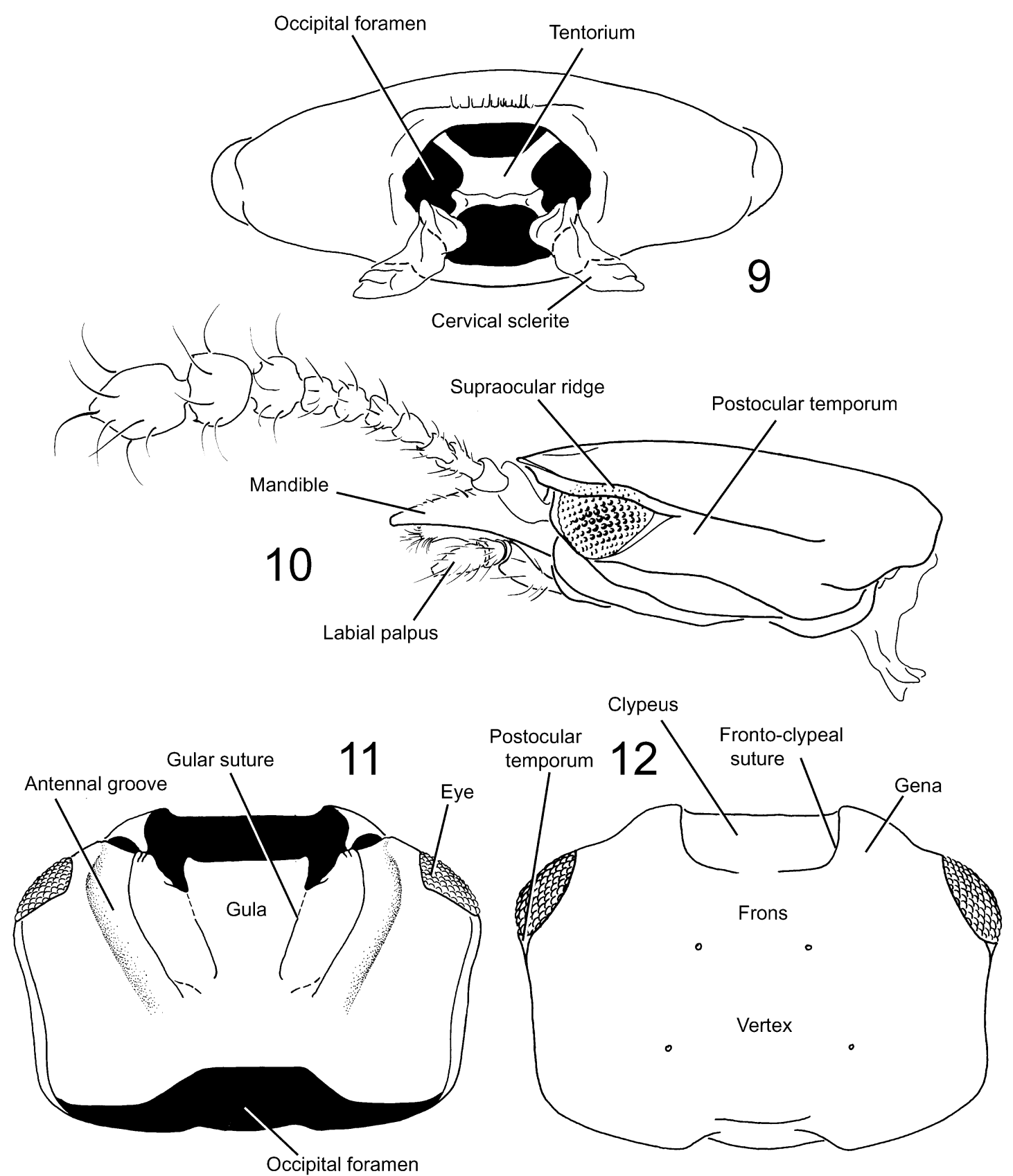

Figs. 9-12. Agathidium oniscoides Palisot de Beauvois, cranium: 9, posterior; 10, lateral; 11, ventral; 12, dorsal.

organs present, opening into periarticular gutter (fig. 14).

Maxilla (fig. 15): Cardo small, quadroid; stipes short, broad, with single lateral seta; lacinia broad, apex truncate; dense minute asperities basally; dense erect setae at apex, obscuring apical row of spines and apical tooth; galea broad, apex rounded, bearing dense long fine setae, basal two-thirds covered by dense minute asperities; palpifer 


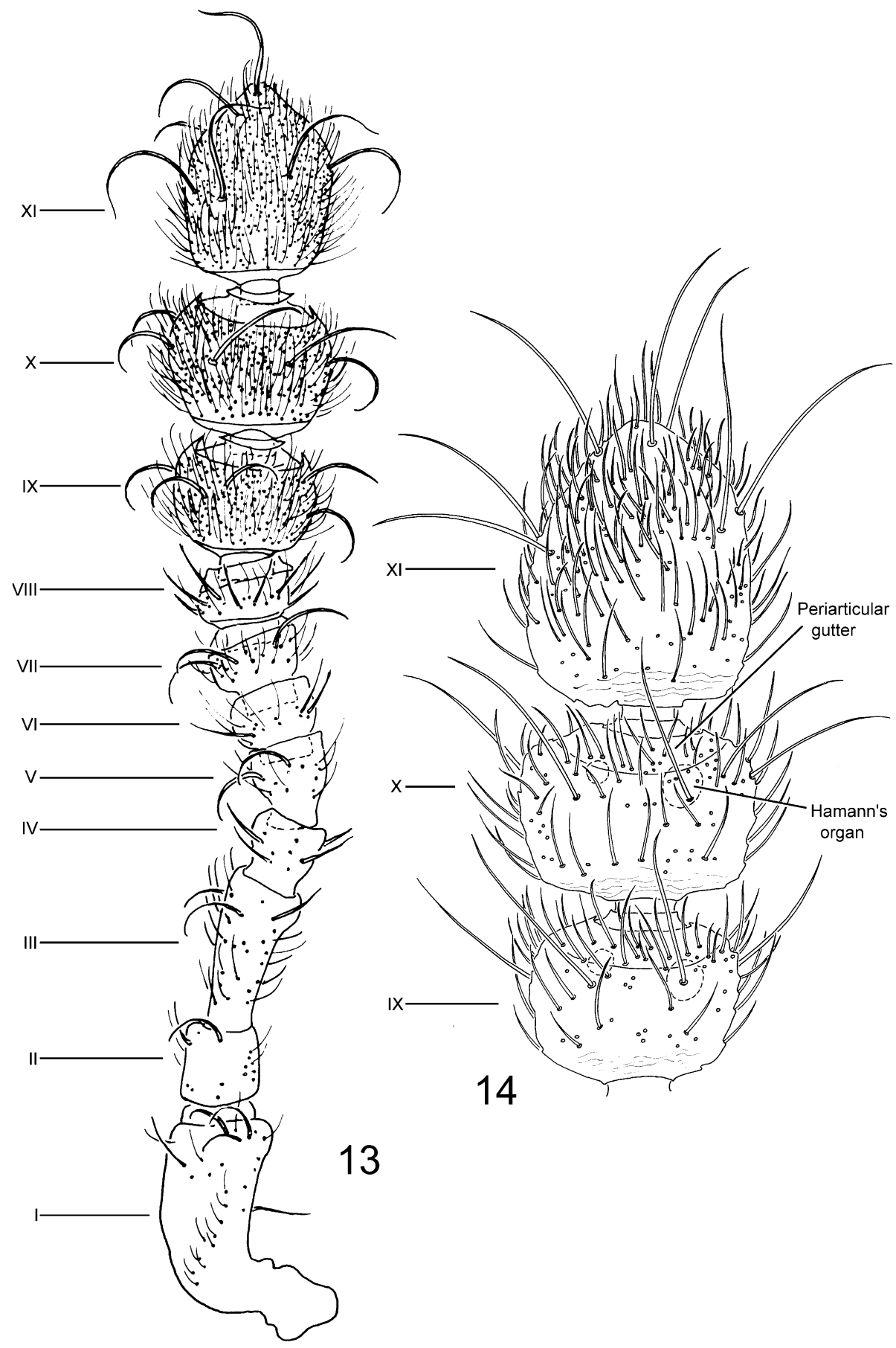

Figs. 13, 14. Agathidium oniscoides Palisot de Beauvois, antennae: 13, antenna; 14, apical antennomeres. 


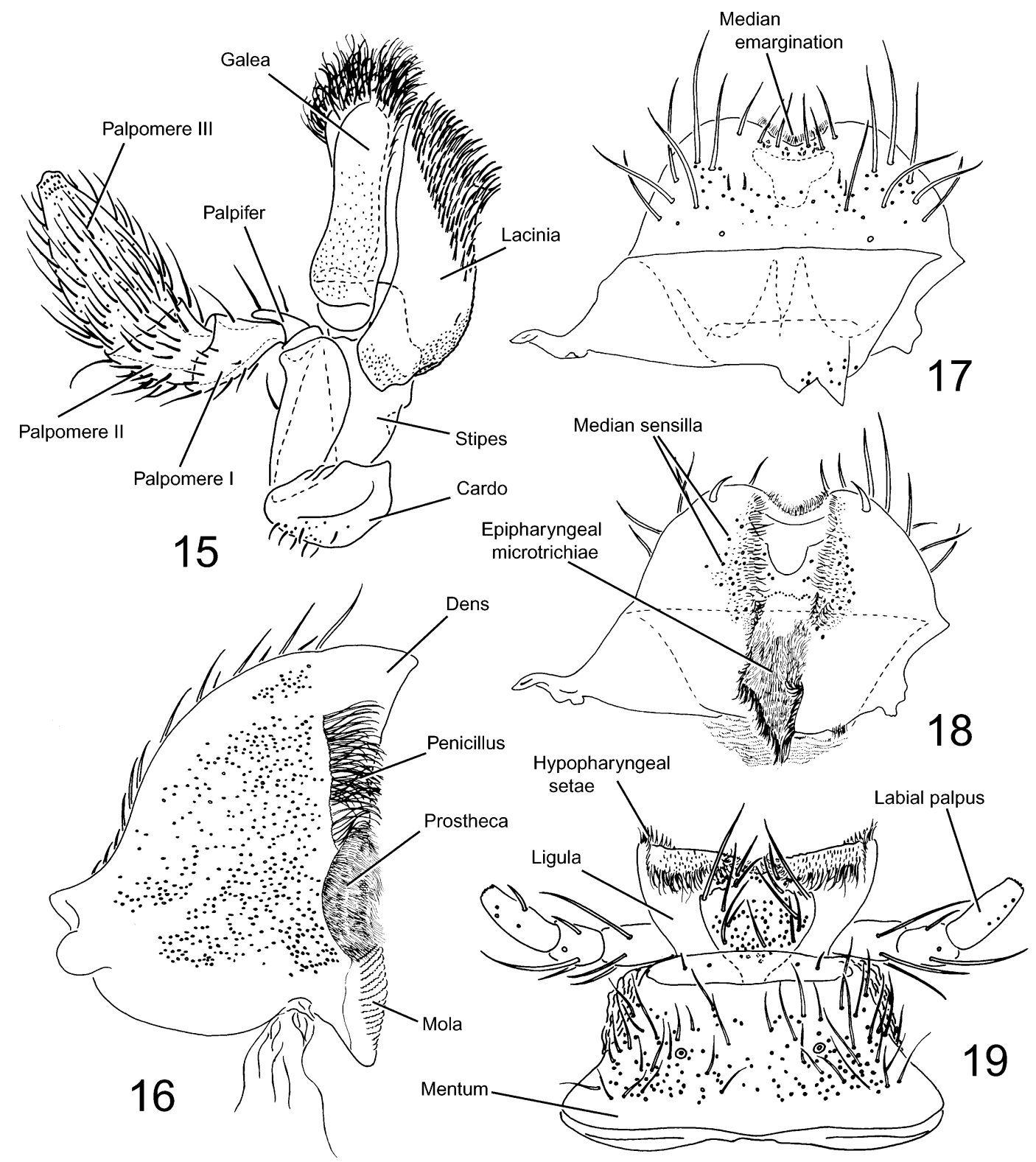

Figs. 15-19. Agathidium oniscoides Palisot de Beauvois, mouthparts: 15, maxilla; 16, mandible; 17, labrum, dorsal; 18, labrum, ventral; 19, labium, ventral.

small; palpus with three palpomeres; palpomere I narrow at base, campanulate, with few setae; palpomere II broader, widened apically, covered by long setae; palpomere III large, narrowed apically, covered by long setae, apex with numerous minute sensilla.

MANDIBLE (fig. 16): Broad, short, robust; with single apical dens; subapical orthogonal penicillus of long, fine setae; subbasal prostheca covered in very dense, fine, short setae; mesobasal mola with poorly defined parallel transverse and slightly serrate lines.

LABRUM AND EPIPHARYNX (figs. 17, 18): Labrum transverse, with median emargination fringed with dense, minute setae; dorsal surface with 3 pairs of short, mesal, subapi- 
cal setae, about 7 pairs of large lateral, dorsal setae, about 2 pairs of minute setae near midline of dorsal surface, and a pair of sensilla near base (fig. 17). Adoral surface with short, broad paired setae near apex, paired median fields of sensilla, and paired median fringe of microtrichiae. Epipharynx membranous, with very dense, fine microtrichiae (fig. 18).

LABIUM (fig. 19): Mentum broad at base, narrowed distally, with paired sensilla near middle, numerous asperities, and moderately dense setae; ligula broad apically, very shallowly emarginate, with median sclerotized plate bearing setae and dense apical setae merging with hypopharyngeal setae.

Pronotum (figs. 3, 20): Wide, very convex; prohypomeron very broad, convex, receiving and overlapping humeral angles of elytra when body contracts; procoxa transverse; procoxal cavity externally closed posteriorly, small, and round; prosternum short; cervical opening broad; prothoracic spiracle elliptical.

Mesosternum (figs. 4, 21): Short; divided by lateral line into anterior and posterior parts; with median carina; mesocoxal cavity large, transverse, closed externally.

Metasternum (figs. 4, 21, 24): With oblique line ("linee fimorali" of Angelini and de Marzo, 1980); metepisternum narrow; intercoxal process narrow (fig. 21). With median fovea in male (see below). Metendosternite compact, furcal arms broad, separated by distinct median lamina (fig. 24).

Elytron (figs. 3, 22): Combined elytra about as broad as long; surface appears impunctate at low magnification, with microscopic setose punctures, barely visible at higher magnifications (e.g., 60-80×); humeral angle obtuse, poorly defined; epipleuron broad, narrowed posteriorly; subcuticular serial vestiges visible posteriorly in cleared specimens under transmitted illumination.

HIND WING (fig. 23): With reduced venation; costa and subcosta fused $(\mathrm{C} / \mathrm{Sc})$, confined to basal 0.40 length anterior margin of wing; median vein (M) well defined in apical half; sclerotized field present between median line and costa-subcosta; cubitus $(\mathrm{Cu})$ well defined in apical half of wing; two well-developed anal veins present (A).

LEGS (figs. 25-31): Elongate, straight; femur broad, partially excavate near apex at tibial insertion when flexed, metafemur of male sometimes with subapical tooth (see below); tibia narrow, with anterior carina, rows of setae; apex fringed with stout crown of spines; tibial spurs small on prothoracic leg, larger on mesothoracic leg, very large on metathoracic leg. Tarsomeres sexually dimorphic: ô 5-5-4 / ㅇ 5-4-4. Pro- and mesobasotarsomeres (especially I + II) expanded in male, bearing dense ventral spatulate setae.

Abdomen (fig. 35): Short, broad; sternite III (first visible sternite) longer, with deep, broad coxal depressions, pointed intercoxal process; IV-VII gradually narrowed; VIII small.

\section{Male Sexual Dimorphism}

Male and female Agathidium differ in a number of secondary sexual characters. Males have enlarged basal tarsomeres on the front and middle pairs of legs and dense, spatulate ventral setae on the expanded tarsomeres, a metasternal fovea, a metafemoral tooth, and (in some) mandibular tusks. Each is described for male A. oniscoides and discussed in general below.

PRO- AND Mesobasotarsomeres: Three basal tarsomeres of front (fig. 30) and middle leg moderately laterally expanded, with dense ventral pad of elongate, spatulate setae.

Metasternal Fovea (fig. 21): Small, round, located medially, bearing tuft of long, golden setae.

The metasternal fovea is present in almost all male Agathidium, although its placement, size, and shape vary considerably. It is always found at the midline. It is usually located near the center of the metasternum, but is sometimes placed near its anterior or posterior margin. The fovea is single or, more rarely, paired. It can be minute and punctiform, larger and circular, or very large and transversely arcuate in shape. The fovea usually bears a tuft of long, fine, golden setae that each stand individually erect or are, frequently, pasted together as a brush.

Similar foveae are found in other male Agathidiini, including Anisotoma species (Wheeler, 1979b). Foveae are also sometimes found on the labium in this taxon. Faustini (1980) and Faustini et al. (1981) examined 

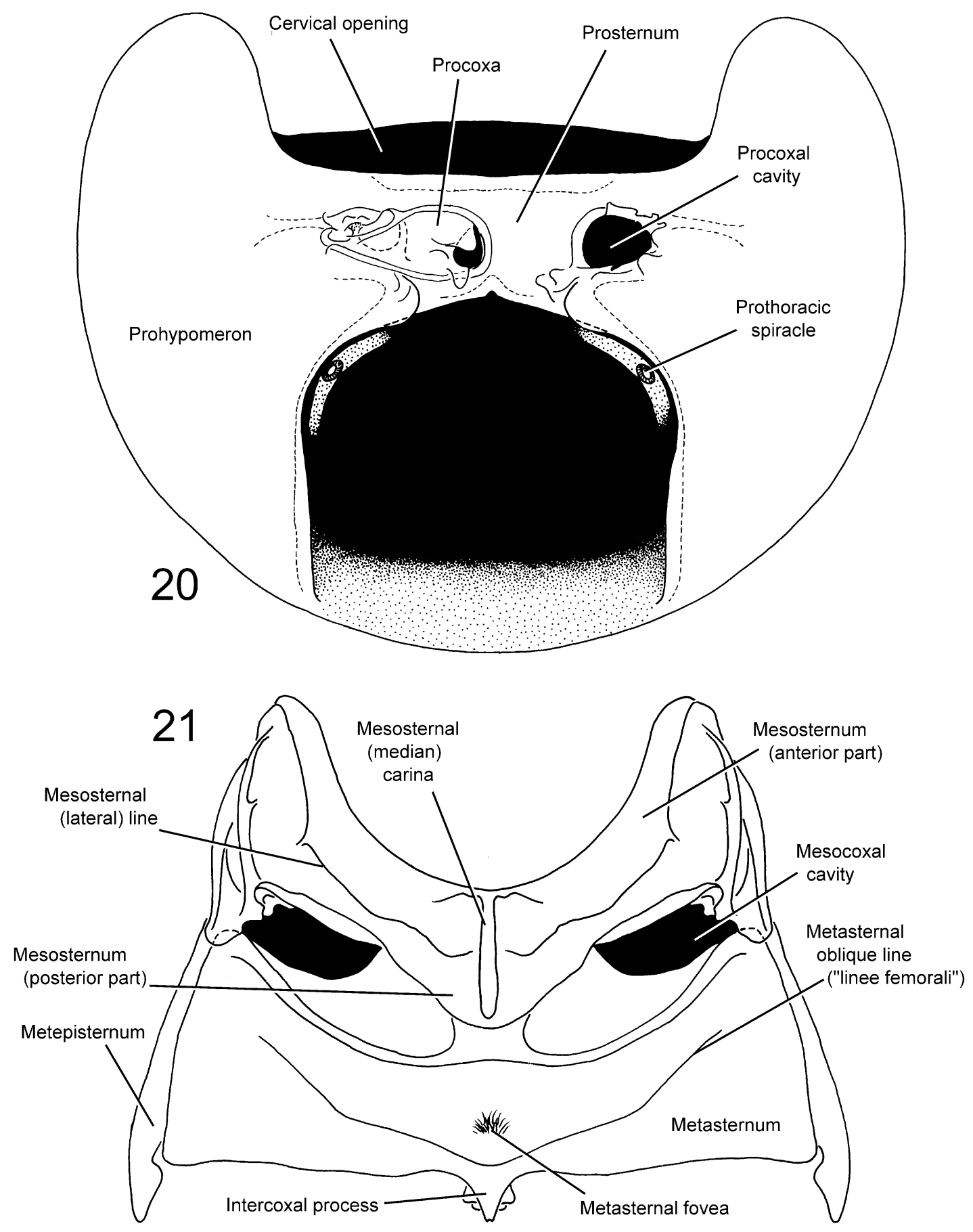

Figs. 20, 21. Agathidium oniscoides Palisot de Beauvois: 20, prothorax, ventral; 21, pterothorax, ventral. 


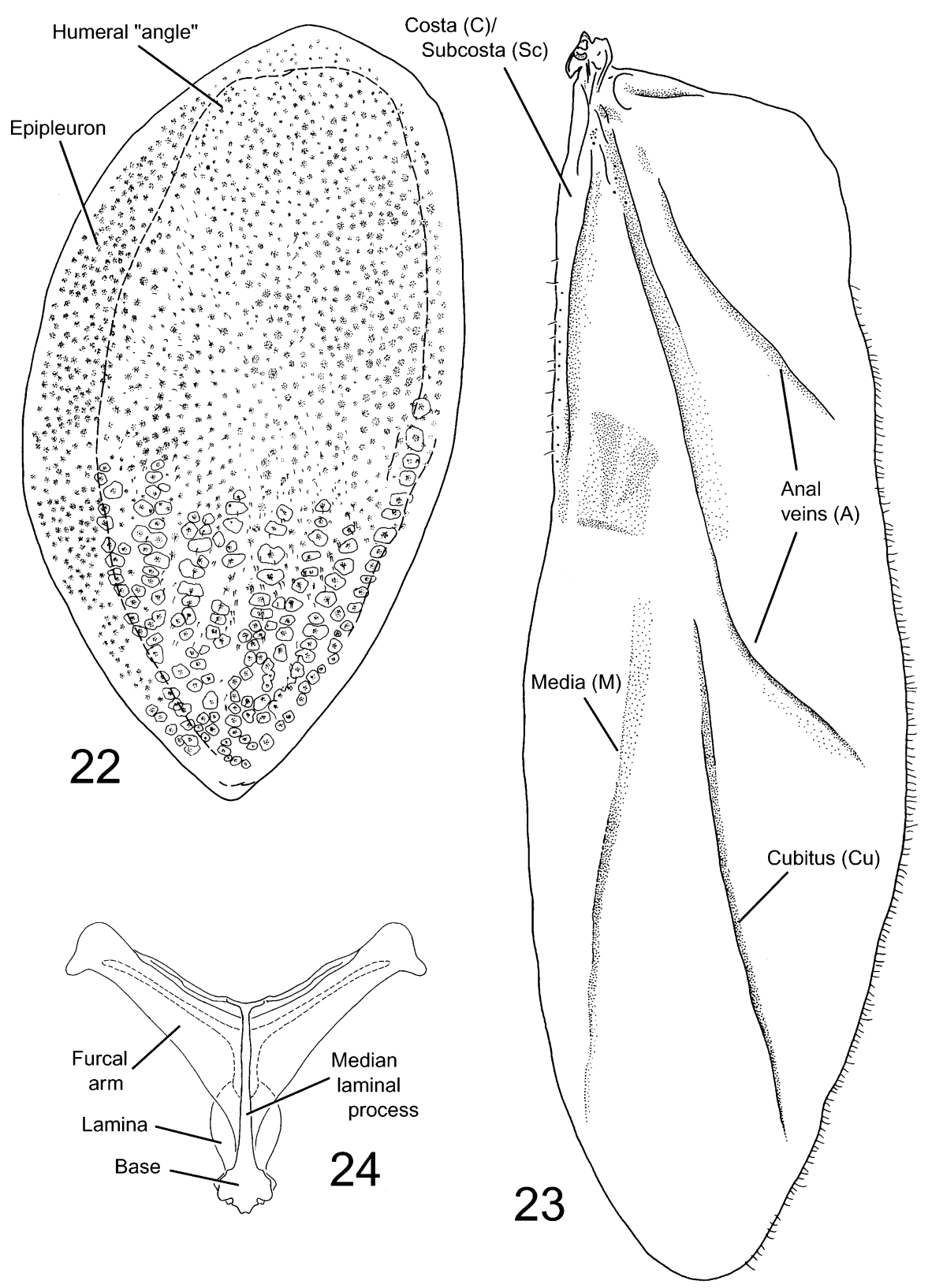

Figs. 22-24. Agathidium oniscoides Palisot de Beauvois: 22, elytron, dorsal; 23, Hindwing hingwing; 24, metepisternite, dorsal.

similar structures in a range of Coleoptera and concluded that they function as external surface areas for the dissemination of secretions.

Metafemoral ToOth: The posterior margin of the male metafemur protrudes posteriorly as a broad, blunt tooth.
Mandibular Tusk: Absent, left mandible not modified.

The left mandibles of a number of other male Agathidium are modified into a horn or tusk (e.g., figs. 89, 90). The development of the tusk varies, both between and within species, from a small bump to a large horn. The 


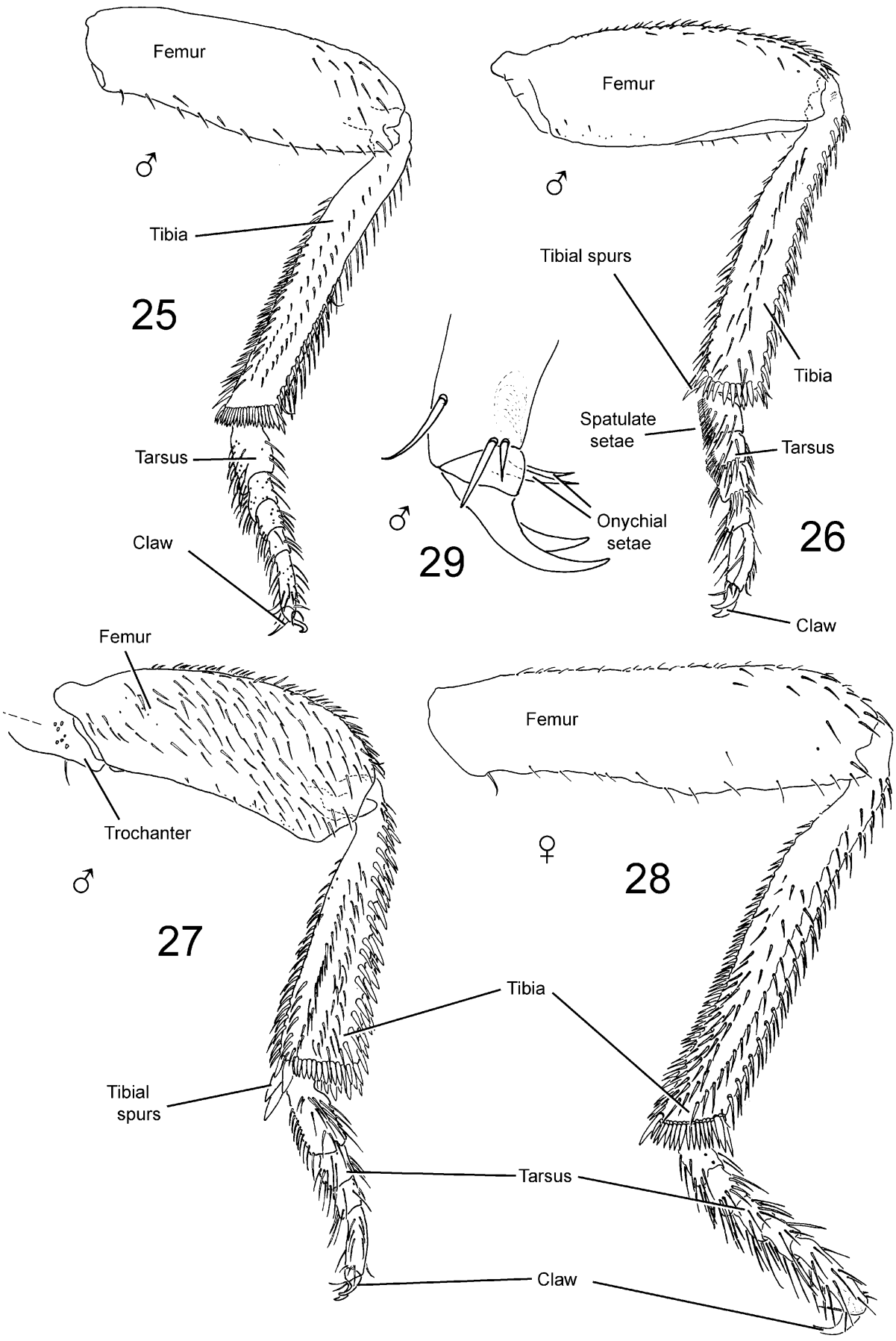

Figs. 25-29. Agathidium oniscoides Palisot de Beauvois, legs: 25, proleg, male; 26, mesoleg, male; 27, metaleg, male; 28, proleg, female; 29, tarsal claw detail, male. 


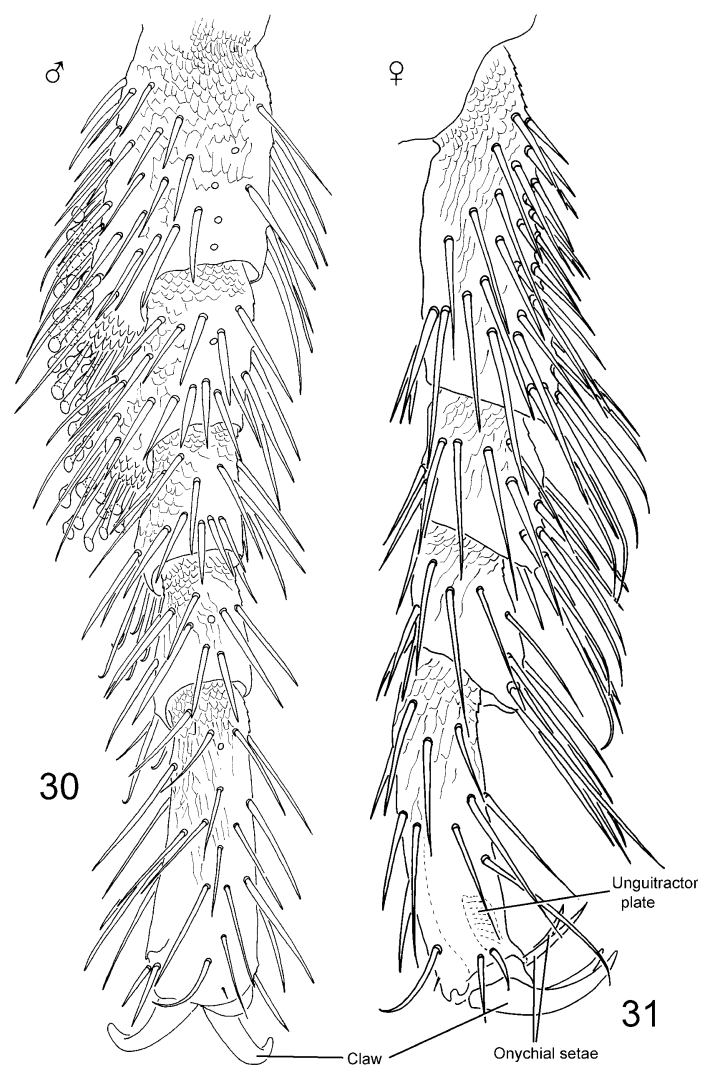

Figs. 30, 31. Agathidium oniscoides Palisot de Beauvois, protarsi: 30, male protarsus detail; 31, female protarsus detail.

horn is sometimes posteriorly curved and bears a tuft of apical setae. At least two apparently distinct kinds of horns occur that may not be homologous with one another. In one form the apex of the mandible is prolonged and dorsally recurved into a hornlike structure (e.g., A. aristerium; Wheeler, 1987). In others, such as A. pulchrum, a tusk arises from the dorsal surface of the mandible, posteriorly removed from the apex, which remains unmodified (see Frontispiece). It is conceivable that one represents a state modified from the other. From a strictly morphological perspective, however, it seems more reasonable to suppose that these represent independent modifications of the left, male mandible, but perhaps with some shared developmental genetic coding considering the unusual asymmetry of the structure.

\section{Male Genitalia \\ Figures 32-34}

Aedeagus: The aedeagus in members of Agathidium is trilobate and characteristic of "primitive" staphylinoids (Crowson, 1955). The basic structure consists of a tubular and curved median lobe, paired lateral lobes which are usually nearly as long as the median lobe and joined basally by the phallobase (formed by a ring like structure encircling the base of the median lobe), and a subapical opening on the ventral face of the median lobe (the distal orifice). In Agathidium the distal orifice is usually partially covered by a sclerotized flap (the operculum or "ventral piece"; Wheeler, 1979b). This structure is highly variable in shape between species and is often an important source of taxonomic information. It is usually clearly articulable basally, but in some cases is apparently not. For the purposes of this revision, any structure extending over the distal orifice from its base is regarded as an operculum, though not all these structures may be necessarily homologous. Internal to the median lobe is a membranous, saclike endophallus which bears a variety of armature in the form of spines, hairs, and sclerotized patches in addition to apical or subapical membranous lobes in the form of elongate digits or lanceolate structures. The median lobe, at least near the apex, and the lateral lobes exhibit a variety of patterns in the distribution of "pores" and "ducts" (see below).

Median Lobe (figs. 32-34): In A. oniscoides the median lobe is elongate, narrow, ventrally curved through its midlength (most sharply near the basal piece), and recurved in the apical one-fifth. The apical portion (one-fifth) is dorsoventrally compressed relative to the basal portions of the median lobe. The basal piece is completely fused to the median lobe dorsally.

"Pores And Ducts" of Median Lobe (fig. 32): The terms "pore" and "duct" are used advisedly. "Pore" has been applied broadly in the larval literature for a variety of structures, including campaniform sensilla (Ashe and Watrous, 1984). In Agathidium genitalia the exact nature of the pores has not been determined. However, based on compound microscopy and a limited amount of scan- 


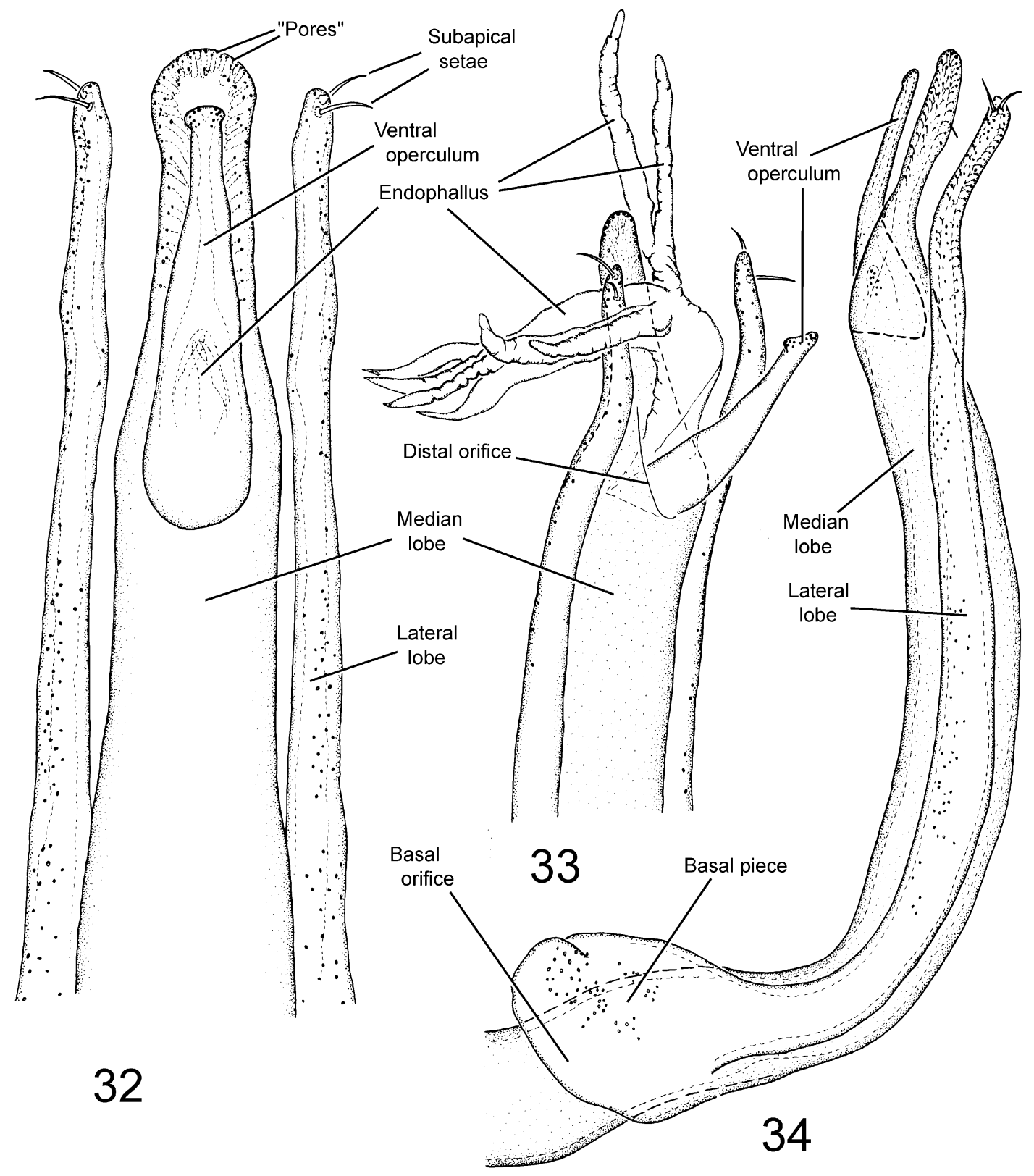

Figs. 32-34. Agathidium oniscoides Palisot de Beauvois, aedeagus: 32, median lobe apex, ventral; 33, median lobe apex, lateral, endophallus partially everted; 34, lateral.

ning electron microscopy, these do not seem to always have any obvious surface structures associated with them. "Pore", then, is purely a descriptive word, since this is what they appear to be under compound microscopy. They may be reservoirs of secretary cells, feeding through the visible "ducts" to a median canal. These may be glandular, but we hesitate to strongly hypothesize this until more detailed fine structure work has been done.

In A. oniscoides the ducts of the median 
lobe radiate from a central region, lining the sides and rounding the apex of the apical one-fifth of the median lobe (fig. 32).

LATERAL LoBEs (fig. 32): The lateral lobes of A. oniscoides are slightly widened at the middle and are narrower at their apices. Pores are irregularly distributed over the surface, but they are more dense apically and absent basally. Two subequal setae are present subapically.

OPERCULUM (figs. 32-34): The operculum is narrowed gradually. Its apex is abruptly wider, forming an apical knob. Pores are present at the apex only. There is some variation in the operculum within the species, particularly in the degree of pronouncement of the apical knob.

ENDOPHALLUS (fig. 33): The endophallus in A. oniscoides, like in other Agathidium, is typically inverted, and details of its structure are difficult to discern. When everted, the endophallus can be seen to be complex (fig. $33)$. In $A$. oniscoides there are few sclerotizations except for a number of long tentaclelike subdivisions of the sac. There are two bifurcate structures that are wrinkled in appearance and several smaller ones, including two smooth, very sharply pointed processes.

Details of endophallic structure have been difficult to assess in the genus. No reliable technique was found for its eversion. Sometimes gentle heating of the fluid, particularly of glycerin, will lead to eversion, but this is not entirely predictable and certainly cannot be counted on for species where large numbers of specimens are not available for dissection. When such techniques or large enough numbers of specimens to support trial-and-error approaches do exist, many additional characters will certainly be found. We predict that the number of endophallic features may well surpass the number of external genitalic ones when they are examined in detail. The fingerlike subdivisions of the sac in A. oniscoides, for example, are present in closely related species and are potentially synapomorphic.

\section{Female Sexual Dimorphism}

The only dimorphism found in females involves a reduction in the number of tarsomeres. As in other members of the tribe
Agathidiini (= Anisotomini auctorum), male and female tarsal formulae differ. Whereas the numbers of tarsomeres vary among males, females consistently have a reduced number in comparison to the male of the same species (e.g $\delta$ 5-5-4 / 9 5-4-4 or $\widehat{0}$ 5-4-4 / ㅇ 4-4-4).

\section{Female Genitalia \\ Figures 36, 37}

Female genitalia (fig. 37) short, membranous; proctiger broadly rounded; coxite narrow, elongate, cylindrical with moderate number of small pores, few small subapical setae; stylus small, narrow, elongate with single long apical seta, pair of short subapical setae.

SPERMATHECA (fig. 36): Spermatheca elongate, curved; with capsule large, bulbous at base; neck narrow, curved; apex rounded, blunt; walls thick and lumen paralleling capsule shape; very long, narrow spermathecal duct inserted into bulb; membranous, amorphous gland inserted near base of spermathecal duct.

\section{PUPA \\ Figures 38-40}

Pupa broad, rounded, and whitish colored. Head inferior to laterally expanded pronotum. Terminal dorsal abdominal segment with paired, pointed, posteriorly-directed spines.

\section{TAXONOMY}

An apparent synapomorphy of the tribe Agathidiini (= Anisotomini) is the sexually dimorphic tarsal formulae. The number of tarsomeres is greater in males than in females with the infrequent exception of when 4-44 tarsi (or, even more rarely, 4-4-3) occur in both sexes of certain species. Whereas male tarsomere numbers are variable, they are usually heteromerous and greater than female tarsomere numbers whether heteromerous or not, for example, ô 5-5-4 / o 54-4 and o 5-4-4 / क 4-4-4. Agathidiines are small, about 1-6 $\mathrm{mm}$ in length, round, and convex. Most are glabrous or very nearly so, and with rare exceptions (e.g., Anisotoma basalis, Agathidium pulchrum, A. maculos- 


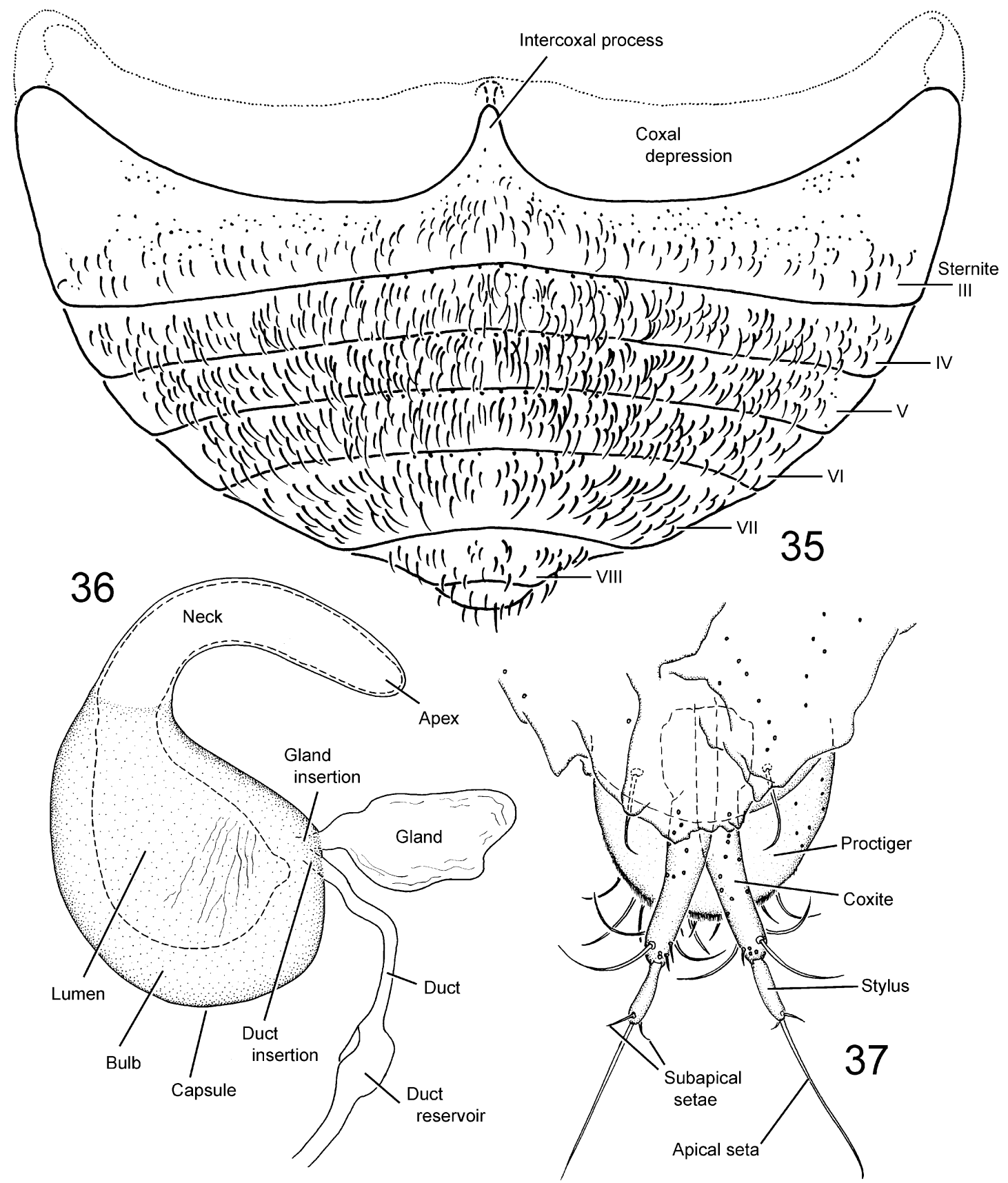

Figs. 35-37. Agathidium oniscoides Palisot de Beauvois, female: 35, abdomen, ventral; 36, spermatheca; 37, genitalia.

um) are uniformly reddish-brown to black. Serial punctation is symplesiomorphically scattered through the tribe and is reduced or lost in many species of Agathidium. Agathi- diini belong to the Leiodinae, one of six subfamilies in Leiodidae (Newton, 1998) (Lawrence and Newton, 1995). Like most leiodids, many agathidiines have the eighth antennom- 

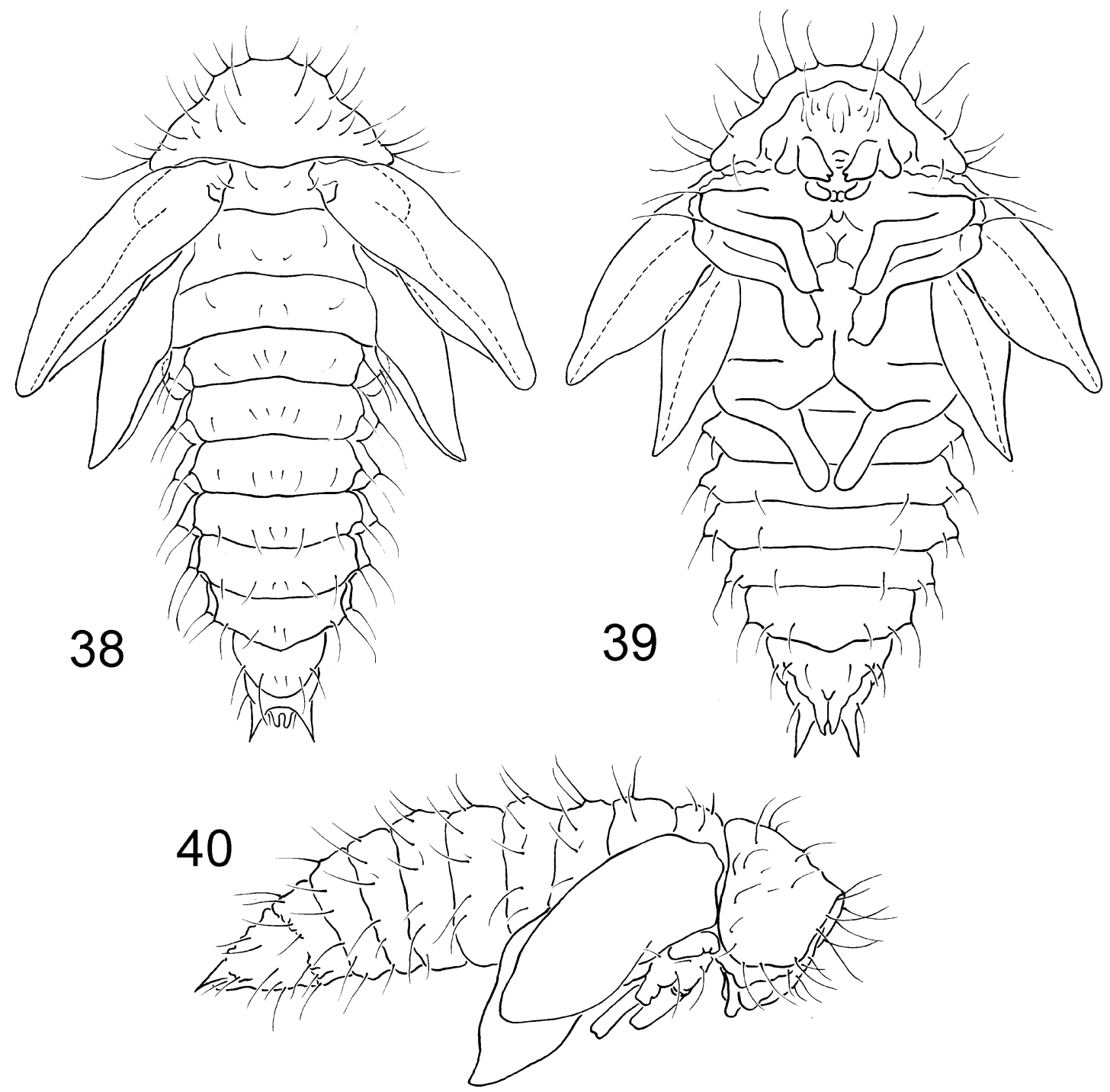

Figs. 38-40. Agathidium oniscoides Palisot de Beauvois, pupa: 38, dorsal; 39, ventral; 40, lateral.

ere narrower than either the seventh or ninth (which are generally more equal in size), creating a characteristically interrupted 5-segmented antennal club. Most Agathidium, however, have the seventh antennomere reduced in size also, and thus they typically possess an abrupt 3-segmented club. In some species of Agathidium the seventh antennomere is slightly larger than the eighth, but both are still much narrower than the ninth. In the few cases when Agathidium has the seventh antennomere large enough to possibly be in- terpreted as part of a 5-segmented antennal club, the postocular temporum and supraocular carinae are prominent and conspicuous, a character combination not found in related taxa like Anisotoma.

Species of Agathidium were first recognized by Linnaeus (1758) and Fabricius (1792). The genus was proposed by Panzer (1797) for Silpha seminulum Linnaeus (= Agathidium globosum Panzer). The first New World species of Agathidium described was A. oniscoides Palisot de Beauvois (1817), be- 
ing one of the largest and most common species native to the United States. The first comprehensive revision of the genus was done by Horn (1880) in his classic treatment of the Silphidae. The second and most recent taxonomic revision was completed by Fall (1934).

Four described genera of Agathidiini are currently recognized in North and Central America and may be distinguished by the following diagnostic key. Keys to the world genera are provided by Angelini and Peck (2000), along with a cladogram for genera of the tribe, and by Peck et al. (2000) for Central and South American genera. In this last treatment the authors also included two putatively undescribed genera which we will be treating separately. A catalog and complete bibliographies and synonymies of world genera are provided by Newton (1998), along with comments on some of the numerous problems with classification of the group.

\section{KEY TO GENERA OF AGATHIDIINI OF NORTH AND CENTRAL AMERICA}

1. Elytron with many (ca. 20) impressed rows of punctures, integument between rows with transverse striations; mesosternum keel-like, interrupted by large excision visible in lateral view; apex of lateral lobe membranous, setose; eastern U.S. . . . . . . . . . . ........... Cainosternum Notman

- Elytron with 9 or fewer rows of punctures, frequently with only irregularly distributed punctures or none; mesosternum with or without carina, never in form of excised keel; apex of lateral lobe not membranous

$\ldots \ldots \ldots \ldots \ldots \ldots \ldots \ldots \ldots \ldots \ldots$ Antennal club distinctly 5-segmented, antennomere VIII narrower than VII; Holarctic, in New World from Alaska and Canada south to Guatemala ....... Anisotoma Panzer

- Antennal club 3-segmented, if antennomere VII slightly wider than VIII, VII much narrower than IX and/or head with prominent postocular temporum ....... 3

3(2). Clypeus not excavate; elytron with distinct punctured striae; postocular temporum absent (in American species); tarsi of 5$5-4 /$ o $5-4-4$ or $4-4-4 \ldots \ldots \ldots$. ......................

Clypeus excavate or not; elytron usually without punctures or, if punctation present, usually confused, if serial punctation present, series often obscured by confused punctation between; postocular temporum present; tarsi ô 5-5-4, 4-4-4 or $4-3-3 /$ ㅇ $5-4-4,4-4-4$ or $4-3-3 \ldots$ .............. Agathidium Panzer

\section{Cainosternum Notman}

Cainosternum Notman, 1921: 147 (Type species: Cainosternum imbricatum Notman, 1921, by monotypy); Hatch, 1929; Wheeler, 1986; Newton, 1998.

Discussion: The genus Cainosternum was originally described from western New York state by Notman (1921) based upon a single specimen of Cainosternum imbricatum Notman. The senior author has made numerous trips to the type locality in Chautauqua County in the vicinity of Westfield in search of this unusual species but failed to collect it from either slime-molds or sifted leaf litter. However, while collecting flightless Agathidium species in the Appalachian Mountains of western North Carolina, C. imbricatum was rediscovered (Wheeler, 1986). No identifiable inclusions were observed in the gut of the North Carolina material, and habits of this elusive species remain unknown. Sexually dimorphic tarsal formulae suggest that the genus belongs within Agathidiini. If this is so, then the widespread and putatively ancestral associations of Agathidiini with Myxomycetes suggest possible slime-mold predation. Plasmodial feeding would be consistent with both the absence of microscopically recognizable material in the gut and absence of specimens on exposed fruiting bodies. Although this inference is not fully justified by available data, such speculation does provide one logical place to search for Cainosternum in the future.

Cainosternum was excluded from Agathidiini and placed in the tribe Pseudoliodini by Newton (1998) and Peck (1998). While pointing out the similarity of this taxon to members of Pseudoliodini, Newton (1998) also remarked that Cainosternum could represent the basal member of the tribe Agathidiini. This taxon does possess an unusual character combination. Since there is no comprehesive cladistic analysis of members of the various tribes of Leiodinae and, therefore, no good hypotheses for the relative plesiomorphy or apomorphy of characters used 
to group these taxa, we have elected to retain this taxon within Agathidiini until such analyses can be presented.

\section{Anisotoma Panzer Figure 41}

Anisotoma Panzer, 1797: 8 (Type species: Tritoma glabra Fabricius, 1787, by subsequent designation of Hatch, 1929b, but see Newton, 1998); Wheeler, 1979a; Angelini and de Marzo, 1988; Newton, 1998.

Pentatoma Schneider, 1792: 339 (Type species: Sphaeridium humerale Fabricius, 1792, by subsequent designation of Hatch, 1929b), preoccupied, nec Pentatoma Olivier, 1789, Hemiptera.

Eucyrta Portevin, 1927: 82 (Type species: Eucyrta didymata Portevin, 1927, by subsequent designation of Hatch, 1929b), preoccupied, nec Eucyrta Felder, 1874, Lepidoptera; Wheeler, 1979a (synonymized with Anisotoma).

Discussion: Species of Anisotoma are among the most common, widespread, and abundant slime-mold-associated Coleoptera in North and Central America. In general habitus, some species of Agathidium (e.g., Ag. sexstriatum and Ag. concinnum groups) strongly resemble Anisotoma species (e.g., fig. 41), from which they may be distinguished by their distinct 3-segmented antennal club or continuation of the supraocular carina posterior of the eye, setting off a distinct posterior temporum.

Anisotoma species of North America were revised by Wheeler (1979b). Since that revision, a few species have been added from México and Panamá (Wheeler, 1980, 1983). Based on the paucity of specimens collected from México and Central America to date and the high proportion of undescribed species found among them, it seems likely that the number of species of Anisotoma will be significantly greater than that now known.

Most slime-mold host records of Anisoto$m a$ are in association with mature sporocarps (Blackwell, 1984; Lawrence and Newton, 1980; Stephenson et al., 1994; Wheeler, 1979b, 1984a), although plasmodial feeding has been observed (Newton, 1984; Russell, 1979; Wheeler, 1980).

\section{Stetholiodes Fall}

Stetholiodes Fall, 1910: 4 (Type species: Stetholiodes laticollis Fall, 1910, by monotypy);
Blatchley, 1910; Wheeler, 1981; Newton, 1982, 1998; Angelini and de Marzo, 1983, 1987b; Perkovskii, 1990.

Agathodes Portevin, 1926: 80 (Type species: Agathodes striatipenne Portevin, 1926, by monotypy) preoccupied, nec Agathodes Guénée, 1854, Lepidoptera.

Agathidiodes Portevin, 1926: 169 (new name for Agathodes Portevin, 1926); Newton, 1983 (synonymized with Stetholiodes).

Discussion: The genus Stetholiodes was described from northern Indiana by Fall (1910), based on material collected from moss (Blatchley, 1910). Wheeler (1981) redescribed S. laticollis Fall and discussed this single North American member of the genus. Additional species are known from Asia and eastern Europe (Angelini and de Marzo, 1987b). Monophyly of the genus has not been firmly established. Habits remain unknown, though slime-mold associations in related genera suggest similar relationships in this taxon.

\section{Agathidium Panzer}

Volvoxis Kugelann, 1794: 535 (Type species: Tetratoma globosa Herbst, $1792(=$ A. seminulum (Linnaeus, 1758), by subsequent designation of Newton, 1998), not preoccupied by Volvox Linnaeus, 1758, Chlorophyta. NOMEN OBLITUM.

Agathidium Panzer, 1797: 13 (Type species: Tetratoma globosa Herbst, 1792 (= Silpha seminulum Linné, 1758, by monotypy); Illiger, 1798; Palisot de Beauvois, 1817; Sturm, 1807; Stephens, 1829, 1839; Leach, 1832; Erichson, 1845; Redtenbacher, 1845, 1849, 1858, 1874; Fairmaire and Laboulbené, 1854; Jacquelín du Val, 1857; Thomson, 1859, 1862; LeConte, 1861; Brisout, 1872; Cox, 1874; Seidlitz, 1891; Horn, 1880; LeConte and Horn, 1883; Fowler, 1889; Everts, 1899; Ganglbauer, 1899; Stierlin, 1900; Schaufuss in Calwer, 1916; Jacobson, 1910; Blatchley, 1910; Kuhnt, 1913; Portevin, 1914, 1926, 1927, 1929; Barthe, 1920-1922; Hansen, 1922a; Houlbert, 1922; Hatch, 1929a, 1929b, 1957; Joy, 1932; Fall, 1934; Javorek, 1947; Horion, 1949; Hlisnikovský, 1964; Arnett, 1971; von Peez, 1971; Hendrichs, 1980; Angelini and De Marzo, 1984, 1987a, 1987b, 1988, 1990, 1995; Angelini, 1984, 1988, 1990; Nunberg, 1987; Wheeler, 1987, 1990a; Newton, 1998; Angelini and Peck, 2000; Peck et al., 2000. NOMEN PROTECTUM.

Agathidium Illiger, 1798: 81, unnecessary replacement name for Volvoxis Kugelann, 1794.

Chaetoceble Sainte-Claire-Deville, 1899: 292 


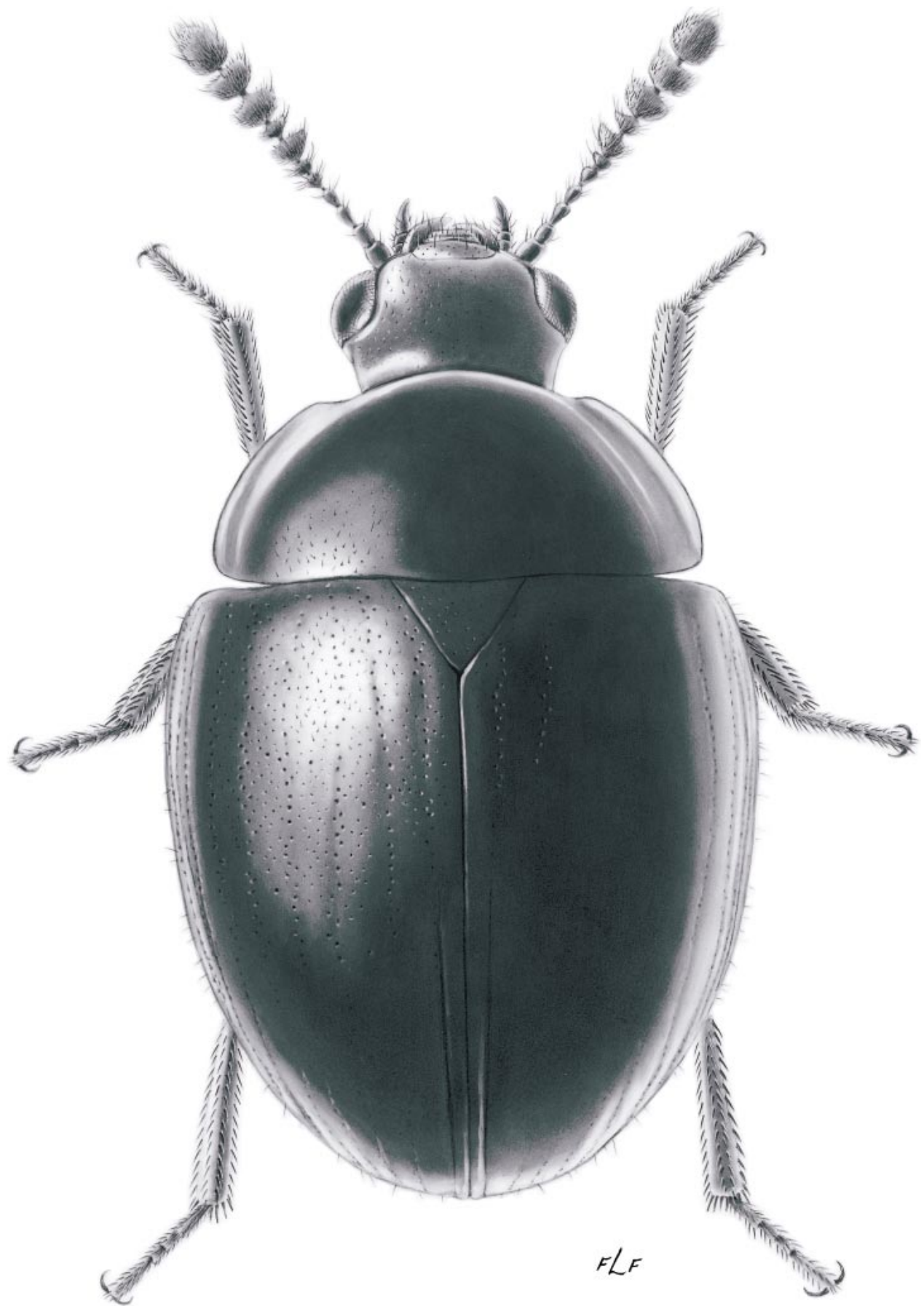

Fig. 41. Anisotoma horni Wheeler, habitus, dorsal. A common and typical species of genus in eastern United States. 
(Type species: Agathidium pilosum Sainte-Claire-Deville, 1899, by original designation) (subgenus).

Cyphoceble Thomson, 1859: 59 (Type species: Anisotoma staphylaeum Gyllenhal, $1810(=A$. nigrinum Sturm, 1807, by original designation) (subgenus).

Saccoceble des Gozis, 1886: 17 (Type species: Agathidium discoideum Erichson, 1845, by original designation) (synonym of Cyphoceble).

Euryceble Hlisnikovský, 1964: 123 (Type species: Agathidium antennatum Hlisnikovský, 1964, by original designation) (subgenus).

Macroceble Angelini, 1993: 30 (Type species: Agathidium shermathangense Angelini and De Marzo, 1981) (subgenus).

Microceble Angelini and De Marzo, 1986: 439 (Type species: Agathidium grouvellei Portevin, 1907, by orginal designation) (subgenus).

Neoceble des Gozis, 1886:16 (Type species: Agathidium marginatum Sturm, 1807, by original designation) (subgenus).

Stigmoceble Hlisnikovský 1964: 119 (Type species: Agathidium longicorne Portevin, 1908, by original designation); Angelini, 1986 (synonymized with Neoceble).

Rhabdoelytrum Hlisnikovský, 1964:31 (Type species: Agathidium sexstriatum Horn, 1880, by original designation) (subgenus).

Diagnosis: Agathidium may be distinguished from other Agathidiini in North and Central America by the following combination of characters: antennal club usually distinctly 3-segmented (5-segmented in a few taxa, including $A$. rusticum Fall); anterior clypeal margin usually not extending beyond anterolateral margins of frons (extending beyond frons in the $A$. sexstriatum group and several species of the A. pulchrum and $A$. concinnum groups); supraocular carina extending from margin of clypeus or clypeal region posteriorly to well behind eye delimiting a postocular temporum that may be short and inconspicuous or long and very conspicuous; elytral punctation usually confused or absent, occasionally serial, but with fewer than nine series and series often obscured by dense confused punctures between; prothorax convex; elytra usually convex, sometimes dorsoventrally compressed.

Discussion: The name Agathidium is derived from "agathidion", Greek for "small ball", and is quite appropriate for many species of the genus which have broad convex bodies capable of rolling into compact, balllike shapes when disturbed.

A complete bibliography and synonymic list for Agathidium is provided by Newton (1998) along with a discussion of some nomenclatural problems including the observation that the original name for this taxon, Volvoxis, is not a homonym as supposed. Volvoxis is the oldest name for the genus, and historically the International Code of Zoological Nomenclature (the Code) would have required either resurrection of the name Volvoxis for this genus or a special ruling by the Commission for conservation of the junior name Agathidium and suppression of Volvoxis. However, according to article 23.9 of the newest Code (ICZN, 1999), the prevailing usage of a junior name may be maintained when the senior name has not been used as a valid name after 1899 (to our knowledge true of Volvoxis) and the junior name has been used as a presumed valid name in at least 25 works published by at least 10 authors in the preceding 50 years and a span of not less than 10 years (true of Agathidium, see bibliography above). Therefore, of the two names Volvoxis Kugelann and Agathidium Panzer, the second is the valid name.

Agathidium has historically been divided into subgenera, several of which were proposed as recently as the 1980s and 1990s (Angelini, 1993; Angelini and De Marzo, 1986). Subgenera recognized for the Palearctic fauna can be used to organize the Nearctic fauna, though with considerable difficulty in some cases, and they may be identified using Angelini's (1995) key. However, because our fauna remains poorly known, and monophyly of the subgenera as currently classified remains equivocal, we have decided to not recognize subgenera and instead arrange the species treated here into informal species groups. Our proposed species groups would loosely belong to previously recognized subgenera in the following way: A. brevisternum group $=A$. (Neoceble) des Gozis; A. oniscoides group $=A$. (Agathidium); A. revolvens group $=A$. (Neoceble $)$ (centered around A. nigripenne Fabricius); A. concinnum group $=A$. (Cyphoceble $)$ Thomson; A. pulchrum group $=A$. (Neoceble) . Our A. iota and $A$. compressidens species groups do not 
appear to fit well into any of the described subgenera.

Especially problematic are those species described by Horn and later placed in their own subgenus, A. (Rhabdoelytrum), by Hlisnikovský (1964). According to our scheme of species groups, the A. sexstriatum group would belong to this subgenus. According to the characters used by Angelini and de Marzo (1987b) to distinguish Agathidium from Stetholiodes, the species of A. (Rhabdoelytrum) would key to Stetholiodes. For now, these controversial and primitive forms are retained in Agathidium although there is merit in considering a different combination. Considering only our fauna, such a combination would appear to make Agathidium species monophyletic, based in part on the relatively excavate clypeus or clypeal region, while making monophyly of Stetholiodes uncertain and based primarily on symplesiomorphic character states.

There have been two cladistic analyses including members of this tribe. Considering the world genera of the tribe, and a small data set of adult characters, Angelini and Peck (2000) proposed the following relationships: (Anisotoma + (Amphicyllis + (Liodopria + (Cyrtoplastus + (Sphaeroliodes + (Stetholiodes + (Afroagathidium + (Pseudoagathidium + (Besuchetionella + (Agathidium()))))))). Relationships among nonAgathidium taxa are beyond the scope of this work, but see Miller and Wheeler (in press) for a discussion of their conclusions.

Kilian (1998) also conducted a cladistic analysis of agathidiine taxa, but one using larval instead of adult characters. She suggested synonymizing Anisotoma with Agathidium based on the conclusion that Agathidium species are nested in several places within Anisotoma. However, Kilian's analysis was based on a relatively limited data set including only characters from larvae and only those from the relatively few species of agathidiines known from larvae (including only several species of Agathidium and Anisotoma and one species of Liodopria). Another recent analysis by Angelini and Peck (2000) (see above) used adult characters coded from many more taxa representing a greater diversity within Agathidiini. They found a solution to the phylogeny radically different from Kilian's (1998). Further analyses incorporating more comprehensive taxon and character sampling are likely to result in different results from each of these. Thus, we would regard any nomenclatural change based on Kilian's (1998) phylogeny to be injudicious at this time. In addition, whereas we would agree that such a conclusion as she presents would call for synonymy of the two names, doing so would likely serve little except to make Agathidium even more heterogeneous in character combinations than it already is. We think that were Agathidium or Anisotoma eventually found to be paraphyletic, it would be more appropriate to break up these two huge groups of species into genera rather than synonymizing them.

Agathidium are sometimes misidentified in collections with the following taxa, from which they may be distinguished by characters given parenthetically: Anisotoma (fig. 41: Agathidium with head not narrowed immediately behind eye [except in some $A$. pulchrum and $A$. sexstriatum species groups] and with antennal club rarely approaching 5segmented); Clambidae (Agathidium never with enlarged hind coxal plates); cybocephaline Nitidulidae (Agathidium with front coxae conical, not transverse); acanthocerine Scarabaeidae (Agathidium with antennae not lamellate); sphaeridiine Hydrophilidae (Agathidium with club not so compact).

During this revision three species previously placed in Agathidium, A. cognatum Matthews, 1887: 77, A. parile Fall, 1934: 117, and A. parvulum LeConte, 1878: 598, were discovered to belong to a separate genus along with several undescribed Central and South American species. These species are treated in a separate revision (Miller and Wheeler, in press).

\section{KEY TO SPECIES GROUPS OF AGATHIDIUM}

1. Mesosternum subhorizontal, in approximately same plane as metasternum (fig. 43) ... 2

- Mesosternum concave posteriorly, anterior portion clearly in different plane from metasternum (fig. 46) . . . . . . . . . . 4

2(1). Size extremely small (TBL $=1.15-1.51$ $\mathrm{mm}$ ); tarsal formula 4-4-3 in both male and female; without oblique femoral carinae on metasternum; male without me- 

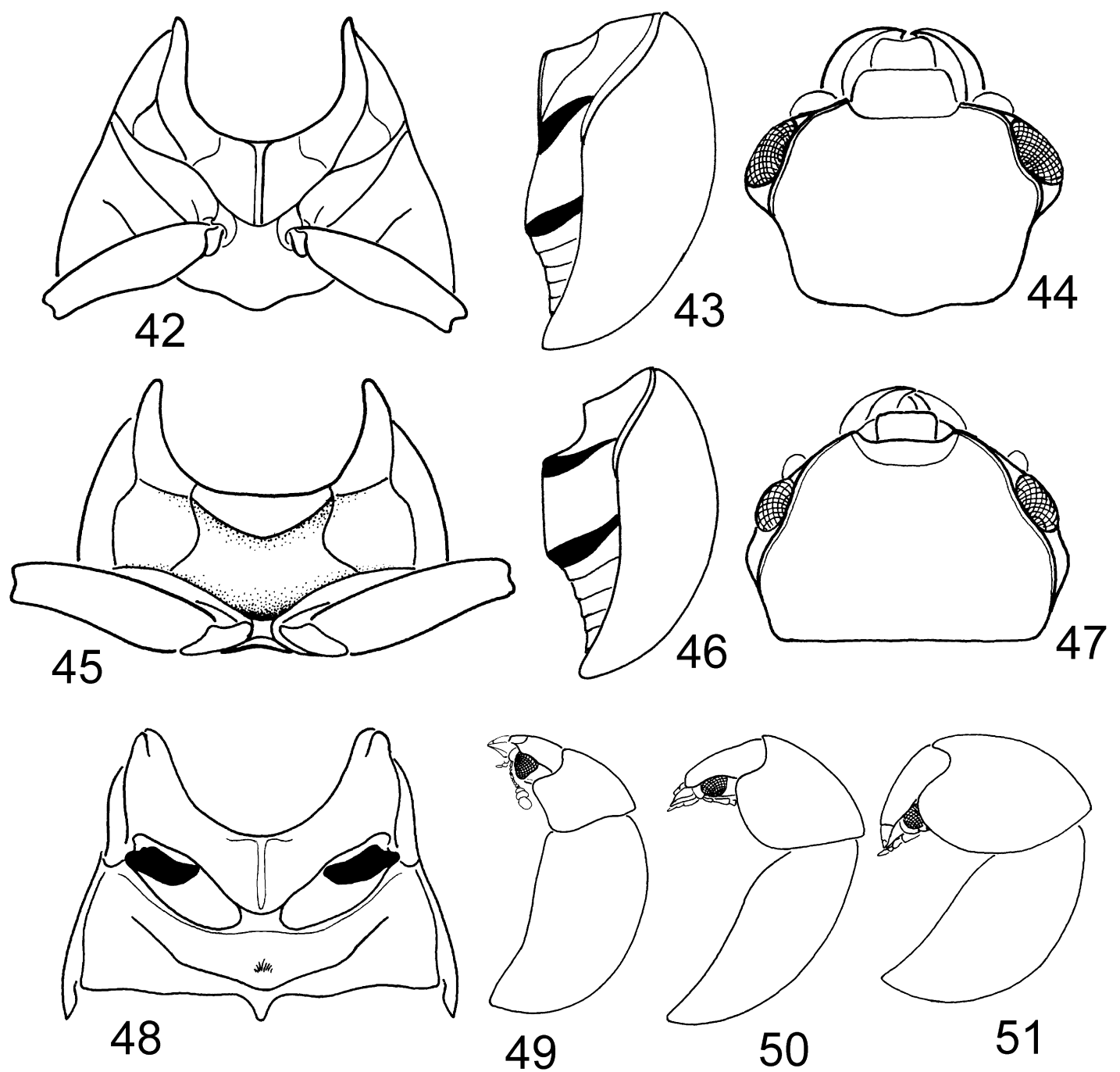

51

Figs. 42-51. Characters of Agathidium: Figs. 42, 43. Mesosternum, horizontal and anteriorly carinate: 42, ventral view; 43, lateral view. Fig. 44, head with short postocular temporum and with protruding clypeus. Figs. 45, 46. Mesosternum, anteriorly concave and noncarinate, subvertical between mesocoxae: 45, ventral view; 46, lateral view. 47. Head with long postocular temporum and without protruding clypeus. 48. Metasternum with paired oblique lateral lines ("femoral lines"). Figs. 49-51, body forms: 49, noncontractile and posterolateral angles of pronotum defined; 50, partially contractile and posterolateral angles of pronotum partially defined but apically rounded; 51, highly contractile and posterolateral angles of pronotum not defined.

tasternal fovea; southern Mexico (this group based on an undescribed species to be treated in part 2 of this revision) .... ............. iota group

Size larger $(\mathrm{TBL}=1.76-5 \mathrm{~mm})$; tarsal formula of 5-5-4, ㅇ 5-4-4; with or without oblique femoral carinae on metasternum; male generally with metasternal fovea though it may be small; widespread . . 3
3(2). Body highly contractile (fig. 51); metasternum with paired oblique femoral carinae which often meet medially along posterior margin (fig. 48), though these carinae may be indistinct; usually dorsally impunctate or nearly so; humeral angle of elytron broadly rounded .......... ........... Aniscoides group Body moderately contractile (fig. 50); me- 
tasternum without paired oblique femoral lines or with faint traces; frequently with conspicuous, confused dorsal punctation; humeral angle of elytron angulate ... $\ldots \ldots \ldots \ldots \ldots$. revolvens group

4(1). Clypeus distinctly protruding beyond anterolateral margins of frons, with onethird to one-half of clypeus occuring beyond sides of front of cranium (fig. 44); body not strongly convex dorsally nor contractile ...... A. sexstriatum group

- Clypeus not or only slightly protruding beyond anterolateral margins of frons, at most with less than one-third of clypeus protruding beyond sides of front of cranium; body generally dorsally convex and moderately to strongly contractile ...5

5(4). Metasternum extremely short, meso- and metacoxae nearly touching; male often with prominent mandibular horn (figs. 80, $81)$; anterior portion of mesosternum moderately broad along center line compared to posterior portion, but without longitudinal carina medially, posterior portion of mesosternum moderately concave; western United States ........

........... brevisternum group

- Metasternum not extremely shortened, meso- and metacoxae at least moderately separated by metasternum; male mandibular horn present or absent; anterior portion of mesosternum generally much shorter than posterior portion, if broad then with prominent longitudinal carina medially; widespread .........6 6

6(5). Postocular temporum long and prominent, when viewed in dorsal aspect extending lateral margin of head posterad of eye about 0.5 to 1.0 times eye length at which point head is narrowed (fig. 47), in some species protruding very prominently laterally beyond eye in rounded bulge when head viewed in dorsal aspect (fig. 47) . . ............. concinnum group

- Postocular temporum short, extending lateral margin of head posterad of eye less than 0.5 times eye length in dorsal aspect (fig. 44), head narrowed immediately posterad of eye ............ 7

7(6). Mesosternum moderately concave posteriorly, anterior portion as broad as or broader along center line than posterior portion and with prominent longitudinal carina medially; metasternum relatively short (MTL/MTW $=0.12-0.16)$; without horn on male left mandible; male metasternal fovea generally very large and sit- uated slightly posterad of middle .... ........... compressidens group Mesosternum generally strongly concave posteriorly, rising nearly vertically between mesocoxae, anterior portion narrower along center line than posterior portion and usually without prominent longitudinal carina medially; metasternum relatively broader (MTL/MTW = $0.19-0.40)$; with or without horn on male left mandible; male metasternal fovea generally smaller and situated medially or slightly anterad of middle ........

............. pulchrum group

\section{AGATHIDIUM SEXSTRIATUM SPECIES GROUP}

Diagnosis: The A. sexstriatum species group is distinguished by the following combination of characters: head narrowed behind eye, without prolonged postocular temporum (fig. 44); body not strongly convex dorsally and not contractile (figs. 49); elytron with $2-$ 8 serial series of punctures; aedeagus with ventral operculum divided into two plates; male tarsal formula 5-5-4, female 4-4-4; pronotum with evident posterolateral angles (fig. 52); clypeus large, separated from frons by impressed frontoclypeal suture, protruding anteriorly, from one-third to one-half of clypeus anterad of lateral margins of frons (fig. 52).

DISCUSSION: The A. sexstriatum species group includes three similar species first described by Horn (1880). Hlisnikovský (1964) proposed the subgenus Rhabdoelytrum for these species. As discussed above, it is conceivable that these species are related to Stetholiodes or other genera (Angelini and de Marzo, 1987b; Angelini and Peck, 2000). They are conservatively maintained in Agathidium until analyses are completed. Species of the group are distributed in the western United States.

This group includes species that exhibit no observed unequivocal synapomorphies, although the rather short and broad form of the median lobe of the aedeagus, serial series of punctures, and prominently protruding clypeus make these species separable from other Agathidium included in this study. The latter character refers to forms in which the clypeus protrudes clearly beyond the anterior an- 


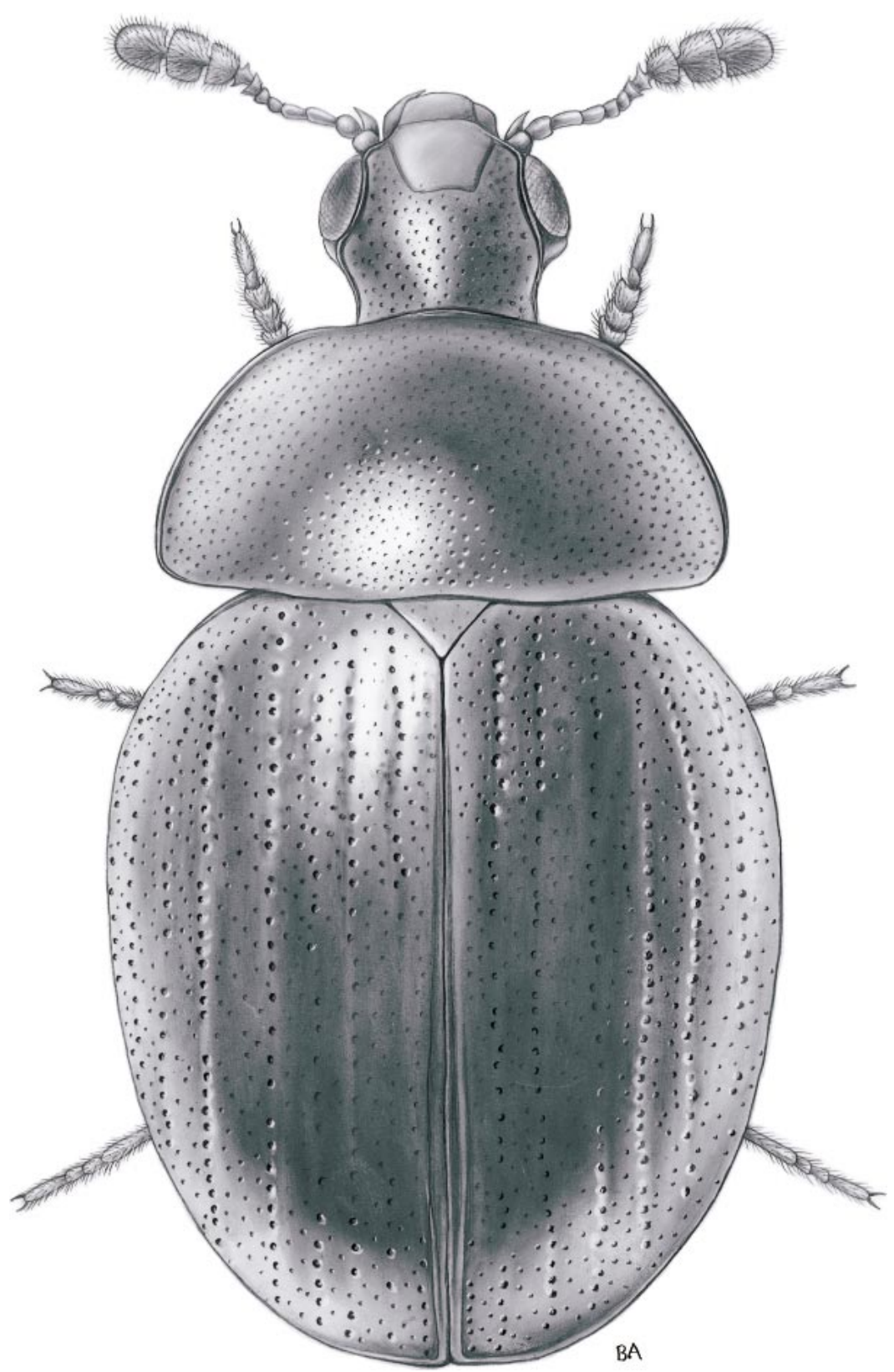

Fig. 52. Agathidium sexstriatum Horn, habitus, dorsal (note: differences in angle of observation result in differences in shape and proportion of structures in this image and that in fig. 67).

gles of the frons located dorsad of the antennal insertions and each side of the clypeus. It is particularly useful in distinguishing the A. sexstriatum group species from most similarly small-sized Agathidium with short postocular tempora. Due to a large number of symplesiomorphic similarities, these species share a general habitus and many specific characters with the related genus Anisotoma (cf. fig. 41, see also Wheeler, 1979b) and other genera. However, the abrupt 3-segmented antennal club and distinct supraocular cari- 
nae distinguish these Agathidium from all Anisotoma species and other genera.

Circumscription of these species is based on external characters, including color and punctation patterns, and male aedeagal shape. Although external characters are used extensively in the key, these features are somewhat less reliable than male aedeagal shape and, when possible, male specimens should be dissected and aedeagal shape compared with the illustrations for the most reliable identifications.

\section{KEY TO A. SEXSTRIATUM SPECIES GROUP}

1. Punctures serially arranged only medially, 2 or 3 series clearly evident; median lobe apically attenuate, apex narrowly rounded (fig. 61) ............... bistriatum Horn

- Punctures arranged in series, at least six serial rows present and more or less evident becoming obscure laterally; median lobe not attenuate apically . . . . . . . . . 2

2(1). Body elongate oval (figs. 52, 67); bicolored, pronotum reddish, elytron dark reddish to nearly black; serial punctures of elytra coarse, deeply impressed (fig. 65); male metasternal fovea paired, large (fig. 66); median lobe broadly truncate apically (fig. 70) ........ A. sexstriatum Horn

- Body broadly oval (fig. 76); concolorous or pronotum reddish and paler than elytra; serial punctures of elytra fine, obscured by dense confused punctures between (fig. 74); male metasternal fovea single, small (fig. 75); median lobe slightly constricted subapically, gradually narrowed apically to moderately rounded apex (fig. 79) ........... A. estriatum Horn

\section{Agathidium bistriatum Horn} Figures 53-62

Agathidium bistriatum Horn, 1880: 304; Leng, 1920; Fall, 1934; Hlisnikovský, 1964.

Type Material: Lectotype (designated here to clarify association of this name with the species), of in MCZC (G.H. Horn Collection) labeled "Nev [with red line on left edge of 'N']/ LectoTYPE 3021 [red label]/ A. bistriatum Horn/ LECTOTYPE, Agathidium bistriatum Horn, des. Q.D. Wheeler \& K.B. Miller, 2001 [red label with black line border]".
Type Locality: United States, western Nevada.

DiAgnosis: This species can be distinguished from other members of the group by the presence of only 2-3 evident series of punctures medially on elytron, punctures more confused laterally, punctures moderately large and dense (fig. 56); head and elytron dark reddish-brown, pronotum more pale red; and aedeagus with median lobe attenuated apically (fig. 61).

DESCRIPTION: Body broadly round, globose, noncontractile (figs. 58, 59); TBL = $3.2 \mathrm{~mm}$. Clypeal region, pronotum, and appendages pale reddish; head, elytra dark reddish-brown.

Head narrow (fig. 58); OHW/MDL = 1.4; dorsal surface with moderately dense punctures (about 10 per $0.01 \mathrm{~mm}^{2}$ ) (fig. 54); postocular temporum short, head narrowed behind eyes; frontoclypeal suture present, fine; clypeus with sparse punctures, half as dense as on head (ca. 5 per $0.01 \mathrm{~mm}^{2}$ ); antenna short with 3-segmented club; length ratio of antennomere II:III = 1:1.4; width ratio of antennomeres VII:VIII:IX $=0.8: 1: 1.3$; labrum similar in form to that of A. sexstriatum. Pronotum short, not convex; PNW/PNL = $2.1 ; \mathrm{PNL} / \mathrm{PNH}=1.3 ; \mathrm{PNW} / \mathrm{PNH}=2.9$; dorsal surface with irregularly distributed, sparse and very poorly defined punctures, generally smaller than those of head and much less distinct (fig. 55). Elytra convex, wider than long; ELW/SEL = 1.2, SEL/ELH $=1.3, \mathrm{ELW} / \mathrm{ELH}=1.5$; dorsal surface with about 2 or 3 poorly defined series of punctures near midline, punctation becoming increasingly confused laterally; punctures larger than those of head, surface between punctures with minute, almost imperceptible punctules; punctures moderately dense and large (ca. 4 punctures per $0.01 \mathrm{~mm}^{2}$, puncture ca. $0.04 \mathrm{~mm}$ diameter) (fig. 56). Mesosternum subhorizontal anteriorly; narrow anterior area set off; carinate posteriorly only; vertical between mesocoxae; surface alutaceous; about half length of metasternum. Metasternum with impunctate areas both in front of and behind center, punctures through middle and laterally, and alutaceous pattern laterally. $\mathrm{MTL} / \mathrm{MTW}=0.2$.

Male tarsi 5-5-4; pro- and mesobasotarsomeres slightly expanded; metasternal fo- 


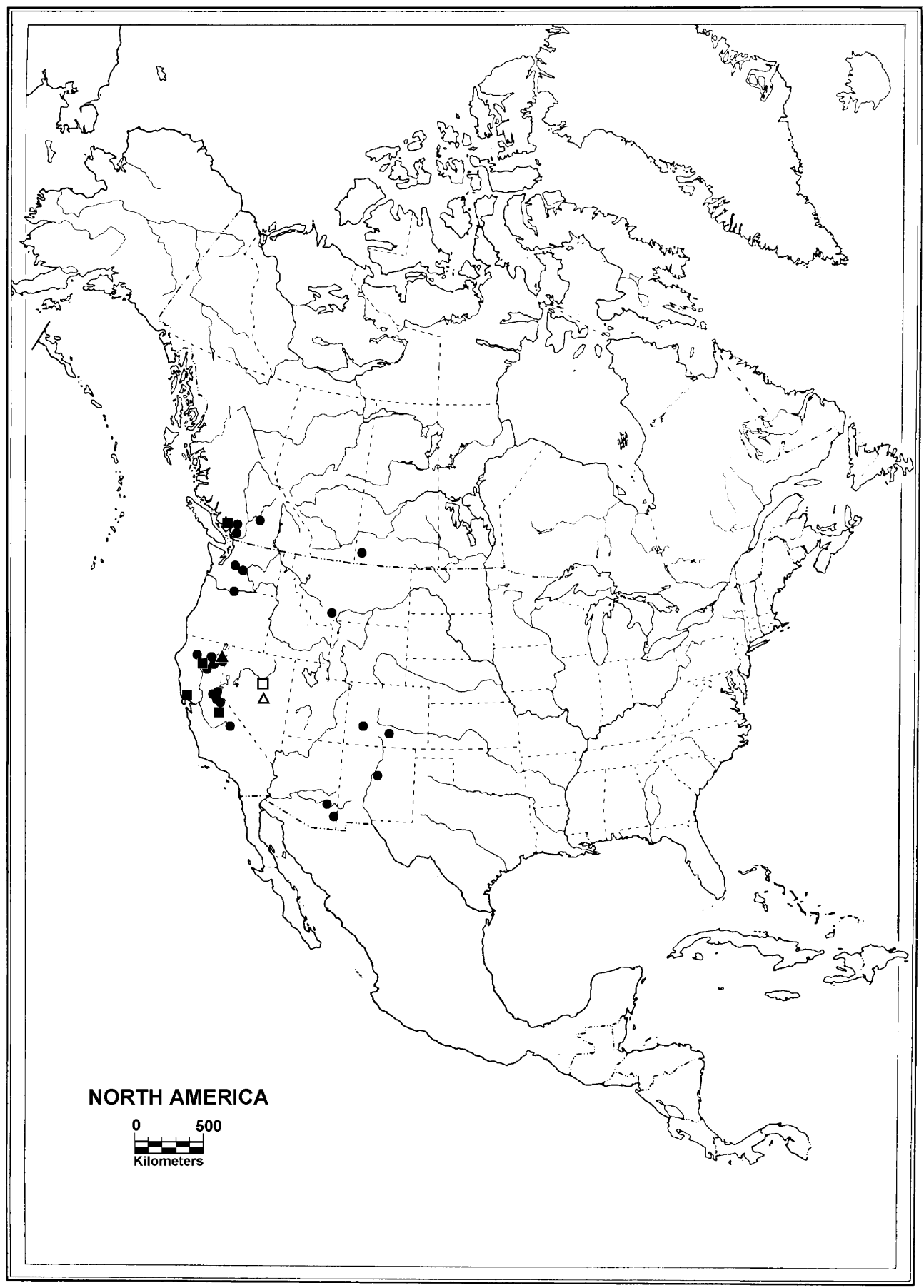

Fig. 53. Agathidium sexstriatum species group geographic distribution: A. bistriatum $=\boldsymbol{\Delta}(\triangle=$ state record only); A. estriatum $=\bullet A$. sexstriatum $=\mathbf{\square}(\square=$ state record only $)$. 

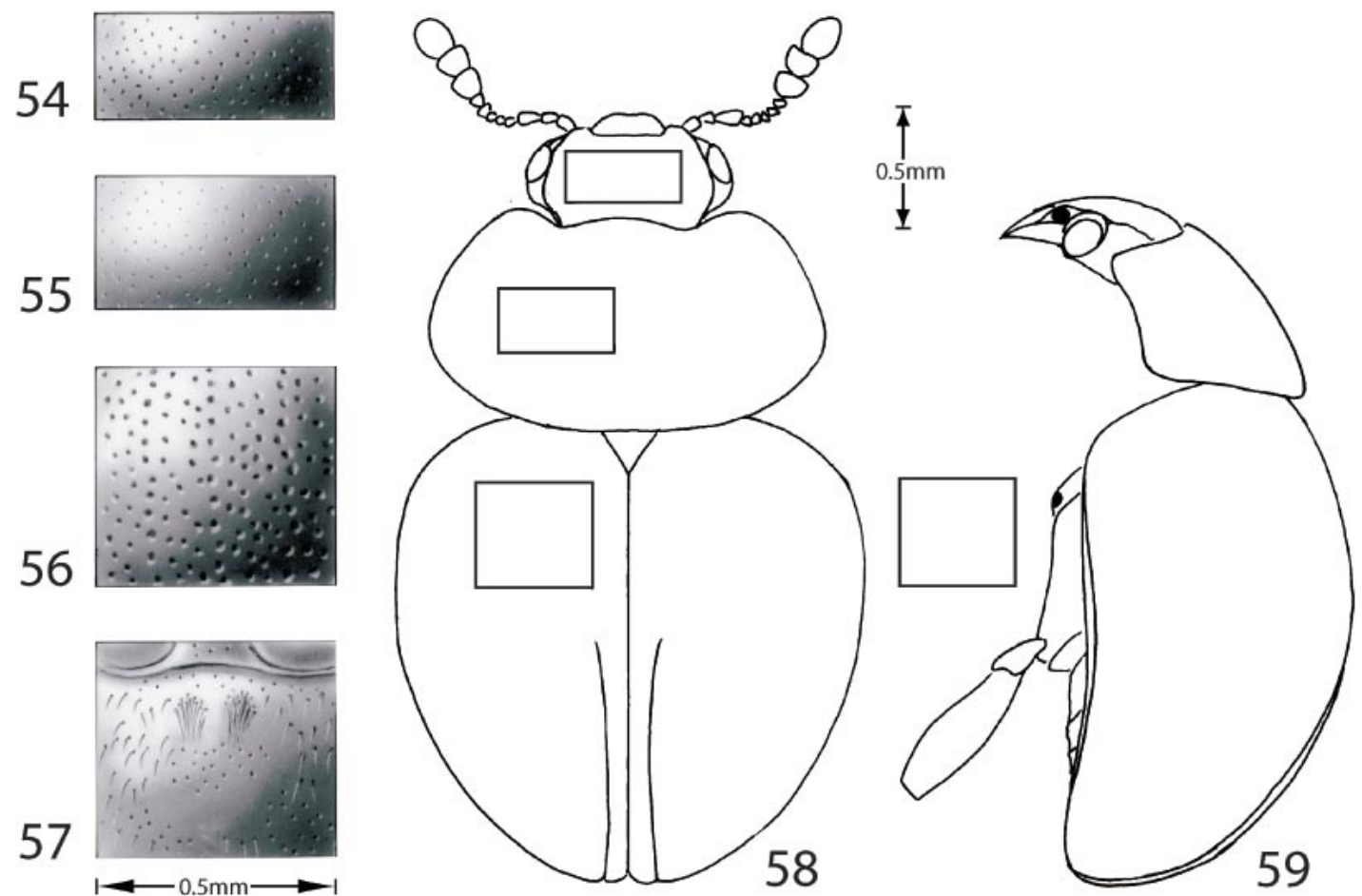

Figs. 54-59. Agathidium bistriatum Horn: Figs. 54-56, punctation detail: 54, head; 55, pronotum; 56, elytron. 57. Male metasternal fovea. Figs. 58, 59, habitus: 58, dorsal; 59, lateral. Bars $=0.5 \mathrm{~mm}$.

veae paired, large, circular, with pencil of fine golden setae (fig. 57), MFD = $0.06 \mathrm{~mm}$; metafemur not modified; left mandible not modified. Aedeagus elongate, narrow; median lobe attenuated apically (fig. 61); apex recurved (figs. 60, 61); operculum platelike, divided (fig. 61); lateral lobes with two subapical setae nearly equal in length (figs. 60, 61).

Female tarsi 4-4-4. Spermatheca bulb small; neck very long, strongly curved and attenuated to fine point apically (fig. 62).

DistRIBUTION: Specimens were examined from California and Nevada (fig. 53).

SPecimens ExAmined: UNITED STATES: $\mathrm{Cal}$ ifornia: Lassen Co.: 4 Jun 1913, paralectotypes (2, MCZC). Nevada: paralectotypes (11, MCZC).

Discussion: This species has been relatively rarely collected, and we did not examine any recently collected specimens. Thus, its status is unknown and nothing is known of its biology.

\section{Agathidium sexstriatum Horn}

Figures 52, 53, 63-71

Agathidium sexstriatum Horn, 1880: 303; Leng, 1920; Fall, 1934; Hlisnikovský, 1964.

TyPe MATERIAL: Lectotype (designated here to clarify association of this name to the species), of in MCZC (G. H. Horn Collection) labeled "Nev [with red line on left edge of N]/ Lectotype 3025 [red label]/ A. sexstriatum Horn/ LECTOTYPE, Agathidium sexstriatum Horn, des. Q. D. Wheeler \& K.B. Miller, 2001 [red label with black line border]".

Type Locality: United States, western Nevada.

DiAGNOSIS: This species can be distinguished from $A$. sextriatum group members by the body being elongate oval (figs. 52, 67) and dorsoventrally compressed (fig. 68) relative to body form of other known species of the group, the head and pronotum generally distinctly red in color, contrasted with 


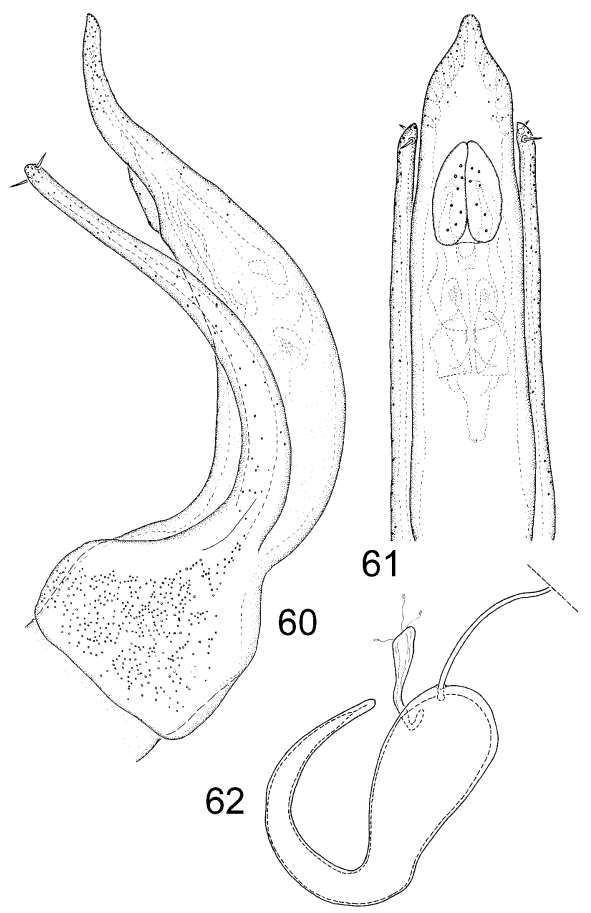

Figs. 60-62. Agathidium bistriatum Horn, genitalia: Figs. 60, 61, aedeagus: 60, lateral; 61, ventral. 62. Spermatheca.

black elytra, the elytra with more than 6 distinct rows of serial punctures, coarse and deeply impressed, and the aedeagus with median lobe broadly truncate (fig. 70).

DESCRIPTION: Body elongate oval, not contractile, only little convex (fig. 68); TBL = 2.3-2.5 mm. Color of head, prothorax, and appendages pale red; of elytra dark reddishbrown; head sometimes darker than pronotum.

Head narrow, more strongly narrowed behind eyes (fig. 67); OHW/MDL = 1.3; dorsal surface with moderately dense (ca. 10 per $0.01 \mathrm{~mm}^{2}$ ), small, irregularly distributed punctules (fig. 63); postocular temporum short; frontoclypeal suture nearly absent; surface of clypeal region paler in color than rest of dorsum and nearly impunctate; antenna short, not reaching posterior margin of pronotum; length ratio of antennomeres II:III = 1:1.5; width ratio of antennomeres VII:VIII: IX $=0.7: 1: 1.4$; labrum narrowed apically (length/width at base $=0.55$; at apex $=0.9$ ); apex shallowly emarginate medially; with fine pubescence. Pronotum short and wide, not strongly convex; PNW/PNL $=2.0 ; \mathrm{PNL} /$ $\mathrm{PNH}=1.2 ; \mathrm{PNW} / \mathrm{PNH}=2.26$; dorsal surface similar to head with dense, small punctures (ca. 10 punctures per $0.01 \mathrm{~mm}^{2}$ ) (fig. 64); surface shiny. Elytra broad, about as wide as long; ELW/SEL = 1.0; dorsal surface with about six serial rows of punctures set in shallow longitudinal impressions; intervals with dense punctures nearly equal to those of series; series obscure laterally, punctation confused (about 6 punctures per 0.01 $\mathrm{mm}^{2}$ ), punctures larger than those of pronotum and head (fig. 65). Mesosternum vertical between mesocoxae; almost indistinct, weak carina medially; length about $0.2 \mathrm{~mm}$; surface minutely alutaceous; with narrow anterior area set off by suture. Metasternum surface smooth, shiny, with dense, irregularly distributed punctures; MTL/MTW $=0.4$.

Male tarsi 5-5-4; pro- and mesobasotarsomeres moderately expanded; metasternal foveae comprised of paired shallow depressions with dense pencils of setae (fig. 66); MFD = max. about $0.07 \mathrm{~mm}$; metafemur unmodified; left mandible unmodified. Aedeagus with median lobe broad, slightly recurved distally in lateral view (fig. 69); broadly truncate (fig. 70); apical pores fanning out from wide central area (fig. 70); operculum divided, each part narrow, truncate (fig. 70); lateral lobes shorter than median lobe, terminating just beyond operculum (figs. 69, 70).

Female tarsi 4-4-4. Spermatheca bulb narrow and neck subapically widened (fig. 71).

DISTRIBUTION: Specimens were examined from Nevada, several sites in California, and southwestern British Columbia (fig. 53).

SPECIMENS EXAMINED: CANADA: British Columbia: Squamish, 25 Jul 1980, FIT, SA Marshall, RS Anderson (1, CNCI).

UNITED STATES: California: state only (5, MCZC); Yosemite Valley, 26 May 1928, FE Blaisdell (1, CASC); Yosemite Valley, 8 Jun 1930 (4, CASC); Marin Co.: SP Taylor State Park entrance, 9 Mar 1963 (2, EMEC); Tehama Co.: 2 mi SW Lassen Lodge, Paynes Ck, 6 Dec 1986, 3700', Douglas fir leaf litter, DS Chandler (3, CASC); $6 \mathrm{mi}$ W Log Springs Mendocino Natl Forest, 29 Nov 1986, 5200', oak leaf litter, DS 


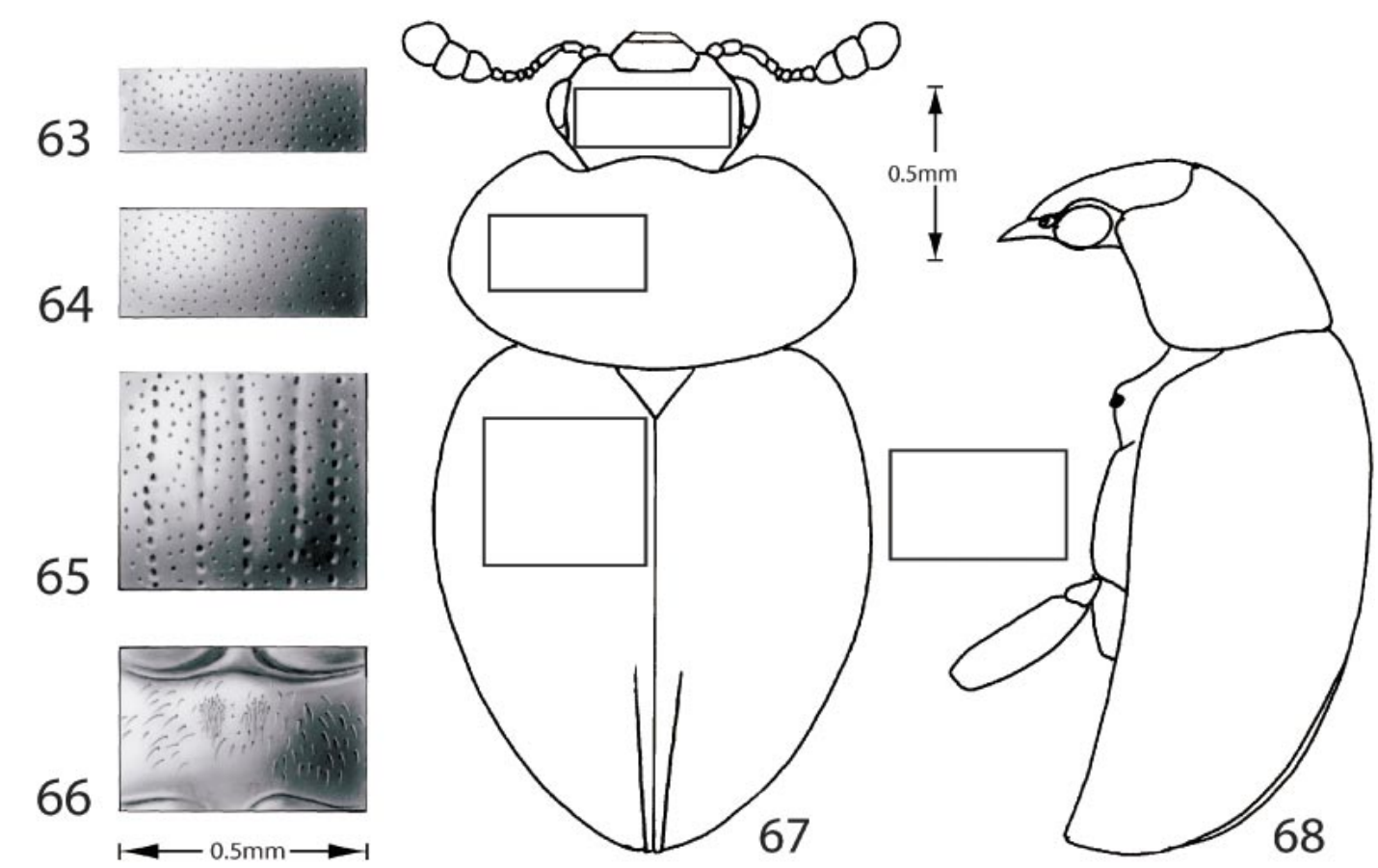

Figs. 63-68. Agathidium sexstriatum Horn: Figs. 63-65, punctation detail: 63, head; 64, pronotum; 65, elytron. Fig. 66, male metasternal fovea. Figs. 67, 68, body form: 67, dorsal; 68, lateral. bars $=0.5$ $\mathrm{mm}$.

Chandler (1, CASC). Nevada: state only, paralectotypes (3, MCZC).

Discussion: This species has been collected from oak and Douglas fir forest litter. Elevation records are from 3700 to $5200 \mathrm{ft}$.

\section{Agathidium estriatum Horn}

Figures 53, 72-79

Agathidium estriatum Horn, 1880: 304; Leng, 1920; Fall, 1934; Hlisnikovský, 1964.

Type Material: Holotype, 0 in MCZC (G. H. Horn Collection) labeled "Garland Col 30.6 ['30.6' handwritten]/ HoloTYPE 3023 [red label, '3023' handwritten]/ A. estriatum [handwritten]/ HOLOTYPE, Agathidium sexstriatum Horn, 1880 [red label with black line border]". Because only a single specimen was available to Horn (1880), it is a holotype by monotypy.

TyPe LocaliTy: United States, Colorado, Garland (probably Fort Garland, Costilla Co.).

Diagnosis: This species is distinguishable by the elytron with confused punctures, only inconspicuously arranged into series, the confused elytral punctation consists of two kinds of punctures, small, dense punctures and minute punctules on integument between (fig. 74), the elytral integument with weak alutaceous pattern, the male metasternum with single, small, round anteromedian fovea (fig. 75), and the aedeagus elongate, median lobe gradually narrowed apically in ventral view (fig. 79).

DESCRIPTION: Body broadly rounded, convex, not contractile (figs. 76, 77); $\mathrm{TBL}=2.2$ $\mathrm{mm}$. Color dark reddish-brown, pronotum, clypeus, labrum, and appendages, except antennal club, paler reddish.

Head narrow, narrowed behind (fig. 76); dorsal surface with moderately dense punctures (ca. 20 per $0.01 \mathrm{~mm}^{2}$ ); punctures larger than those of pronotum, smaller than those of elytra; with minute secondary punctules irregularly distributed between punctures (fig. 72); punctures smaller and less dense on clypeus; postocular temporum indistinct; frontoclypeal suture distinct; length ratio of antennomere II:III $=1.3: 1$; width ratio of an- 


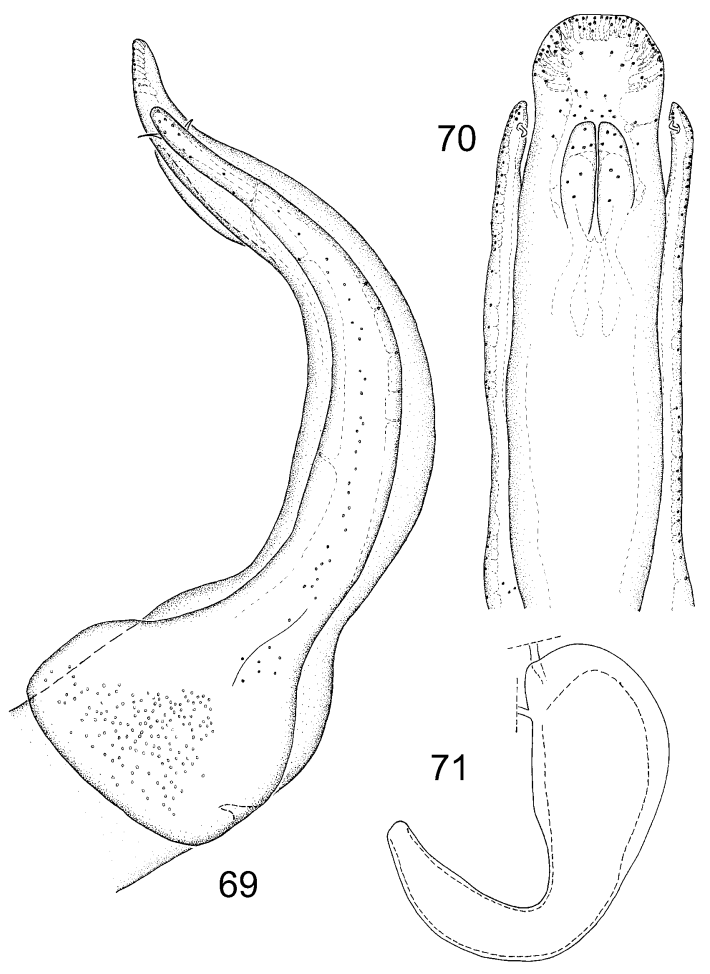

Figs. 69-71. Agathidium sexstriatum Horn: Figs. 69, 70, aedeagus: 69, lateral; 70, ventral. 71. Spermatheca.

tennomeres VII:VIII:IX $=0.9: 1: 1.1$; labrum separated by broad membrane; subquadrate, apically emarginate; with very sparse, fine pubescence; punctures smaller and less dense on clypeus. Pronotum short, wide, and not very convex $(\mathrm{PNW} / \mathrm{PNH}=2.2 ; \mathrm{PNL} / \mathrm{PNH}$ $=1.6$ ); dorsal surface with moderately dense punctures, with minute secondary punctules (fig. 73). Elytra very broad and convex; $\mathrm{ELW} / \mathrm{SEL}=1.0, \mathrm{SEL} / \mathrm{ELH}=2.0, \mathrm{ELW} /$ $\mathrm{ELH}=1.9$; dorsal surface with dense irregular punctures larger than those of head; areas between punctures with minute irregularly distributed punctules; punctures dense (ca. 9 per $1 \mathrm{~mm}^{2}$ ) (fig. 74). Mesosternum flat, nearly vertical between mesocoxae; weak, indistinct carina medially; anterior part set off by distinct suture; surface densely and minutely alutaceous. Metasternum large, MTL/MTW $=0.8$; punctures indistinct to absent anteriorly, moderately dense posteriorly and laterally; impunctate anteromedial region with dense, poorly defined alutaceous pattern.

Male tarsi 5-5-4; pro- and mesobasotarsomeres moderately expanded; metasternal fovea small, single, round, anteromedial in position, with short tuft of setae (fig. 75); MFD $=0.03 \mathrm{~mm}$; metafemur not modified; left mandible not modified. Aedeagus elongate and subparallel-sided (figs. 79); median lobe narrowed apically, with slight subapical constriction (fig. 79); operculum consisting of two small plates (fig. 79); lateral lobes short, with unequal pair of subapical setae (figs. 78, 79).

Female tarsi 4-4-4.

DISTRIBUTION: This is the most broadly distributed member of the group. Specimens were examined from British Columbia, Saskatchewan, Arizona, California, Colorado, Montana, New Mexico, Oregon, and Washington (fig. 53).

SPeCimens ExAmined: CANADA: British Columbia: 2 mi E Squamish (1, CNCI); Midday Valley, Merritt, 18 May 1925, J Stanley (1, CASC); Manning Pk E Gate, 2 Jun 1984, lodgepole pine forest, FIT, D Miller (1, CNCI); Vancouver, B Stephens (1, CASC). Saskatchewan: Cedar Hills Prov. Park (1, CNCI).

UNITED STATES: Arizona: Barfoot Park, Chiricahuas, 18 Jul 1963, PSB (1, CASC); Barfoot Park, Chiracahuas, 18 Jul 1963, PSB (4, CASC); Barfoot Park, Chiricahuas, 18 Jul 1963, PSB (1, CASC); Cochise Co.: Rustler Park, 7 Sep 1976, FG Andrews (9, FGAC); Graham Co.: Hospital Flat Pinaleno Mts, 2 Aug 1965, 8950', on Daldinia-like fungus, HB Leech (6, CASC). California: Amador Co.: $1 \mathrm{mi}$ W Pine Grove, 24 Jun 1975, leaf litter mixed hardwood conifer forest, A Newton, M Thayer (1, MCZC); Calaveras Co.: 2.7 mi N Camp Connell, 4 May 1976, litter, berlese, SC Kuba (1, FGAC); Eldor Co.: 2 mi E Lake Edson Dam, 12 Jul 1971, Ponderosa pine duff, DS Chandler (1, CASC); Lassen Co.: Norval Flats, 13 May 1920, 5500', JO Martin (2, CASC); Mono Co.: White Mts S Fk Cottonwood Crk, 18 Jun 1987, 9200', pitfall, D Giuliani (1, FGAC); Shasta Co.: Buckhorn Summit, 15 Feb 1983, oak duff, TR Haig (1, FGAC); Trinity Co.: Junction City, 12 Mar 1981, TR Haig (2, FGAC); Douglas City, 23 Jan 1980, oak duff, berlese, TR Haig (1, FGAC); Douglas City, 6 Mar 1975, TR Haig (1, FGAC); Tulare Co.: Sequoia Natl Park, Mineral King, 25 May 1984, 7700', R Baranwoski (4, LUND); Kaweah, 10 Apr 1907 (1, CASC); Sequoia Natl Park, Halstead Crk, 23 May 1984, 

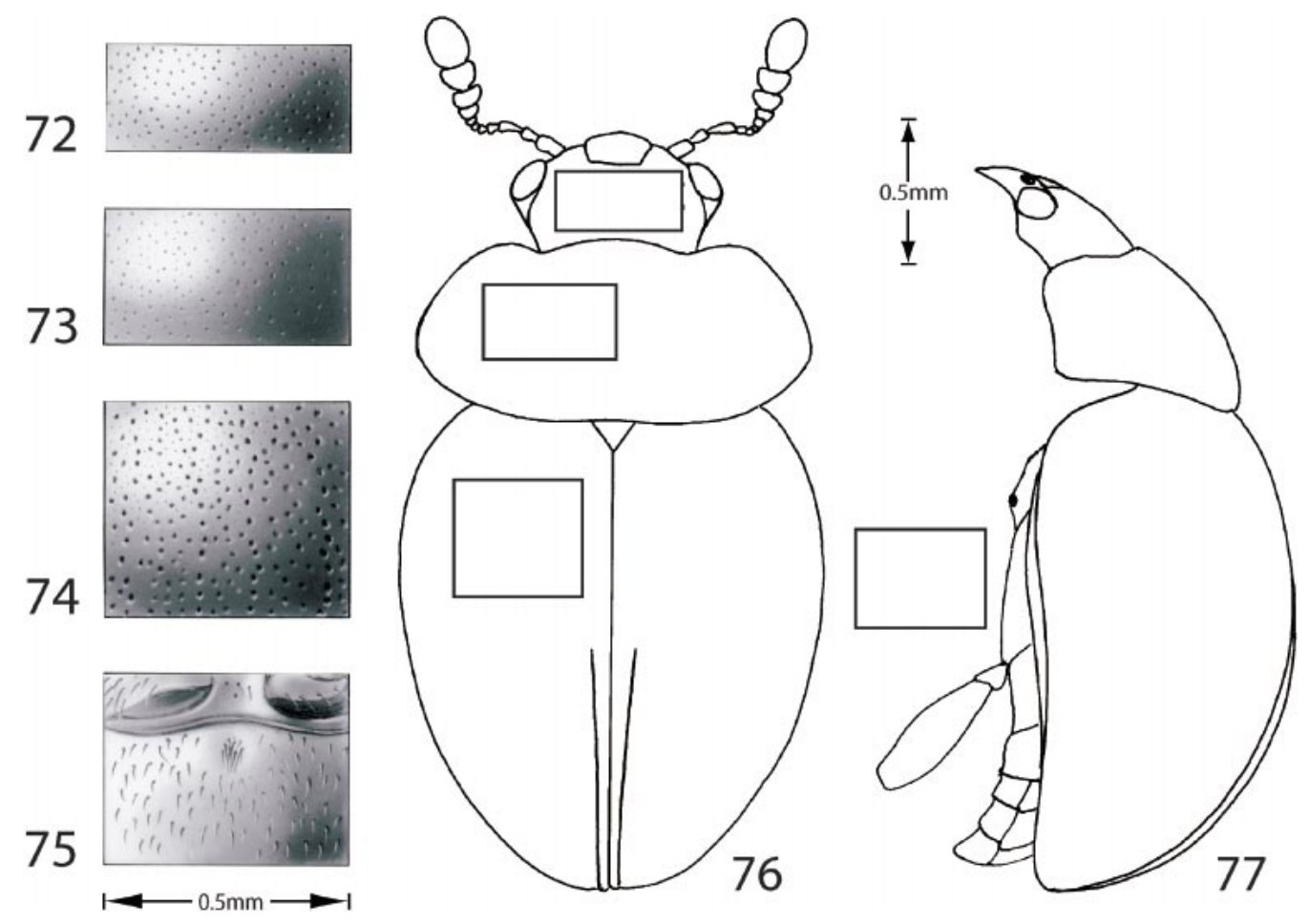

Figs. 72-77. Agathidium estriatum Horn: Figs. 72-74, punctation detail: 72, head; 73, pronotum; 74, elytron. 75. Male metasternal fovea. Figs. 76, 77, habitus: 76, dorsal; 77, lateral. Bars $=0.5 \mathrm{~mm}$.

7000', R Baranwoski (1, LUND); Tuolene Co.: 5 mi W Dardanelle, 18 Aug 1953, white fir and cedar, GA Marsh (1, CASC). Colorado: Garland, 30 Jun, Hubbard and Schwarz (3, USNM); Garland, 30 Jun (5, MCZC); Ouray, 1 Jul 1897, 8000', HF Wickham (2, USNM); Ouray, 1 Jul 1897, 8000' (1, MCZC). Montana: Madison Co., Hidden Lake Ranch (1, USNM). New Mexico: Torrance Co.: 6 mi SW Manzano, Red Can. Camp, 17 Jun 1979, 9000', spruce-fir litter, S and J Peck (3, PECK). Oregon: Lake Co.: Quarts Mt, 14 Jun 1984, 1600 m, R Danielsson (1, LUND); Wasco Co.: Wapinitia Pass, 11 Jul 1975, 4000', on Fuligo septica, A Newton, M Thayer (1, MCZC). Washington: Pierce Co.: Mt Rainier Natl Park, 4.7 mi W Longmire, 20 Jul 1975, 2200', on Fuligo septica, A Newton, M Thayer (3, MCZC); Skaminia Co.: Gifford Pinchot Natl Forest, 20 Jul 1984, old growth, D Thomas (1, PECK); Yakima Co.: $8 \mathrm{mi}$ SW Tieton RS Snoqualmie NF Bear Crk, 11 Jun 1973, WJ Turner (1, WSUC).

Discussion: Depending upon variation among individuals and the angle of light under which specimens are examined, evidence of serial punctation is variable. Whereas series are not as prominent as in A. sexstriatum and $A$. bistriatum, given proper illumination six or more serial rows of punctures can generally be seen among the dense and slightly smaller punctures present between them. Some specimens, possibly teneral ones, have the head and especially pronotum reddish in contrast to distinctly darker reddish elytra. In some of these bicolored specimens (e.g., Ouray, Colorado; Norval Flats, California) the apex of the median lobe is more gradually narrowed than in most other specimens and the ventral operculum is slightly more elongate. In the most extreme cases, specimens from Cochise Co., Arizona, have the pronotum rather brightly orange-red in sharp contrast to the dark head and elytra. Another specimen, from Douglas City, Trinity Co., California, is similar, but with reddish clypeus and labrum also. The latter material is so brilliantly bicolored as to be confused with A. sexstriatum initially. The dense elytral punctation, smaller serial punctures, and less parallel-sided elytra distinguish such specimens from A. sexstriatum. Unfortunately, all 


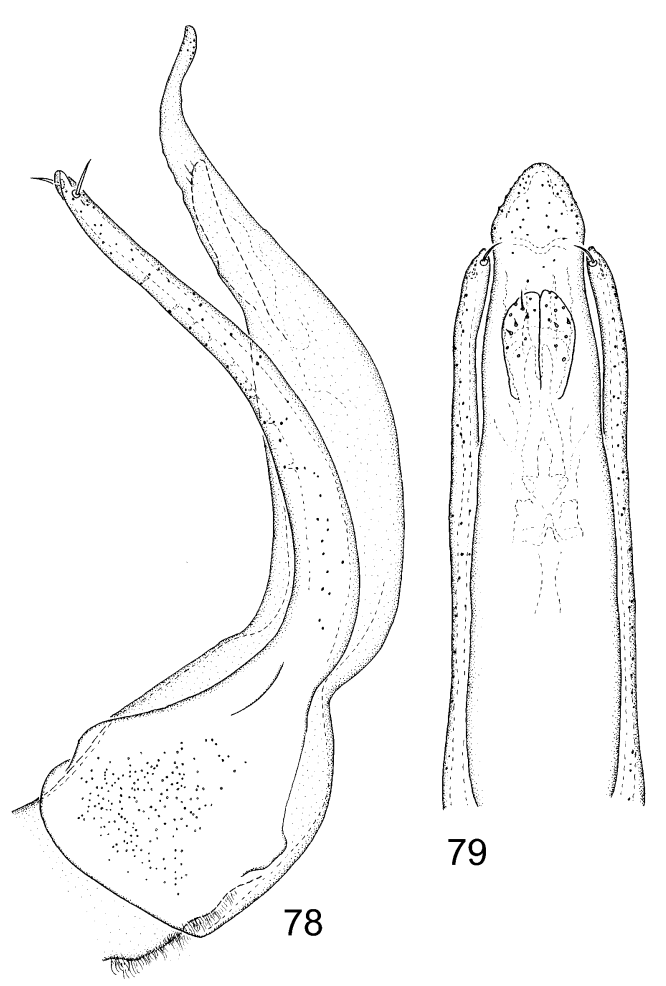

Figs. 78, 79. Agathidium estriatum Horn, aedeagus: 78, lateral; 79, ventral.

these specimens are females so that their conspecificity with other $A$. estriatum rests on these external features alone. Considering this structural variation, the broad geographic distribution of the species, and the paucity of existing specimens, infraspecific variation and the possibility of more than one species here should be reconsidered when sufficient numbers of specimens have accumulated. Other specimens, however, are more uniformly darkly colored, aside from pale markings of the pronotum.

A series of specimens from Arizona (Hospital Flat) are labeled as having been collected from a "daldinia-like fungus", which could easily describe Lycoperdales slimemolds. The species has also been reported from the myxomycete, Fuligo septica (Lawrence and Newton, 1980). Specimens have been collected from a variety of forest litter types, including ponderosa pine, white fir, cedar, spruce, lodgepole pine, and others. Elevation records are from 2200 to $9200 \mathrm{ft}$.

\section{AGATHIDIUM BREVISTERNUM SPECIES GROUP}

DiAgnosis: The A. brevisternum group species may be recognized by the following combination of characters: minute size, extreme convexity, strong contractility (figs. 80,81 ), tusked left male mandible (not present on all males) (figs. 80, 81), exceptionally short metasternum with meso- and metacoxae nearly touching, aptery, disproportionately large and broad head (fig. 80), articles of antennal stem very elongate, narrow, parallel-sided with subapical whorl of setae.

DisCUSSION: Although the extremely shortened metasternum of this group is undoubtedly apomorphic and unusual within the genus, its potential synapomorphic significance is less convincing. This is because such shortened metasterna are correlated with flightlessness in other Coleoptera and, like other loss characters, can mask convergence. Nonetheless, this short metasternum combined with the minute size, disproportionately large cranium, and horned left male mandible combine to make the species assigned to this group distinct and easily identified.

The ventral operculum of the median lobe is very thin and fragile and, after clearing, is easily overlooked. Care must be taken in preparing the aedeagus so as to not make the operculum too transparent. A pair of sclerotized structures on the endophallus are more evident in cleared specimens than is the operculum.

The majority of these species are identifiable at this time based only upon the shape of the median lobe.

\section{KEY TO A. BREVISTERNUM SPECIES GROUP}

1. Rami of operculum broad, not strongly divergent apically (fig. 84) ............ .............. A. brevisternum Fall

- Rami of operculum narrow, strongly divergent apically (figs. 92, 93, 95) . . . . . . 2

2(1). Rami of operculum with medial fold, apices entirely separated (figs. 92, 93) .... ....... A. rhinocerellum, new species

- Rami of operculum without medial fold, apically connected by truncate, hyaline shield (fig. 95) ................ ....... A. dioperculum, new species 


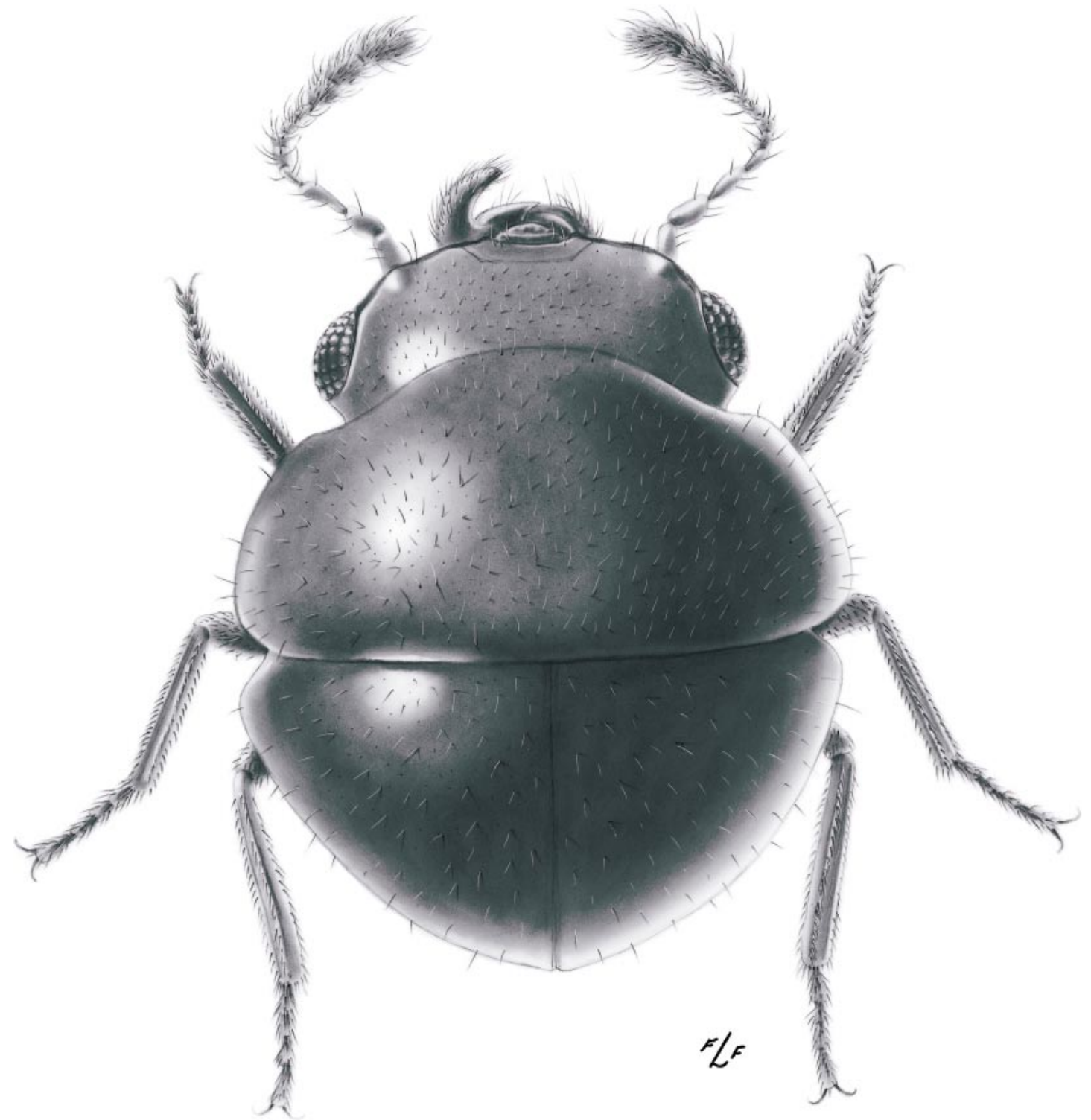

Figs. 80. Agathidium brevisternum Fall, habitus, dorsal.

Agathidium brevisternum Fall

Figures 80, 81, 82-85

Agathidium brevisternum Fall, 1934: 122; Hatch, 1957.

Type MATERIAL: Holotype, $\widehat{0}$ in MCZC labeled "Eureka 29.5 Cal ['29.5' handwritten]/ HS Barber Collector/ ơ/ H. C. FALL COLLECTION/ TYPE brevisternum ['TYPE' with red underline, 'brevisternum' handwrit- ten]/ M.C.Z. Type 24030 [red label]/ HOLOTYPE, Agathidium brevisternum Fall, 1934 [red label with black line border]'.

TyPe Locality: United States, California, Humboldt Co., Eureka.

Diagnosis: This species is distinguished from other members of the group by male genitalia with deeply emarginate operculum of median lobe with apices convergent (fig. 84). The carina bordering the anterior margin 


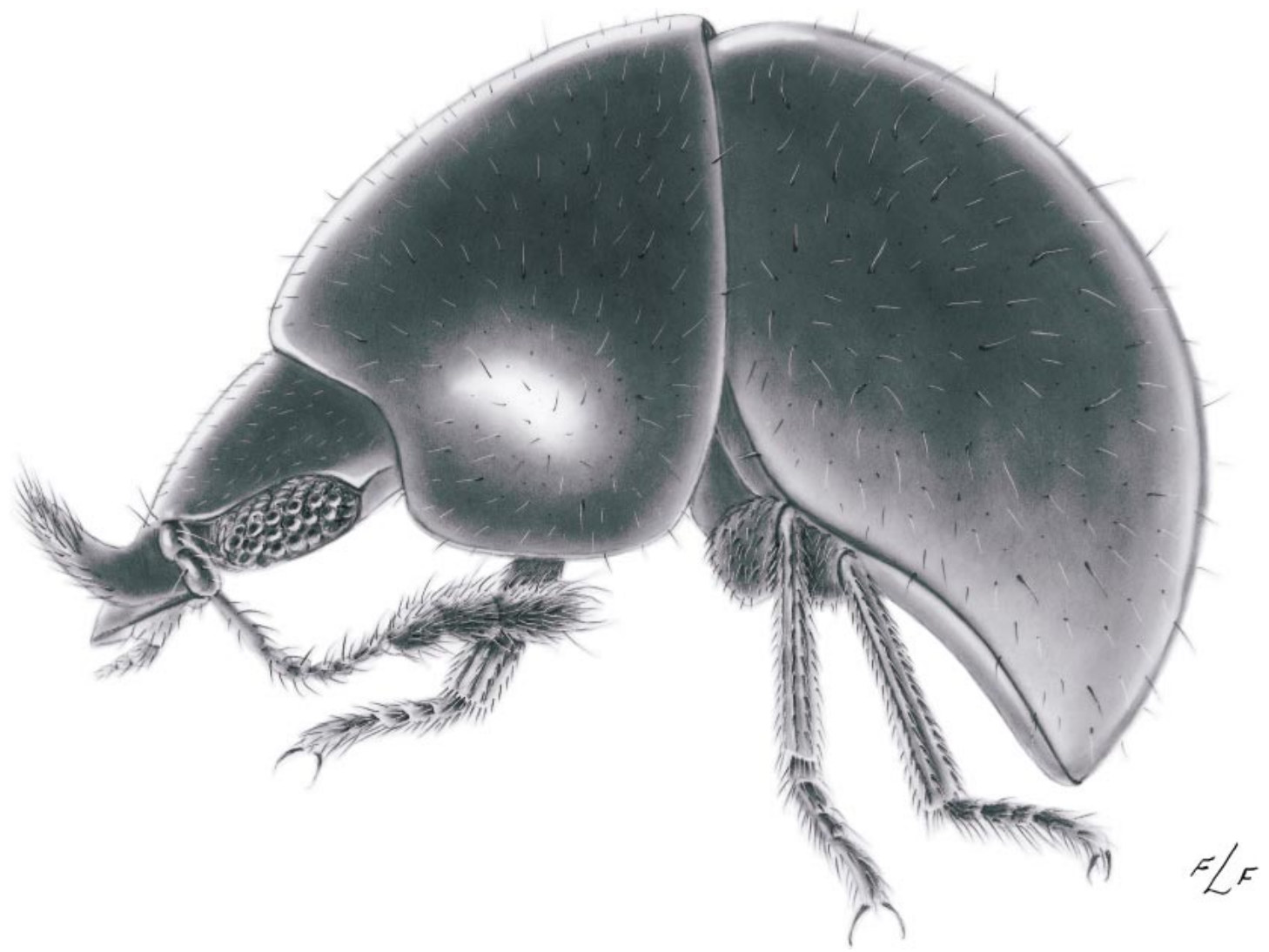

Fig. 81. Agathidium brevisternum Fall, habitus, lateral.

of the cranium is less distinctly sinuate above the bases of the antennae than in A. rhinocerellum which, in combination with the relatively simple, platelike halves of the operculum distinguish $A$. brevisternum from that species.

DESCRIPTION: Body very broadly rounded, strongly convex, and partially contractile (figs. 80, 81); TBL $=2 \mathrm{~mm}$. Color reddishtestaceous; dorsum somewhat reddish; antenna pale, concolorous; venter and appendages testaceous.

Head large, very wide, broadly rounded in front, more or less quadrate and dorsoventrally flattened (figs. 80, 81); OHW/MDL = 2 ; eyes very large, elongate, situated on sides of head, with large, coarse facets numbering less than 36; postocular temporum short, inconspicuous; OHW/PHW $=1.1$; anterior marginal carina conspicuous from edge of labrum to point posterior to eye, narrowly bor- dering eye; antenna with abrupt 3-segmented club; antennomere III elongate, narrow, longer than II, subequal to length of I; II:III = 1:1.8; VII, VIII subequal, small, submoniliform; VII:VIII:IX = 0.7:1:1.4; frontoclypeal suture absent, extremely faint hint of suture under high magnification; surface of head shiny, impunctate; under high magnification, sparse, microscopic punctules exist bearing very fine setae; labrum narrow, elongate, with blunt apex at most slightly emarginate medially. Pronotum very broad, convex; anterior margin broadly rounded and protruding anterad medially; posterior angles weakly defined; surface shiny, nearly impunctate, as on head, except punctures slightly less dense. $\mathrm{PNW} / \mathrm{PNL}=1.6 ; \mathrm{PNL} / \mathrm{PNH}=1.1 ; \mathrm{PNW} /$ $\mathrm{PNH}=1.8$. Combined elytral width, in dorsal view, about equal to length (ELW/SEL = $1)$; in posterior view, elytral apex attenuate; sutural stria evident in apical half; surface 


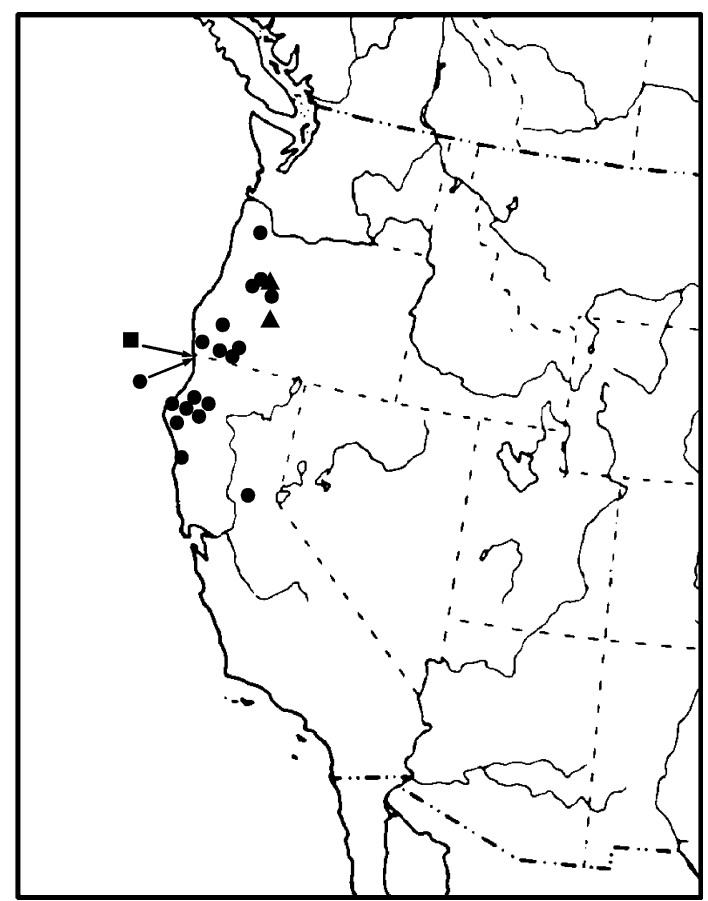

Fig. 82. Agathidium brevisternum group geographic distribution: $A$. brevisternum Fall = ; $A$. dioperculum, n.sp. $=\square ; A$. rhinocerellum, n.sp. $=\boldsymbol{\Delta}$.

shiny, nearly impunctate, as on pronotum; epipleuron very wide, bordered by sharp carinae, ending shortly before apex of elytron. Mesosternum large, simple; without lateral carinae; without median carina; surface microscopically alutaceous; MSL/MTL = 3.2. Metasternum very short medially, sides at widest point shorter than mesosternum medially, narrowed to bands between meso- and metacoxae, narrower than one-half maximum width of metacoxa; surface with microscopic alutaceous pattern; MTL/MTW $=0.12$.

Male tarsi 5-5-4; pro- and mesobasotarsomeres slightly expanded, with spatulate ventral setae; metasternal fovea median, punctiform, with few long setae; metafemur narrow, without tooth; left mandible usually with dorsally directed, curved, apically blunt tusk arising dorsally from side near base of mandible (figs. 80, 81); with tuft of apical setae. Aedeagus with median lobe short, bullet-shaped, pointed, narrowed before apex (fig. 84); apical pores number approximately 16 , ducts longitudinally oriented and parallel

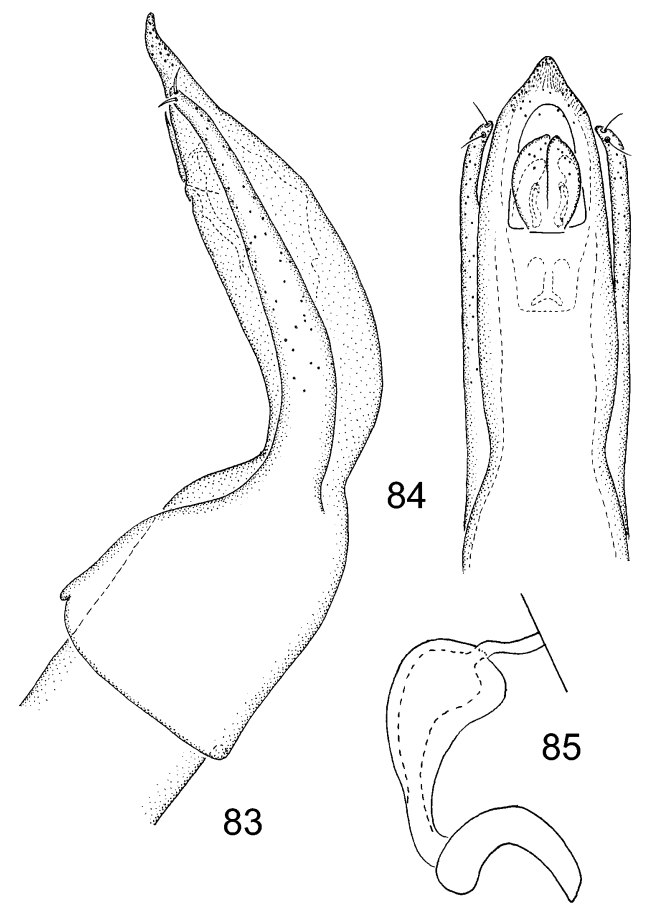

Figs. 83-85. Agathidium brevisternum Fall, genitalia: Figs. 83, 84, aedeagus: 83, lateral; 84, ventral. 85. Spermatheca.

to one another; lateral lobes narrow, terminating at point of median lobe constriction at about apex of operculum, with paired subapical setae and moderately dense, irregularly distributed pores along length (fig. 83-84); operculum broad, flat, paired, together narrowed apically, slightly emarginate between at apex, each with about 6 subapical pores, 4 in oblique row (fig. 84); endophallus apparently with two membranous apical digits; with paired, median, slightly C-shaped sclerites with minute, blunt, toothlike median ridges.

Female tarsi 5-4-4; spermatheca with neck very long, slender, and twisted (fig. 85).

DISTRIBUTION: This species is known from areas of northern California, particularly in the northwest corner of the state, and western Oregon (fig. 82).

SPECIMENS EXAMINED: UNITED STATES: $\mathrm{Cal}$ ifornia: Del Norte Co.: Crescent City, 24 Apr 1991, TR Haig (7, CASC); 2 mi N Ft Dick, 21 Nov 1953, VD Roth (1, CASC); 6 mi NE Crescent City, 25 Jun 1978, J Schuh, L and N Herman (1, AMNH); Humboldt Co.: Eureka, 7 Jun, HS 


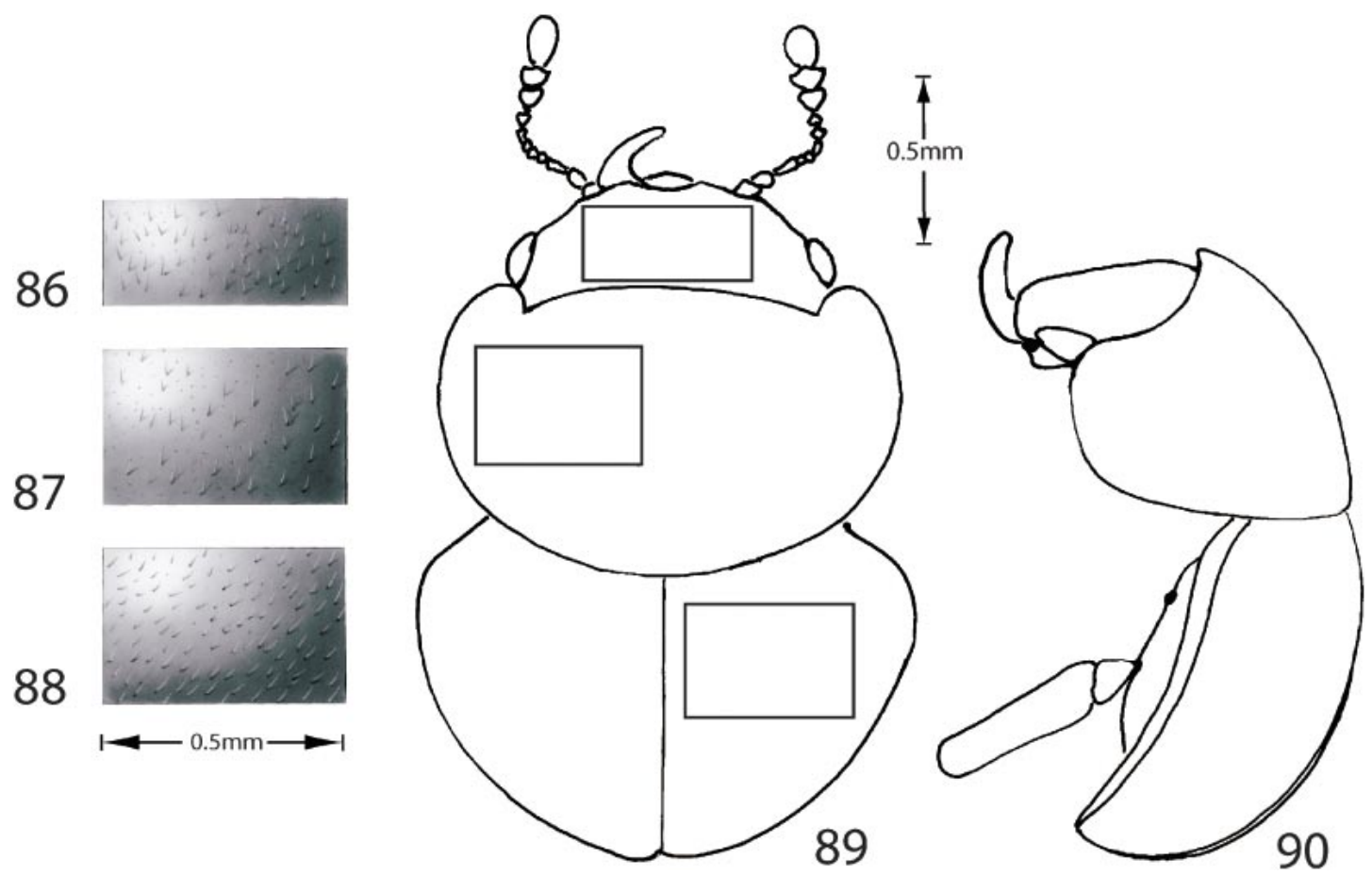

Figs. 86-90. Agathidium rhinocerellum, n.sp.: Figs. 86-88, punctation detail: 86, head; 87, pronotum; 88, elytron. Figs. 89, 90, habitus: 89, dorsal; 90, lateral. Bars $=0.5 \mathrm{~mm}$.

Barber (1, MCZC); Arcata Comm. Forest, 4 Dec 1962, berlese, J Pinto (4, CASC); Berry Summit, 12 Dec 1973, oak duff, berlese, TR Haig (2, CASC); Kneeland, 1 Sep 1979, redwood duff, berlese, TR Haig (8, CASC); Weott, 17 Mar 1976, redwood duff, TR Haig (1, CASC); Willow Creek, 15 Mar 1979, oak duff, TR Haig (1, CASC); Mendocino Co.: Westport, 14 Dec 1973, bark and moss, berlese, TR Haig (2, CASC); Trinity Co.: $8.5 \mathrm{mi}$ E Salyer, 12 Apr 1971, oak litter, berlese, TR Haig (1, CASC); Del Loma, 12 Mar 1980, Douglas fir duff, TR Haig (3, CASC). Oregon: New Era, 30 Apr 1954, deciduous duff, V Roth (1, RLWE); nr Bridge, 13 Oct 1954, VD Roth (1, MCZC); Curry Co.: 3 mi N Shasta Creek Rogue River, 10 Mar 1972, 600', oak duff, E Benedict (2, CUIC); Jackson Co.: Applegate, 19 Jun 1958, duff, K Goeden (1, RLWE); 3.5 mi S Ruch 2 mi from Hwy 238, 13 Nov 1971, 1500', pine oak fir duff, E Benedict (1, CUIC); Josephine Co.: O'Brien, 18 Dec 1971, 1600', live oak duff, E Benedict (1, CUIC); Lane Co.: Dolly Varden For. Cpgd., 4 Mar 1972, 1100', alder maple, E Benedict (1, CASC); Dolly Varden Forest Cpgd, 4 Mar 1972, 1100', alder maple, E Benedict (4, CUIC); Leaburg, 10 Nov 1974, G Cooper (1, CASC); Linn Co.: 2 mi S 2 mi E Cascadia, 29 Apr 1972, 1900', maple duff, E Benedict (3, CUIC); Wash- ington Co.: 10 mi N Forest Grove, 9 Apr 1967, EM Benedict (1, CASC).

Discussion: All measurements except those of antennomere lengths and widths were taken from the holotype. Antennal measurements are from a female from Eureka, California (MCZC). This species has been collected from a variety of different litter types including oak, fir, pine, alder, maple, redwood, and general wood and leaf litter. Elevation records are from 600 to1900 ft.

Agathidium rhinocerellum Wheeler and Miller, new species

Figures 82, 86-90

Type Material: Holotype, $\widehat{o}$ in OSUC labeled "Ore., Lane Co. Spensers Butte $2 \mathrm{mi}$ S Eugene 23 Nov. 1959 John D. Lattin/ HOLOTYPE Agathidium rhinocerellum Wheeler and Miller, 2002 [red label with black line border]".

TyPe Locality: United States, Oregon, Lane County, 2 miles S Eugene.

DiagnOSIS: This species is distinguished from other A. brevisternum group members 


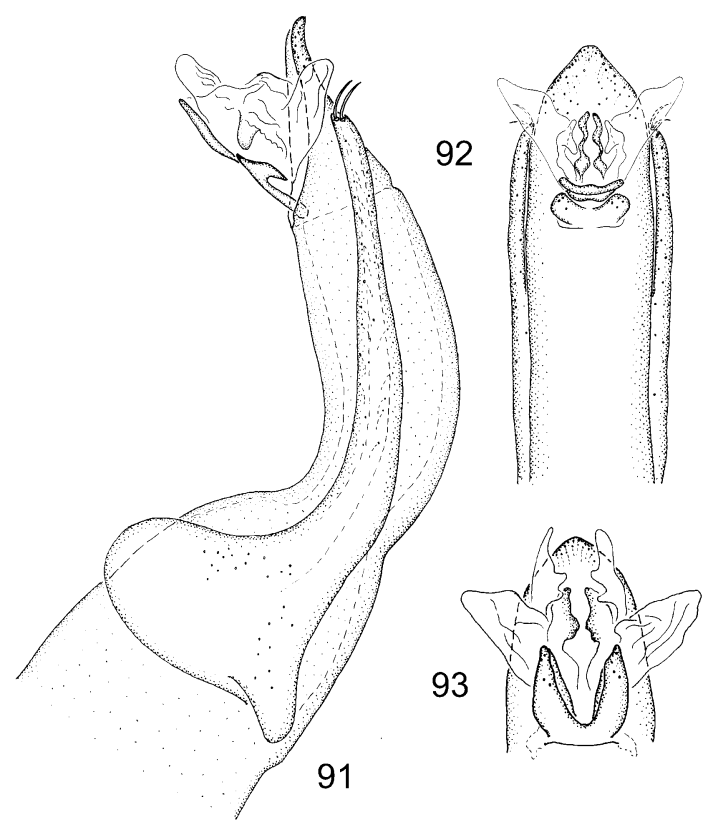

Figs. 91-93. Agathidium rhinocerellum, n.sp., aedeagus: 91, lateral; 92, ventral; 93, apex of median lobe, ventral.

by the male genitalia with the ventral operculum of the median lobe large, deeply emarginate and with the halves narrow, strongly divergent, and with a distinct medial, irregular fold (figs. 91-93). The carina bordering the anterior margin of the cranium is more distinctly sinuate above the bases of the antennae than in $A$. brevisternum which, in combination with the sinuate pair of sclerites of the endophallus of the aedeagus (figs. 9193), distinguishes $A$. rhinocerellum from that species.

DESCRIPTION: Body very broadly rounded, strongly convex and partially contractile (figs. 89, 90); TBL $=2.25 \mathrm{~mm}$. Color dark reddish-brown to black, eyes pale, venter and appendages yellowish-brown, antenna pale, concolorous.

Head large, very wide, broadly rounded in front, more or less quadrate and dorsoventrally flattened (figs. 89, 90); OHW/MDL = 1.8; eyes very large, elongate, situated on sides of head, with large, coarse facets numbering less than 36; postocular temporum short, inconspicuous; OHW/PHW $=1.02$; anterior marginal carina conspicuous from edge of labrum to point posterior to eye, nar- rowly bordering eye, sharply angled and terminating immediately posterior to eye, sinuate above base of antenna; antenna with abrupt 3-segmented club; antennomere III elongate, narrow, longer than II, subequal to length of I; II:III = 1:1.3; VII, VIII subequal, small, submoniliform; VII:VIII:IX $=0.8: 1$ : 1.6; frontoclypeal suture absent, extremely faint hint of suture under high magnification; surface of head shiny, impunctate; under high magnification, sparse, microscopic punctules exist bearing very fine setae (fig. 86); labrum short, wide, blunt at apex. Pronotum very broad, convex; anterior margin posterior to head emarginate, nearly straight; posterior angles weakly defined; surface shiny, nearly impunctate, as on head, except punctures slightly less dense (fig. 87); PNW/ $\mathrm{PNL}=0.7 ; \mathrm{PNL} / \mathrm{PNH}=1.2 ; \mathrm{PNW} / \mathrm{PNH}=$ 1.7. Combined elytral width, in dorsal view, slightly greater than length; ELW/SEL = 1.02; in posterior view, apex attenuate; sutural stria evident in apical half; surface shiny, nearly impunctate, as on pronotum (fig. 88); epipleuron very wide, bordered by sharp carinae, ending shortly before apex of elytron. Mesosternum large, simple; without lateral carinae; without median carina; surface microscopically alutaceous; posterior portion between mesocoxae triangular; MSL/ MTL $=1.4$. Metasternum very short medially, sides at widest point shorter than mesosternum medially, narrowed to bands between meso- and metacoxae, narrower than one-half maximum width of metacoxa; surface with microscopic alutaceous pattern; anterior margin between mesocoxae elevated as transverse carina; MTL/MTW $=0.14$.

Male tarsi 5-5-4; pro- and mesobasotarsomeres slightly expanded, with spatulate ventral setae; metasternal fovea median, punctiform, with few long setae; metafemur narrow, without tooth; left mandible usually with dorsally directed, curved, apically blunt tusk arising dorsally from side near base of mandible, with tuft of apical setae (figs. 89, 90). Aedeagus with median lobe short, parallel-sided, narrowed at apex (figs. 91, 92); apical pores reaching margin numbering approximately 24 , with similar number not attaining margin, pores more or less longitudinally oriented and parallel to one another; lateral lobes narrow, terminating at point of 
median lobe constriction at about apex of operculum, with paired subapical setae, and moderately dense, irregularly distributed pores along length (fig. 92); endophallus with two membranous apical winglike flaps; with paired, median, strongly sinuate sclerites (figs. 92, 93).

Female tarsi 5-4-4; spermatheca not observed.

ETYMOLOGY: This species is named from rhino, Greek for "nose", keros, Greek for "horn", and the diminutive suffix "ellum". The name reflects both the rhinoceroslike horn on the left male mandible and the diminutive size of beetles of this species.

DISTRIBUTION: This species is only known from western Oregon (fig. 82).

PaRATYPes: UNITED STATES: Oregon: Douglas Co.: 20 mi ENE Glide, 23 Mar 1961, 2450', moss and ground litter, D Fellin (1, CASC); Lane Co.: Spensers Butte, 2 mi S Eugene, 23 Nov 1959, JD Lattin (1, CASC).

Discussion: One female from Douglas Co., Oregon, is tentatively assigned to this species because the supraantennal carina is more strongly sinuate above the antennal insertion. All measurements were taken from the holotype with the exception of antennomeres VII, VIII, and IX. Because the apical portion of the antenna of the type was not visible, apical antennomeres of the paratype were measured instead. One specimen was collected from "moss and ground litter". A single host record is from Fuligo septica (Russell, 1979).

\section{Agathidium dioperculum Wheeler and Miller, new species Figures 82, 94, 95}

Type Material: Holotype, 0 in AMNH (deposited from California Department of Food and Agriculture) labeled "CALIF:Del Norte Co. Crescent City IX-19-1978 T.R.Haig,Coll. [date handwritten]/ Berlesed from Redwood Duff/ HOLOTYPE Agathidium dioperculum Wheeler and Miller, 2002 [red label with black line border]".

Type Locality: United States, California, Del Norte Co., Crescent City, redwood duff.

Diagnosis: This species is separable from other A. brevisternum group members by the male median lobe with operculum deeply di-

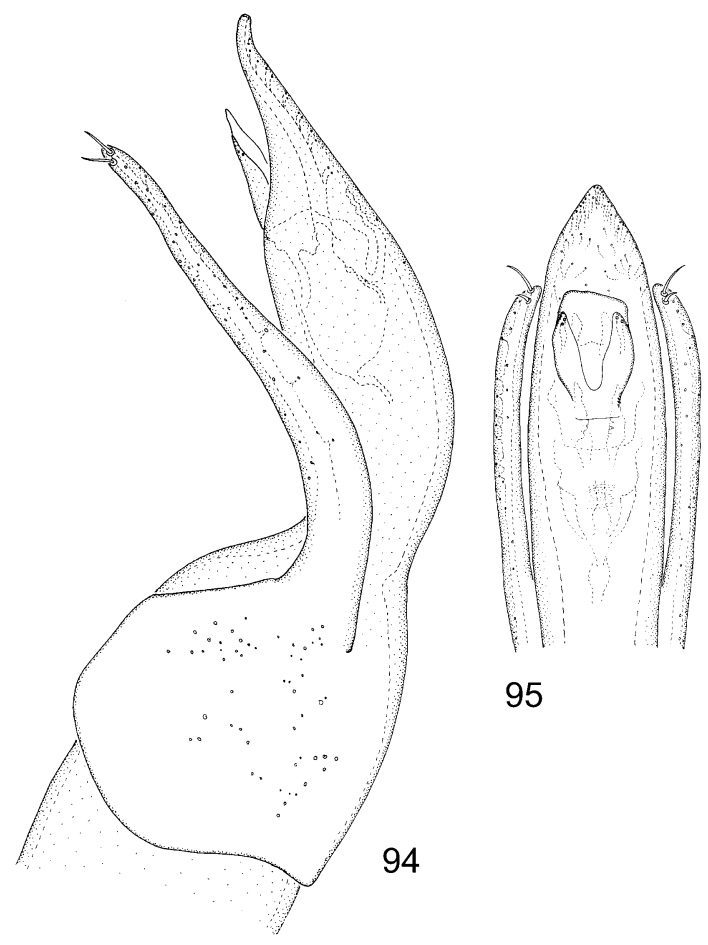

Figs. 94, 95. Agathidium dioperculum, n.sp., aedeagus: 94, lateral; 95, ventral.

vided into two elongate plates diverging apically, with halves connected by a broad, truncate, hyaline plate (fig. 95).

DESCRIPTION: Body very broadly rounded, strongly convex, and partially contractile; $\mathrm{TBL}=$ about $2.2 \mathrm{~mm}$. Color reddish-brown; antenna pale, concolorous; venter and appendages testaceous.

Head large, very wide, broadly rounded in front, more or less quadrate and dorsoventrally flattened; $\mathrm{OHW} / \mathrm{MDL}=2.0$; eyes very large, elongate, situated on sides of head, with large, coarse facets numbering less than 36 in dorsal view; postocular temporum short, inconspicuous; OHW/PHW $=1.1$; anterior marginal carina very conspicuous from edge of labrum to point posterior to eye, narrowly bordering eye; antenna with abrupt 3segmented club; antennomere III elongate, narrow, longer than II, subequal to length of I; II:III = 1:1.8; VII, VIII subequal, small, submoniliform; VII:VIII:IX = 0.7:1:1.4; frontoclypeal suture absent, extremely faint hint of suture under high magnification; surface of head shiny, nearly impunctate; under 


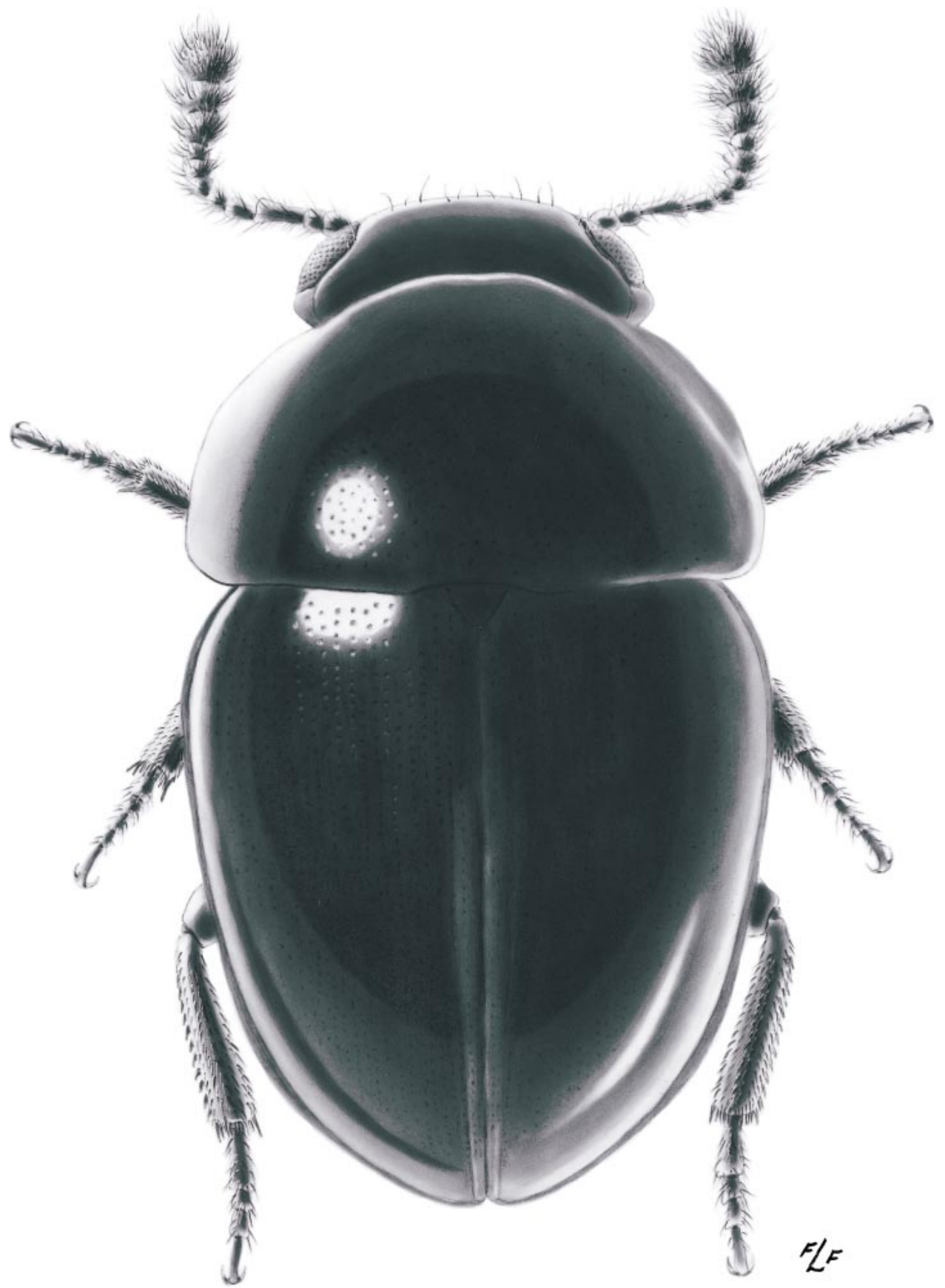

Fig. 96. Agathidium depressum Fall, habitus, dorsal.

high magnification, sparse, microscopic punctules exist bearing very fine setae; labrum narrow, elongate, distally tapered with blunt apex slightly emarginate medially.
Pronotum very broad, convex; anterior margin broadly rounded; posterior angles weakly defined; surface shiny, nearly impunctate, as on head, except punctures slightly less dense; 


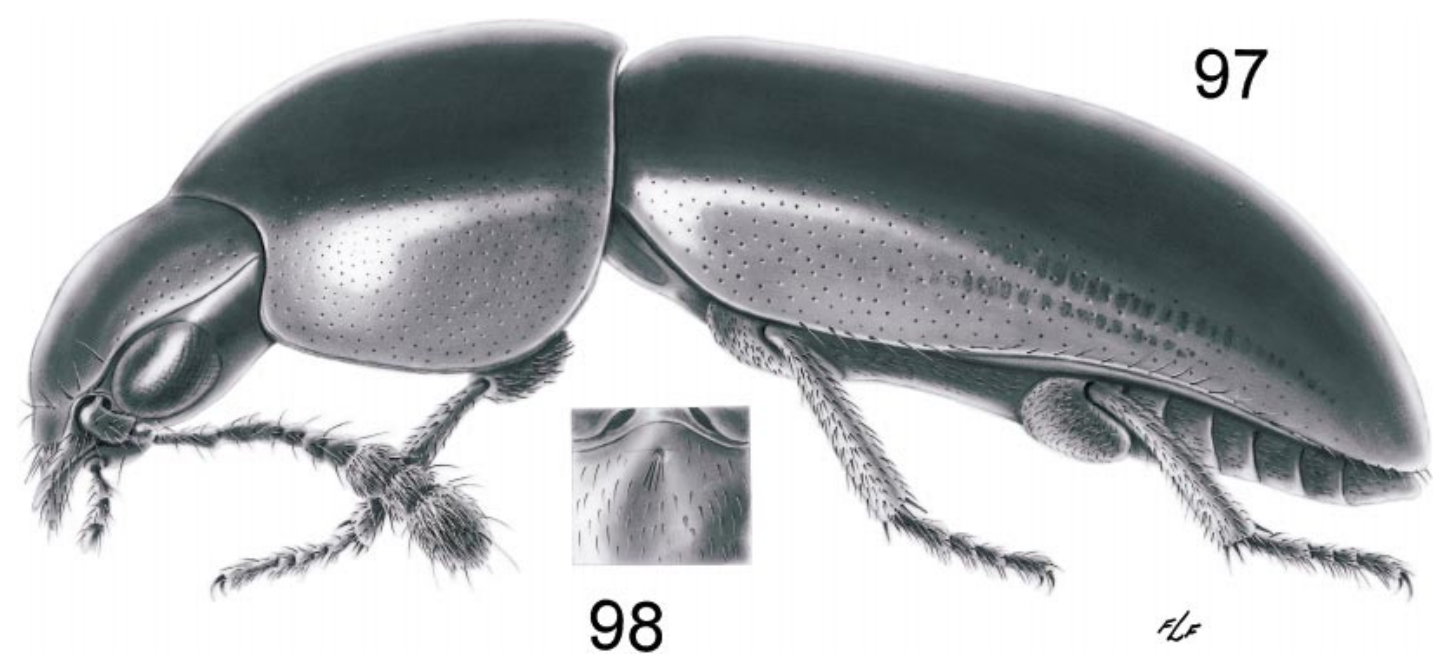

Figs. 97, 98. Agathidium depressum Fall: 97, habitus, lateral; 98, male metasternal fovea.

$\mathrm{PNW} / \mathrm{PNL}=1.8 ; \mathrm{PNL} / \mathrm{PNH}=1.6 ; \mathrm{PNW} /$ $\mathrm{PNH}=2.8$. Combined elytral width, in dorsal view, about equal to length $(\mathrm{ELW} / \mathrm{SEL}=$ $1.3)$; in posterior view, extreme apex attenuate; sutural stria evident in apical half; surface shiny, nearly impunctate, as on pronotum; epipleuron very wide, bordered by sharp carinae, ending shortly before apex of elytron. Mesosternum large, simple; without lateral carinae; without median carina; surface microscopically alutaceous; MSL/MTL $=2.1$. Metasternum very short medially, sides at widest point shorter than mesosternum medially, narrowed to bands between meso- and metacoxae, narrower than onehalf maximum width of metacoxa; surface with microscopic alutaceous pattern; MTL/ $\mathrm{MTW}=0.11$.

Male tarsi 5-5-4; pro- and mesobasotarsomeres slightly expanded, with spatulate ventral setae; metasternal fovea median, punctiform, with few long setae; metafemur narrow, without tooth; left mandible with dorsally directed, curved, apically blunt tusk arising dorsally from side near base mandible; with tuft of apical setae. Aedeagus with short, stout median lobe, narrowed at apex in ventral view, curved ventrad with apex recurved dorsad (fig. 95); operculum with sclerotized basal and lateral areas forming deeply emarginate, divided parts, the apices of which bear two pores and the medial surfaces of which are not excavated, the distal region between two sclerotized "arms" connected by truncate, transparent, extremely fine, membranelike structure (fig. 95); lateral lobes gradually narrowed apically, subapical setae similar in size (figs. 94, 95) (foreshortened due to angle of vision in ventral drawing, fig. 95).

Female tarsi 5-4-4; spermatheca not examined.

ETYMOLOGY: This species is named from $d i$, Latin for "two", and operculum, Latin for "lid", in reference to the deeply divided operculum of the median lobe in males of this species.

DISTRIBUTION: This species is only known from the type locality in extreme northwestern California (fig. 82).

PARATYPEs: UNITED STATES: California: Del Norte Co.: Crescent City, 24 Apr 1991, pine duff, berlese, TR Haig (4, CASC, deposited from California Department of Food and Agriculture).

Discussion: This form is hypothesized to be a distinct species largely because the connective structure between the two sclerotized lateral arms of the operculum was not seen in individuals of related species. Because this form appears to by sympatric with related species and because variation in some structures have been observed, including the number of pores on the operculum, it is possible that this is simply a variant of $A$. brevisternum. The type series was collected from pine duff. 


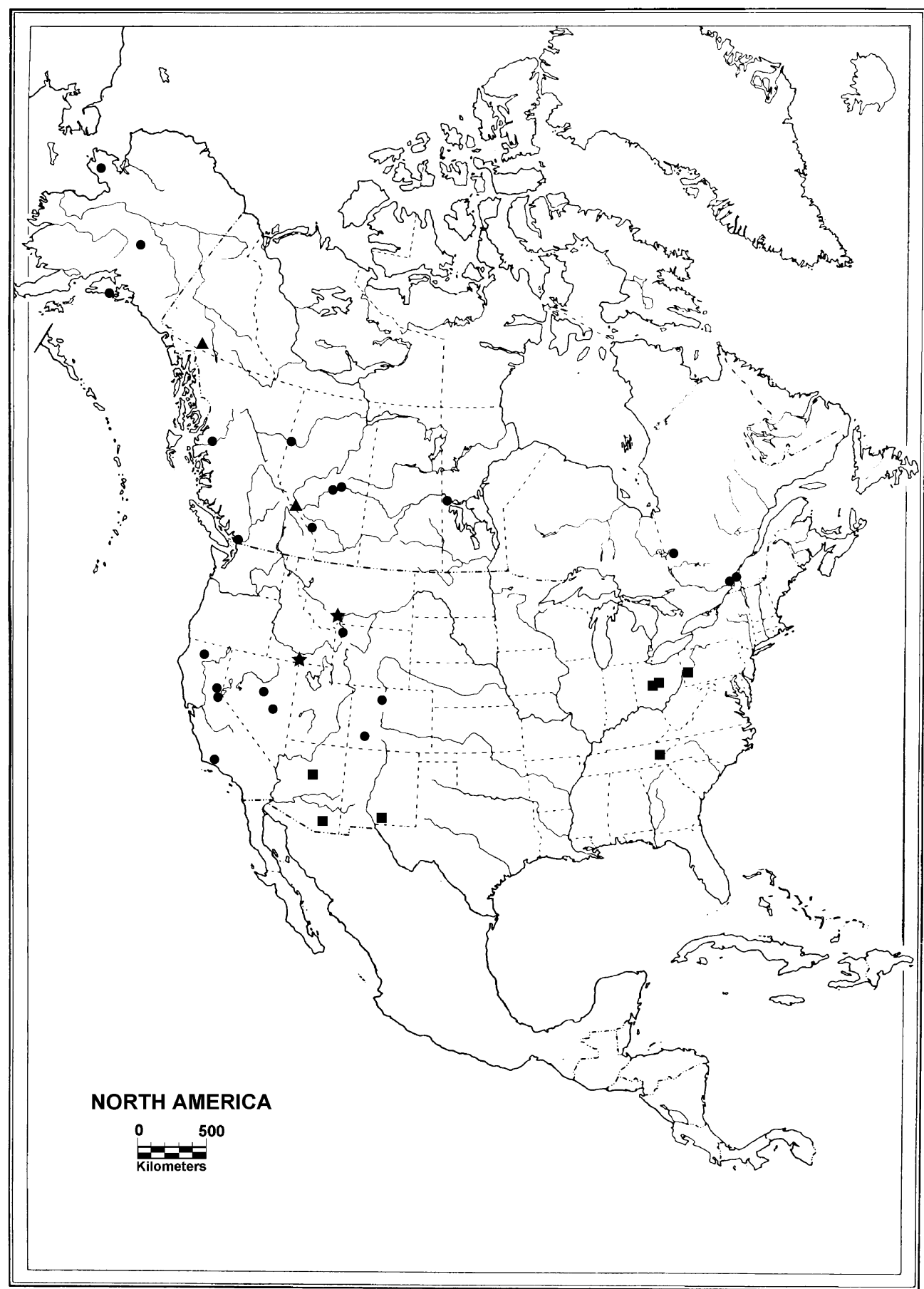

Fig. 99. Geographic distribution of Agathidium revolvens group species: A. depressum Fall = A. dubitanoides, n.sp. $=\star ;$ A. dubitans Fall $=\mathbf{\square} ;$ A. jasperanum Fall $=\mathbf{\Lambda}$. 


\section{AGATHIDIUM REVOLVENS SPECIES GROUP}

DiAgnosis: Body convex, somewhat elongate, elytra sometimes distinctly dorsoventrally compressed; pronotum more or less convex; body partially contractile; color nearly uniform, pale to dark reddish-brown, rarely nearly black; head with postocular temporum more or less prominent, always much shorter than eye; tarsal formula male: female 5-5-4:5-4-4; mesosternum nearly horizontal between mesocoxae, divided into anterior and posterior parts, anterior part with distinct median carina; metasternum without paired oblique lines or, if present, no more than very short, indistinct traces; elytra usually distinctly punctate, punctures sometimes in more-or-less evident serial rows.

Discussion: Our A. revolvens species group appears to be related to certain Palearctic members of the subgenus A. (Neoceble) centered around $A$. nigripenne Fabricius. The group, as interpreted here, includes seven species recognized by Fall (1934) plus several species described as new. Fall (1934) separated these species into two informal groups. One group included species that, like A. revolvens, are relatively broadly oval. The other group included putatively related species that are comparatively dorsoventrally compressed and elongate, a form most fully expressed in A. depressum. The distinction between the comparatively broader, more convex forms and the elongate, more depressed forms is not consistent, however, and this supposed contrast is useful only in comparative descriptions of pairs of species.

In general, the species in this group possess easily discerned differences in shape of the aedeagus, and dissection of males presents the best avenue for species identification. However, there are a number of external differences, including subtle variation in the type and degree of punctation on head, pronotum and elytron, body shape, and the male metasternal foveae. These characters are less consistent and require critical examination of specimens. The following key relies heavily on external characters. However, most certain species identification is best done by dissection of male specimens and comparison of aedeagi with the illustrations.

\section{KEY TO A. REVOLVENS SPECIES GROUP}

1. Elytron with evident serial rows of punctures

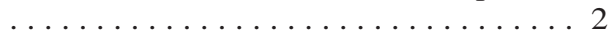

- Elytral punctation confused, without serial rows, or, at most, with indistinct serial rows of punctures largely obscured by dense, confused intervening punctures .....6 6

2(1). Body relatively broadly ovate (fig. 108); punctures of head (fig. 104) small and sparse, slightly smaller and less dense than those of pronotum which are also relatively small and weakly impressed (fig. 105) ........ revolvens LeConte

Body relatively elongate, dorsoventrally compressed; density of punctures of head and pronotum approximately equal or punctures of head larger than those of pronotum .............. 3

3(2). Punctures of head larger than those of pronotum (figs. 110, 111); median lobe in ventral aspect slender, abruptly narrowed subapically, apex narrowly rounded (fig. 117) ............ jasperanum Fall

- Punctures of head and pronotum approximately same size; median lobe broader, not abruptly narrowed subapically, with apex more broadly rounded ......4 4

4(3). Elytron with serial rows of punctures often irregularly double, punctation very dense, most punctures separated by no more than 0.5-1.5 $\times$ puncture diameter; median lobe in ventral aspect subapically broad, not constricted, evenly narrowed to rounded apex (fig. 120) ..... A. depressum Fall

- Elytron with rows of punctures comprised of series of single punctures, punctures less dense, most punctures separated by $1-2 \times$ puncture diameter; median lobe in ventral aspect subapically distinctly constricted, apex more narrowly rounded ..

5(4). Endophallus with apical arms of median armature blunt, divergent, without distinct tooth between or with tooth inconspicuous, basal and lateral arms blunt (fig. 130) .............. dubitans Fall

- Endophallus with apical arms of median armature acutely pointed, convergent, with distinct, sharply pointed tooth between basal and lateral arms acutely pointed (fig. 131) ..... A. dubitanoides, n.sp.

6(1). Punctures of head less dense than those of pronotum .............. 7

- Punctures of head about as dense as those of pronotum ........... 8 
7(6). Body broadly ovate (fig. 136); male with metasternal fovea absent or, at most, weakly present (fig. 135); punctures of head larger than those of pronotum (figs. 132, 133); rami of operculum of median lobe broad, each half with large subapical laterally directed hook (fig. 139) .... .............. omissum Fall Body relatively elongate (fig. 145); male with metasternal fovea in large depressed anteromedial area of metasternum (fig. 144); punctures of head smaller than those of pronotum (figs. 141, 142); rami of operculum of median lobe relatively broad, but without subapical laterally directed hook (fig. 148)

............. A cavisternum Fall

8(6). Elytron with punctures large, shallowly impressed, comparatively sparse (fig. 151); metasternal fovea in large, round shallow depression (fig. 152); median lobe generally slender or arrowhead-shaped and narrowly rounded apically (fig. 156); rami of operculum narrow medially, broadly expanded and truncate apically (fig. 156) ................. virile Fall Elytron with punctures fine, dense, more deeply impressed; fovea small, not in large depression; median lobe and operculum various in shape ........9

9(8). Elytral punctures variable in size, relatively small (fig. 159); fovea circular (fig. 160); median lobe generally broadly arrowhead-shaped and narrowly rounded apically (fig. 165); rami of operculum very broad throughout length, lateral margins approximately parallel (fig. 164) .... ........... A. conjunctum Brown

- Elytral punctures nearly uniform in size, relatively large and coarse; fovea transverse $\ldots \ldots \ldots \ldots \ldots \ldots \ldots$

10(9). Apex of median lobe broad, bluntly rounded (fig. 168); rami of operculum constricted medially, apically broad, truncate (fig. 167) ................ ........ A. angustoperculum, n.sp. Apex of median lobe narrowed, constricted subapically, apex relatively narrowly rounded (fig. 177); rami of operculum with medial margins concave, apices curved medially, apicomedial apices pointed (fig. 177) .............. ........ A. falcatoperculum, n.sp.

\section{Agathidium revolvens LeConte}

Figures 100, 104-109

Agathidium revolvens LeConte, 1850: 222, 1853;

Horn, 1880; Leng, 1920; Fall, 1934.
TyPe Material: Holotype (by monotypy), $q$ in MCZC [LeConte Collection] labeled "[small green disc]/ Type 3178 [red and white label, number handwritten]/ A. revolvens Lec./ HOLOTYPE, Agathidium revolvens LeConte, 1850 [red label with black line border]".

TyPE LOCALITY: Thought to be north shore of Lake Superior (United States, Minnesota, or Canada, Ontario) (exact locality unknown).

Diagnosis: This species is distinguishable from others in the group by the body broadly ovate (fig. 107), the punctures on head somewhat smaller and less dense than those of pronotum, which are also small and weak (figs. 104, 105), the punctation of the elytron (fig. 106) coarser and denser than that of pronotum and head, the elytral punctation confused, but with more-or-less evident serial arrangement of punctures (fig. 106), the sutural stria, and approximately three additional parallel, incompletely impressed striae. The head has a single pair of setose punctures near the posterolateral corners of the poorly defined clypeus, with these punctures being much larger than others on the head.

DESCRIPTION: Body broadly elongate oval, partially contractile, only moderately convex (figs. 107, 108); TBL = $3.6 \mathrm{~mm}$. Color of head and elytron dark reddish-brown, nearly black, pronotum and clypeal spot paler reddish-brown, mouthparts and appendages pale reddish-testaceous.

Head large, broad, subquadrate (fig. 107); with distinct, angulate, short postocular temporum; OHW/MDL $=1.8 ; \mathrm{OHW} / \mathrm{PHW}=$ 1.0; dorsal surface with small, sparse, irregularly distributed punctures, surface between smooth, shiny with sparse, microscopic punctules (fig. 104); frontoclypeal suture nearly absent, incomplete and faintly impressed, head with single pair of setose punctures much larger than other cranial punctation situated behind posterolateral "corners" of clypeal area; clypeal punctation as on frons. Antennae of holotype damaged, apical portions missing; antennomere III much longer than II, ratio II:III = 1:2.7; labrum small, apex rounded (not emarginate), dorsum with sparse setae; eye large, conspicuous, faintly faceted; postocular temporum short, about $0.2 \times$ length eye; supraocular ridge from edge 


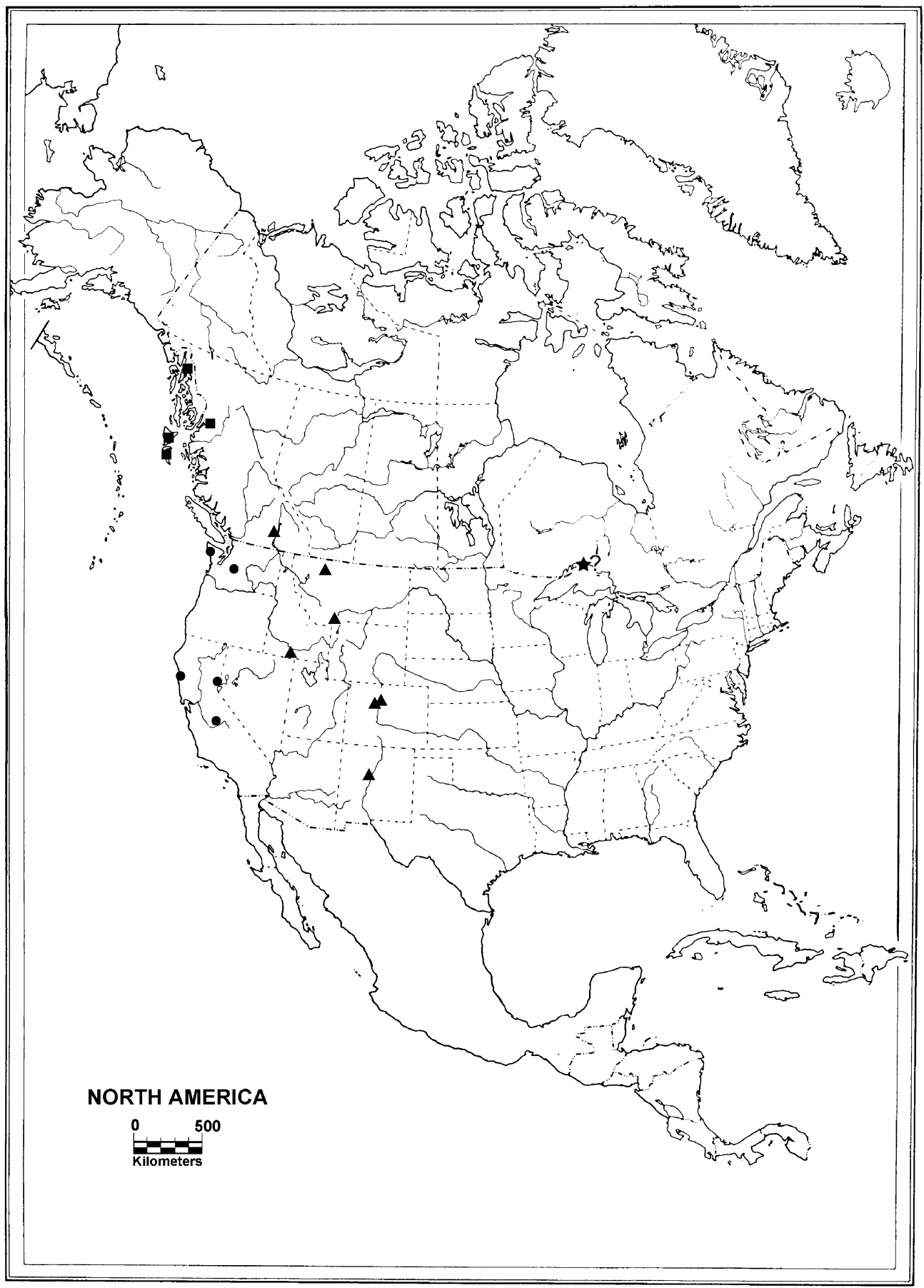

Fig. 100. Geographic distribution of Agathidium revolvens group species: A. cavisternum Fall = A. falcatoperculum, n.sp. $=$; A. revolvens LeConte $=\star ;$ A. omissum Fall $=\boldsymbol{\Delta}$. 

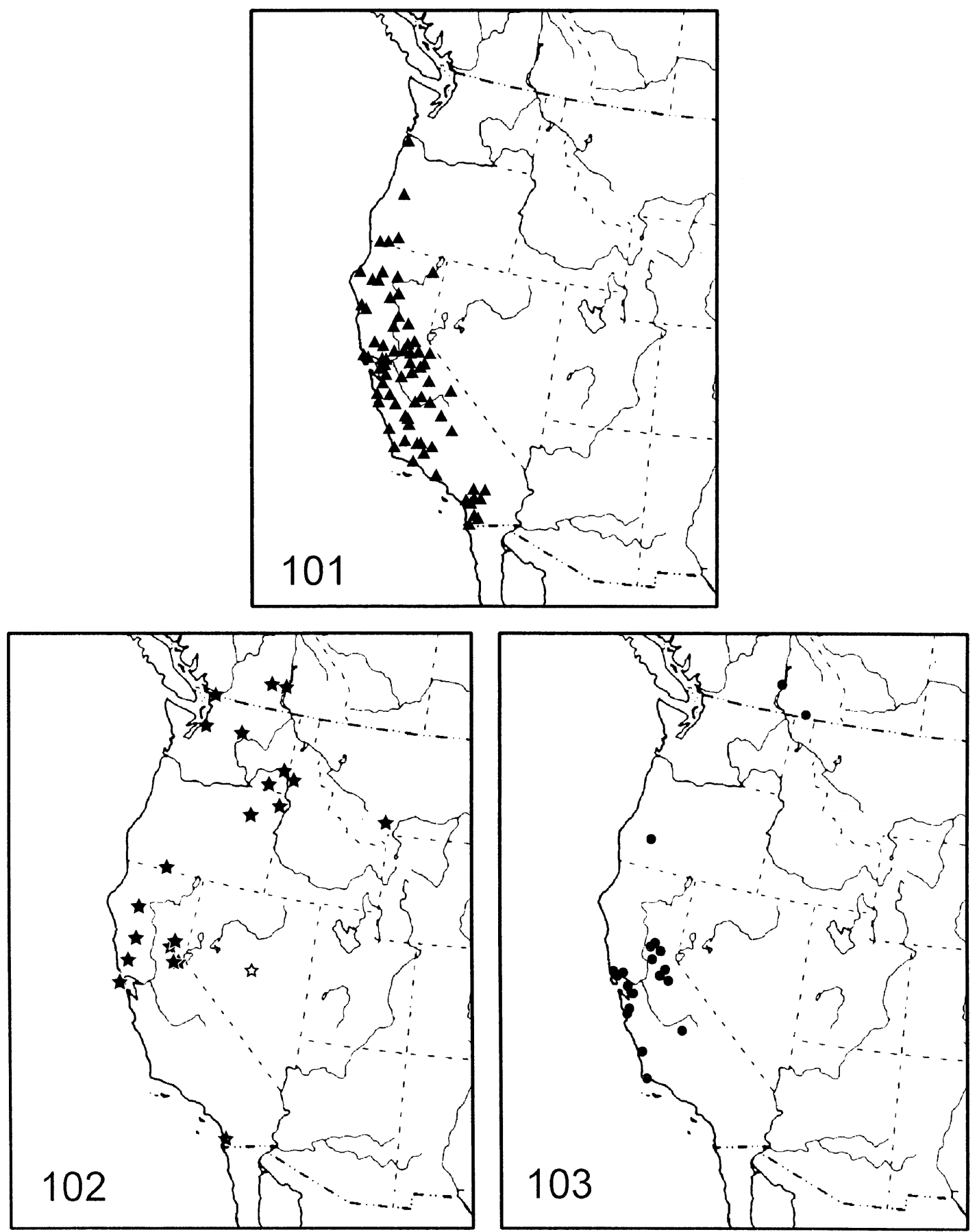

Figs. 101-103. Geographic distribution of Agathidium revolvens group species: 101, A. virile Fall; 102, A. conjunctum Brown ( $\hbar=$ state record only); 103, A. angustoperculum, n.sp. 

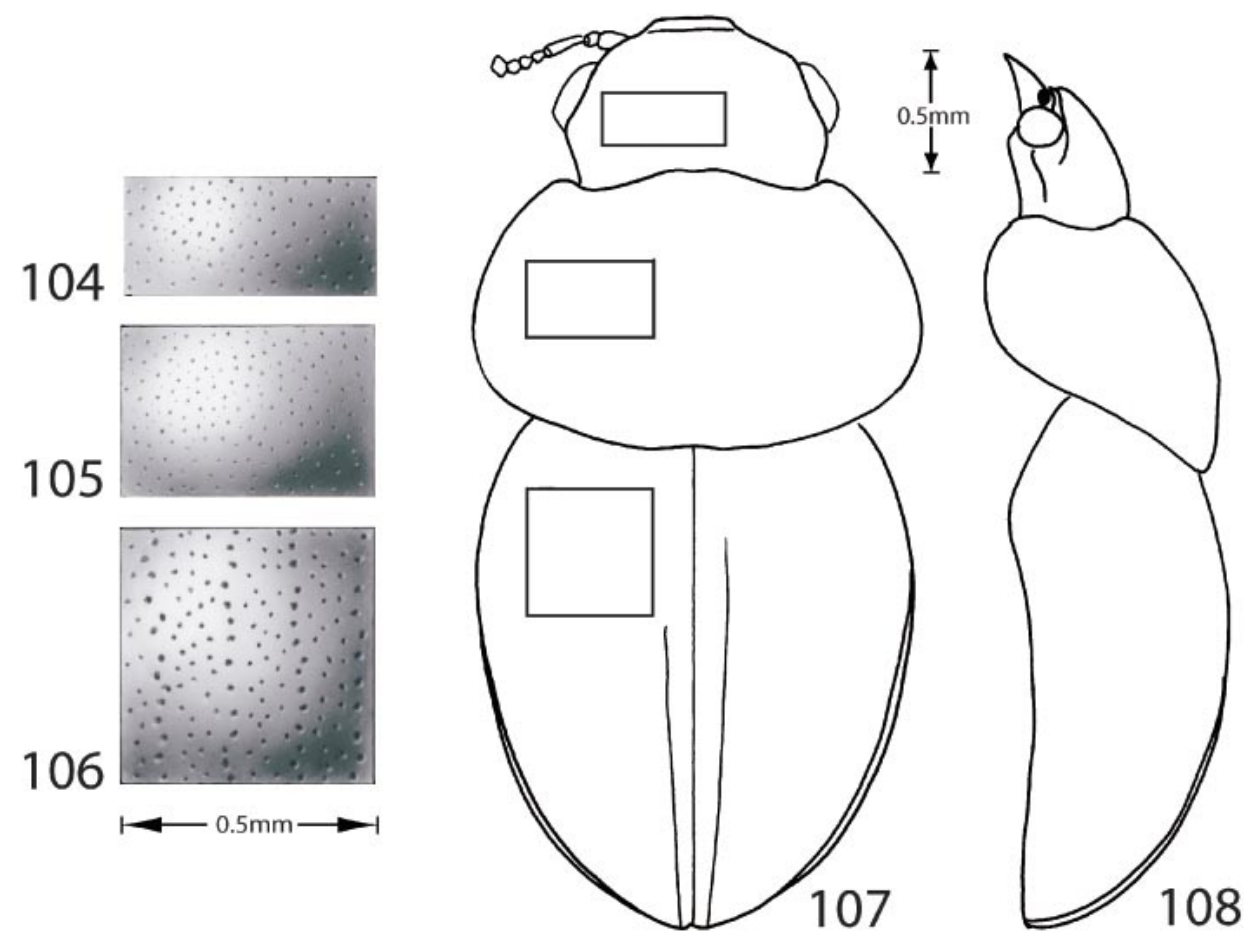

Figs. 104-108. Agathidium revolvens LeConte: Figs. 104-106, punctation detail: 104, head; 105, pronotum; 106, elytron. Figs. 107, 108, body form: 107, dorsal; 108, lateral. Bars $=0.5 \mathrm{~mm}$.

of labrum to point far beyond eye; pair of setae above ridge, near anterior end of eye. Pronotum very wide, convex; PNW/PNL = $1.6 ; \mathrm{PNL} / \mathrm{PNH}=1.2 ; \mathrm{PNW} / \mathrm{PNH}=1.9 ;$ punctation similar to cranium except less

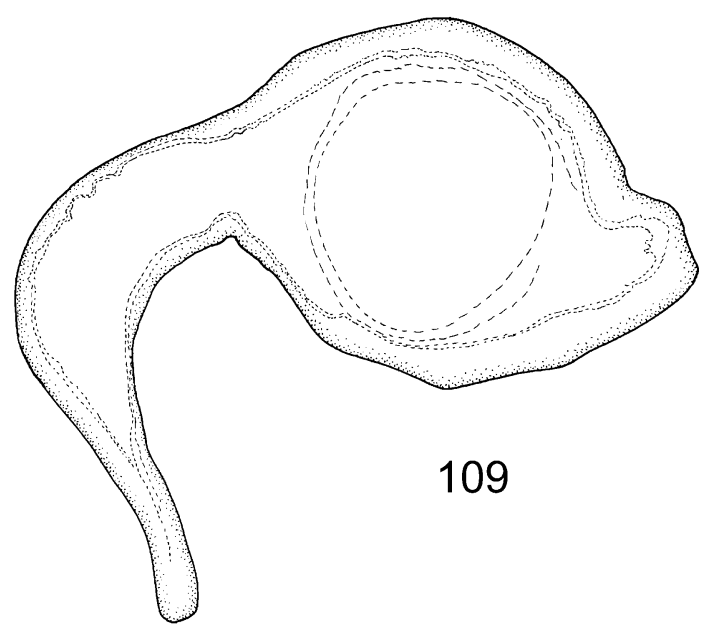

Fig. 109. Agathidium revolvens LeConte, spermatheca. dense (fig. 105); surface anteromedially with microscopic, faint alutaceous pattern. Elytra broadly rounded; ELW/SEL $=0.9$; dorsal surface with large, irregularly distributed, weakly impressed punctures, with very poorly defined series of slightly larger punctures (fig. 106); sutural stria impressed in apical half; surface between punctures smooth, shiny, with microscopic, faint, sparse, transverse lines. Mesosternum relatively large; anterior portion with distinct longitudinal median carina, surface alutaceous, subdivided by oblique line. Metasternum with fine, broadly distributed finely setose punctures; surface between punctures finely alutaceous.

Male unknown.

Female tarsi 5-5-4. Spermatheca (fig. 109) with neck narrowed at base, swollen medially, and apically pointed; bulb globose, with duct insertion terminal on short protuberance.

DistRIBUTION: This species is known only from the type locality (fig. 100).

Discussion: As Fall (1934) reported, specimens later added to the LeConte collection 


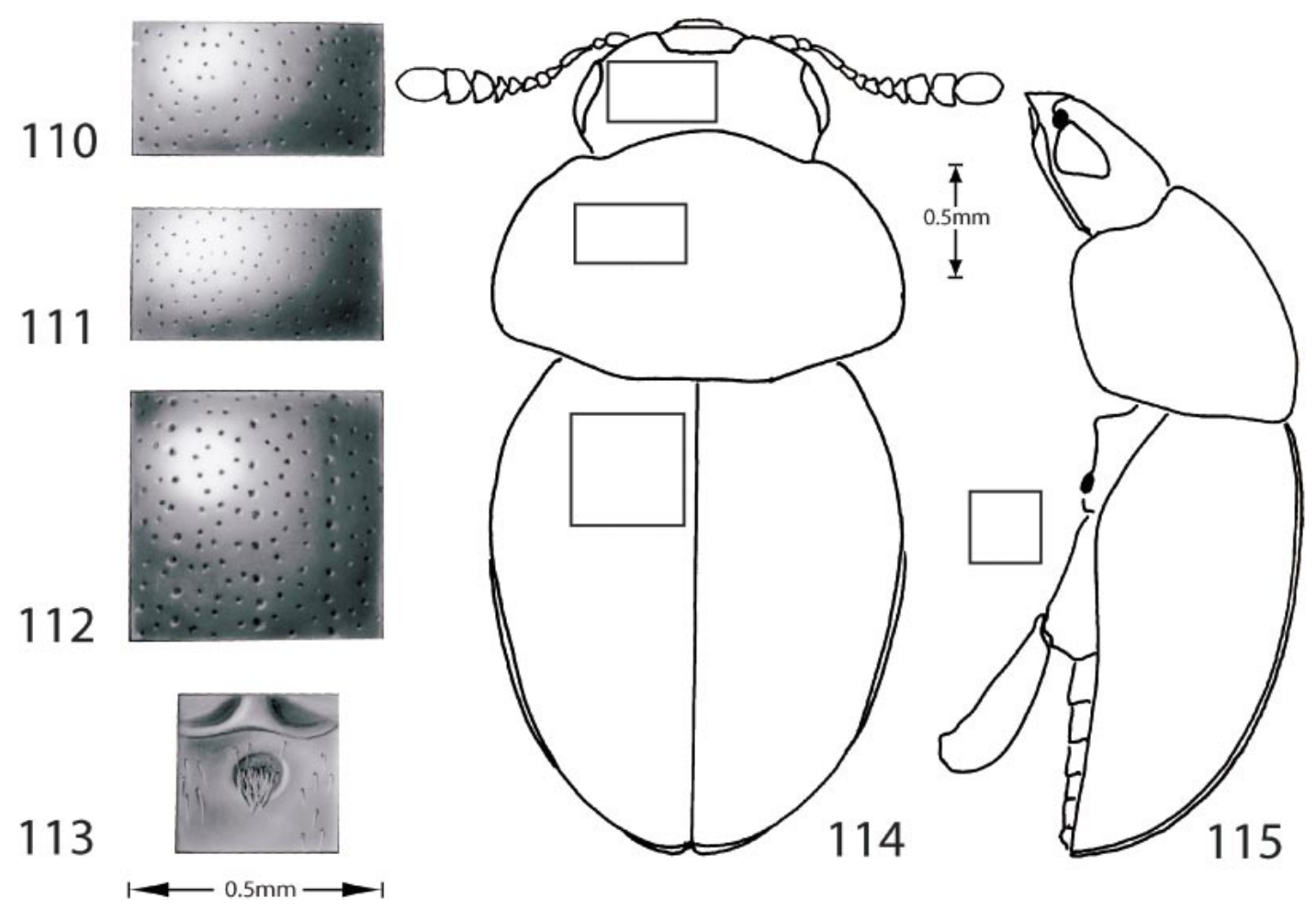

Figs. 110-115. Agathidium jasperanum Fall: Figs. 110-112, punctation details: 110, head; 111, pronotum; 112, elytron. 113. Male metasternal fovea. Figs. 114, 115, habitus: 114, dorsal; 115, lateral. Bars $=0.5 \mathrm{~mm}$.

as "A. revolvens" are not conspecific with the unique type specimen taken from the northern shore of Lake Superior by LeConte, nor are specimens in the Horn collection determined to be "A. revolvens" actually assignable to this species. No additional specimens attributable to this species were examined during this study, either. Thus, A. revolvens remains known from the female type specimen alone. Apical portions of the antennae of this specimen are missing, and the ventral sclerites were not measured.

\section{Agathidium jasperanum Fall}

Figures 99, 110-118

Agathidium jasperanum Fall, 1934: 109.

Agathidium jasperinum Hatch, 1957: 35 (incorrect subsequent spelling).

TyPe MATERIAL: Holotype, $\widehat{o}$ in MCZC labeled "Jasper Pk. Alb. VIII 4 '24/ ô/ TYPE jasperanum ['TYPE' underlined in red, 'jasperanum' handwritten]/ M.C.Z. Type 24038 [red label]/ H.C. FALL COLLECTION/ HOLOTYPE, Agathidium jasperanum Fall, 1934 [red label with black line border]'.

TyPe Locality: Canada, Alberta, Jasper Park.

Diagnosis: This species is distinguishable from others in the group by the body somewhat elongate (fig. 114), the punctures on the head distinctly larger than those of pronotum, but similar in density (figs. 110, 111), the elytral punctation coarser and denser than on head and pronotum and with some punctures more or less serially arranged (fig. 112), and the median lobe of the aedeagus elongate and narrow, subapically abruptly narrowed, with the apex slender and apically narrowly rounded (fig. 117). Agathidium jasperanum is less elongate and has a somewhat less conspicuously serially arranged elytral punctation than does $A$. depressum.

DESCRIPTION: Body elongate oval, strongly dorsoventrally depressed, attenuate posteri- 


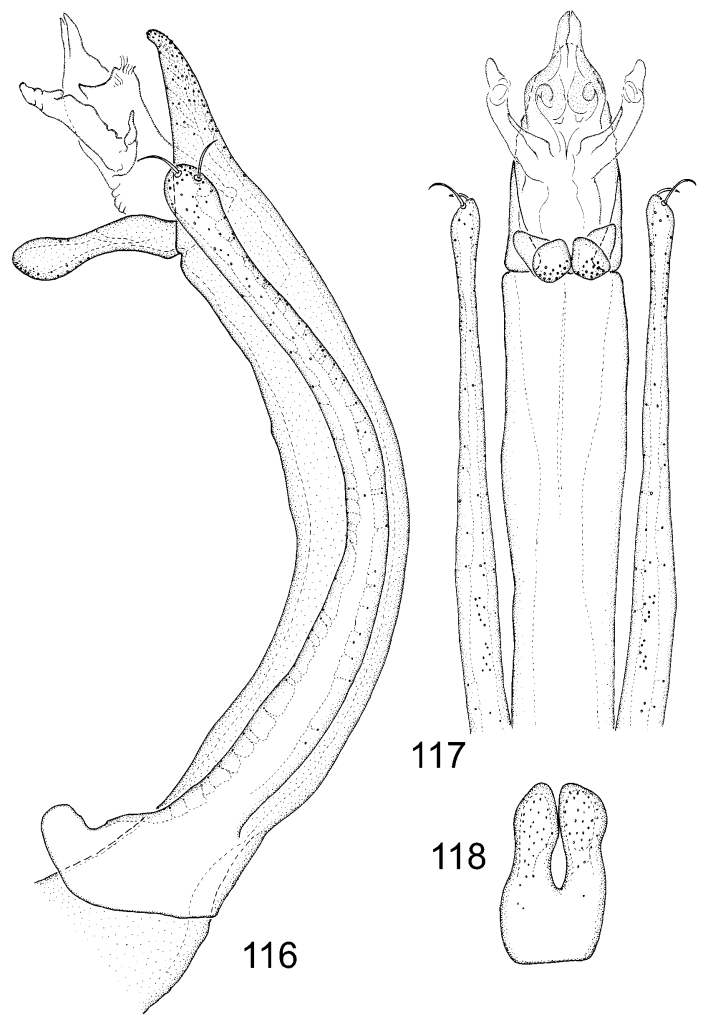

Figs. 116-118. Agathidium jasperanum Fall, aedeagus: 116, lateral; 117, ventral; 118, ventral operculum.

orly, weakly contractile (figs. 114, 115); TBL $=3.7 \mathrm{~mm}$. Color reddish-brown, except elytra darker, castaneous; cranium with pale central spot, antenna including club testaceous; pronotum paler than elytra, slightly paler than head; venter and tibiae reddishbrown.

Head subquadrate, dorsoventrally flattened, wider than long (figs. 114, 115), OHW/MDL $=1.8$; surface shiny, with moderately dense, irregularly distributed, small punctures (fig. 110); labrum small, transverse, emarginate medially, surface punctate with long, fine setae; frontoclypeal suture absent laterally, present only as lightly impressed, basal arc; mandible with evident dorsal suture; dorsal surface shiny, with moderately dense, irregularly distributed small punctures; area between punctures with irregularly distributed, indistinct micropunctules; eye large, conspicuous, anterolateral, finely faceted; with short postocular tempo- rum, gradually narrowed immediately behind eye, separated from frons by distinct supraocular carina running from lateral margin of clypeal region to posterior margin of cranium; without a larger puncture above each eye; antennomere III longer than IV $+\mathrm{V}$; ratio length II:III $=1: 2$; VII twice as long, slightly wider than VIII, much smaller than IX; ratio width VII:VIII:IX $=1.1: 1: 1.4$; with abrupt 3-segmented club. Pronotum broad, transversely oval, not strongly convex; with very shallow posterior emargination medially; width/length $=1.6$; length $/$ height $=1.2$; punctures smaller, slightly more dense than those of head, irregularly distributed (fig. 111); area between punctures smooth, shiny, with sparse, irregularly distributed indistinct micropunctules. Elytra elongate oval, ELW/ SEL $=0.84$; punctures coarser, larger, less dense than those of head or pronotum; punctures larger than those of head; with several poorly defined serial rows of punctures, about a single puncture in width, blending with slightly smaller, irregularly distributed punctures between; smaller punctures sometimes nearly forming parallel series; surface between punctures smooth, shiny, with irregularly distributed, very sparse, very indistinct micropunctules (fig. 112); sutural stria impressed in apical three-fourths; area between sutural striae elevated as slight median "carina"; sutural stria confluent with suture before apex; humeral angle broadly rounded, obtuse. Mesosternum relatively large; anterior portion with longitudinal median carina, surface lightly alutaceous, subdivided by oblique line. Metasternum with small, very fine, widely distributed setose punctures; surface between densely, finely alutaceous to imbricate.

Male tarsi 5-5-4; pro- and mesobasotarsomeres enlarged, with spatulate setae beneath; left mandible without tusk; metafemur with apical posterior tooth, relatively small, broad, not well defined, more or less defined by apical angle of femur; metasternal fovea anteromedial, moderate-sized, round, depressed, with tuft of long, fine setae (fig. 113). Aedeagus elongate, narrow; median lobe apically abruptly narrowed, apex slender, narrowly rounded at apex (fig. 117); operculum with rami relatively short and rounded (fig. 118); lateral lobes wide at base, 


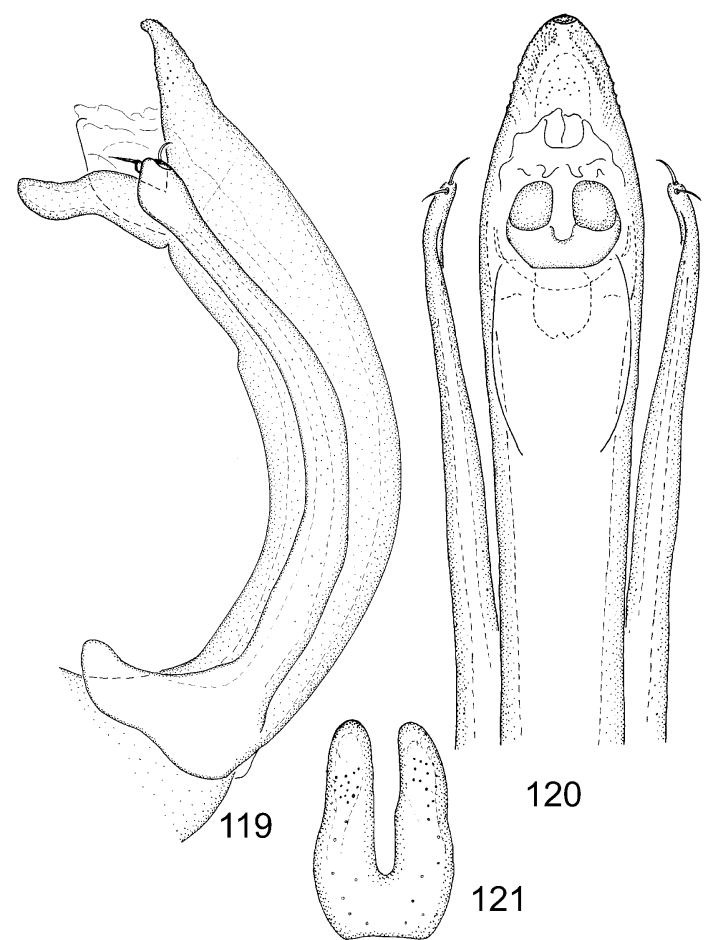

Figs. 119-121. Agathidium depressum Fall, aedeagus: 119, lateral; 120, ventral; 121, ventral operculum.

gradually narrowed, apex spatulate, bisetose; endophallus with small pair apical digits, paired larger subapical arms, lateral blunt plates (figs. 116, 117)

Female 5-4-4.

DisTRIBUTION: Specimens were examined from Alberta and the Yukon, Canada (fig. 99).

SPECIMENS EXAMINED: CANADA: Alberta: Jasper Pk., 4 Aug 1924, paratype (1, MCZC) Yukon: White Horse, 21 Jun 1924, paratype (1, MCZC).

Agathidium depressum Fall Figures 96-99, 119-121

Agathidium depressum Fall, 1934: 108; Hatch, 1957.

Type Material: Holotype, ô in MCZC labeled “Terrace BC Mrs WW Hip pisley/ $ぇ /$ TYPE depressum ['TYPE' underlined in red, 'depressum' handwritten]/ M.C.Z. Type 24035 [red label]/ H.C. FALL COLLECTION/ HOLOTYPE, Agathidium depressum
Fall, 1934 [red label with black line border]'.

TyPe Locality: Canada, British Columbia, Terrace.

Diagnosis: Agathidium depressum can be separated from other species of the A. revolvens group by the following combination of characters: body elongate-oval, dorsoventrally flattened (figs. 96, 97); color dark reddishbrown; elytral punctation coarser, denser than pronotal punctation, with several poorly defined serial rows of punctures, series often comprised of an irregular double row of punctures; aedeagus with median lobe swollen subapically (fig. 120), operculum with deep, rounded emargination, each lobe of operculum with conspicuous, rounded terminal disk (fig. 121); and lateral lobes apically flattened, spatulate (figs. 119, 120).

DESCRIPTION: Body elongate oval, strongly dorsoventrally depressed, attenuate posteriorly, weakly contractile (figs. 96, 97); TBL = about $3.6 \mathrm{~mm}$. Color dark reddish-brown; cranium with pale central spot, antenna reddish-brown, club slightly darker; pronotum paler than elytra, particularly and broadly around margins; elytra paler at apices and along narrow marginal band; venter dark reddish-brown, legs paler.

Head subquadrate, dorsoventrally flattened, wider than long (figs. 96, 97), OHW/ $\mathrm{MDL}=1.3$; labrum small, transverse, emarginate medially, surface punctate with long, fine setae; frontoclypeal suture incomplete, lightly impressed basal arcuate line only, with no vestige of lateral portions of suture; surface shiny, with moderately dense, irregularly distributed punctures, area between punctures with irregularly distributed micropunctules; a single, shallow puncture larger than others of head located above each eye, posterior to middle of eye, just above supraocular carina; eye large, conspicuous, anterolateral, finely faceted; with short postocular temporum, gradually narrowed immediately behind eye, separated from frons by distinct supraocular carina running from lateral margin of clypeal region to posterior margin of cranium; antennomere III about as long as IV $+\mathrm{V}$, ratio of length of II:III $=0.8: 1$; VII distinctly longer, but about same width as VIII, much smaller than IX, ratio of width VII:VIII:IX = 1.1:1:1.3; with abrupt 3 -seg- 
mented club. Pronotum broad, transversely oval, not strongly convex; with shallow posterior emargination medially; $\mathrm{PNW} / \mathrm{PNL}=$ 1.7, $\mathrm{PNL} / \mathrm{PNH}=1.6$; punctures smaller, less dense than those of head, irregularly distributed; area between punctures smooth, shiny, with sparse, irregularly distributed micropunctules. Elytra elongate, dorsoventrally compressed; ELW/SEL $=0.83$; with coarser, denser punctation than pronotum; punctures larger than those of head; with several poorly defined serial rows of punctures, about a single puncture wide, blending with slightly smaller, irregularly distributed punctures between; smaller punctures sometimes nearly forming parallel series; surface between punctures smooth, shiny, with irregularly distributed, sparse micropunctules; sutural stria impressed in apical three-fourths; area between sutural striae elevated as slight rooflike median prominence; sutural stria confluent with suture shortly before apex; humeral angle broadly rounded. Mesosternum relatively large; anterior portion with longitudinal median carina, surface alutaceous, subdivided by oblique line. Metasternum with small, moderately dense, setose punctures; surface between densely, finely alutaceous.

Male tarsi 5-5-4; pro- and mesobasotarsomeres enlarged, with spatulate setae beneath; left mandible without tusk; metafemur with apical posterior tooth, relatively small, broad, not well defined; metasternal fovea very small, anteromedial, transverse, with a few setae slightly longer than those of metasternal surface (fig. 98). Aedeagus elongate, median lobe with apex laterally minutely serrate, small, pointed, ventrally recurved (figs. 119, 120); apical pores dense, in double row (fig. 119); operculum broad at base, deeply bifurcate, emargination rounded, each lobe with distinct elevated oval apical area (figs. 120, 121), apices spatulate in lateral view (fig. 119); lateral lobe stout, elongate, apex laterally flattened, spatulate with setae nearly terminal (figs. 119, 120); endophallus with paired, large, heavily sclerotized spines.

Female tarsi 5-4-4.

Distribution: Agathidium depressum was reported by Fall (1934) from British Columbia, Seward and McKinley Park, Alaska, Edmonton, Alberta, and Montreal and Rigaud,
Quebec. Another specimen from Urbana, Illinois, was "doubtfully referred" to the species by Fall. We did not examine this specimen, but it may be better assigned to $A$. $d u b$ itans. Fall also assigned two specimens from California of the type series of $A$. revolvens in the LeConte collection to A. depressum. The species is the most broadly distributed of the species in this group (fig. 99).

SPECIMENS ExAmined: CANADA: Alberta: Sibbold Flats Rec Area, 6 Sep 1981, FIT, RS Anderson (2, QDWC); Banff, 7 May 1930, O Bryant (1, CASC); Whitford L., 18 May 1924, O Bryant (3, CASC); Demmitt, $3 \mathrm{~km} \mathrm{~W} 90 \mathrm{~km}$ NW Grand Prairie, 12 Jun 1984, poplar forest, FIT, S and J Peck (1, PECK); 11 mi NE Robb, 4 Aug 1985, lodgepole pine forest, FIT, RS Anderson (1, CNCI); Edmonton, 21 Aug 1917, FS Carr, paratype (1, MCZC). British Columbia: Stanley, K Graham (1, CASC); Stanley, 15 Aug 1932, K Graham (2, CASC); Stanley, 1932, K Graham (1, CASC). Manitoba: The Pas, 28 May 1930, O Bryant (3, CASC). Quebec: Montreal, paratypes (2, MCZC); Duparquet, 3 Jun 1938, GS Smith (1, CASC); Rigaud, paratype (1, MCZC); Duparque, 26 Aug 1934, under Poplar bark, GS Smith (1, CASC).

UNITED STATES: Alaska: McKinley Park, 8 Jul 1924, paratypes (2, MCZC); Pligrim Hot Springs nr Nome, 6 Aug 1995, on Stemonitus fusca, SL Stephenson (2, CUIC); Pligrim Hot Springs nr Nome, 6 Aug 1995, on Badhamia sp., SL Stephenson (6, CUIC); Pligrim Hot Springs nr Nome, 6 Aug 1995, decaying log, SL Stephenson (1, CUIC); Seward, 15 Jun 1911, WS McAlpine, paratype (1, MCZC). California: Santa Barbara Mts, 21 Jul 1892, paratypes (2, MCZC); El Dorado Co.: 10 mi E Kyburz, 29 Jun 1975, Ponderosa pine duff, FG Andrews (4, CASC); Inyo Co.: Sierra Nevada Mts S Fk Lubkin Ck, 5 Apr 1982, 6300', D Giuliani (1, CASC); Nevada Co.: Sagehen Creek nr Hobart Mills, 24 Jun 1964, SG Seminoff (1, CASC); Independence Lake, 13 Sep 1969, FG Andrews (1, CASC); San Bernadino Co.: 30 mi ENE Redlands, South Fk Campgroundd, Santa Ana River, 13 May 1981, 6300', L Herman (1, AMNH); San Bernardino Co.: Lake Fulmore, Nov 1967, litter, Tullgren funnel, D Hagstrum (1, CASC); Snow Creek nr Forest Home, San Bern. Mts, 16 Jul 1961, in wash, EL Sleeper (1, CASC); Siskiyou Co.: Mt Shasta, 30 Oct 1969 (1, CASC). Colorado: Rabbit Ears Pass, 1 Jul 1953, 8000', under stone, Bryant (1, CASC); Hinsdale Co.: Martin Ranch, Weminuche Valley, 14 Aug 1977, FG Andrews (1, CASC). Illinois: Urbana, 1 May 1921, CP Alexander, paratype (1, MCZC). Nevada: Eureka Co.: Monitor Range, 21 
mi S 28 mi W Eureka, 1987-1988, 8000', D Giuliani (1, CASC); Nye Co.: $5 \mathrm{mi} \mathrm{N} 10 \mathrm{mi}$ E Currant, Currant Summit, 28 Mar 1987, 7000', D Giuliani (1, CASC). Washington: Spokane Co.: Bald Knob Cmgr. Mt Spokane SP, 24 Jul 1978, 4800', WJ Turner (5, WSUC); Whitman Co.: Lyle Grove 8 mi SW Pullman, 29 Mar 1973, under bark Pinus ponderosa, SD Berkenkamp (1, WSUC). Wyoming: Park Co.: Yellowstone Natl Park, Cub Creek, 2 Jul 1984, FG Andrews (1, CASC).

Discussion: Specimens from Alaska, Nome County, Pilgrim Hot Springs (CUIC), were collected from Stemonitis fusca and Badhamia sp. The species has been collected from a variety of litter sources including rotting $\operatorname{logs}$ and pine duff. Elevation records are from 4800 to $8000 \mathrm{ft}$.

\section{Agathidium dubitans Fall}

Figures 99, 122-130

Agathidium dubitans Fall, 1934: 110.

TyPe MATERIAL: Holotype, ô in MCZC labeled “ $\delta /$ TYPE dubitans ['TYPE' underlined in red, 'dubitans' handwritten]/ M.C.Z. Type 24036 [red label]/ H.C. FALL COLLECTION/ Agathidium dubitans Fall [handwritten, with red line around label]/ HOLOTYPE, Agathidium dubitans Fall, 1934 [red label with black line border]".

Type Locality: United States, New Mexico, Otero Co., Cloudcroft.

DiAGNOSIS: Agathidium dubitans can be separated from other species in this group by the following combination of characters: body elongate-oval, dorsoventrally flattened (figs. 126, 127); color reddish-brown; elytral punctation coarser and denser than pronotal punctation (figs. 123, 124), with several poorly defined serial rows of punctures, series generally comprised of a single row of punctures; aedeagus with median lobe in ventral aspect distinctly constricted subapically (fig. 129); operculum deeply emarginate, each lobe of operculum apically rounded (fig. 129); lateral lobes apically flattened, spatulate (figs. 128, 129); and endophallus with arms of median armature blunt and without prominent apicomedial tooth between apical arms (fig. 130).

DESCRIPTION: Body elongate oval, strongly dorsoventrally depressed, attenuate posteriorly, weakly contractile (figs. 126, 127); TBL
$=$ about $3.2 \mathrm{~mm}$. Color reddish-brown; cranium with pale central spot, antenna testaceous, club reddish-brown; pronotum paler than elytra, yellowish-red; venter and tibiae reddish-brown, femora testaceous.

Head subquadrate, dorsoventrally flattened, wider than long (figs. 126, 127), $\mathrm{OHW} / \mathrm{MDL}=1.4$; labrum small, transverse, emarginate medially, surface punctate with long, fine setae; frontoclypeal suture present, indistinct; dorsal surface shiny, with moderately dense, irregularly distributed small punctures (fig. 122); area between punctures with randomly distributed micropunctules; without large punctures behind frontoclypeal suture; eye large, conspicuous, anterolateral, finely faceted; with short postocular temporum, gradually narrowed immediately behind eye, separated from frons by distinct supraocular carina running from lateral margin of clypeal region to posterior margin of cranium; without a larger puncture above each eye; antennomere III longer than IV $+\mathrm{V}$; ratio length II:III = 1:1.7; VII distinctly longer, slightly wider than VIII, much smaller than IX; ratio width VII:VIII:IX = 1.4:1:1.5; with abrupt 3-segmented club. Pronotum broad, transversely oval, not strongly convex; $\mathrm{PNW} / \mathrm{PNL}=1.9 ; \mathrm{PNL} / \mathrm{PNH}=1.3$; with very shallow posterior emargination medially; punctures smaller, slightly more dense than those of head, irregularly distributed (fig. 123); area between punctures smooth, shiny, with sparse, irregularly distributed micropunctules. Elytra broadly ovate, SEL/ELW $=1.1$ with punctation coarser, but less dense than that of head or pronotum; punctures larger than those of head; with several poorly defined serial rows of punctures, more or less single puncture wide, blending with slightly smaller, irregularly distributed punctures between; smaller punctures sometimes nearly forming parallel series (fig. 124); surface between punctures smooth, shiny, with irregularly distributed, sparse micropunctules; sutural stria impressed in apical three-fourths; area between sutural striae elevated as slight median "carina"; sutural stria confluent with suture before apex; humeral angle broadly rounded. Mesosternum relatively large; anterior portion with weak longitudinal median carina, surface alutaceous, subdivided by oblique 


\section{2}

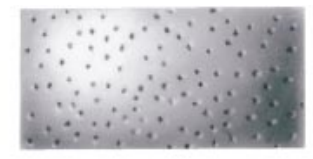

123

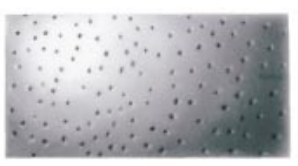

124
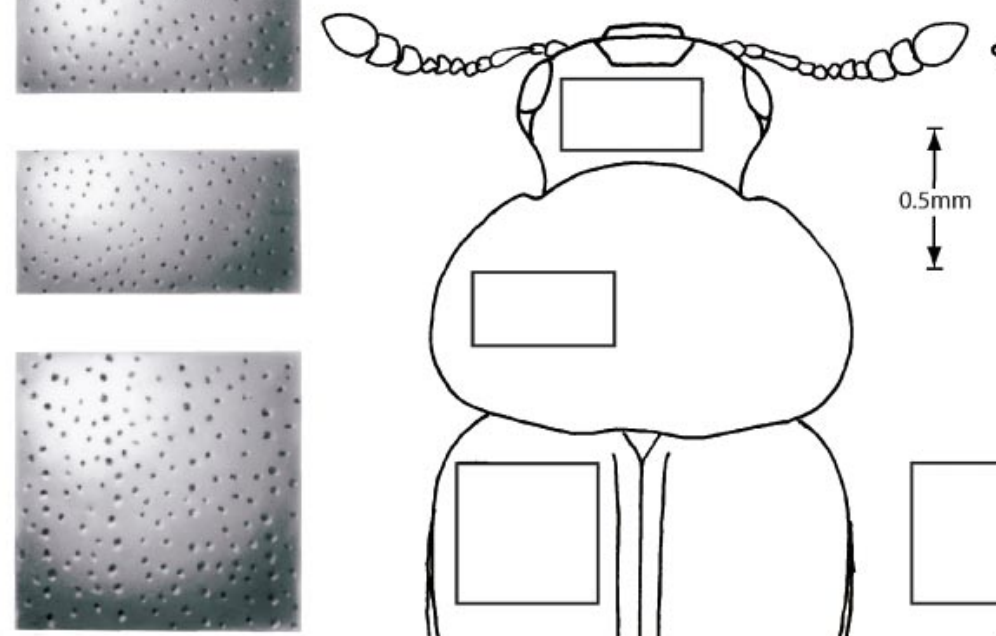

125
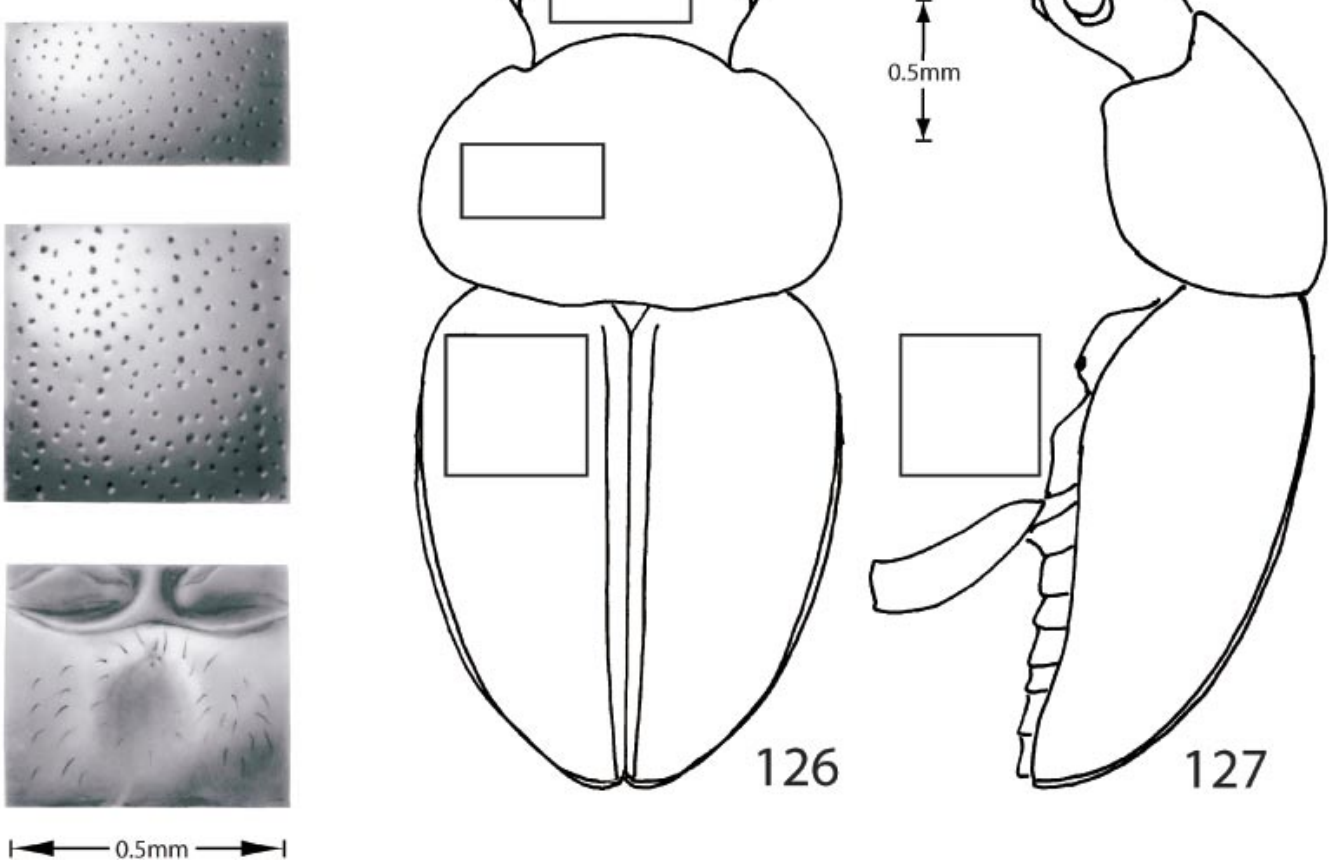

Figs. 122-127. Agathidium dubitans Fall: Figs. 122-124, punctation details: 122, head; 123, pronotum; 124, elytron. 125. Male metasternal fovea. Figs. 126, 127, habitus: 126, dorsal; 127, lateral. Bars $=0.5 \mathrm{~mm}$.

line. Metasternum with small, moderately dense, setose punctures; surface between densely, finely alutaceous to imbricate.

Male tarsi 5-5-4; with pro- and mesobasotarsomeres enlarged, with spatulate setae beneath; left mandible without tusk; metafemur with apical posterior tooth relatively small, broad, not well defined, more or less defined by apical angle of femur; metasternal fovea minute, punctiform, set in broad depression, anteromedial (fig. 125). Aedeagus elongate, narrow, ventrally curved; median lobe narrowed at apex, sharply ventrally curved, with lateral pectinate pattern of apical ducts, with minute serrations in lateral view (fig. 128); lateral lobes attain base of operculum, apices expanded, abruptly spatulate in lateral view, compressed in ventral view (fig. 129); operculum bifurcate, lobes bluntly rounded apically (fig. 129); endophallus with medial armature with apically, basolaterally, and basally directed arms which are short and bluntly rounded, without distinct, pointed tooth between apical arms or with short, rounded prominence only (fig. 130).

Female tarsi 5-4-4.

Distribution: This species is known from Arizona, New Mexico, Ohio, Pennsylvania, and Tennessee. The seemingly disjunct distribution of this species from the southwestern United States and areas from Tennessee to Pennsylvania may indicate that the species is more widespread than current collection information indicates.

SPECIMENS EXAMINED: UNITED STATES: Arizona: $10 \mathrm{mi}$ NW Flagstaff, San Franciso Mts, 18 Jul 1979, 9500', spruce fir aspen meadow, malaise, S and J Peck (1, PECK); $10 \mathrm{mi} \mathrm{W}$ Greer Mt, Baldy, Ft Apache Indian Res., 3 May 1979, R Baranowski (2, LUND); Pima Co.: Sta. Catalina Mts, Mt Lemmon, 5 Sep 1974, 9300' (1, MCZC). 


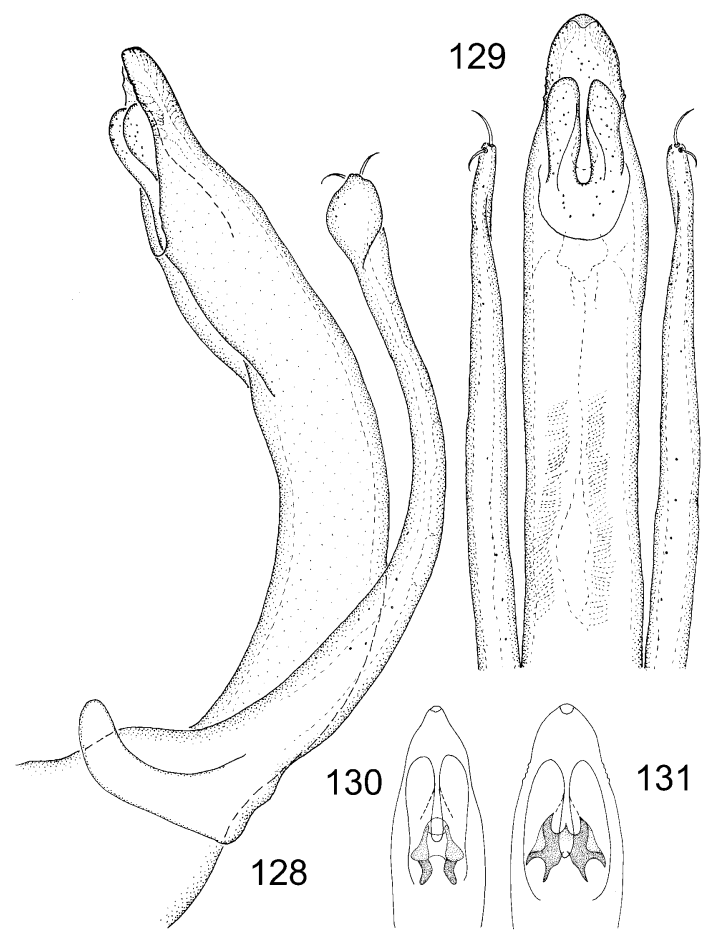

Figs. 128-131. Agathidium revolvens group species: Figs. 128-130, A. dubitans Fall, aedeagus: 128, lateral; 129, ventral; 130, apex of median lobe and armature of endophallus, ventral aspect. 131. A. dubitanoides, apex of median lobe and armature of endophallus, ventral aspect.

Ohio: Champaign Co.: Cedar Bog, 4 mi SW Urbana (1, AMNH); Delaware Co.: colr. (1, AMNH). Pennsylvania: Jeannette, 16 Sep 2002 (2, CMNH); Pittsburgh, 24 Aug (1, CMNH). Tennessee: Gr. Smokey Mts, NP (1, AMNH).

DisCUSSION: Elevation records are from 9300 to $9500 \mathrm{ft}$.

Agathidium dubitanoides Wheeler and Miller, new species

Figures 99, 131

Type Material: Holotype, ô in AMNH (deposited from MTEC) labeled "MONT: Gallatin Co. Bozeman Crk 6200' 28 APR 1987 D.L. Gustafson Col./ HOLOTYPE Agathidium dubitanoides Wheeler and Miller, 2002 [red label with black line border]'.

Type Locality: United States, Montana, Gallatin Co., Bozeman Creek.

DiAgnosis: This species is nearly identical with $A$. dubitans except for slight differences in the endophallus of the aedeagus. In $A$. dubitanoides the apical, lateral, and basal arms of the median armature are acutely pointed and there is a distinctly pointed tooth between the apical arms (fig. 131), whereas in A. dubitans the arms are short and blunt and there is no tooth between the apical arms or this tooth is short and blunt (fig. 130)

DESCRIPTION: Body elongate oval, strongly dorsoventrally depressed, attenuate posteriorly, weakly contractile; $\mathrm{TBL}=$ about 3.2 mm. Color dark reddish-brown; cranium with pale central spot, antenna testaceous, club reddish-brown; pronotum medially slightly paler than elytra, distinctly paler around margins; venter and tibiae reddishbrown, femora testaceous.

Head subquadrate, dorsoventrally flattened, wider than long, OHW/MDL $=1.4$; labrum small, transverse, emarginate medially, surface punctate with long, fine setae; frontoclypeal suture present, indistinct; dorsal surface shiny, with moderately dense, irregularly distributed small punctures; area between punctures with irregularly distributed micropunctules; without large punctures behind frontoclypeal suture; eye large, conspicuous, anterolateral, finely faceted; with short postocular temporum, gradually narrowed immediately behind eye, separated from frons by distinct supraocular carina running from lateral margin of clypeal region to posterior margin of cranium; without a larger puncture above each eye; antennomere III longer than IV $+\mathrm{V}$; ratio length II:III $=1$ : 1.7; VII distinctly longer, slightly wider than VIII, much smaller than IX; ratio width VII: VIII:IX = 1.4:1:1.5; with abrupt 3-segmented club. Pronotum broad, transversely oval, not strongly convex; PNW/PNL = 1.9; PNL/ $\mathrm{PNH}=1.3$; with very shallow posterior emargination medially; punctures smaller, slightly more dense than those of head, irregularly distributed; area between punctures smooth, shiny, with sparse, irregularly distributed micropunctules. Elytra broadly ovate, $\mathrm{SEL} / \mathrm{ELW}=1.1$ with punctation coarser, but less dense than that of head or pronotum; punctures larger than those of head; with several poorly defined serial rows of punctures, more or less single puncture wide, blending with slightly smaller, irregularly distributed punctures between; smaller 
punctures sometimes nearly forming parallel series; surface between punctures smooth, shiny, with irregularly distributed, sparse micropunctules; sutural stria impressed in apical three-fourths; area between sutural striae elevated as slight median "carina"; sutural stria confluent with suture before apex; humeral angle broadly rounded. Mesosternum relatively large; anterior portion with weak longitudinal median carina, surface alutaceous, subdivided by oblique line. Metasternum with small, moderately dense, setose punctures; surface between densely, finely alutaceous to imbricate.

Male tibia 5-5-4; with pro- and mesobasotarsomeres enlarged, with spatulate setae beneath; left mandible without tusk; metafemur with apical posterior tooth, relatively small, broad, not well defined, more or less defined by apical angle of femur; metasternal fovea minute, punctiform, anteromedial. Aedeagus elongate, narrow, ventrally curved; median lobe narrowed at apex, apex sharply ventrally curved, with lateral pectinate pattern of apical ducts, with minute serrations in lateral view; lateral lobe attains base of operculum, apex expanded, abruptly spatulate in lateral view, compressed in ventral view; operculum bifurcate, lobes bluntly rounded apically; endophallus with conspicuous medial armature with apically, basolaterally, and basally directed arms which are acutely pointed, with distinct, pointed tooth between apical arms (fig. 131).

Female not examined.

ETYMOLOGY: This species is named from the word dubitans and the suffix -oides for the great similarity between this species and A. dubitans.

Distribution: This species is known from Montana and Idaho (fig. 99).

PARATYPES: UNITED STATES: Idaho: Cassia Co.: Howell Canyon, 20 Jun 1976, under fir bark, RD Allen (1, PECK). Montana: Gallatin Co.: Bozeman Crk, 25 Jul 1989, 6000', funnel trap, DL Gustafson (1, MTEC).

Discussion: A single elevation record is from $6000 \mathrm{ft}$.

\section{Agathidium omissum Fall}

Figures 100, 132-140

Agathidium omissum Fall, 1934: 113.

Agathidium conjunctum, Hatch; 1957: 36 (misidentification).
Type Material: Holotype, $\widehat{o}$ in MCZC labeled "Glac. Pk Mont. 10Jy 29/ Cut Bank E. Mank/ o/ NB.2. p.334 [handwritten]/ TYPE omissum ['TYPE' underlined in red, 'omissum' handwritten]/ M.C.Z. Type 24040/ Agathidium omissum Fall [handwritten, red line around label]/ H.C. FALL COLLECTION/ HOLOTYPE, Agathidium omissum Fall, 1934 [red label with black line border]".

Type Locality: United States, Montana, Glacier Park.

Diagnosis: This species is distinguishable from other members of the group by the body broadly ovate (fig. 136), the punctation of the head distinctly larger and less dense than those of pronotum (figs. 132, 133), the elytral punctation not arranged serially, the male metafemoral tooth prominent, pointed, and located subapically, the male without metasternal fovea (fig. 135), and the operculum of the median lobe deeply divided, each half with a large apicolateral hook (fig. 139).

DESCRIPTION: Body broadly elongate oval, pronotum convex, elytra dorsoventrally compressed (figs. 136, 137); TBL $=3.4 \mathrm{~mm}$. Color of pronotum and apex of elytron testaceous, antenna testaceous, concolorous, club slightly darker, appendages reddishbrown, head, base of elytron, ventral surface darker, nearly black.

Head subquadrate (fig. 136) with dorsal transverse depression near posterior margin; $\mathrm{OHW} / \mathrm{MDL}=1.4$; surface with moderately dense, poorly defined, shallowly impressed, irregularly distributed punctures (fig. 132), surface between punctures alutaceous; eye large, conspicuous, forming anterolateral angle of head, facets fine; postocular temporum short, less than $0.5 \times$ eye length; OHW/PHW $=0.9$; anterior marginal carina distinct, from clypeus to postocular temporum; with abrupt 3-segmented club; antennomere III elongate, narrow, twice as long as II; II:III = 1:2; VII and VIII short, transverse; width VII:VIII:IX $=0.9: 1: 1.8$; frontoclypeal suture absent; labrum small, narrow, emarginate medially of apical margin separated from clypeal region by wide membrane. Pronotum broad, convex, anterior margin deeply emarginate to receive head, base of emargination nearly straight; posterolateral angles not defined, 


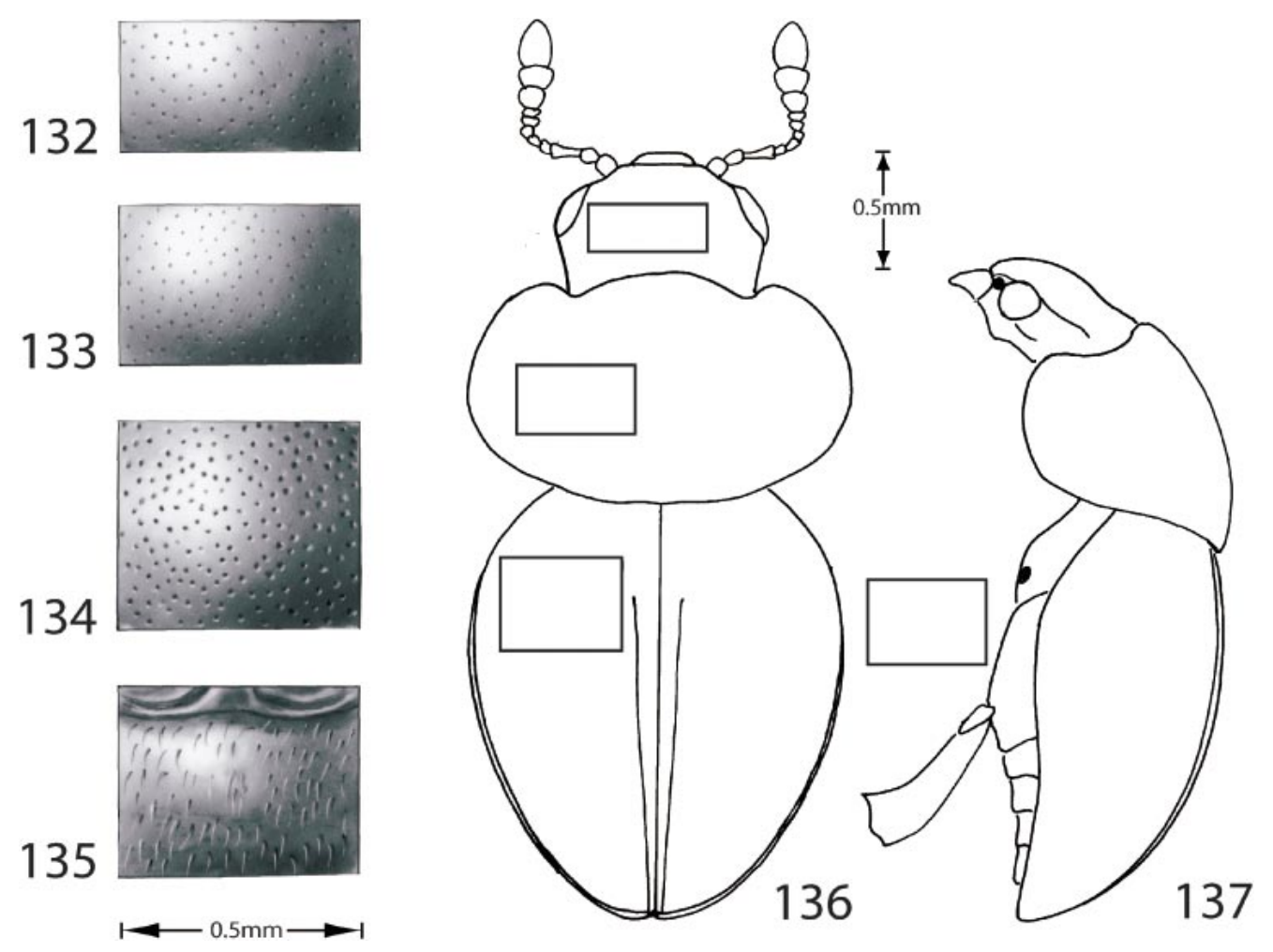

Figs. 132-137. Agathidium omissum Fall: Figs. 132-134, punctation details: 132, head; 133, pronotum; 134, elytron. 135. Male metasternal fovea. Figs. 136, 137, habitus: 136, dorsal; 137, lateral. Bars $=0.5 \mathrm{~mm}$.

obtusely rounded; surface with punctures smaller than those of head, separated by about $1-3 \times$ diameter individual puncture, more distinctly impressed than punctures of head (fig. 133), surface between punctures shiny, with microscopically nearly invisible alutaceous pattern. Elytra with narrow plicate margin extending to apex; sutural stria impressed in apical three-fourths, area between sutural striae elevated; elytral surface with dense, poorly defined punctures separated by about $1-2 \times$ individual puncture diameter (fig. 134); without serial arrangement of punctures; surface between punctures alutaceous; epipleuron narrowed, ending before apex; ELW/SEL = 0.8. Mesosternum large; anterior portion with median carina, surface densely alutaceous, subdivided by oblique line; posterior part with oblique lateral ridges, surface alutaceous. Metasternum large; with very slight, short trace of oblique lines, surface densely alutaceous; MSL/MTL = 1.1; MTL/MTW $=0.3$.

Male tarsi 5-5-4; with pro- and mesobasotarsomeres expanded with dense spatulate setae beneath; left mandible without tusk; metafemur with large, prominent, pointed, subapical tooth; metasternal fovea absent (fig. 135). Aedeagus robust, elongate; median lobe sinuate in lateral view, curved from base toward apex first ventrally then dorsally (fig. 138); in ventral aspect gradually narrowed then abruptly narrowed in apical fifth (figs. 139, 140), apex with dense, irregularly distributed ducts in fanlike pattern (figs. 139, 140); operculum divided entirely in apical half, partially in basal half, apex of each process in form of asymmetrical, laterally produced and recurved hook, with sparse, irregularly distributed pores on apical half (fig. 139); lateral lobes gradually narrowed, apices slightly clavate, with 2 setae, 1 apical, 1 


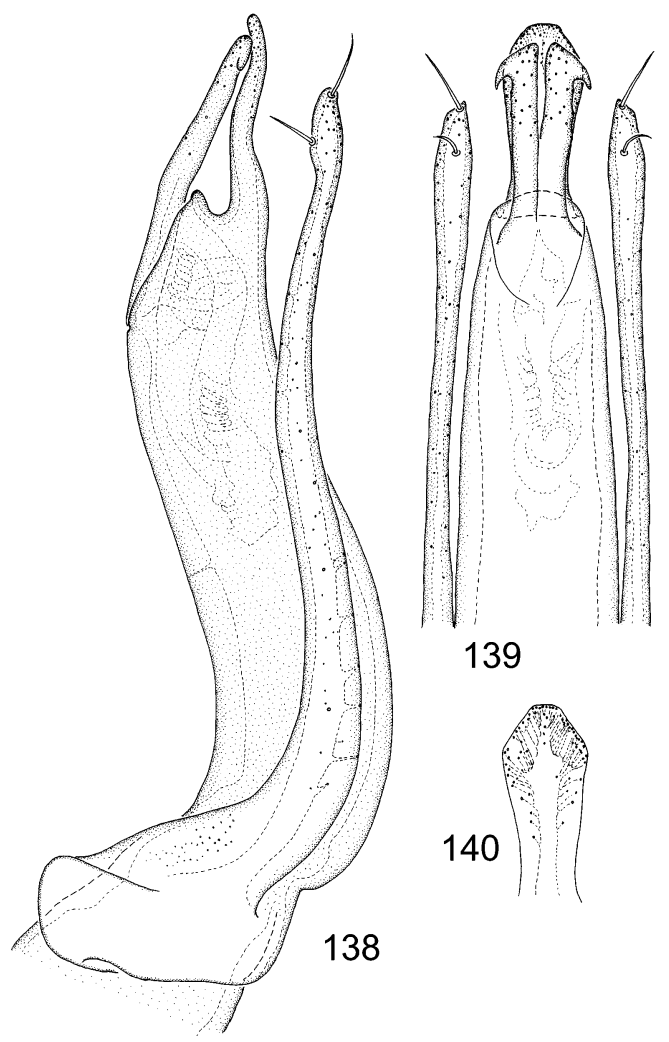

Figs. 138-140. Agathidium omissum Fall, aedeagus: 138, lateral; 139, ventral; 140, apex of median lobe.

subapical, with sparse, irregularly distributed pores (figs. 138, 139).

Female unknown.

Distribution: This species occurs in the central and southern Rocky Mountains (fig. 100).

SPECIMENS ExAmined: CANADA: British Columbia: Midday Valley, Merritt, 14 May 1925, Pinus ponderosa, J Stanley (1, CASC); Monashee Mtn nr. Cherryville, 11 Aug 1982, 1400', M Sorenson (2, LUND).

UNITED STATES: Colorado: Eagle Co.: $5 \mathrm{mi}$ E Avon, 25 May 1986, 7500', M Sorenson (2, LUND); Grand Co.: 9 mi SE Jct US 40 and CO 14, 21 Jun 1975, 7700', squirrel middens under conifer, A Newton, M Thayer (1, FMNH). Idaho: Twin Falls, Magic Mt, 15 May 1976, AD Miller (1, FMNH). New Mexico: Bernalillo Co.: $10 \mathrm{mi}$ E Albuquerque Sandia Mt, Capulin Spg, 21 Aug 1975, 9300', S Peck (1, CUIC).

Discussion: Based on Hatch's (1957: pl. IV, fig. 20) key and illustration of the male genitalia, his concept of $A$. conjunctum appears to be the same as ours of A. omissum. This may have led to his description of a new species (A. obtusum Hatch) for specimens that we regard to be $A$. conjunctum (see below under treatment of $A$. conjunctum).

This species has been collected from "squirrel middens under conifer" and elevations from 7700 to 9300 '.

\section{Agathidium cavisternum Fall Figures 100, 141-148}

Agathidium cavisternum Fall, 1934: 111; Hatch, 1957.

Type Material: Holotype, $\widehat{o}$ in MCZC labeled 'Sifting moss ['moss' handwritten]/ Terrace BC Mrs WW Hip pisley IV-8-1924 [date handwritten]/ ô/ TYPE cavisternum ['TYPE' underlined in red, 'cavisternum' handwritten]/ M.C.Z. Type 24031 [red label]/ H.C. FALL COLLECTION/ HOLOTYPE, Agathidium cavisternum Fall, 1934 [red label with black line border]".

TyPe Locality: Canada, British Columbia, Terrace.

Diagnosis: This species is distinguishable from others in the group by the following character combination: body relatively large and elongate (fig. 145); punctation of head finer and less dense than on pronotum (figs. $141,142)$; elytral punctation confused, without serially arranged punctures (fig. 143); with large metasternal fovea placed in a depressed area anteromedially on the metasternum (fig. 144); and aedeagus with median lobe apically slender and elongate, apex blunt (fig. 148).

DESCRIPTION: Body broadly oval, moderately dorsoventrally compressed, partially contractile (figs. 145, 146); TBL $=4.0 \mathrm{~mm}$. Color reddish-brown; elytra darker reddishbrown at base approaching black, paler apically; appendages paler, slightly orange.

Head large, subquadrate, dorsoventrally flattened (figs. 145, 146); surface with moderately dense, small, irregularly distributed punctures (fig. 141); areas between punctures smooth, shiny, with irregularly distributed micropunctules; OHW/MDL $=1.3$; OHW/ PHW = nearly 1.0 ; postocular temporum short, distinct; eye large, oval, anterolateral, conspicuous, finely faceted; supraocular ca- 


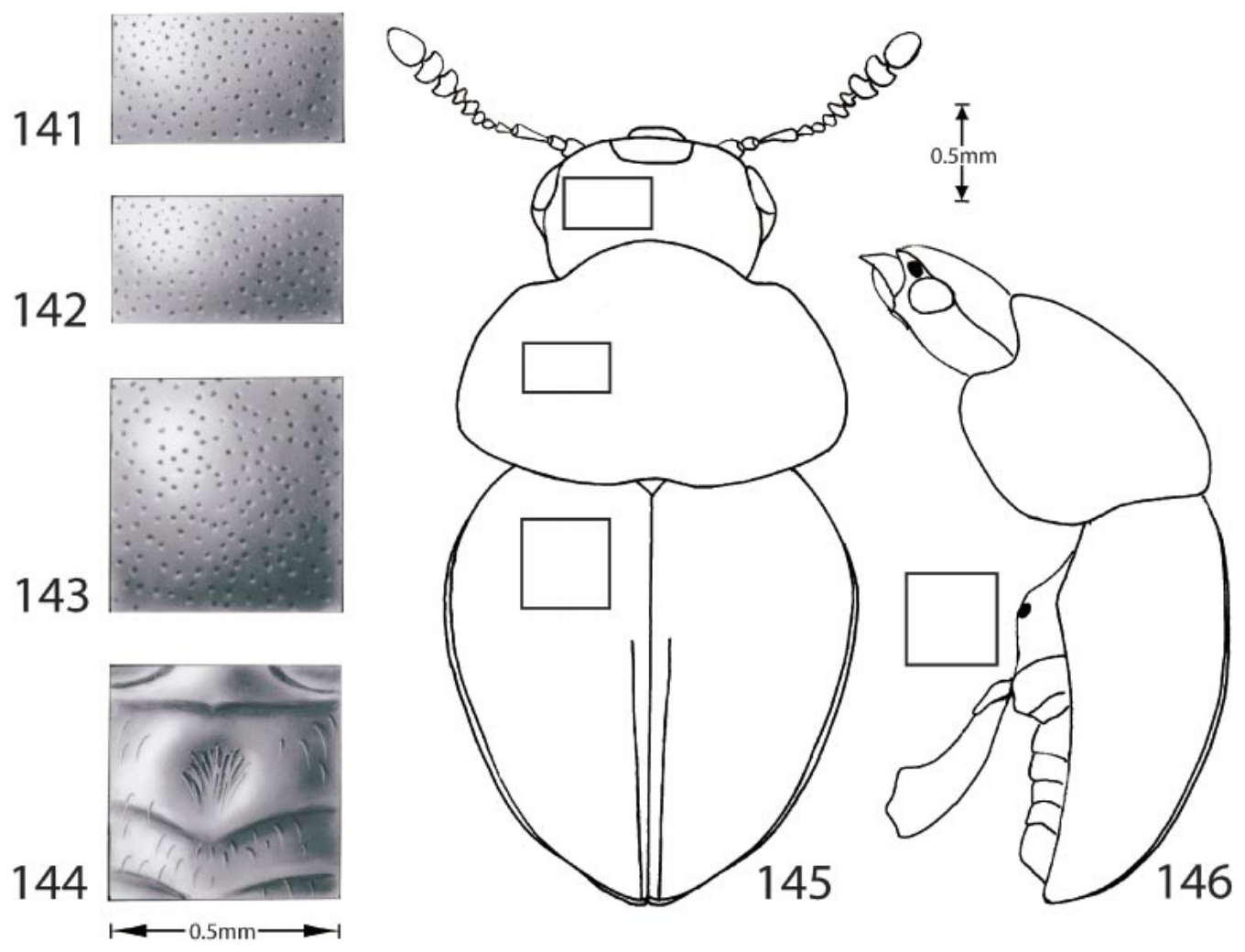

Figs. 141-146. Agathidium cavisternum Fall: Figs. 141-143, punctation detail: 141, head; 142, pronotum; 143, elytron. 144. Male metasternal fovea. Figs. 145, 146, habitus: 145, dorsal; 146, lateral. Bars $=0.5 \mathrm{~mm}$.

rina present from lateral edge clypeal region to approximately one eye-length posterior to eye; antennomere III long, about as long as next three antennomeres combined; II:III = 1:2; antennomere VII larger than VIII, much smaller than IX; VII:VIII:IX $=0.9: 1: 1.7$; with abrupt 3-segmented club. Pronotum large, broad, convex; posterior edge with shallow median emargination; corners broadly rounded; surface with punctation similar to that of head; punctures slightly more dense, area between as on head except with sparse, irregularly distributed, short pairs or sets of parallel microscopic impressions (fig. 142); $\mathrm{PNW} / \mathrm{PNL}=1.5 ; \mathrm{PNL} / \mathrm{PNH}=1.5$; $\mathrm{PNW} / \mathrm{PNH}=2.2$. Elytra broadly oval, not sharply attenuate posteriorly; ELW/SEL = about 1.0; humeral angles obtuse, broadly rounded; punctures larger than those of head or pronotum, dense, irregularly distributed, area between smooth, shiny, with sparse mi- cropunctules, without serial punctures (fig. 143); sutural stria present, extending from slightly forward of half elytral length to apex, apically convergent. Mesosternum carinate, with lateral oblique lines; MSL/MTL $=$ about 1.0. Metasternum large, densely minutely alutaceous, with weak transverse rugulose lines, including in male arced line forming posterior edge of median depressed, smooth area; MTL/MTW $=0.3$.

Male tarsi 5-5-4; pro- and mesobasotarsomeres strongly expanded, with dense spatulate setae; left mandible not modified; metafemur with large tooth located about onefourth length femur before apex, with oblique line between apex of tooth and apex of femur; metasternal fovea large, located near middle in large, smooth depression, bearing long setae (fig. 144). Aedeagus with median lobe elongate, ventrally curved, apical portion relatively slender, constricted, 


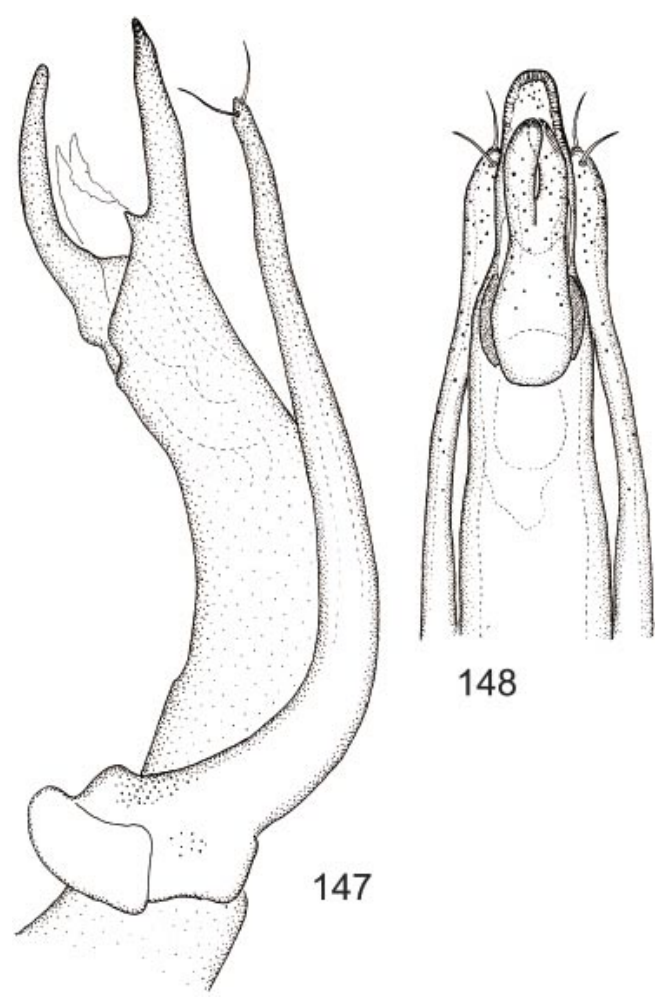

Figs. 147-148. Agathidium cavisternum Fall, aedeagus: 147, lateral; 148, ventral.

slightly expanded subapically, apex blunt (fig. 148), in lateral aspect apex recurved dorsally, apical quarter approximately straight, irregularly shaped along ventral orifice, with almost toothlike projection (fig. 147); operculum deeply emarginate, each part elongate, bluntly rounded (fig. 148); lateral lobes blunt (figs. 147, 148).

Female tarsi 5-4-4.

DisTRIBUTION: This species is known from British Columbia, Canada (fig. 100).

Specimens Examined: CANADA: British $\mathrm{Co}$ lumbia: Toco, 28 Apr 1984, R and J Camenisch (1, PECK); Queen Charlotte Islands, Moresby Island, $2.5 \mathrm{mi}$ N Mosquito Lake Campground, 5 Jun 1984, Spruce forest litter, RS Anderson (1, PECK); Charlotte Islands, Graham Island $1 \mathrm{mi}$ NW Tlell, 27 Jun 1984, Sitka spruce, hemlock forest, RS Anderson (1, PECK); Stickeen R. Canyon, Liebeck (1, MCZC).

Discussion: There have been no reported hosts. The type was collected from "sifting moss". Other specimens have been collected from spruce and hemlock forests.

Two female specimens reported from the type locality were reported by Fall (1934), but these appear to have been returned to C.A. Frost, are not at the MCZC, and were not examined by us.

\section{Agathidium virile Fall \\ Figures 101, 149-156}

Agathidium virile Fall, 1901: 219, 1934.

Agathidium hebetatum Hatch, 1957: 35. NEW SYNONYM.

Type MATERIAL: Agathidium virile: holotype, 0 in MCZC labeled " $\delta /$ Pom Cal Mar. 25.93 [date handwritten]/ TYPE virile ['TYPE' underlined in red, 'virile' handwritten]/ M.C.Z. Type 24045 [red label]/ H.C. FALL COLLECTION/ HOLOTYPE, Agathidium virile Fall, 1901 [red label with black line border]".

Agathidium hebetatum: holotype, ô, USNM, labeled "McMinnville, ORE X-2041 [handwritten]/ TYPE o A Agathidium (s.str.) hebetatum 1955-M. Hatch [handwritten, red label]/ HOLOTYPE Agathidium hebatatum Hatch, 1957 [red label with black line border]".

TyPe Locality: Agathidium virile: United States, California, Los Angeles Co., Pomona. Agathidium hebatatum: United States, Oregon, Yamhill Co., McMinnville.

DiAGNOSIS: This variable species is distinguished from others in the A. revolvens species group by the following combination of characters: body broadly oval, convex, partially contractile (figs. 153, 154); dorsal punctation dense, confused, coarsely to weakly impressed (figs. 149-151); metafemoral tooth apical, broad; aedeagus narrowed at apex, sometimes slightly widened and spatulate at apex (fig. 156); and ventral operculum deeply divided, each lobe apically truncate (fig. 156).

DESCRIPTION: Body very broadly elongate oval, partially contractile, moderately convex (figs. 153, 154); TBL $=3.2 \mathrm{~mm}$. Color of head and pronotum reddish-brown; elytra darker, except apex; metasternum conspicuously darker; mouthparts and appendages reddish-brown; antenna uniformly yellowish 

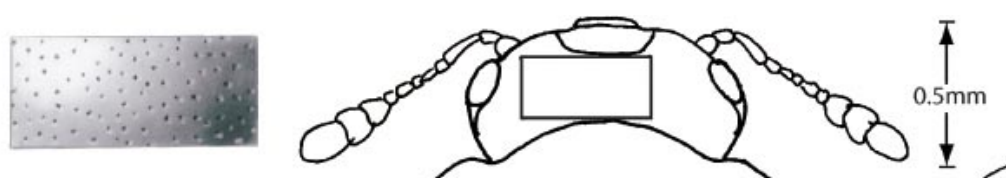

150

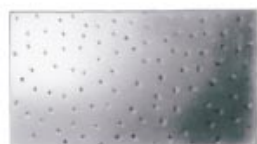

151

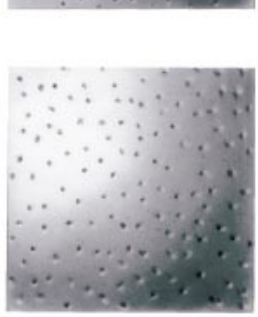

152
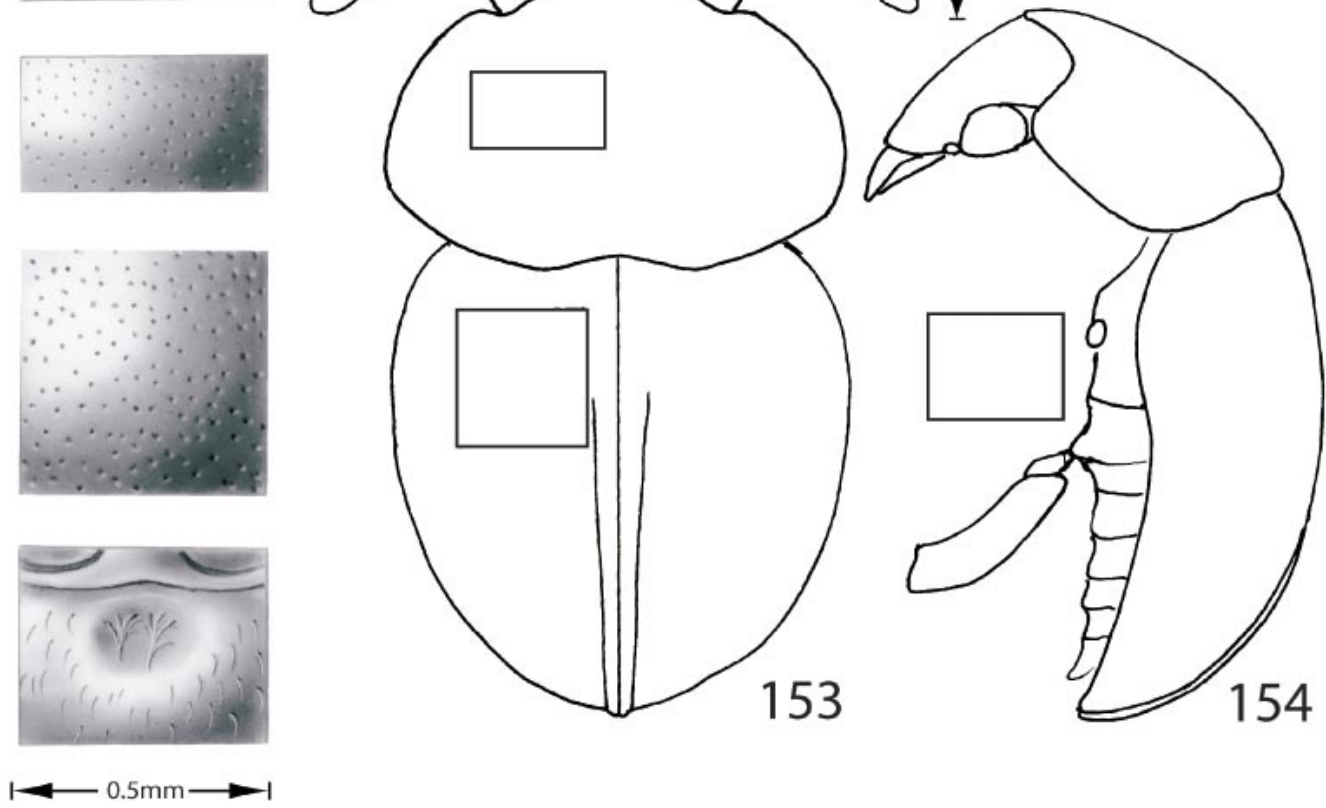

Figs. 149-154. Agathidium virile Fall: Figs. 149-151, punctation detail: 149, head; 150, pronotum; 151, elytron. 152. Male metasternal fovea. Figs. 153, 154, habitus: 153, dorsal; 154, lateral. Bars $=0.5$ $\mathrm{mm}$.

red-brown; coxae, femora, mesosternum, and prosternum paler, somewhat testaceous.

Head large, broad, subquadrate in shape; head narrowed behind eye, temporum short (figs. 153, 154) (about three-fifths length of eye), defined only by supraocular carina extending from posterior end of temporum to frontoclypeal suture; $\mathrm{OHW} / \mathrm{MDL}=1.5$; $\mathrm{OHW} / \mathrm{PHW}=$ about 1.0 ; dorsal surface with sparse, irregularly distributed, weakly impressed, small setigerous punctures, surface between with sparse, small, irregularly distributed punctules (fig. 149); eye large; frontoclypeal suture very finely impressed, nearly absent, clypeal region made distinct only by subcuticular darkened lines; surface of clypeus as on frons; without larger setae at posterolateral corners of clypeal region; labrum small, transverse, very shallowly emarginate medially; antennomere III about as long as IV + V + VI; length II:III $=1: 2.2$; VII very slightly wider than VIII, nearly equal in size; width VII:VIII:IX $=1: 1: 2.4$.
Pronotum broad, convex; PNW/PNL = 1.6; $\mathrm{PNL} / \mathrm{PNH}=1.4 ; \mathrm{PNW} / \mathrm{PNH}=2.2 ;$ punctation similar to that of head, a little more faintly impressed (fig. 150). Elytra very wide; length little more than combined width; only slightly attenuate at apex; humeri not angulate, broadly obtuse; punctures much larger than those of head and pronotum, more coarsely impressed, irregularly distributed and moderately dense, distance between punctures about 0.5-1.5 diameter of single puncture, surface between smooth, shiny, with microscopic, nearly invisible and very sparse micropunctules and random faint curving lines (fig. 151). Mesosternum divided into anterior and posterior parts; anterior part with longitudinal median carina and fine alutaceous sculpturing; with oblique carinae and lateral, longitudinal carinae. Metasternum finely alutaceous, with laterally curved, concentric, rugose ridges, surface covered by fine setae. $\mathrm{MSL} / \mathrm{MTL}=0.7$; MTW/MTL $=$ 0.3 . 


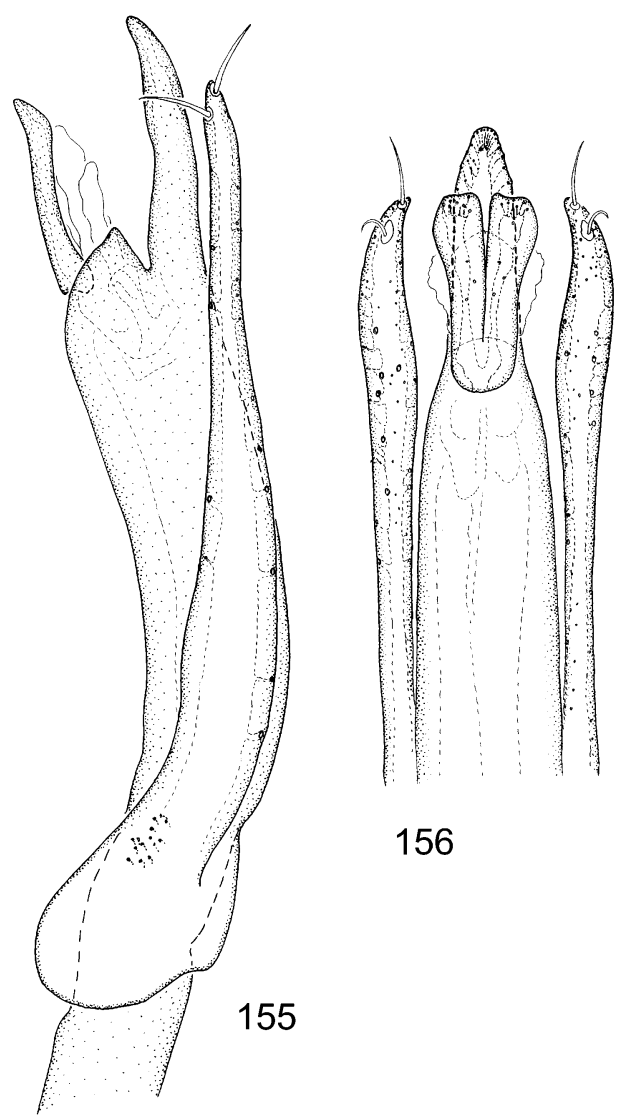

Figs. 155, 156. Agathidium virile Fall aedeagus: 155, lateral; 156, ventral.

Male tarsi 5-5-4; with pro- and mesobasotarsomeres moderately laterally expanded; left mandible not modified; metafemur with conspicuous, broad, nearly apical tooth with small median protruding point; metasternal fovea in large anteromedial oval depression, with long fine setae (fig. 152). Aedeagus with median lobe elongate, robust, ventrally curved, recurved dorsally subapically, apical one-fifth dorsoventrally compressed and laterally narrowed before apex; apex of median lobe narrowed, slender to more or less arrowhead-shaped, with fanlike arrangement of ducts apically (fig. 156); operculum deeply bisected into two pieces, each nearly parallelsided or slightly expanded apically and truncate or very broadly rounded at apex, with apical concentration of pores (fig. 156); lateral lobes long, gradually narrowed before apex that is slightly enlarged, especially in ventral view, with pair of subapical setae and irregularly distributed pores (figs. 155, 156); endophallic armature not extensive.

Female tarsi 5-4-4.

DISTRIBUTION: This species is nearly ubiquitous in California and occurs into western Oregon, though it does not appear to occur extensively outside California (fig. 101).

SPECIMENS EXAmined: UNITED STATES: California: state only (3, MCZC); Berkeley, 7 Dec 1919 (3, MCZC); Poway (1, CASC); Carmel, 5 Jan 1924 (1, CASC); Willows, 13 Jun 1966, RP Allen (1, FGAC); Santa Barbara, 20 Dec 1980, pan trap, S Miller (4, CUIC); Descanso Jct, 31 Mar 1969 (1, CNCI); Poway, FC Bowdin (1, MCZC); Sequoia Natl Park, 12 May 1979, R Baranowski (7, LUND); Yosemite Valley, 8 Jun 1930 (1, CASC); San Diego (1, CASC); Sacramento, 7 Apr 1931, HH Keifer (1, FGAC); Pasadena (8, MCZC); Pomona (1, MCZC); Pasadena, Mar, A Fenyes (1, CMNH); Santa Cruz Mts (2, MCZC); Castro Valley, 27 Mar 1938, CT Sierra (1, FGAC); Stanford Univ., 30 Apr 1950, P Bartholomew (1, CASC); Pasadena (2, CASC); Alameda Co.: Livermore, 11 Apr 1958, JT Doyen (1, EMEC); Strawberry Can., 11 May 1984, J Whitefield (1, CASC); Corral Hollow, $10 \mathrm{mi}$ E Livermore, 10 Mar 1976, J Doyen (1, CASC); 4 mi SE Livermore, Arroyo Mocho, 24 Mar 1976, FG Andrews (1, FGAC); Oakland, 22 Mar 1952, Quercus agrifolia, H Schuster (1, EMEC); Alpine Co.: 1.2 mi E Monitor Base, 25 Jun 1983, 8000', FG Andrews (1, FGAC); Woodfords, 18 Oct 1962 (1, FGAC); Amado Co.: Pine Grove, 5 Mar 1971, FG Andrews, RF Wilkey (1, FGAC); Butte Co.: 4.4 mi SW Rackerby, 24 Mar 1983, A Hardy, F Andrews (1, FGAC); 4.4 mi SW Rackerby, 6 Feb 1980, pitfall, AR Hardy (5, FGAC); 3 mi E Chico, 17 Jan 1979, Bermuda grass, DS Chandler (1, QDWC); Colusa Co.: Rumsey, 1 May 1970, oak litter, FL Blano (1, FGAC); Contra Costa Co.: Mt Diablo, 24 Nov 1953 (2, EMEC); Antioch, $1 \mathrm{mi}$ E, 24 Jan 1975, J Doyen (1, CASC); Vine Hill, 12 Apr 1908, FE Blaisdell (1, CASC); Antioch Natl Wildlife Refuge, 13 Mar 1982, pitfall traps, Powell (1, CASC); El Dorado Co.: Peavine Ridge Rd 7 mi SW Ice House, 16 Apr 1992, Quercus kellogi litter, FG Andrews (1, FGAC); $1 \mathrm{mi} \mathrm{E} \mathrm{Pa-}$ cific House, 10 Jun 1994, under bark of dead oak, CB Barr (11, CASC); 1.3 mi S Pacific House, 15 Feb 1991, F Andrews, T Eichlin (3, FGAC); Blodgett Exp. For. 14 mi E Georgetown, 8 May 1976, J Doyen (1, CASC); 2 mi SE Latrobe, 18 Apr 1978, oak duff, Stanley, C Kuba (3, FGAC); Blodgett Forest $13 \mathrm{mi}$ E Georgetown, $28 \mathrm{Apr}$ 1976, Quercus kellogi litter, J Doyen (2, CASC); 3 mi W Grizzly Flat, 24 Mar 1982, under oak 
bark, F Andrews (1, FGAC); 7.7 mi SE Virner Blodgett Forest, 29 Mar 1984, under bark Pseudotsuga trifolia, FG Andrews (1, FGAC); $7.7 \mathrm{mi}$ SE Virner Blodgett Forest, 29 Mar 1984, under bark Ponderosa pine, FG Andrews (2, FGAC); 3 mi SW Somerset, 26 Oct 1971, R Wharton (11, FGAC); 3.5 mi NW Rescue, 30 Nov 1976, Quercus litter, FG Andrews (1, FGAC); Fresno Co.: 8 mi W Coalinga Wartham Canyon, 16 Apr 1980, Andrews, Paddock (27, FGAC); Cierro Hills, 16 Apr 1980, CY Kitayama (17, CASC); $8 \mathrm{mi} \mathrm{W}$ Coalinga Warthan Canyon, 16 Apr 1980, flying at dusk, Andrews (12, FGAC); 2 mi N Tollhouse, 28 Nov 1977, Ceanothus duff, A Gilbert (3, FGAC); 2 mi NE Auberry, 13 Feb 1981, AJ Gilbert, HN Smith (1, FGAC); 9 mi E Coalinga, 20 Feb 1981, Andrews, Gilbert (5, FGAC); Dinky Crk, 5 Apr 1970, pine duff, TR Haig (1, FGAC); $8 \mathrm{mi} \mathrm{W}$ Coalinga, Warthan Canyon, 16 Apr 1980, Andrews, Paddock (1, FGAC); 9 mi E Coalinga, 20 Feb 1981, pitfall, Andrews, Gilbert (4, FGAC); 15 mi E Fresno, 16 Mar 1984, oak litter, AJ Gilbert (2, FGAC); 11 mi W Coalinga, 28 Oct 1971 (11, FGAC); Humboldt Co.: Eureka, 27 May 1981, salix litter, TR Haig (1, FGAC); Kern Co.: 1 mi N McKittrick, 24 Mar 1981, pitfall, RL Aalbu (2, FGAC); Kern River, 6 mi E Tupman, 21 Mar 1975, Atriplex litter, J Doyen (1, CASC); Frazier Park, 13 Jan 1961, EL Sleeper (1, FGAC); Arvin Hills, 9 Mar 1986, under rock, J Schuh (1, MCZC); 12 mi NW Taft, 9 Apr, DB Wahl (1, AMNH); $1.4 \mathrm{mi} S$ Valley Acres, 30 Jan 1979, Andrews, Hardy (1, FGAC); Kings Co.: 1 mi SW Kettleman City, 4 Mar 1988, pitfall trap in sand, RL Aalbu (1, CNCI); 8 mi SSW Avenal, 29 Apr 1980, Andrews, Kuba, Paddock (1, FGAC); 8 mi SSW Avenal, 17 Sep 1980, litter at base of oak, Andrews, Kuba, Paddock (4, FGAC); 1 mi SW Kettleman City, 4 Mar 1988, pitfall, RL Aalbu (1, FGAC); 1 mi SW Kettleman City, 4 Mar 1988, pitfall trap, RL Aalbu (2, FGAC); Tar Canyon SE Avenal, 8 Mar 1973, pitfall, Gilbert, Bookout (1, FGAC); 10 mi S Avenal, Sunflower Velley, 9 Jan 1980, oak, pitfall, A Gilbert (2, FGAC); Tar Canyon SE Avenal, 8 Mar 1975, pitfall trap, Gilbert and Bookout (1, FGAC); 10 mi SW Avenal, 6 Feb 1980, oak juniper duff, A Gilbert (2, FGAC); 8 mi SSW Avenal, 17 Apr 1980, base of oak, Andrews, Kuba, Paddock (1, FGAC); Lake Co.: Butte Canyon 10 mi SE Middletown, 3 Apr 1981, Hardy, Andrews (1, FGAC); Lassen Co.: Ravendale, 16 Apr 1975, FG Andrews (1, FGAC); Los Angeles Co.: San Gabriel Canyon, 9 Feb 1961, FG Andrews (1, FGAC); Pine Canyon $6 \mathrm{mi} \mathrm{W}$ Lake Hughs, 27 Feb 1978, A Hardy, F Andrews (1, FGAC); Madera Co.: $32 \mathrm{mi}$ NE Fresno USDA Exp. Station, 25 Jan 1980, woodrat nest, N Smith (1, FGAC); Marin Co.: Pt Reyes Station, 11 Mar
1976, oak duff, F Andrews, KS Corwin (1, FGAC); McClure's Beach, 17 Dec 1976, rock crevices, upper intertidal, J Doyen (1, CASC); Taylor State Park, 20 Apr 1947, HB Ross (1, CASC); Samuel P Taylor State Park, 31 Mar 1976, FG Andrews (1, FGAC); Samuel P Tayler State Park, 31 Mar 1976, FG Andrews, TD Eichlin (2, FGAC); Novato, 22 Nov 1969, swimming pool, T Haig (2, FGAC); Pt Reys Mt Vinson, 25 Feb 1982, on myxomycete, FG Andrews (1, FGAC); Taylor State Park, 20 Jun 1947, ES Ross (1, CASC); Mariposa Co.: Tioga Rd, $1.9 \mathrm{mi}$ E Crane Flat, 18 May 1976, 6600 ', conifer forest litter, A Newton, M Thayer (1, MCZC); Mendocino Co.: 18 Mar 1938, J Helfer (1, CASC); 2 Jul 1926 (1, CASC); 29 Jul 1952 (1, EMEC); Hopland Field Sta. HQ Lake, 15 May 1977, J Powell (1, CASC); Hopland Filed Sta. HQ Lake, 15 May 1979, J Powell (1, CASC); Merced Co.: Los Banos Creek, 1 Apr 1987, 400', pitfall, D Giuliani (2, FGAC); Modoc Co.: 5 mi NE Altura, 20 Mar 1980, oak duff, TR Haig (3, FGAC); 5 mi NE Altura, 20 May 1980, Juniperus occidentalis duff, TR Haig (4, FGAC); Mono Co.: 6 mi SW Toms Place, 8 Aug 1969, 9000 ', A Smetana (1, CNCI); Monterey Co.: 19.4 mi E San Lucas, 16 Nov 1971, Heteromeles arbutifolia, FG Andrews (1, FGAC); 19.4 mi E San Lucas, 16 Nov 1971, oak duff, FG Andrews (1, FGAC); Preist Valley, 20 Mar 1981, pitfall, Gilbert, Andrews (1, FGAC); Arroyo Seco, 9 Feb 1982, under oak bark, F Andrews (1, FGAC); 17 mi E San Lucas, 20 Mar 1981, pitfall, Gilbert, Andrews (2, FGAC); Mt Palo Exctio, Jun 1972, oak duff, D Giuliani (1, FGAC); Carmel, 1915 (1, MCZC); 6.7 mi N Hwy 1, 23 Feb 1984, oak litter, berlese, AJ Gilbert (1, FGAC); Cast Rd along Sierra Ck 2.4 mi SE Bixby landing, 21 Feb 1989, F Andrews, T Eichlin (1, FGAC); Napa Co.: 2 mi N St Helena White's Cave entrance, 26 Apr 1981, pitfall, R Aalbu (1, FGAC); 3 mi W Cordelia, 1 Oct 1971, oak duff, WW Wiard (7, FGAC); 2 mi ENE St Helena, 24 Jan 1981, RL Aalbu (2, FGAC); Nevada Co.: 4 mi S Rough and Ready, 5 May 1980, under bark of Quercus kellogi, JT Doyen (38, CASC); Orange Co.: Buena Park, 16 Feb 1967 (1, FGAC); Riverside Co.: 0.5 mi SE Aguanga Chaparral Scrub, 7 Jan 1979, pitfall, RL Aalbu (2, FGAC); Menifee Valley, 28 May 1980, JD Pinto (1, FGAC); Sacramento Co.: Sacramento, 5 Apr 1977, TR Haig (1, FGAC); Nimbus, Alder Creek at US Hwy 50, 2 Mar 1990, under bark, CB Barr, WD Shepard (1, CASC); 9 Sep 1930, blue oak (1, FGAC); 1 mi E Folsom Humberg Gr, 8 Sep 1978, pitfall, S Kuba (1, FGAC); Folsom, 1 Jan 1938, Q Tomich (1, EMEC); San Benito Co.: 17 mi N New Idris, 9 Apr 1982, ptifall, A Gilbert, N Smith (5, FGAC); 14 mi S San Benito, 16 Nov 
1971 (2, FGAC); 1.8 mi SW Idria, 25 Mar 1981, pitfall, AJ Gilbert, N Smith (5, FGAC); $1.4 \mathrm{mi} \mathrm{N}$ New Idris, 8 Jun 1981, manzanita, AJ Gilbert N Smith (1, FGAC); 18.4 mi NE Idris, 25 Apr 1981, AJ Gilbert, HN Smith (1, FGAC); $8.2 \mathrm{mi} \mathrm{W}$ on Panochee Rd, 1 Jan 1979, AJ Gilbert (1, FGAC); San Bernardino Co.: 3 mi E Summit, 2 May 1978, KW Cooper (2, FGAC); 2 mi E Mentone, 15 May 1978, KW Cooper (1, FGAC); 6 mi W Wrightwood, 14 Apr 1986, under bark, F Andrews, TD Eichlin, A Hardy (2, FGAC); 1.4 mi N New Idris, 8 Jun 1981, manzanita, pitfall, AJ Gilbert, $\mathrm{N}$ Smith (1, FGAC); 3 mi E Summit, 2 May 1978, Neotoma nest, KW Cooper (1, FGAC); Seven Oaks, 26 Jan 1963, oak duff, FG Andrews (2, FGAC); 3 mi E Summit, 2 May 1978, Neotoma nest, KW Cooper (9, FGAC); Lake Fulmore, Nov 1967, 6000', tullgren funnel, D Hagstrum (1, FGAC); San Diego Co.: Pine Hills, William Heise Co. Park, 19 Mar 1979, poison oak, berlese, KW Cooper (1, FGAC); 4 mi E Campo, 26 Mar 1961, EE Lindquist (2, EMEC); 7.5 mi E Julian, Banner Crk., 2 May 1981, 2700', L Herman (1, AMNH); Borego, 28 Apr 1955 (1, EMEC); San Luis Obispo Co.: Cambria, 29 Oct 1971, oak duff, FG Andrews (1, FGAC); Arroyo Grande, 7 Aug 1987, pitfall, J McLaughlin (1, FGAC); $7.5 \mathrm{mi} \mathrm{W} \mathrm{Si-}$ mmler, 30 Jan 1979, pitfall, Andrews, Hardy (12, FGAC); Santa Barbara Co.: Carpinteria, 19 Jan 1989, J McLaughlin (1, FGAC); Refugio, 7 Apr 1972, D Teiman (1, FGAC); Santa Clara Co.: Saratoga Gap, 19 Apr 1976, FG Andrews (1, FGAC); 24 Apr 1923, ER Leach (1, CMNH); Sveadal, 27 Apr 1968, A and A Gillogly (1, FGAC); Santa Cruz Co.: $7.5 \mathrm{mi}$ S Los Gatos, Santa Cruz Mts, 23 Nov 1963, Irwin, Westcott (1, FGAC); Shasta Co.: Redding, 1 Mar 1980, TR Haig (5, FGAC); 4 mi NE Montgomery Ck, 19 Apr 1984, oak duff, berlese, TR Haig (4, FGAC); Redding, 1 Apr 1979, oak duff, TR Haig (4, FGAC); Redding, 1 Apr 1980, TR Haig (2, FGAC); 4 mi NE Montgomery Ck, 9 Feb 1986, oak duff, berlese, TR Haig (1, FGAC); Sierra Co.: Gold Lake, 14 Jul 1921 (1, CASC); Slano Co.: Travis AFB, 6 Apr 1971 (3, FGAC); Sonoma Co.: Trinity, 30 Nov 1933 (1, CASC); Armstrong Park, 14 Mar 1954, J Helfer (1, EMEC); Sta Clara Co.: Guadalupe Res, 1 Apr 1973, under bark blue oak, CY Kitayama (5, CASC); Sta Cruz Co.: S end Sunset Bch, 4 May 1973, J Doyen (1, CASC); Stanislaus Co.: Knights Ferry, 25 Mar 1987, meadow, Andrews, Eichlin, Hard (1, FGAC); La Grange, Oct 1975, RP Allen (1, FGAC); La Grange, 5 Oct 1970, at light, RP Allen (11, FGAC); Tehama Co.: $1 \mathrm{mi}$ SW Dales, 13 Feb 1971, DS Chandler (5, CASC); 15 mi W Red Bluff, 14 Feb 1971, DS Chandler (3, CASC); Red Bluff, 16 Feb 1973, TR Haig (1, FGAC); S Fk Battle Creek, 25 Dec 1970, oak lit- ter, DS Chandler (3, CASC); 2 mi NE Dales, 13 Feb 1971, DS Chandler (2, EMEC); Trinity Co.: Junction City, 12 Mar 1981, TR Haig (1, FGAC); Junction City, 04 Jan 1990, madrone duff, TR Haig (1, FGAC); Weaverville, 15 Apr 1981, litter, TR Haig (1, FGAC); Del Loma, 5 Jan 1985, Alnus duff, TR Haig (10, FGAC); Del Loma, 23 Jan 1980, TR Haig (10, FGAC); Big Bar, 3 Aug 1976, leaf litter, FG Andrews (1, FGAC); 5 mi W Coffee Ck Ranch, 19 Jun 1972, pine duff, DS Chandler, DP Levin (2, CASC); Tulare Co.: Ash Mt nr Three Rivers, 11 Feb 1983, flume debris trap, R Haines (1, FGAC); Ash Mt, 17 Mar 1984, at flume forebay, R Haines (22, FGAC); Wood L., 19 Dec 1947, rotary trap, NW Frazier (4, EMEC); Kaweah, 16 Nov 1971, oak duff, FG Andrews (1, FGAC); 1 Jun 1933, FT Scott (5, FGAC); Ashe Mt HQ, 28 Apr 1979, Douglas fir litter, JT Doyen (9, CASC); Camp Wishon $10 \mathrm{mi}$ NE Springville, 1 May 1979, J Doyen (1, CASC); S FK Camp 13 mi SE Three Rivers, 29 Apr 1979, Arctostaphylos litter, JT Doyen (1, CASC); 10 mi SE Three Rivers, S FK Kaweah R., 29 Apr 1979, Quercus litter, JT Doyen (1, CASC); Sequoia Nat. Pk. Huckleberry Meadow, 28 May 1984, 6000', R Baranowski (1, LUND); Tuolumne Co.: Strawberry, 23 Jun 1953, JG Rozen (1, EMEC); Ventura Co.: Moorpark, 23 Mar 1971, oats and barley, Anderson, Johnson (1, FGAC); Yolo Co.: 2 mi W Rumsey, Cache Crk, 8 Nov 1971, Bermuda grass, sweeping, DS Chandler (2, CASC); Davis, 15 Nov 1956, Pyrecantha litter, RO Shuster (4, CASC); Yuba Co.: Sierra Foothill Feild Sta 6 mi N Smartville, 4 May 1980, under bark Pinus sabiniana, JA Powell (4, CASC); Dry Crk 4 mi NW Smartville, 3 May 1980, under bark Pinus sabiniana, JT Doyen (3, CASC); 15 mi E Marysville, 6 Feb 1980, pitfall, AR Hardy (16, FGAC); 19 Apr 1913 (1, MCZC); Spencerville Wildlife Area, 9 Apr 1978, F Andrews (7, FGAC). Oregon: Clatsop Co.: 5 mi N 7 mi W Elsie, 13 Aug 1973, 700', duff, E Benedict (1, QDWC); Douglas Co.: 16 km E Steamboat, 16 Oct 1972,3200 ', duff, E Benedict (1, QDWC); $5.5 \mathrm{mi} \mathrm{NE} \mathrm{Idleyld} \mathrm{Pk.,} 1$ Apr 1972, 1200 ', duff, E Benedict (1, QDWC); Jackson Co.: 4 mi E Eagle Point, Kanutcham Ck, 22 Jan 1972, 1400', madrone oak duff, E Benedict (2, QDWC); 9 mi N Central Point, 22 Jan 1972, 1400', oak duff, E Benedict (4, QDWC); Josephine Co.: $1 \mathrm{mi} \mathrm{S}, 5 \mathrm{mi}$ W O'Brien, Hwy 99, 18 Dec 1971, 1400', debris, E Benedict (1, PECK); Linn Co.: Swamp Mt Rd 2 mi E Cascadia, 29 Apr 1972, maple duff and wood, EM Benedict (1, PECK).

DisCUSSION: The holotype of A. hebetatum Hatch (USNM) was examined and found to be a synonym of $A$. virile based on similarity 
in punctation and shape of the median lobe of the aedeagus. This specimen is well within the variation of typical members of $A$. virile.

Agathidium virile is a common and morphologically variable species in the far western region of the United States. Specimens assigned to this species are diverse in punctation and, to a certain extent, in the form of the aedeagus. The elytra are densely punctate, but the punctures vary from rather feebly impressed to very deep and coarsely impressed. Among those with coarse elytral punctation, punctures of the head and especially the pronotum may be somewhat smaller but similarly strikingly coarse and deep ranging to rather small and decidedly weakly impressed. The apex of the median lobe varies from slender and gradually narrowed to more broadly expanded. The branches of the operculum vary from very slender and elongate to distinctly broader, but generally the branches are narrowed medially with the apices broadly expanded and truncate.

It is possible that additional species exists within what we regard as A. virile. However, no correlations were found among these variable traits that suggest a reasonable inference of species status for any of the included variable specimens, and we regard the species as simply polymorphic. A male from Stanford, California (CASC), has a relatively broad median lobe apex, gradually broadened and apically spatulate ventral opercula, in combination with rather weakly impressed pronotal and elytral punctation. In this sense it is somewhat intermediate in condition with A. angustoperculum. Considering the known variation within $A$. virile, however, this specimen is most reasonably assigned here for the present. Another specimen from Santa Clara County, California (CNMH), and one from Linn County, Oregon (PECK), are tentatively assigned to this species and have the apical portion of the median lobe much more slender than in most specimens, with the lateral margins nearly parallel.

A specimen from McClure's Beach, Marine County, California (CASC), was collected from "rock crevices, upper intertidal", though this must certainly be an accidental occurrence for this species.

\section{Agathidium conjunctum Brown}

Figures 102, 157-165

Agathidium conjunctum Brown, 1933: 46; Fall, 1934.

Agathidium obtusum Hatch, 1957: 36. NEW SYNONYM.

TyPe Material: Agathidium conjunctum: holotype, $\sigma^{t}$ in CNCI, labeled "Langley B.C. 7.III 1931/ K.Graham [handwritten]/ HOLOTYPE Agathidium conjunctum Brown, 1933 [red label with black line border]'.

Agathidium obtusum: holotype not examined.

TyPe Locality: Agathidium conjunctum: Canada, British Columbia, Langley.

Agathidium obtusum: Canada, British Columbia, Creston.

DiAGNOSIS: This species is distinguished from others in the group by the elongate oval body, the elytra dorsoventrally compressed (figs. 161, 162), the punctures of the head similar in density to those of pronotum (figs. $157,158)$, the elytron without serial series of punctures, punctation dense, confused (fig. 159), the male metasternal fovea small, circular (fig. 160), and the aedeagus with the apex of the median lobe arrowhead-shaped with a median ventral ridge (figs. 164, 165).

DESCRIPTION: Body broadly oval, contractile, moderately convex (figs. 161, 162); TBL $=2.0-2.5 \mathrm{~mm}$. Color dark reddish-brown, nearly black; clypeal region, perimeter of pronotum, mouthparts, and appendages slightly paler.

Head broad, subquadrate, dorsoventrally flattened (figs. 161, 162); OHW/MDL = 1.6; $\mathrm{OHW} / \mathrm{PHW}=1.1$; dorsal surface with moderately dense, shallow punctures (fig. 157), surface between shiny but with microscopic, sparse punctules and slightly alutaceous; clypeal suture absent; eyes large, slightly protruding; postocular temporum distinct, short; antennomere III long, about as long as $\mathrm{IV}+\mathrm{V}+\mathrm{VI}$; length II:III = 1:3; VII slightly broader than VIII; width VII:VIII:IX = 1: 1:2.1. Pronotum broad, convex; PNW/PNL $=1.6 ; \mathrm{PNL} / \mathrm{PNH}=1.4 ; \mathrm{PNW} / \mathrm{PNH}=2.2$; without defined posterior angles, slightly emarginate posteromedially; surface with punctation similar to head (fig. 158). Elytra broad, but longer than wide, moderately dorsoventrally flattened; dorsal surface with 


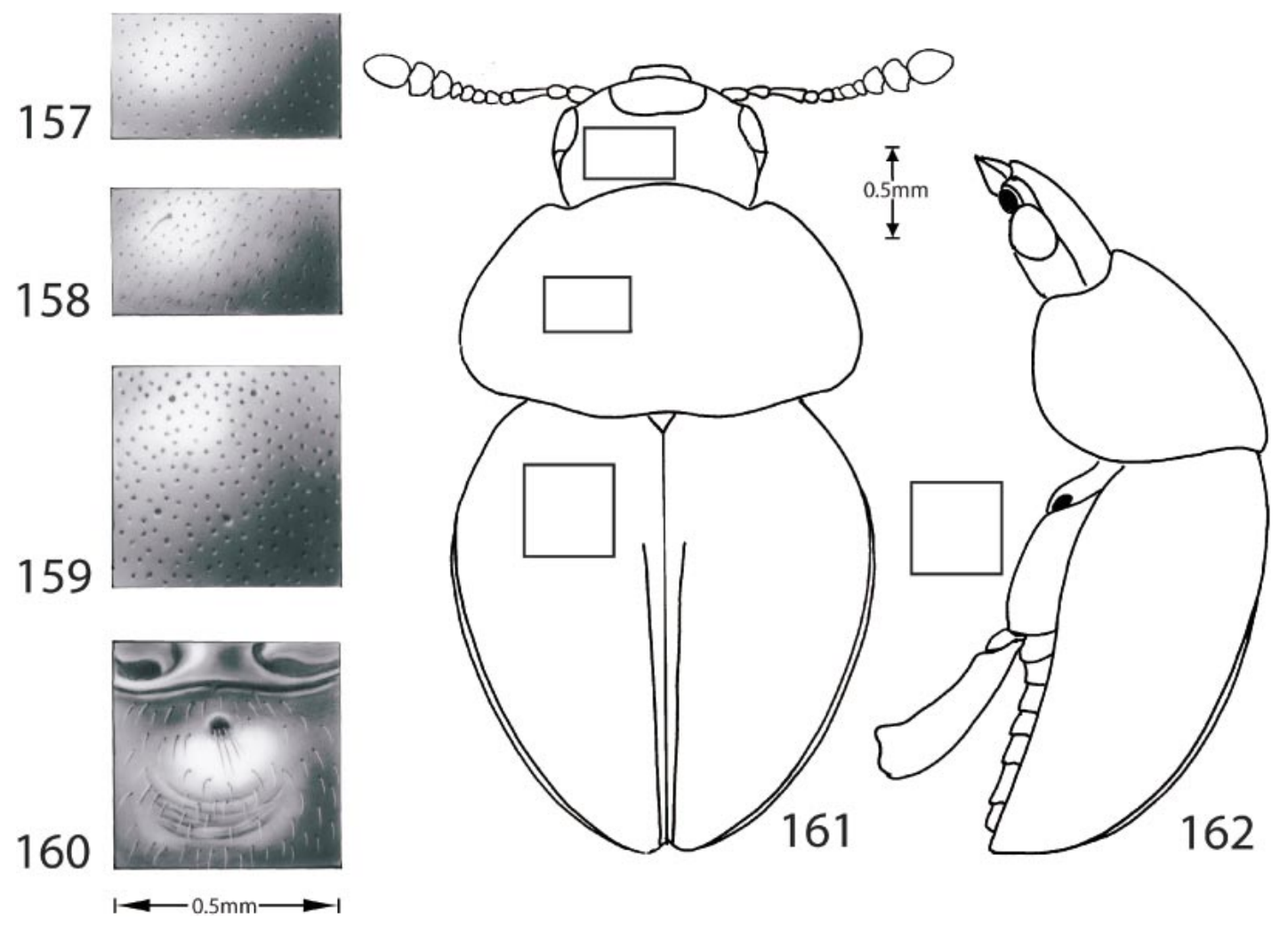

Figs. 157-162. Agathidium conjunctum Brown: Figs. 157-159, punctation detail: 157, head; 158, pronotum; 159, elytron. 160. M male metasternal fovea. Figs. 161, 162, habitus: 161, dorsal; 162, lateral. Bars $=0.5 \mathrm{~mm}$.

dense, irregular punctures only slightly larger than those of head and pronotum (fig. 159), surface between as on head and pronotum, including subalutaceous microscopic pattern; sutural stria present, strongly impressed, complete. Mesosternum horizontal, with median carina; surface densely alutaceous. Metasternum surface alutaceous, pattern dense laterally. MSL/MTL $=0.7$; $\mathrm{MTL} / \mathrm{MTW}=$ 0.4 .

Male tarsi 5-5-4; with pro- and mesobasotarsomeres moderately expanded; left mandible unmodified; metasternal fovea small, round, with fine setae, in smooth impunctate area anteromedially (fig. 160); metafemur gradually widened into blunt, subapical, posterior tooth defined on apical side only. Aedeagus long, narrow, curved, apical one-fifth abruptly narrowed, ventrally curved but arched slightly dorsally (fig. 163); median lobe narrowed, distinctly spatulate near apex, apex pointed, with ducts obliquely fanning to each side of midline (figs. 164, 165); ventral operculum deeply emarginate, each branch long, parallel-sided, and truncate, pores sparse and irregular except moderately dense in apical transverse line (fig. 165); lateral lobes nearly as long as median lobe, enlarged in apical fifth in ventral aspect, with two large subapical setae (figs. 163, 164).

Female not observed.

DISTRIBUTION: This species was recorded by Fall (1934) from British Columbia, Washington, "W.T." (Washington Territory?), and Nevada. In this study, numerous specimens were examined from southern British Columbia south to extreme southwestern California and east to southwestern Montana (fig. 102).

SPecimens Examined: "W.T." [probably Washington Territory] (2, MCZC). 

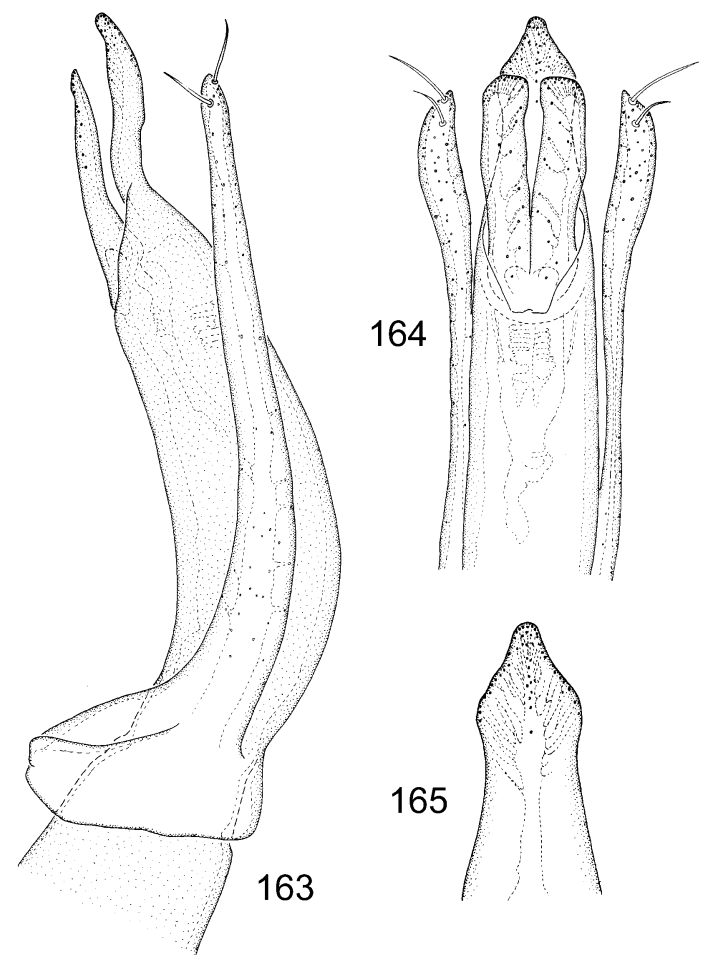

Figs. 163-165. Agathidium conjunctum Brown, aedeagus: 163, lateral; 164, ventral; 165, apex of median lobe, ventral.

CANADA: British Columbia: Trinity Valley, 14 May 1929, JR Howell (1, CASC); Midday Valley, Merritt, 14 May 1925, J Stanley (1, CASC); Lorna, 10 Jul 1925, Pinus contorta, H Richmond (1, MCZC); Trinity Valley, 1 Jun 1928 (1, CASC).

UNITED STATES: California: Calistoga, 12 Jul 1934, Bryant (1, CASC); Poway, FC Bowdin (1, MCZC); Butte Co.: Feather Falls, 16 May 1971, DS Chandler (1, CASC); Feather Falls, 16 Feb 1971, RF Lagler (1, WSUC); Feather Falls, 16 May 1971, DS Chandler (1, QDWC); El Dorado Co.: $3 \mathrm{mi} \mathrm{W}$ Grizzly flat, 24 Mar 1982, on polypore slimemold under oak bark, F Andrews (5, FGAC); 2 mi NE Riverton, 30 Nov 1976, under bark of Pinus, F Andrews (1, FGAC); $0.5 \mathrm{mi}$ N Stumpy Meadows Lake, 20 Apr 1989, 4200', litter from Quercus kellogi, F Andrews, T Eichlin (6, FGAC); 1 mi W Grizzly Flat, 24 Mar 1982, under oak bark, F Andrews (10, FGAC); Lake Co.: Adams Springs, 24 Apr 1976, under bark, JF Lawrence (3, MCZC); Marin Co.: 2 mi N Taverness, 23 Mar 1965, WJ Turner (1, WSUC); Pt Reyes Natl Seashore, Mt Vinson overlook, 29 Nov 1977, F Andrews (2, FGAC); Mendocino Co.: UC Hopland Field Station nr HQ, 13 Apr
1968, malaise, WJ Turner (2, WSUC); Nevada Co.: Sagehen Crk, 15 Jul 1970, DS Chandler (1, CASC); Sagehen Crk, 24 Jun 1970, DS Chandler (1, CASC); Sierra Co.: 9 mi W Alleghany, 4 Apr 1985, under logs, Pinus sabiniana, F Andrews, A Hardy (2, FGAC); Trinity Co.: 5 mi W Coffee Crk Ranch, 19 Jun 1972, pine duff, DS Chandler, DP Levin (1, CUIC); Yuba Co.: Sierra Foothill Field Station 3 mi N Smartville, 3 May 1980, Quercus litter, JT Doyen (9, CASC). Idaho: Latah Co.: Moscow Mt, 28 Apr 1973, WJ Turner (2, WSUC). Montana: Gallatin Co.: Bozeman Crk (1, MTEC). Nevada: state only (1, MCZC). Oregon: state only (1, MCZC); Jackson Co.: Soda Mt Rd, 7 mi S 13 mi E Ashland, 15 Oct 1972, under willow bark, E Benedict (1, PECK); Umatilla Co.: $25 \mathrm{~km} \mathrm{E}$ Ukiah, Frazier Camp, 25 Aug 1982, M Sorenson (1, LUND); Wallowa Co.: Wallow Pk St Prk, 8 Jun 1921, under bark, D Ferro (1, WSUC). Washington: Seattle, OB Johnson (1, WSUC); Seattle, 4 May 1912 (2, MCZC); Chelan Co.: Squillchuck St Pk, 8 mi SSW Wenachee, 14 May 1983, 2900', WJ Turner (7, WSUC); Columbia Co.: Tucannon Riv. 22 mi S Mareugo Umatilla NF, 18 May 1974, under bark of Pinus ponderosa, WJ Turner (2, WSUC); Whitman Co.: 8 mi SW Pullman, Lyle Grove, 14 Apr 1974, JA Logan (1, WSUC).

Discussion: Agathidium obtusum Hatch is synonymized here with this species based on Hatch's (1957) description and illustration of the ventral view of the aedeagus. His specimens appear to fit well within the range of variation observed for $A$. conjunctum. Hatch's (1957: pl. IV, fig. 20) concept of $A$. conjunctum appears to actually refer to $A$. omissum based on the key and his illustration of the male genitalia.

Agathidium conjunctum has been collected frequently under bark of various trees, including pine and oak. It has also been collected from various litter types, including oak leaf litter and pine duff. Elevation records are from 2900 to $4200 \mathrm{ft}$.

Agathidium angustoperculum Wheeler and Miller, new species

Figures 103, 166-168

Type Material: Holotype, of in AMNH (from California Department of Food and Agriculture collection) labeled "Sveadal Santa Clara Co., Calif IV-27-1968 [date handwritten]/ A. \& A. Gillogly collectors/ Agathidium angustoperculum Wheeler det. Q.D.Wheeler "95/ HOLOTYPE Agathidium 

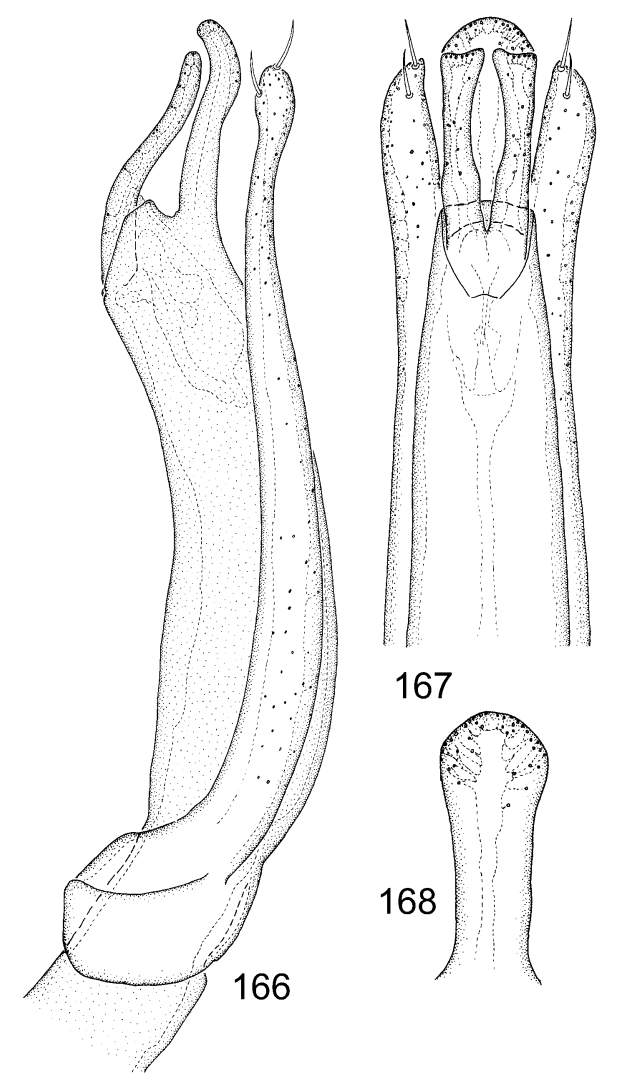

167

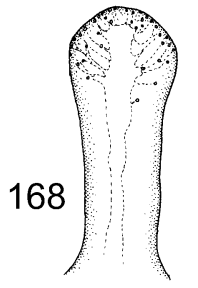

Figs. 166-168. Agathidium angustoperculum, n.sp., aedeagus: 166, lateral; 167, ventral; 168, apex of median lobe, ventral.

angustoperculum Wheeler and Miller, 2002 [red label with black line border]".

TyPe Locality: United States, California, Santa Clara Co., Sveadal.

DiAGNOSIS: Agathidium angustoperculum closely resembles $A$. virile and $A$. conjunctum from which it may be distinguished by the following combination of characters: pronotal punctures coarse, only infrequently as coarse as in $A$. virile; male metasternal fovea small, transversely oval, anteromedial; male metafemoral tooth protruding, pointed; apex of median lobe of aedeagus spatulate (figs. 167, 168); and rami of ventral operculum long, narrow, expanded and truncate at apex (fig. 167).

DESCRIPTION: Body broadly elongate oval, partially contractile, moderately convex; $\mathrm{TBL}=3.0 \mathrm{~mm}$. Color dark reddish-brown, nearly black, antennal stem reddish-brown, club darker, legs somewhat paler.

Head large, broad, subquadrate in shape; head narrowed behind eye, temporum short (about three-fifths length eye), defined only by supraocular carina extending from posterior end of temporum to frontoclypeal suture; $\mathrm{OHW} / \mathrm{MDL}=1.6 ; \mathrm{OHW} / \mathrm{PHW}=$ about 1.0 ; dorsal surface with irregularly distributed, weakly impressed, small setigerous punctures; surface between with very sparse, microscopic, irregularly distributed, nearly invisible punctules; eye large; frontoclypeal suture very finely impressed, clypeal region made distinct by subcuticular darkened lines; surface of clypeus as on frons; without larger setae at posterolateral corners of clypeal region; labrum small, transverse, very shallowly emarginate medially; antennomere III about as long as IV $+\mathrm{V}+\mathrm{VI}$; length II:III $=1: 1.8$; VII very slightly wider than VIII, nearly equal in size; width VII:VIII:IX $=1$ : 1:1.8. Pronotum broad, convex; PNW/PNL $=1.7 ; \mathrm{PNL} / \mathrm{PNH}=1.2 ; \mathrm{PNW} / \mathrm{PNH}=2.2$; punctation similar to that of head, a little more faintly impressed. Elytra very wide; length about equal to combined width; only slightly attenuate at apex; humeri not angulate, broadly obtuse; punctures much larger than those of head and pronotum, more coarsely impressed, irregularly distributed and moderately dense; distance between punctures about 0.5-1.5 diameter of single puncture; surface between smooth, shiny, with microscopic, nearly invisible and very sparse micropunctules and random faint curving lines. Mesosternum divided into anterior and posterior parts; anterior part with median longitudinal carina and fine alutaceous sculpturing; with oblique carinae and lateral, longitudinal carinae. Metasternum finely alutaceous, with laterally curved, concentric, rugose ridges, surface covered by fine setae. $\mathrm{MSL} / \mathrm{MTL}=0.7 ; \mathrm{MTL} / \mathrm{MTW}=$ 0.4 .

Male tarsi 5-5-4; with pro- and mesobasotarsomeres moderately expanded beneath; left mandible not modified; metafemur with conspicuous, subapical tooth, broad with small median protruding point; metasternal fovea in large transverse anteromedial oval depression, with long fine setae clumped in two tufts. Aedeagus with median lobe elon- 
gate, robust, ventrally curved, recurved dorsally subapically, apical one-fifth dorsoventrally compressed and laterally narrowed before apex (fig. 168); apex of median lobe spatulate, with fanlike arrangement of ducts apically around margin (figs. 167, 168); operculum deeply bisected into long, narrow pieces, each expanded and truncate apically, with row of apical pores (fig. 168); lateral lobes long, gradually narrowed before apex which is enlarged, bulbous in lateral view, bluntly rounded in ventral view, with pair of subapical setae, with irregularly distributed pores (figs. 166, 167); endophallic armature not extensive.

Female 5-4-4.

ETYMOLOGY: This species is named from the Latin angustus, "narrow", and operculum, "lid", in reference to the paired, elongate, narrow ventral opercula of the median lobe of the male genitalia.

DisTRIBUTION: This species is found from south-central California north to southern British Columbia (fig. 103).

PARATYPES: CANADA: British Columbia: nr Mabel Lake, Squaw Valley, 4 Aug 1982, M Sorenson (1, LUND); $20 \mathrm{mi}$ NE Creston, 16 Aug 1958, M Sorenson (1, LUND).

UNITED STATES: California: state only (1, AMNH); Berkeley, 4 Mar 1915, EP van Dyke (2, CASC); Berkeley, 13 Apr 1961, J Lawrence (1, MCZC); Santa Cruz, Jun 1896 (1, MCZC); Alameda Co.: Laundry Farm, 25 Apr 1907, FE Blaisdell (1, CASC); Amador Co.: $1 \mathrm{mi}$ W Pine Grove, 24 Jun 1975, mixed hardwood conifer forest, A Newton, M Thayer (2, MCZC); Calaveras Co.: 3 mi NW West Point, 20 May 1976, 2250', leaf litter, mixed hardwood conifer forest, A Newton, M Thayer (2, MCZC); El Dorado Co.: $1 \mathrm{mi} \mathrm{W}$ Grizzly Flat, 24 Mar 1982, oak duff, F Andrews (1, FGAC); Marin Co.: $3.1 \mathrm{mi}$ NW Inverness, 8 May 1976, 200', berlese, litter, old flood debri Alnus forest, A Newton, M Thayer (2, MCZC); Taylorville (1, MCZC); Taylorville, 28 Dec 1919, JO Martin (1, CASC); Tocaloma, 18 May 1952, tree litter, HS Dybas (1, FMNH); Samuel P. Taylor State Park, 31 Mar 1976, F Andrews (1, FGAC); Nevada Co.: $4 \mathrm{mi}$ S Rough and Ready, 5 May 1980, Quercus kellogi litter, JT Doyen (5, CASC); Wolf Mt 5 mi SW Grass Valley, 6 May 1980, Quercus kellogi litter, JT Doyen (27, CASC); Sacramento Co.: Sacramento, 1 Feb 1971, F Andrews (1, FGAC); San Luis Obispo Co.: Creston, $2.5 \mathrm{mi}$ S, 10 Apr 1961, on Polyporus anceps, J Lawrence (1, MCZC); Santa Barbara Co.: Refugio Canyon
8 mi E Gaviota, 7 May 1952, HS Dybas (2, CASC); Sonoma Co.: 9 Dec 1910, EP van Dyke (1, CASC); 24 Feb 1911, Van Dyke (1, CASC); Tulare Co.: $10 \mathrm{mi}$ SE Three Rivers, S Fk Kaweah R., 3 May 1979, dead Pseudostuga, JT Doyen (2, CASC); Yuba Co.: Sierra Foothill Field Sta, 6 mi N Smartville, 4 May 1980, 1500', JA Powell (1, CASC); Willow Glen Creek 5 mi SW Brownsville, 6 May 1980, on Polyporus sulfureus, JT Doyen (1, CASC). Oregon: Douglas Co.: $5.5 \mathrm{mi}$ NE Idlewild Pk. Rock Crk Rd, 1 Apr 1972, 1200', chinkapin duff, E Benedict (1, PECK).

Discussion: This species has been collected from a variety of litter types including chinkapin, oak, pine, and fir. Elevation records are from 200 to $2250 \mathrm{ft}$. Host records include Polyporus anceps and P. sulfureus.

Agathidium falcatoperculum Wheeler and Miller, new species

Figures 100, 169-177

Type Material: Holotype, $\widehat{\sigma}$ in FMNH labeled "WASH:Jefferson Co Olympic NP, 0-3.4 mi SW Hoh 400-500' VII.16.1975 A.Newton, M.Thayer/ leaf litter mixed hardwood-conifer forest/ HOLOTYPE Agathidium falcatoperculum Wheeler and Miller, 2002 [red label with black line border]".

TyPE Locality: United States, Washington, Jefferson Co., Olympic National Park, $3.4 \mathrm{mi} \mathrm{SW}$ Hoh.

DiAgnOSIS: This species very closely resembles $A$. virile and $A$. angustoperculum, from which it may be distinguished by the curved, convergent, and sometimes apically overlapping rami of the ventral operculum of the median lobe (fig. 177).

DESCRIPTION: Body very broadly elongate oval, partially contractile, moderately convex (figs. 173, 174); TBL = 3.0-3.1 mm. Color of head, pronotum, and elytra red; ventral surface red; mouthparts and appendages reddish-brown; antenna uniformly reddishbrown; legs reddish-brown.

Head large, broad, subquadrate in shape, narrowed behind eye, temporum short (figs. $173,174)$ (about three-fifths length of eye), present only as supraocular carina extending from posterior end of temporum to frontoclypeal suture; OHW/MDL $=1.5 ; \mathrm{OHW} /$ $\mathrm{PHW}=1.0$; dorsal surface with sparse, irregularly distributed, weakly impressed, small setigerous punctures, surface between 

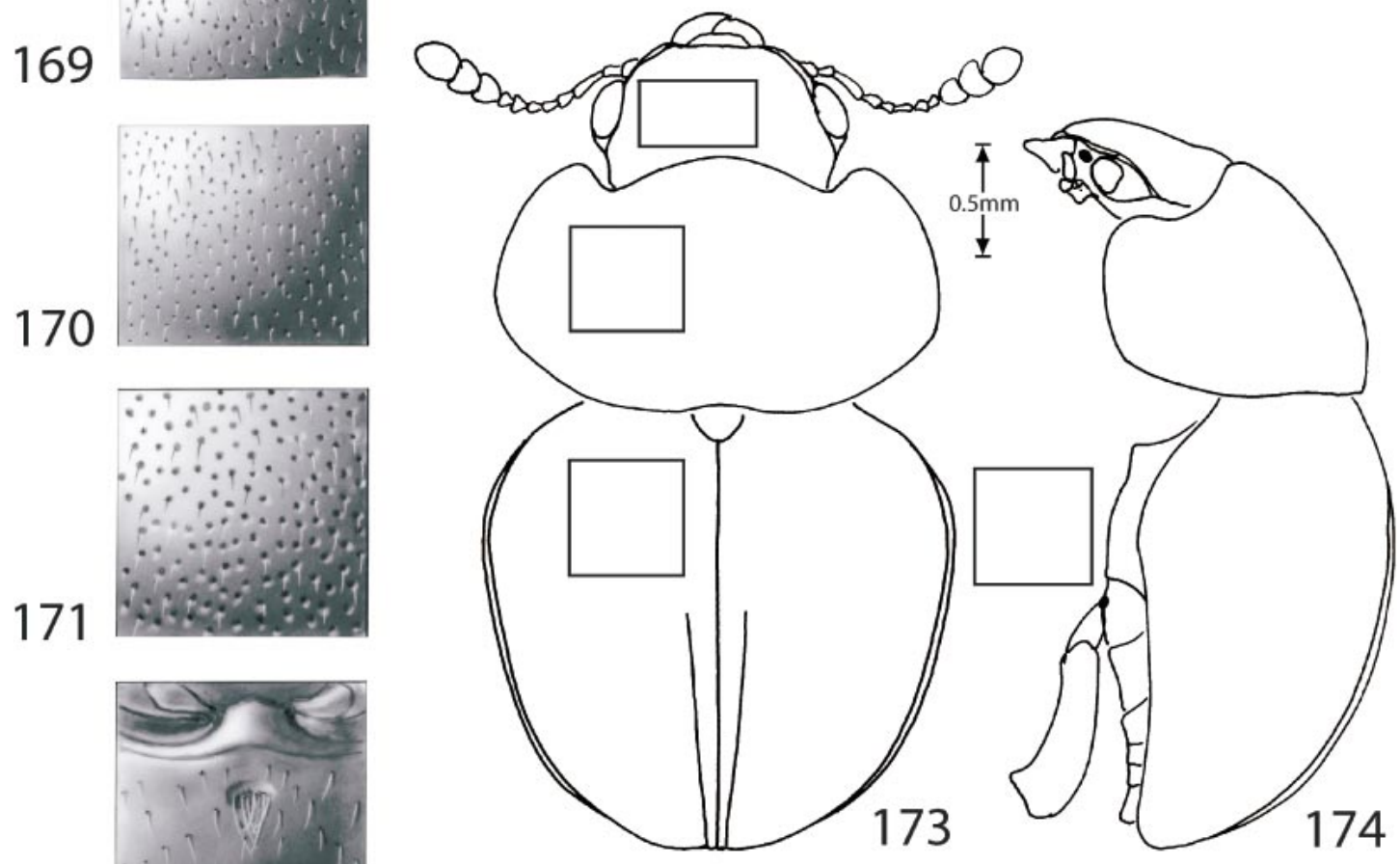

172

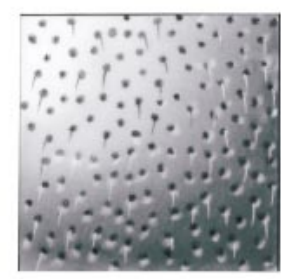

171

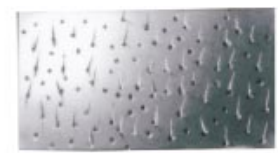

(a) 


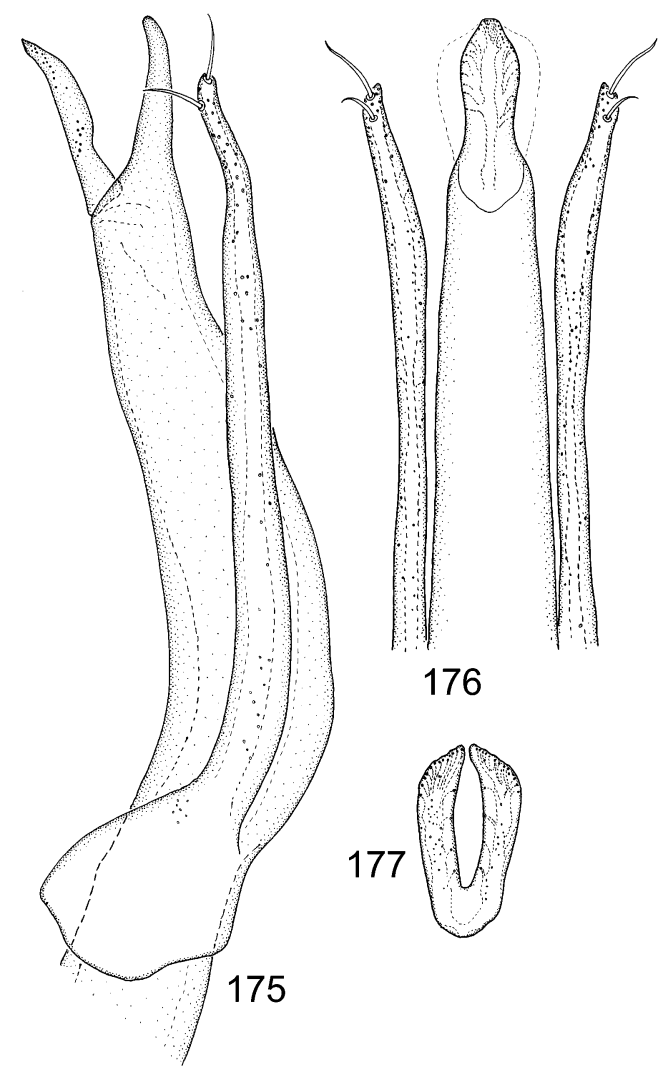

Figs. 175-177. Agathidium falcatoperculum, n.sp., aedeagus: 175, lateral; 176, ventral; 177, operculum.

transverse, with long fine setae (fig. 172). Aedeagus with median lobe elongate, robust, ventrally curved, in lateral view slightly recurved dorsally subapically, apical $1 / 5$ dorsoventrally compressed and laterally narrowed before apex (fig. 176); in ventral view apex of median lobe narrowed, more-or-less arrowhead-shaped, with fanlike arrangement of ducts apically (fig. 176); operculum deeply bisected into pieces, each elongate, broad, with medial margin concave, curved, apex pointed and directed medially (fig. 177); lateral lobes long, gradually narrowed before apex that is slightly expanded subapically in ventral view, with pair of subapical setae and irregularly distributed pores (figs. 175, 176); endophallic armature not extensive.

Female tarsi 5-4-4.

ETYMOLOGY: This species is named from the words falcatus, Latin for "curved", and operculum Latin for "lid", signifying the curved condition of the rami of the operculum of the median lobe.

Distribution: This species is distributed in the Pacific Northwest (fig. 100).

PARATYPES UNITED STATES: California: Fresno Co.: Sierra NF Tamarack Ridge, $34 \mathrm{~m} \mathrm{SE}$ Cal. 168, 16 May 1976, under conifer bark, A Newton, M Thayer (1, FMNH); Mendocino Co.: MacKerricher State Park, 1 Dec 1978, FG Andrews (1, CASC). Washington: Pierce Co.: Mt Rainier NP 4.7 mi W Longmire, 20 Jul 1975, 2200 ', A Newton, M Thayer (1, MCZC).

DisCUSSION: This species has been collected from mixed hardwood-conifer leaf litter and from under bark. Elevation records are from 400 to $2200 \mathrm{ft}$.

\section{CHECKLIST OF AGATHIDIUM SPECIES: PART 1}

\section{Agathidium sexstriatum species group}
A. bistriatum Horn, 1880
A. sexstriatum Horn, 1880
A. estriatum Horn, 1880

\section{Agathidium brevisternum species group}

A. brevisternum Fall, 1934

A. rhinocerellum Wheeler and Miller, new species

A. dioperculum Wheeler and Miller, new species

\section{Agathidium revolvens species group}

A. revolvens LeConte, 1850

A. jasperanum Fall, 1934

A. depressum Fall, 1934

A. dubitans Fall, 1934

A. dubitanoides Wheeler and Miller, new species

A. omissum Fall, 1934

A. cavisternum Fall, 1934

A. virile Fall, 1934

$=$ A. hebetatum Hatch, 1957, new synonym

A. conjunctum Brown, 1933

$=$ A. obtusum Hatch, 1957, new synonym

A. angustoperculum Wheeler and Miller, new species

A. falcatoperculum Wheeler and Miller, new species

\section{ACKNOWLEDGMENTS}

This study has profited from the advice, counsel, and encouragement of many colleagues, only some of which are singled out for acknowledgment here. To those who have contributed to the project in one or more ways and who are inadvertently omitted go 
thanks and apologies. The senior author thanks C.A. Triplehorn (The Ohio State University), his advisor, mentor, and friend, for taking an aspiring undergraduate coleopterist on an expedition to Mexico that forged a commitment to the study of beetles (including Leiodidae), systematics, and biological diversity. L.E. Watrous accompanied him on several early collecting trips that were instrumental in elucidating the complex of flightless species of the Appalachians, and was a constant source of inspiration, sound advice, and stimulating theoretical arguments. K.C. Nixon (L. H. Bailey Hortorium, Cornell University) collaborated in the development of the phylogenetic species concept used here, is an eternal fountainhead of innovation and insights, and has made several versions of his programs ClaDOS, Dada, MDP, and WinClada available. The following students, friends, colleagues, wife, and children assisted on one or more collecting trips: B. Lindsay, J.V. McHugh, J. Pakaluk, D. Peters, K.A. Wheeler, K.J. Wheeler, and M.A. Wheeler.

Without the generous lending of material from collections listed in the appendix this work would have not been possible. Curators enumerated therein are heartily thanked. Long-term loans by the Canadian National Collection, Field Museum of Natural History, and Museum of Comparative Zoology were especially valuable.

This research was supported by grants from the U.S. National Science Foundation (BSR-8315457, BSR-8717401), the Highlands Biological Research Station Foundation, the American Philosophical Society, and the College of Agriculture and Life Sciences in Cornell University, especially Hatch Project NY(C)139426 to the senior author.

Two individuals who completed an incredible amount of quality work, including dissections of specimens, library research, specimen measurement, working with databases, editing materials, and such, deserve special thanks: P.R. Fraissinet and J.V. McHugh. McHugh also provided a very useful and careful review of an earlier version of the manuscript. D.A. Grimaldi, while a graduate student at Cornell, developed strategies for measuring Agathidium. The late B. Alexander, also while a grad student, completed the frontispiece illustrations. Many individuals, particularly student assistants, have made important contributions to the database MYCOL over the past decades. Last, but foremost, F. Fawcett deserves considerable thanks for her superb scientific illustrations that combine artistic beauty with scientific precision and communicate as much or more than is possible through the text. Her contributions to this project are incalculable in quality and quantity.

\section{REFERENCES}

Allen, A.A. 1954. Rhynchites cupreus L. (Col., Attelabidae) etc., in West Sussex. Entomologists Monthly Magazine 90: 87.

Ammann, J., and H. Knabl. 1922. Die Käferfauna des nordwestlichen Tirol. Entomologische Blaetter fuer Biologie und Systematik der Kaefer 18: 28-36, 49-64, 97-112, 145-160.

Angelini, F. 1984. Reports of Agathidiini from Mongolia (Coleoptera, Leiodidae). Folia Entomologica Hungarica 45: 9-13.

Angelini, F. 1986. XXX contributo allo studio degli Anisotomini. Note sinonimiche (Coleoptera: Leiodidae). Bollettino della Società Entomologica Italiana 118: 147-160.

Angelini, F. 1988. Gli Anisotomini del Museo Civico di Storia Naturale di Milano (Coleoptera, Leiodidae). Atti della Societa Italiana di Scienze Naturali e del Museo Civico di Storia Naturale in Milano 129: 305-366.

Angelini, F. 1990. Anisotomini from Caucasus (Coleoptera, Leiodidae). Annales Historico-Naturales Musei Nationalis Hungarici 82: 91-122.

Angelini, F. 1993. Studi sugli Agathidium. Designazione di un nuovo genere, un nuovo sottogenere e gruppi di specie (Coletopera Leiodidae). Bollettino della Società Entomologica Italiana 125: 29-44.

Angelini, F. 1995. Revisione tassonomica delle specie paleartiche del genere Agathidium Panzer (Coleoptera: Leiodidae: Agathidiini). $\mathrm{Mu}-$ seo Regionale di Scienze Naturali Monografie (Turin) 18: 1-485.

Angelini, F., and L. de Marzo. 1980. Utilita di nuovi caratteri nella sistematica del genere Agathidium Panzer (Coleoptera, Leiodidae) e loro impiego nella designazione di due sinonimi. Entomologica (Bari) 16: 47-76.

Angelini, F., and L. de Marzo. 1983. Anisotomini nuovi o poco conosciuti reperti in Nepal e Kashmir dal Prof. H. Franz (Coleopter, Leiodidae). Entomologica (Bari) 18: 5-16.

Angelini, F., and L. de Marzo. 1984. Note sistematiche sugli Agathidium dell'Africa centrale 
con descrizione di tre specie nuove (Coleoptera, Leiodidae). Fragmenta Entomologica Roma 17: 347-358.

Angelini, F., and L. De Marzo. 1986. Agathidium from India and Malaya: expeditions of Geneva Natural History Museum (Coleoptera, Leiodidae, Anisotomini). Revue Suisse de Zoologie 93: 423-455.

Angelini, F., and L. de Marzo. 1987a. Agathidium and Afroagathidium dell'Africa centrale (Coleoptera, Leiodidae, Anisotomini). Entomologica (Bari) 20: 69-80.

Angelini, F., and L. de Marzo. 1987b. Notes on the genus Stetholiodes Fall with descriptions of four new species (Coleoptera, Leiodidae, Anisotomini). Revue Suisse de Zoologie 94: 3-15.

Angelini, F., and L. de Marzo. 1988. Anisotomini del Mediterraneo orientale e Iran con descrizione di una nuova specie (Coleoptera, Leiodidae). Revue Suisse de Zoologie 95: 277-288.

Angelini, F., and L. de Marzo. 1990. Anisotomini del Giappone (Coleoptera, Leiodidae). Entomologica (Bari) 23: 47-122.

Angelini, F., and L. de Marzo. 1995. Agathidiini from Taiwan collected by Ales Smetana (Coleoptera, Leiodidae, Agathidiini). Revue Suisse de Zoologie 102: 175-255.

Angelini, F., and S. Peck. 2000. Besuchetionella, new genus, with descriptions of 18 new species from Asia (Coleoptera: Leiodidae: Agathidiini). Zoological Studies 39: 328-343.

Angus, R.B. 1965. Further notes on northern Scottish Coleoptera. Entomologists Monthly Magazine 101: 9-12.

Anonymous. 1889. Chasse dans les champignons qui croissent sur les arbres, piege a truffes. Feuille des Jeunes Naturalistes 20: 9-10.

Arnett, R.H. 1971. The beetles of the United States. Ann Arbor, MI: American Entomological Institute. 1112 pp.

Ashe, J., and L. Watrous. 1984. Larval chaetotaxy of Aleocharinae (Staphylinidae) based on a description of Atheta coriaria Kraatz. Fieldiana Zoology 51: 165-179.

Bagnall, R.S. 1905. Notes on further additions, etc., to the Coleoptera of the Northumberland and Durham district. Entomologist's Record and Journal of Variation 17: 331-333.

Barner, K. 1922. Beitrage zur Käferfauna des westfälisch-lippischen Weserberglandes. Bericht Naturwiss. Vereins Bielefeld Umgegend 4: 266-283.

Barthe, E. 1920-1923. Tableaux analytiques des Coléoptères de la faune franco-thënane. Fam. XIV. Liodidae. Miscellanea Entomologica 2526: 83-108.

Beare, T.H. 1899. Coleoptera at Boat of Garten,
Strathsprey, Inverness-shire. Entomologists Monthly Magazine 35: 267-268.

Benick, L. 1952. Pilzkäfer und Käferpilze. Ökologische und statistische Untersuchungen. Acta Zoologica Fennica 70: 1-250.

Bennett, W.H. 1893. Coleoptera at Fairlight during 1892. Entomologists Monthly Magazine 29: 19.

Bennett, W.H. 1899. Coleoptera in the New Forest. Entomologist's Record and Journal of Variation 11: 46.

Blackwelder, R. 1944. Checklist of the Coleopterous insects of Mexico, Central America, the West Indies, and South America. Bulletin of the United States National Museum 185: 1-188.

Blackwell, M. 1984. Myxomycetes and their arthropod associates. In Q.D. Wheeler and M. Blackwell (editors), Fungus-insect relationships. Perspectives in ecology and evolution: 67-90.New York: Columbia University Press.

Blatchley, W.S. 1910. An illustrated descriptive catalogue of the Coleoptera or beetles (exclusive of the Rhyncophora) known to occur in Indiana. Indianapolis: Nature Publishing, 1386 pp.

Brisout de Barneville, C. 1872. Essai monographique du genre Agathidium Illig. Annales de la Société Entomologique de France 2: 169-198.

Brown, W.J. 1928. New Silphidae and Melyridae in the Canadian National Collection. Canadian Entomologist 60: 141-148.

Brown, W.J. 1930. New species of Coleoptera I. Canadian Entomologist 62: 87-92.

Brown, W.J. 1933. New species of Coleoptera IV. Canadian Entomologist 65: 43-47.

Brundin, L. 1934. Die Coleopteren des Torneträskgebietes: Ein Beitrag zur Ökologie und Geschichte der Käferwelt in Schwedisch-Lappland. Lund: Carl Bloms Boktryckeri, 436 pp.

Calwer, C.G. 1916. Käferbuch, Einführung in die Kenntniss der Käfer Europas. Stuttgart: E. Schweizerbart'sche Verlagsbuchhandlung, 722 pp.

Champion, G.C. 1907. Eumicrus nufus Muell., \&c., near Guilford. Entomologists Monthly Magazine 43: 233.

Cooper, K.W. 1935. A supplement to the section of the New York State list of insects devoted to Coleoptera. Additions, notes and corrections. Bulletin of the Brooklyn Entomological Society 30: 142-159.

Cooter, J. 1978. A notable congregation of beetles. Entomologists Monthly Magazine 114: 7.

Cox, H.E. 1874. A handbook of the Coleoptera or beetles of Great Britain and Ireland. London: Janson.

Cracraft, J. 1983. Species concepts and speciation analysis. Current Ornithology 1: 159-187.

Cracraft, J. 1992. The species of the birds-of-paradise (Paradisaeidae): applying the phylogenet- 
ic species concept to a complex pattern of diversification. Cladistics 8: 1-43.

Cronquist, A. 1978. Once again, what is a species? In J.A. Romberger (editor), Biosystematics in agriculture: 3-20. Montclair, NJ: Allanheld and Osmun.

Crowson, R. 1955. The natural classification of the families of Coleoptera. London: Nathaniel Lloyd, $187 \mathrm{pp}$.

Dajoz, R. 1966. Ecologie et biologie des Coléoptères xylophages de la Hetraie. Vie et Milieu C: $525-763$.

de Queiroz, K., and M.J. Donoghue. 1988. Phylogenetic systematics and the species problem. Cladistics 4: 317-338.

Derksen, W. 1941. Die Succession der pterygoten Insekten im abgestorbenen Buchenholz. Zeitschrift für Morphologie der Tiere 37: 683-734.

des Gozis, M. 1886. Recherche de l'espèce typique de quelques anciens genres. Rectifications synonymiques et notes diverses. Herbin: Montluçon, 36 pp.

Donisthorpe, H.S.J.K. 1911. Coleoptera in the highlands in June, 1911. Entomologist's Record and Journal of Variation 23: 309-311.

Donisthorpe, H.S.J.K. 1929. Agathidium reitteri Ganglb., a species of Coleoptera new to the British Isles. Entomologists Monthly Magazine 65: 82-83.

Donisthorpe, H.S.J.K. 1935. The British fungicolous Coleoptera. Entomologists Monthly Magazine $71: 21-31$.

Donisthorpe, H.S.J.K. 1939. Preliminary list of the Coleoptera of Windsor Forest. London: Nathaniel, $126 \mathrm{pp}$.

Donoghue, M.J. 1985. A critique of the biological species concept and recommendations for a phylogenetic alternative. Bryologist 88: 172-181.

Eisfelder, I. 1963. Kaefer als Pilzbewohner. Zeitschrift für Pilzkunde 29: 77-97.

Eldredge, N., and J. Cracraft. 1980. Phylogenetic patterns and the evolutionary process. New York: Columbia University Press, 349 pp.

Erichson, W.F. 1845. Naturgeschichte der Inseckten Deutschlands. Abt. 1. Coleoptera. 3: 1-320.

Everts, E. 1899. Coleoptera Neerlandica. De schildveugelige Insecten van Nederland en het aangrenzend Geied. Gravenhage 1: 369-677.

Fabricius, J.C. 1792. Entomologia Systematica. Volume 1 (part 1). Hafniae, 330 pp.

Fairmaire, L., and A. Laboulbené. 1854. Faune entomologique française ou description des insectes qui se trouvent en France. Coléoptères. Paris, 180 pp.

Fall, H.C. 1901. List of the Coleoptera of southern California, with notes on habits and distribution of new species. Occasional Papers of the California Academy of Sciences 8: 1-282.
Fall, H.C. 1910. New Silphidae of the tribe Anisotomini. Canadian Entomologist 42: 4-8.

Fall, H.C. 1934. A review of the North American species of Agathidium. Entomologica Americana 14: 99-131.

Faustini, D.L. 1980. Characterization of an aggregation pheromone and its site of production in Tribolium castaneum (Herbst) (Coleoptera: Tenebrionidae) with comparative notes on analagous structures in other Coleoptera families. Dissertation abstracts international. B. Sciences and engineering 41: 60 .

Faustini, D.L., W.E. Burkholder, and R.J. Laub. 1981. Sexually dimorphic setiferous sex patch in the male red flour beetle Tribolium castaneum (Herbst). (Coleoptera: Tenebrionidae): site of aggregation pheromone production. Journal of Chemical Ecology 7: 465-480.

Fleischer, A. 1910. Zur Kenntnis der Coleopterenfauna von Maehren. Wiener Entomologische Zeitung 29: 328-330.

Fowler, W.W. 1889. The Coleoptera of the British Islands. Vol. III. Clavicornia. London: L. Reeve, 399 pp.

Franz, H. 1943. Die Landtierwelt der mittleren Hohen Tauern. Eien Beitrag zur tiergeographischen und soziologischen Erforschung der Alpen. Denkschriften der kaiserlichen Akademie der Wissenschaften. Mathematisch-naturwissenschaftliche Klasse. Wien. 107: 1-552.

Ganglbauer, L. 1899. Die Käfer von Mitteleuropa. Wien: Druck und Verlag von Carl Gerold's Sohn, 1046 pp.

Gerhardt, J. 1890. Sammelbericht pro 1889. Deutsche Entomologische Zeitschrift 1890: 200-203.

Gerhardt, J. 1910. Verzeichnis der Käfer Schlesiens Preussischen und Österreichischen Anteils, Geordnet nach dem Catalogus coleopterorum Europae vom Jahre. Berlin: Verlag J. Springer, $431 \mathrm{pp}$.

Gusmann, P. 1914. Beitrage zur Käferfauna der Untertrave und ihrer Umgebung, ein Nachtrag zu dem Verzeichnis der in der Umgebung von Hamburg gefunden Käfer von W. Koltze. Verhandlungen Vereins für Naturwissenschaften Unterhaltung Hamburg 15: 85-193.

Gusmann, P. 1925. Dritter Beitrag zur Käferfauna der Untertrave und ihrer Umgebung. Entomologische Blaetter fuer Biologie und Systematik der Kaefer 21: 1-9, 49-58.

Hamilton, J. 1895. Catalogue of the Coleoptera of southwestern Pennsylvania, with notes and descriptions. Transactions of the American Entomological Society 22: 317-381.

Hansen, V. 1922a. Biller V. Danmarks Fauna. 26: $1-228$.

Hansen, V. 1922b. Nye og sjaeldne danske Biller. Entomologiske meddelelser 23: 23-24. 
Harwood, P. 1925. Coleoptera in Inverness-shire. Entomologists Monthly Magazine 61: 14-15.

Hatch, M.H. 1929a. Coleopterorum Catalogus. Leiodidae, Clambidae. Berlin, W. Junk 105: 1100.

Hatch, M.H. 1929b. The genera and subgenera of Leiodidae and Clambidae. Journal of the New York Entomological Society 37: 1-6.

Hatch, M.H. 1957. The beetles of the Pacific Northwest. Part II. Staphyliniformia. University of Washington Publications in Biology 16: 1384.

Heiss, E. 1971. Nachtrag zur Käferfauna Nordtirols. Innsbruck: University of Innsbruck, 178 pp.

Hendrichs, J. 1979. Nuevo Agathidium de Mexico y sus relaciones zoogeograficas. Folia Entomologica Mexicana 41: 103-114.

Hennig, W. 1966. Phylogenetic systematics. Chicago: University of Illinois Press, $263 \mathrm{pp}$.

Hill, C.R., and P.R. Crane. 1982. Evolutionary cladistics and the origin of angiosperms. In K.A. Joysey and A.E. Friday (editors), Problems of phylogenetic reconstruction: 269361.New York: Academic Press.

Hincks, W.D., and S. Shaw. 1951. Some insects from Dovedale, Derbyshire. Journal of the Society for British Entomology 3: 279-281.

Hingley, M. 1971. The ascomycete fungus Daldinia concentrica as a habitat for animals. Journal of Animal Ecology 40: 17-32.

Hisamatsu, S. 1957. Two new species of the family Leiodidae (Coleoptera). Entomological Review of Japan 8: 1-3.

Hlisnikovský, J. 1964. Monographische Bearbeitung der Gattung Agathidium Panzer (Coleoptera). Acta Entomologica Musaei Nationalis Pragae Suppl. 5: 1-255.

Horion, A. 1949. Faunistik der mitteleuropäischen Käfer. Band II. Palpicornia-Staphylinoidea (ausser Staphylinidae). Frankfurt: Vittoria Klostermann, 388 pp.

Horn, G.H. 1880. Synopsis of the Silphidae of the United States with reference to the genera of other countries. Transactions of the American Entomological Society 8: 219-322.

Houlbert, C. 1922. Les Coléoptères d'Europe, France et région voisines. Paris: Librairie Octave Doin.

ICZN. 1999. International Code of Zoological Nomenclature. London: The International Trust for Zoological Nomenclature.

Ihssen, G. 1939. Zusammenstellung der im Zugspitzgebiet festgestellten Koleopteren. Mitteilungen der Münchner Entomologischen Gesellschaft 29: 321-336.

Illiger, J.K.W. 1798. Verzeichniss der käfer Preussens, entworfen von Johann Gottlieb Kugelann. Halle: J. J. Gebauer, 510 pp.
Ing, B. 1967. Myxomycetes as food for other organisms. Proceedings of the South London Entomological and Natural History Society 1967: $18-23$.

Jacobson, G.G. 1910. Di Käfer Russlands und Westeuropas. In Ein Handbuch zum Bestimmen der Käfer: 561-640. St. Petersburg: A.J. Devrient.

Jacquelin du Val, P.N.C. 1857. Manuel entomologique. Genera des coléoptères d'Europe. Paris: Chez A. Deyrolle. 140 pp.

Jansson, A. 1918a. Coleopterologiskt fraan Hjaelmarstraenderna. Entomologisk Tidskrift 39: 10-29.

Jansson, A. 1918b. Intressantare Coleoptera och Hemiptera heteroptera iakttagna i Skedevi socken, Oestergoetland. Entomologisk. Tidskrift 39: 195-201.

Jansson, A. 1924. Coleopterologiska bidrag. 8. Foer Sverige nya och andra maerkligare skalbaggar. Entomologisk Tidskrift 45: 145-155.

Jansson, A. 1946. Coleopterologiska bidrag. 32. Agathidium marginatum Sturm en torrmarksart? Entomologisk Tidskrift 67: 1-3.

Jansson, A., and T. Palm. 1936. Resultat av en coleopterologisk studieresa till nordvaestra jaemtlands fjaelltrak-ter. Entomologisk Tidskrift 57: 180-192.

Jansson, A., and O. Sjöberg. 1932. Bidrag till Kaennedomen om insektfaunan i Hamra nationalpark. Kunglia Svenska Vetenskapsakademiens skrifter i Naturskyddsärenden. 20: 1-88.

Javorek, V. 1947. Klic kurcovàni broku CSR. Olomouc: R. Prombergr.

Johnson, C. 1962. Two species of Coleoptera new to the faunal area of Lancashire and Cheshire. Entomologists Monthly Magazine 98: 272.

Johnson, W.F. 1890. Coleoptera. Entomologist's Record and Journal of Variation 1: 104.

Joy, N.H. 1904. Coleoptera from Berkshire. Entomologists Monthly Magazine 40: 182.

Joy, N.H. 1932. A practical handbook of British beetles. Vol. 1. London: H.F. \& G. Witherby, $142 \mathrm{pp}$.

Kilian, A. 1998. Morphology and phylogeny of the larval stages of the tribe Agathidiini (Coleoptera: Leiodidae: Leiodinae). Annales Zoologici (Warszawa) 48: 125-220.

Koch, K. 1961. Seltenheiten der rheinischen Kaferfauna aus der Umgebung Duesseldorfs. Entomologische Blätter 57: 103-118.

Koltze, W. 1901. Fauna Hamburgensis. Verzeichnis der in der Umgegend von Hamburg gefundenen Käfer. Verhandlungen des Naturwissenschaftlichen Vereins in Hamburg 11: 1-194.

Kugelann J.G. 1794. Verzeichniss der in einigen Gegenden Preussens bis jetzt entdeckten KäferArten, nebst kurzen Nachrichten von densel- 
ben. Neuestes Magazin für die Liebhaber der Entomologie 1: 513-582.

Kuhnt, P. 1913. Illustrierte Bestimmungstabellen der Käfer Deutschlands. Stuttgart, 1138 pp.

Lawrence, J.F. 1977. Extraordinary images show how beetles have adapted to live off plants, and each other. Horticulture 55: 8-13.

Lawrence, J.F. 1989. Mycophagy in the Coleoptera: Feeding strategies and morphological adaptations. In N. Wilding, N.M. Collins, P.M. Hammond, and J.F. Webber (editors), Insectfungus interactions: 1-23.London: Academic Press.

Lawrence, J.F., and A.F. Newton. 1980. Coleoptera associated with the fruiting bodies of slime molds (Myxomycetes). Coleopterists Bulletin 34: 129-143.

Lawrence, J.F., and A.F. Newton. 1995. Families and subfamilies of Coleoptera (with selected genera, notes, references and data on family group names). In J. Pakaluk (editor), Biology, phylogeny, and classification of Coleoptera: papers celebrating the 80th birthday of Roy A. Crowson: 560-1092.Warsaw: Muzeum i Instytut Zoologii Pan.

Leach. 1832. Systematic catalogue of the specimens of the indigenous mammalia and birds in the British Museum. London: R. and A. Taylor.

LeConte, J.L. 1850. General remarks upon Coleoptera of Lake Superior. In L. Agassiz (editor), Lake Superior: Its physical character, vegetation and animals: 209-241.Boston: Gould, Kendall and Lincoln.

LeConte JL. 1853. Synopsis of the Silphales of America, North of Mexico. Proceedings of the Academy of Natural Sciences of Philadelphia 6: $274-287$.

LeConte, J.L. 1861. Classification of the Coleoptera of North America. Washington, DC, 208 pp.

LeConte J.L. 1878. The Coleoptera of Michigan. Descriptions of new species. In H.G. Hubbard and E.A. Shwarz (editors), Proceedings of the American Philosophical Society: 593-669.

LeConte, J.L., and G.H. Horn. 1883. Classification of Coleoptera of North America. Smithsonian Miscellaneous Collections 26: 77-83.

Leng, C.W. 1920. Catalogue of the Coleoptera of America north of Mexico. Mt. Vernon, NY: J.D. Sherman, 470 pp.

Lentz, F. 1879. Catalog der Preussischen Käfer. Neu Bearbeitet Königsberg. Kaliningrad: W. Koch, 64 pp.

Lindberg, H. 1933. Untersuchungen in N-Petsamo über die Käferfauna hochnordischer Biotopen. Memoranda Societatis Pro Fauna et Flora Fennica 9: 103-125.

Lindberg, H. 1937. Nykomlingar till Finlands skalbaggsfauna. Notulae Entomolgica 17: 17-23.
Lindroth, C.H., and T. Palm. 1934. Bidrag till Kaennedomen om Coleopterfaunan i Oevre Norrlands Kustland. Faunistika, ekologiska och djurgeografiska studier. Göteborgs Kunglia Vetenskaps-Vitterhets-Samhälles Handlingar Femte Följden, Ser. B 4: 1-127.

Linnaeus, C. 1758. Systema naturae per regna tria naturae secundum classes, ordines, genera, species, cum characteribus, diffeventiis, synonymis, locis. Editio Decima. Holmiae. Volume 1, $823 \mathrm{pp}$.

Luigioni, P. 1920. Contributo allo studio delta fauna coleotterologica del Lazio. Pontificia Accademia delle Scienze 73: 186-214.

Lundberg, S. 1960. Bidrag till kännedom om svenska Coleoptera. 3. Entomologisk Tidskrift 81: 108-112.

Lundberg, S. 1984. Den braenda skogens skalbaggsfauna i Sverige. Entomologisk Tidskrift 105: 129-141.

Martin, G.W., and C.J. Alexopoulos. 1969. The Myxomycetes. Iowa City: University of Iowa Press, 477 pp.

Matthews, A. 1887. Insecta, Coleoptera, Silphidae, Corylophidae, Trichopterygidae, Sphaeriidae, Scaphidiidae. In F.C. Godman and O. Salvin (editors), Biologia Centrali-Americana; or, contributions to the knowledge of the fauna and flora of Mexico and Central America: 7296.London: R.H. Porter.

Mayr, E. 1942. Systematics and the origin of species from the viewpoint of a zoologist. New York: Columbia University Press, 334 pp.

Mayr, E. 1963. Animal species and evolution. Cambridge: Belknap Press, 797 pp.

Mayr, E. 1982. The growth of biological thought: Diversity, evolution, and inheritance. Cambridge: Belknap Press, 974 pp.

McHugh, J.V. 1993. A revision of the world Eurysphindinae with a review of classification and phylogeny in Sphindidae. Systematic Entomology 18: 57-92.

Meinert, F. 1893. Fortegnelse over Zoologisk Museums Billelarver. Larvae Coleopterorum Musaei Hauniensis. Entomologiske Meddelelser 4: $1-110$.

Miller, K.B., and Q.D. Wheeler. In press. Two new genera of Agathidiini from the Nearctic and Neotropical regions (Coleoptera: Leiodidae). The Coleopterists Bulletin.

Minch, E.L. 1952. Insect inhabitants of Polyporus betulinus. Journal of the New York Entomological Society 60: 31-35.

Mishler, B.D., and M.J. Donoghue. 1982. Species concepts: A case for pluralism. Systematic Zoology 31: 491-503.

Morley, C. 1899. Coleoptera of Suffolk. Plymouth: J. H. Keys, 113 pp. 
Nelson, G. 1978. Ontogeny, phylogeny, paleontology and the biogenetic law. Systematic Zoology 27: 324-345.

Nelson, G., and N. Platnick. 1981. Systematics and biogeography. Cladistics and vicariance. New York: Columbia University Press, 567 pp.

Newton, A.F. 1983. Agathidoides Portevin, new synonym of Stetholiodes Fall (Coleotpera: Leiodidae: Anisotomini). Psyche 89: 337-338.

Newton, A.F. 1984. Mycophagy in Staphylinoidea. In Q.D. Wheeler and M. Blackwell (editors), Fungus-insect relationships. Perspectives in ecology and evolution: 302-353.New York: Columbia University Press.

Newton, A.F. 1998. Phylogenetic problems, current classification and generic catalog of World Leiodidae (including Cholevidae). In P.M. Giachino and S.B. Peck (editors), Phylogeny and evolution of subterranean and Endogean Cholevidae (= Leiodidae Cholevinae). Proceedings of a Symposium (30 August, 1996, Florence, Italy), XX International Congress of Entomology: 41-178:Torino: Museo Regionale di Scienze Naturali.

Newton, A.F., and S.L. Stephenson. 1990. A beetle/slime mold assemblage from northern India (Coleoptera; Myxomycetes). Oriental Insects 24: 197-217.

Nixon, K.C., and Q.D. Wheeler. 1990. An amplification of the phylogenetic species concept. Cladistics 6: 211-223.

Nixon, K.C., and Q.D. Wheeler. 1992. Measures of phylogenetic diversity. In M.J. Novacek and Q.D. Wheeler (editors), Extinction and Phylogeny: 216-234.New York: Columbia University Press.

Notman, H. 1921. Some new genera and species of Coleoptera collected at Westfield, Chautauqua Co., N.Y. Journal of the New York Entomological Society 29: 145-160.

Nunberg, M. 1987. Klucze do oznaczania owadow Polski. XIX. Coleoptera. 15. Leiodidae. Panstwowe Wydawnictwo Naukowe. Warszawa: $1-59$.

Nuss, I. 1975. Zur Ökologie der Porlinge: Untersuchungen über die Sporulation einiger Porlinge und die an ihnen gefundenen Käferarten. Bibliotheca Mycologica 45: 1-258.

Olivier, A.G. 1789. Encyclopedie methodique, dictionnaire des insectes, Vol. 4. Paris: Pankouke, $373+331$ pp.

Palisot de Beauvois, A.M.F.J. 1817. Insectes recueillis en Afrique et en Amérique, dans les royaumes d'Oware et de Benin, á Saint-Dominique et dans les États-Unis, pendant les années 1786-1797: 157-172. Paris: Impr. de Fain et compagnie.
Palm, T. 1947. Foer Sverige nya Coleoptera. IX. Entomologisk Tidskrift 68: 37-44.

Palm, T. 1951. Die Holz- und Rinden-Käfer der nordschwedischen Laubbaeume. Meddelanden Fran Statens Skogsforslmingsinstitut. Stockholm. 40: 1-241.

Palm, T. 1953. Anteckningar om svenska skalbaggar. VII. Entomologisk Tidskrift 74: 8-23.

Palm, T. 1959. Die Holz- und rinden-Käfer der Sued- und Mittelschwedischen Laubbäume. Opuscula Entomologica Supplementum 16: 1374.

Palmen, E. 1946. Materialien zur Kenntnis der Käferfauna im westlichen Swir-Gebiet (SowjetKarelien). Acta Societatis Pro Fauna et Flora Fennica 65: 1-198.

Panzer, G.W.F. 1797. Faunae Insectorum Germanicae inita, oder Deutschlands Insecten. Nürnberg: Felsecker.

Park, O. 1931. Studies in the ecology of forest Coleoptera II. The relation of certain Coleoptera to plants for food and shelter, especially those species associated with fungi in the Chicago area. Ecology 12: 188-207.

Park, O., J.A. Lockett, and D.J. Myers. 1931. Studies in nocturnal ecology with special reference to climax forest. Ecology 12: 709-725.

Peck, S.B. 1998. Revision of the Colenis of America north of Mexico (Coleoptera: Leiodidae: Leiodinae: Pseudoliodini). Canadian Entomologist 130: 55-65.

Peck, S.B., and A.E. Davies. 1980. Collecting small beetles with large-area 'window' traps. Coleopterists Bulletin 34: 237-239.

Peck, S.B., P. Gnaspini, and A.F. Newton. 2000. Catalogue and generic keys for the Leiodidae of Mexico, West Indies, and Central and South America (Insecta: Coleoptera). Giornale Italiano di Entomologia 9: 37-72.

Perkovskii, E.E. 1990. A new species of the genus Stetholiodes (Coleoptera: Leiodidae) from Indochina. Vestnik Zoologii 1990: 63-64.

Perris, E. 1851. Quelques mots sur les metamorphoses de Coléoptères mycetophages, le Triphyllus punctatus Fab.; le Diphyllus lunatus Fab.; I'Agathidium seminulum Linn., et l'Eucinetus (Nycteus Latr.) meridionalis de Castelnau. Annales de la Société Entomologique de France Ser. 2, t. 9: 39-53.

Platnick, N.I. 1979. Philosophy and the transformation of cladistics. Systematic Zoology 28: 537-546.

Platnick, N.I., and Q.D. Wheeler. 2000. A defense of the phylogenetic species concept (sensu Wheeler and Platnick). In Q.D. Wheeler and R. Meier (editors), Species concepts and phylogenetic theory: a debate: 185-197.New York: Columbia University Press. 
Platonoff, S. 1942. Beitriige zur Kenntnis der Käferfauna im suedlichen Petsamo. Notulae Entomolgica 22: 44-76.

Polentz, G. 1938. Beitrage zur schlesischen Käerfauna. Entomologische Gesellschaft zu Halle (Saale) Mitteilungen 16: 48-60.

Poppius, B. 1905. Kola-Halföns och Enare Lappmarks Coleoptera. Helsingfors, 200 pp.

Portevin, G. 1914. Révision des Silphides, Liodides et Clambides du Japon. Annales de la Société Entomologique de Belgique 58: 212-236.

Portevin, G. 1926. Les Liodidae de 1'Inde. Encyclopédie Entomologique, Coleoptera 1: 75-83.

Portevin, G. 1927. Les Liodidae du Japon. Encyclopédie Entomologique, Coleoptera 2: 73-94.

Portevin, G. 1929. Historie naturelle des coléoptères de France, vol. I. Adephaga-Polyphaga: Staphylinoidea. Encyclopédie entomologique (A). Paris: P. Lechevalier, 630 pp.

Redtenbacher, L. 1845. Die Gattung der deutschen Kaeferfauna. Wien: C. Ueberreuter, 177 pp.

Redtenbacher, L. 1849. Faune Austriaca. Käfer. Wien: Verlag von Carl Gerold, 883 pp.

Redtenbacher, L. 1858. Fauna Austriaca. Käfer. Wien: C. Gerold's Sohn, 1017 pp.

Redtenbacher, L. 1874. Faune Austriaca. Käfer. Wien: C. Gerold's Sohn, 571 pp.

Rehfous, M. 1955. Contribution a l'etude des insectes des champignons. Mitteilungen der Schweizerischen Entomologischen Gesellschaft 28: $1-106$.

Reitter, E. 1910. Das Insektensieb, dessen Bedeutung beim Fange von Insekten, insbesondere Coleopteren, und dessen Anwendung. Entomologische Blätter 6: 65-69, 92-97, 133-137.

Richards, O.W. 1926. Studies on the ecology of English heaths. 111. Animal communities of the felling and burn successions at Oxshott Heath, Surrey. 1. Ecology 14: 244-281.

Ridley, M. 1989. The cladistic solution to the species problem. Biology and Philosophy 4: 1-16.

Roeben. 1907. Fuenfter Nachtrag zum systematischen Verzeichnis der bis jetzt im Herzogtum Oldenburg gefunden Kaeferarten von C. F. Wiepken. Abhandlungen-Naturwissenschaftlicher Verein zu Bremen 19: 301-312.

Rosen, D.E. 1978. Vicariant patterns and historical explanation in biogeography. Systematic Zoology 27: 159-188.

Rottenberg, v. 1864. Eine Excursion nac Albendorf in der Grafschaft Glatz. Berliner Entomologische Zeitschrift 8: 394-395.

Roubal, J. 1909. Ein Beitrag zur Kenntnis der Coleopteren-Fauna von den Julischen Alpen. Entomologische Blätter 5: 183-186, 227-232.

Roubal, J. 1924. Zur Käferfauna der Ost-Karpathen (Corna Hora). Entomologische Blätter 20: 244-247.
Roubal, J. 1926. Zur Käferfauna der Ost-Karpathen (Coma Hora). Entomologische Blätter 22: 10-12.

Roubal, J. 1927. Une biocoenose coleopterologique des champignons du hetre. Miscellanea Entomologica 30: 24-25.

Roussin, L. 1947. La faune des champignons. l'Entomologiste 3: 84-86.

Rueschkamp, F. 1928. Unsere heimischen Anistomini (Agathidiini). Entomologische Blätter 24: 27-34.

Russell, L.K. 1979. Beetles associated with slime molds (Mycetozoa) in Oregon and Califonia (Coleoptera: Leiodidae, Sphindidae, Lathridiidae). Pan-Pacific Entomologist 55: 1-9.

Rye, E.C., and D. Sharp. 1865. Coleoptera at Rannoch. Entomologists Monthly Magazine 2: 4953.

Saalas, U. 1917. Die Fichtenkaefer Finnlands. I. Suomalaisen Tiedeakatemian Toimituksia, Ser. A 8: 1-547.

Saalas, U., and C. Schaufuss. 1923. Die Fichtenkaefer Finnlands. II. Liodidae. Suomalaisen Tiedeakatemian Toimituksia, Ser. A 22: 1-746.

Sainte-Claire-Deville, J. 1899. Description d'un Agathidium nouveau de France [Col.]. Bulletin de la Société Entomologique de France 1899: 292-293.

Schiødte, J.C. 1862. De metamorphose eleutheratorum observationes. Bidrag til Insektemes. Naturhistorisk Tidsskrift, udgivet af Henrik Krøyer Ser. 3 bd. 1: 193-232.

Schneider, D.H. 1792. Auszug aus der sehr einsichtsvollen Rezension eben dieses Wertes, in der Jenaischen allgemeinen Litteratur-Zeitung pro 1792. Nro. 78. Nuestes Magazin für die Leibhaber der Entomologie 1: 334-339.

Seidlitz. 1891. Fauna baltica. Die kaefer (Coleoptera) der deutschen ostseeprovinzen Russlands. Von dr. Georg Seidlitz. Königsberg: Hartungsche verlagsdruckerei, $818 \mathrm{pp}$.

Sharp, D. 1871. The Coleoptera of the Scotch Fir. Scottish Naturalist 1: 36-42.

Sick, F. 1930. Fuenfter Beitrag zur Käferfauna Ostholsteins. Entomologische Blätter 26: 115-118.

Sick, F. 1939. Siebenter Beitrag zur Käferfauna Ostholsteins. Entomologische Blätter 35: 97-110.

Singer, K. 1955. Die Käfer (Coleoptera). Beitrage zur Fauna des unteren Maingebietes von Hanau bis Wuerzburg mit Einschluß des Spessarts. Nachricten des Naturwißenschaftlichen Museums der Stadt Aschaffenburg 7: 3-272.

Sjöberg, O. 1928. Foer Sveriges fauna nya eller saeusynta Coleoptera huvudsakligen fraan det norrlaendska skogsomraadet. Entomologisk Tidskrift 49: 115-125.

Stephens, J.F. 1829. Illustrations of British entomology: or a synopsis of indigenous insects: 
containingtheir generic and specific distinctions; with an account on their metamorphoses, times of appearance, localities, food, and economy as far as practicable. Mandibulata 2: 1-200.

Stephens, J.F. 1839. A manual of British Coleoptera, or beetles; containing a brief description of all the species of beetles hitherto ascertained to inhabit Great Britain and Ireland; together with a notice of their chief localities, times and places of appearance, etc. London: Longman, Orme Brown, Green and Longmans, 443 pp.

Stephenson, S.L., Q.D. Wheeler, J.V. McHugh, and P.R. Fraissinet. 1994. New North American associations of Coleoptera with Myxomycetes. Journal of Natural History 28: 921-936.

Stierlin, G. 1900. Fauna coleopterorum helvetica. Die Käfer-Fauna der Schweiz nachder analytischen Methode. Schaffhausen: Bolli \& Böcherer, 667 pp.

Strand, A., and H.K. Hanssen. 1932. Maalselvens Koleoptera. Norsk Entomologisk Tidsskrift 3: 17-71.

Sturm, J. 1807. Deutschlands Insecten. Nürnberg: Gedruckt auf Kosten des Verfassers, 279 pp.

Thérond, J. 1975. Catalogue des Coléoptères de la Camargue et du Gard. Nîmes: Société d'Étude des Sciences Naturelles de Nîmes, 410 pp.

Thomson, C.G. 1859. Skandinaviens Coleoptera, synoptiskt bearbetade. Lund: Tryckt uti Lundbergska Boktryckereit, 290 pp.

Thomson, C.G. 1862. Skandinaviens Coleoptera, synoptiskt bearbetade. Lund: Tryckt uti Lundbergska Boktryckereit, 269 pp.

Tomlin, J.R.L. 1915. Coleoptera in Herefordshire (V). Entomologists Monthly Magazine 51: 57, 33-34.

Uhmann. 1925. Zweiter Beitrag zur Käferfauna Deutschlands. Entomologische Blätter 21: 7981.

van Valen, L. 1976. Ecological species, multispecies, and oaks. Taxon 25: 233-239.

Vit, S. 1977. Contribution to knowledge of Eucinetidae (Coleoptera). Revue Suisse de Zoologie 84: 917-935.

von Peez, A. 1971. Leiodidae. In H. Freude, K.W. Harde and G.A. Lohse (editors), Die Käfer Mitteleuropas: Ökologie.Krefeld: Goecke and Evers.

von Wanka, T. 1908. Coleopterologische Ergebniße einer Reise in die Herzegowina. Entomologische Blätter 4: 167-171, 188-194, 209214, 228-233.

von Wanka, T. 1915. Beitrag zur Coleopterenfauna von Oesterr.-Schlesien. Wiener Entomologische Zeitung 34: 199-214.

Walker, J.J. 1874. Notes on rare Kentish Coleoptera. Entomologists Monthly Magazine 11: 3739.
Walker, J.J. 1875. Sphindus dubius, \&c., at Chatham. Entomologists Monthly Magazine 12: 109.

Weber, L. 1916. Die Lebenserscheinungen der Käfer. Entomologische Blätter 12: 211-236.

Weber, L. 1925. Liodidae (=Anisotomidae). In H. Blunck (editor), Syllabus der Insektenbiologie. Coleopteren: Leiferung 1.: 136.Berlin: Verlag von Gebrüder Bornträger.

West, A. 1925. Bidrag til Kundskaben om Sendejyllands_-isaer Aabenraaegnens-Billefauna. Entomologiske Meddelelser 14: 389-393.

West, A. 1940. Fortegnelse over Danmarks Biller deres udbredelse I Danmark Forekomststeder ogtider biologi. Entomologiske Meddelelser 21: 1-284.

Wheeler, Q.D. 1979a. Revision and cladistics of the Middle American genus Creagrophorus Matthews (Coleoptera: Leiodidae). Quaestiones Entomologicae 15: 447-479.

Wheeler, Q.D. 1979b. Slime-mold beetles of the genus Anisotoma (Leiodidae): Evolution and classification. Systematic Entomology 4: 251309.

Wheeler, Q.D. 1980. Studies on Neotropical slime mold/beetle relationships. Part 1: natural history and description of a new species of Anisotoma from Panama (Coleoptera: Leiodidae). Proceedings of the Entomological Society of Washington 82: 493-498.

Wheeler, Q.D. 1981. Diagnosis and phylogenetic relationships of the monotypic genus Stetholiodes (Coleoptera: Leiodidae). Ohio Journal of Science 81: 165-168.

Wheeler, Q.D. 1983. Slime mold beetles of the genus Anisotoma (Leiodidae): supplement 1. Description of a new species of the scopula subgroup from Mexico. Coleopterists Bulletin 37: 45-48.

Wheeler, Q.D. 1984a. Associations of beetles with slime molds: Ecological patterns in the Anisotomini (Leiodidae). Bulletin of the Entomological Society of America 30: 14-18.

Wheeler, Q.D. 1984b. Evolution of slime mold feeding in leiodid beetles. In Q.D. Wheeler and M. Blackwell (editors), Fungus-insect relationships: Perspectives in ecology and evolution: 446-479.New York: Columbia University Press.

Wheeler, Q.D. 1984c. Notes on host associations and habitats of Dasyceridae (Coleoptera) in the southern Appalachian Mountains. Coleopterists Bulletin 38: 227-231.

Wheeler, Q.D. 1986. Rediscovery and cladistic placement of the genus Cainosternum (Coleoptera: Leiodidae). Annals of the Entomological Society of America 79: 377-382.

Wheeler, Q.D. 1987. A new species of Agathi- 
dium associated with an epimycetic slime mold plasmodium on Pleurotus fungi (Coleoptera: Leiodidae-Myxomycetes: Physarales-Basidiomycetes: Tricholomataceae). Coleopterists Bulletin 41: 395-403.

Wheeler, Q.D. 1990a. Morphology and ontogeny of postembryonic larval Agathidium and Anisotoma (Coleoptera: Leiodidae). American $\mathrm{Mu}-$ seum Novitates 2986: 1-41.

Wheeler, Q.D. 1990b. Ontogeny and character phylogeny. Cladistics 6: 225-264.

Wheeler, Q.D., and J.V. McHugh. 1987. Watrous trays: A storage system for disarticulated and dissected insects. Curator 30: 73-76.

Wheeler, Q.D., and J.V. McHugh. 1994. A new southern Appalachian species, Dasycerus bicolor (Coleoptera: Staphylinidae: Dasycerinae), from declining endemic fir forests. Coleopterists Bulletin 48: 265-271.

Wheeler, Q.D., and R. Meier. 2000. Preface. In Q.D. Wheeler and R. Meier (editors), Species concepts and phylogenetic theory: a debate: ixxii.New York: Columbia University Press.

Wheeler, Q.D., and K.C. Nixon. 1990. Another way of looking at the species problem: a reply to de Queiroz and Donoghue. Cladistics 6: 7781 .
Wheeler, Q.D., and N.I. Platnick. 2000a. A critique from the Wheeler and Platnick phylogenetic species concept perspective: Problems with alternate concepts of species. In Q.D. Wheeler and R. Meier (editors), Species concepts and phylogenetic theory: a debate: 133145.New York: Columbia University Press.

Wheeler, Q.D., and N.I. Platnick. 2000b. The phylogenetic species concept (sensu Wheeler and Platnick). In Q.D. Wheeler and R. Meier (editors), Species concepts and phylogenetic theory: a debate: 55-69.New York: Columbia University Press.

Wiepken, C.F. 1886. Nachtrag zu dem Systematischen Verzeichnisse der bis jetzt im Herzogthum. Oldenburg gefundenen Käferarten. Naturwissenschaftlicher Verein zu Bremen 9: 339-354.

Williams, B.S. 1924. Coleoptera collected in the Harpenden District. Entomologists Monthly Magazine 60: 76-80.

Woerndle, A. 1950. Käfer von Nordtirol. Innsbruck: Universitätsverlag Wagner, 388 pp.

Woodroffe, G.E. 1968. Some rare Coleoptera from Wychwood Forest National Nature Reserve, Oxon., with records of six species of $\mathrm{He}-$ miptera-Heteroptera new to Oxfordshire. Entomologists Monthly Magazine 104: 22.

\section{APPENDIX}

The following is a list of collections from which specimens were borrowed for this project.

AMNH American Museum of Natural History, Division of Invertebrate Zoology, Central Park West at 79th St., New York, NY 10024 (L. Herman).

ANSP Academy of Natural Sciences, Department of Entomology, 1900 Benjamin Franklin Parkway, Philadelphia, PA 19103 (D. Otte).

BMNH The Natural History Museum, Cromwell Road, London, SW7 5BD, United Kingdom (P. Hammond).

CASC California Academy of Sciences, Department of Entomology, Golden Gate Park, San Francisco, CA 94118 (D.H. Kavanaugh).

CMNC Canadian Museum of Nature Collection, 240 McLeod Street, Ottawa, ON K1P 6P4, Canada (R.S. Anderson).
CMNH Carnegie Museum of Natural History, Section of Invertebrate Zoology, 4400 Forbes Ave., Pittsburgh, PA 15213 (R. Davidson).

CNCI Canadian National Collection of Insects, Canadian Museum of Nature, Entomology-Collections Division, P.O. Box 3443, Station 'D', Ottawa, ON, K1P 6P4, Canada (Bousquet, Y.).

CUIC Cornell University Insect Collection, Department of Entomology, Comstock Hall, Cornell University, Ithaca, NY 14853 (J. Liebherr).

DENH Entomological Museum, Department of Zoology, University of New Hampshire, Nesmith Hall, Durham, NH 03824 (D.S. Chandler).

EMEC Essig Museum of Entomology, University of California, Berkeley, CA 94720 (C. Barr). 
FAIC F. Angelini Collection, SS7 Latiano, Km 0-500, I-72021 Francavilla Fontana, Brindisi, Italy.

FGAC F.G. Andrews Collection, CDFA Plant Pest Diagnostics Center, 3294 Meadowview Rd., Sacramento, CA 95832.

FMNH Field Museum of Natural History, Department of Zoology, Roosevelt Road at Lake Shore Dr., Chicago, IL 60605 (A.F. Newton).

FSCA Florida State Collection of Arthropods, Museum of Entomology, 1911 SW 34th Street, Gainesville, FL 32608 (M.C. Thomas).

JRAC J.R.A. Baranowski Collection, University of Lund, Department of Systematic Zoology, Helgonav, S-22362 Lund, Sweden.

KSIC K. Stephan Collection, Route 1, Box 913, Red Oak, OK 74563.

LACM Natural History Museum of Los Angeles County, Entomology Section, 900 Exposition Boulevard, Los Angeles, CA 90007 (C. Bellamy).

MCMC Museo de Historia Natural de al Ciudad de Mexico, Nuevo Bosque de Chapultepec, Apartado Postal 18-845 Delegacion Miguel Hidalgo 11800 Mexico, (G. Quinters) .

MCZC Museum of Comparative Zoology, Harvard University, Cambridge MA 02138 (P. Perkins).

MNHN Entomologie, Museum National d'Histoire Naturelle, 45 bis, Rue de Buffon, Paris, 75005, France (J.J. Menier).

MTEC Montana Entomological Collection, Department of Entomology, Montana State University, Bozeman, MT 59717 (M.A. Ivie).

MZLU Museum of Zoology and Entomology, Lund University, Helgonavägen $3 \mathrm{~S}$ 22362 Lund, Sweden (R. Danielsson).

NAUF The Colorado Plateau Museum of Arthopod Biodiversity, Northern Arizona University, Flagstaff, AZ 86001 (N. Cobb).

OSAC Oregon State University Entomological Museum, Department of Entomology, Oregon State University, Corvallis, OR 97331 (D.D. Judd).
OSUC Museum of Biological Diversity, Department of Entomology, Ohio State University, 1315 Kinnear Road, Columbus, OH 43212 (N. Johnson).

PECK Stewart B. Peck Collection, Carleton University, Department of Biology, Ottawa, ON, K1S 5B6, Canada.

PSUC Frost Entomological Museum, Department of Entomology, Pennsylvania State University, University Park, PA 16802 (K.C. Kim).

QDWC Quentin D. Wheeler Collection, Department of Entomology, Comstock Hall, Cornell University, Ithaca, NY 14853.

SEMC Snow Entomological Museum, University of Kansas Natural History Museum, University of Kansas, Lawrence, KS 66045 (J.S. Ashe).

TAMU Texas A\&M University Insect Collection, Department of Entomology, Texas A\&M University, College Station, TX 77843 (J.D. Oswald).

UASM E.H. Strickland Entomological Museum, University of Alberta, Edmonton, AB, Canada T6G 2M7 (F.A.H. Sperling).

UGCA University of Georgia Museum of Natural History Collection of Arthropods, University of Georgia, Athens, GA 30602 (J.V. McHugh).

UMMZ University of Michigan Museum of Zoology, Insect Division, University of Michigan, Ann Arbor, MI 48109 (B.M. O'Connor).

USNM National Museum of Natural History, Smithsonian Institution, Washington, DC 20560 (D.G. Furth).

WSUC M.T. James Entomological Collection, Washington State University, Department of Entomology, Pullman, WA 99164 (R.S Zack).

ZMHB Museum für Naturkunde der Humboldt-Universität, Humboldt-Universität zu Berlin, D-10099 Berlin, Germany (M. Uhlig). 